\title{
Smoothelins and smooth muscle contractility
}

Citation for published version (APA):

Niessen, P. M. G. (2008). Smoothelins and smooth muscle contractility. [Doctoral Thesis, Maastricht University]. Universiteit Maastricht. https://doi.org/10.26481/dis.20080411pn

Document status and date:

Published: 01/01/2008

DOI:

10.26481/dis.20080411pn

Document Version:

Publisher's PDF, also known as Version of record

\section{Please check the document version of this publication:}

- A submitted manuscript is the version of the article upon submission and before peer-review. There can be important differences between the submitted version and the official published version of record.

People interested in the research are advised to contact the author for the final version of the publication, or visit the DOI to the publisher's website.

- The final author version and the galley proof are versions of the publication after peer review.

- The final published version features the final layout of the paper including the volume, issue and page numbers.

Link to publication

\footnotetext{
General rights rights.

- You may freely distribute the URL identifying the publication in the public portal. please follow below link for the End User Agreement:

www.umlib.nl/taverne-license

Take down policy

If you believe that this document breaches copyright please contact us at:

repository@maastrichtuniversity.nl

providing details and we will investigate your claim.
}

Copyright and moral rights for the publications made accessible in the public portal are retained by the authors and/or other copyright owners and it is a condition of accessing publications that users recognise and abide by the legal requirements associated with these

- Users may download and print one copy of any publication from the public portal for the purpose of private study or research.

- You may not further distribute the material or use it for any profit-making activity or commercial gain

If the publication is distributed under the terms of Article $25 \mathrm{fa}$ of the Dutch Copyright Act, indicated by the "Taverne" license above, 


\title{
Smoothelins and smooth muscle contractility
}

\author{
PROEFSCHRIFT \\ ter verkrijging van de graad van doctor \\ aan de Universiteit Maastricht, \\ op gezag van de Rector Magnificus, \\ Prof. mr. G.P.M.F. Mols \\ volgens het besluit van het College van Decanen, \\ in het openbaar te verdedigen \\ op vrijdag 11 april 2008 om 10.00 uur \\ door \\ Petronella Maria Godefrida Niessen \\ Geboren te Roermond op 18 augustus 1978
}


Promotor:

Prof. Dr. M.H. Hofker

Copromotor:

Dr. G.J.J.M.van Eys

Beoordelingscommissie:

Prof. Dr. M.J. Post (voorzitter)

Dr. M-L. Bochaton-Piallat (CMU - Genève)

Prof. Dr. M.J.A.P. Daemen

Prof. Dr. F.C.S. Ramaekers

Dr. C.J.M. de Vries (AMC - Amsterdam)

Financial support by the Netherlands Heart Foundation for the publication of this thesis is gratefully acknowledged. Printing of this thesis was also financially supported by Pie Medical Imaging, J.E. Jurriaanse stichting and MUbio Products. 


\section{Contents}

Chapter 1

General Introduction

Chapter 2

31

Smoothelins

Aim of the thesis 38

Chapter $3 \quad 41$

Biochemical evidence for interaction between smoothelin and filamentous actin

Chapter 4

59

Contribution of serum response factor and myocardin to transcriptional regulation of smoothelins

Chapter 5

Smoothelin-A is essential for functional intestinal smooth muscle contractility in mice

\section{Chapter 6}

Smoothelin-B deficiency results in reduced arterial contractility, hypertension, and cardiac hypertrophy in mice

\section{Chapter 7}

Identification of novel smoothelin binding proteins

\section{Chapter 8}

General Discussion

Summary

Samenvatting 
Chapter 1

General Introduction 


\section{Introduction}

Smooth muscle cells (SMCs) constitute an important part of the walls of various hollow organs and tubes, including blood vessels, the gastro-intestinal tract, the lungs, and the urogenital system. By contracting in a coordinated fashion, the SMCS propel the luminal contents of the organ or vary the diameter of a tube to regulate the flow of its contents. While they develop force and perform work, smooth muscle tissues must also serve as a skeleton to stabilize organ dimensions against imposed loads.

Smooth muscle cells do not differentiate terminally, which means that they can modulate their phenotype from a contractile to a synthetic state. In general the contractile SMC is considered to be most differentiated. In this state, the main function of the SMC is contraction. In the synthetic state, in contrast, the cells gain other properties that allow them to proliferate, migrate and produce components of the extracellular matrix, at the expense oftheir contractile capacity. In this way smooth muscle cells can adapt to chronically changing conditions by structural remodeling of a tissue.

In contrast to cardiac and skeletal muscle, smooth muscle cells lack the striated banding pattern of the contractile apparatus. Instead, the contractile filaments are organized in bundles (in cultured cells referred to as stress fibers) that are oriented at a shallow angle to the long axis of the cell. The contractile bundles, existing of actin and myosin molecules and their associated proteins, are connected to each other and to the intermediate filaments by $\alpha$-actinincontaining dense bodies ${ }^{1,2}$. The SMC cytoskeleton is mainly composed of the intermediate filaments which are involved in shape maintenance and form a structural framework that surrounds and supports the contractile apparatus.

Smooth muscle contracts or relaxes in response to 1 ) changes in load or length (stretch), 2) stimuli from the autonomic nervous system, 3) hormones or autocrine/paracrine agents, and 4) other local chemical signals. Regardless of the stimulus, SMCs, like other muscle cell types, use interactions (so called crossbridges) between actin and myosin to develop force. These crossbridges are initiated by changes in the cytoplasmic concentration of calcium ions $\left(\mathrm{Ca}^{2+}\right)$ and the presence of adenosine tri-phosphate (ATP). Smooth muscle contractile activity is primarily determined by phosphorylation of the myosin regulatory light chain (MRLC) by myosin light chain kinase (MLCK) and dephosphorylation by myosin light chain phosphatase $(M L C P)^{3,4}$. The phosphorylation of MRLC increases myosin MgATPase activity and subsequently contraction.

Smooth muscle contraction is a complicated and yet incompletely understood process in which the characteristics of the interaction between actin and myosin are determined by chemical modifications of the myosin complex and complementation of the actin filaments with a set of associated proteins. 
General Introduction

In the first part of this introduction the most relevant components of the contractile apparatus of SMCs will be described. The second part of the introduction will provide an overview of the present understanding of smooth muscle contraction and its regulation.

\section{The contractile apparatus}

The contractile apparatus of SMCs is a complex of many proteins, among which actin and myosin are the two major components forming the thin and thick filaments, respectively. The globular head of the myosin heavy chain can undergo conformational changes resulting in its movement along the actin filaments. This process is regulated by a number of thin filament associated proteins, which will be discussed below.

\subsection{Contractile filaments}

\subsubsection{Actin}

Actin is a major contractile as well as structural component in all eukaryotic cells. It is involved in the generation of contractile force and plays a role in diverse cellular processes such as cell motility, adhesion, cytokinesis, and control of cellular shape 5 . For most of these functions the globular actin monomer (G-actin) polymerizes into actin filaments (F-actin) ${ }^{6,7}$, which is a continuous and dynamic process.

At least six highly conserved actin isoforms have been described. They are products of separate genes and are divided into two classes: muscle actins (cardiac, skeletal and smooth muscle actins) and non-muscle or cytoplasmic actins. Based on iso-electric focusing, three isoforms of smooth muscle actins, $\alpha$, $\beta$, and $\gamma$, have been distinguished. In smooth muscle cells half of the actin content is non-muscle actin $^{8}$, which contributes to the non-contractile cytoskeletal processes ${ }^{9} . \alpha$-Smooth muscle actin $(\alpha-S M A)$ is the muscular isoform involved in contraction of the vasculature, while $\gamma$-smooth muscle actin ( $\gamma$-SMA) is the major contractile actin isoform in the gastrointestinal tract. Despite their remarkable conservation at the amino acid level, actins are expressed in a tissue-specific manner. The differences between the various actins resides in the 4- 6 residues at the $\mathrm{N}$-terminal end ${ }^{10}$. This part of the molecule is not involved in filament formation, but is the site for interaction with various actin-binding proteins. This may lead to isoform specific functions and, indirectly, to differences in contractile characteristics ${ }^{11}$. 
Although during adulthood actin isoform expression is strictly tissue-specific, the expression pattern during embryogenesis is more complicated. For example, during cardiogenesis, $\alpha$-SMA is transiently expressed in the heart followed by $\alpha$ cardiac actin and a transient $\alpha$-skeletal actin co-expression ${ }^{12}$. Also, in pathological situations, expression of the actin isoforms changes ${ }^{13}$. For instance, in atrial fibrillation, $\alpha$-SMA partly replaces the regular actin in cardiomyocytes, $\alpha$-cardiac actin ${ }^{14}$. Many questions remain about the specific functions of the different actin isoforms. Nevertheless, it has become clear that the $\alpha$-actins are not interchangeable, since up- or down-regulation of other isoforms is not able to fully compensate for the loss of a particular actin at the physiological level. This is clearly demonstrated in $\alpha$-SMA null mice, in which despite increased expression of $\alpha$-skeletal actin in the aorta, the mice showed highly compromised vascular contractility and blood flow, resulting in a reduced basal blood pressure ${ }^{15}$. Also in myofibroblasts Hinz et al. showed that treatment with an $\alpha$ SMA-NH2 terminal decoy abolished contraction, while similar decoys of betaactin and skeletal actin had no effect ${ }^{16}$. This finding confirms that tissue-specific functions of the actins reside in the $\mathrm{N}$-terminal domain.

\subsubsection{Myosin}

The myosin molecule is a hexamer composed of two $230 \mathrm{kDa}$ heavy chains, a pair of phosphorable regulatory light chains (MRLC) of $20 \mathrm{kDa}$ each, and a pair of non-phosphorable alkali light chains of $17 \mathrm{kDa}$. The myosin heavy chain dimers form coiled-coil carboxy-terminal tails and globular amino tail heads. The myosin head contains a binding site for actin and an actin-activated $\mathrm{Mg}^{2+}$ ATPase, through which myosin transforms the chemical energy stored in ATP into mechanical work associated with muscle contraction ${ }^{17}$. This actin-activated myosin ATPase activity and force production is regulated by the MRLC ${ }^{18,19}$ (see part 2 of the introduction).

Smooth muscle myosin heavy chain (SMMHC) isoforms are encoded by a single gene. By alternative splicing four isoforms are generated of the primary transcript. The SM1 and SM2 isoforms contain different C-termini, 43 versus 9 amino acids. At the amino terminus, the SM-B isoform contains 7 extra amino acids as compared to the SM-A isoform. Combinations of these isoforms are differentially expressed during smooth muscle development and in different SMC types. The mechanical properties of smooth muscle are correlated with both the myosin heavy chain content and the isoform expression ${ }^{20,21}$. The SM-A isoforms have been shown to influence the organization of the myosin filaments ${ }^{21}$. On the other hand the SM-B isoforms are associated with an increased shortening velocity ${ }^{22,}{ }^{23}$. Recent data, obtained from transgenic mice, also indicate different functional properties of the C-terminal isoforms. SM1 
transgene expression increased isometric force and shortening velocity whereas the SM2 transgene had opposite effects ${ }^{24}$.

Although smooth muscle contraction involves many proteins, only deletion of the SMMHC gene has been demonstrated to cause smooth muscle dysfunction severe enough to be embryonically lethal ${ }^{25}$. None of the other smooth musclespecific proteins, currently described, are required for embryonic and long term survival. SMMHC-deficient mice revealed that the initial, transient phase of smooth-muscle contraction, which requires SMMHC, is essential for long-term survival after birth and maintenance of key physiological processes such as closure of the Ductus arteriosus, development of normal blood pressure, and micturition. This stresses the primary role of myosin in development and function of the contractile apparatus.

Smooth muscle also contains non-muscle myosin, although in most tissues in low quantities ${ }^{26}$. As shown in SMMHC-deficient mice, the contraction of nonmuscle myosin is characterized by a low tension development and slow shortening velocity ${ }^{25}$, caused by properties of the contractile system itself rather than by its activation ${ }^{27}$. This shows that the smooth muscle and non-muscle myosin types have different roles during contraction ${ }^{25}$.

\subsection{Thin filament associated proteins}

\subsubsection{Tropomyosin}

Tropomyosin is a coiled-coil $\alpha$-helix and spans seven actin monomers. It is inserted in the grooves of the actin helix ${ }^{28}$. By interacting head to tail, the individual molecules create a continuous strand along the actin filament. In striated muscle tropomyosin has been shown to block most potential myosin binding sites on actin in the absence of $\mathrm{Ca}^{2+}$. After $\mathrm{Ca}^{2+}$ binding by the troponin complex, tropomyosin moves around the actin filament and provides the calcium switch for turning myosin ATPase activity on and off $^{29}$. By this movement and because it spans seven actin monomers, tropomyosin confers properties of cooperativity along the actin filaments ${ }^{30}$. This means that the interaction between the actin filament and a small number of myosin heads will shift the position of tropomyosin, allowing myosin to interact with the remaining positions on the actin filament. Thus tropomyosin determines the activation state of the thin filament. Haeberle et al. confirmed the mechanism of cooperative reattachment of the unphosphorylated cross-bridges proposed by Somlyo et al. ${ }^{31}$ and that tropomyosin is essential for this mode of activation ${ }^{32}$. Since troponins are not expressed in smooth muscle, the function of tropomyosin in smooth muscle is less clear. However, a number of studies suggest that tropomyosin provides cooperativity in smooth muscle as well, 
possibly in cooperation with other smooth muscle-specific proteins. In addition, smooth muscle tropomyosin enhances actomyosin ATPase activity ${ }^{33}$ and is necessary for full inhibition of actomyosin ATPase activity by caldesmon ${ }^{34,35}$.

\subsubsection{Caldesmon}

The two isoforms of caldesmon are differentially expressed but are derived from a single gene. The heavy caldesmon (h-caldesmon) is exclusively expressed in smooth muscle, while the light isoform (1-caldesmon) is expressed ubiquitously ${ }^{36}$. $\mathrm{H}$-caldesmon is a $89 \mathrm{kDa}$ molecule with binding sites for myosin, actin, tropomyosin and calmodulin. It contains a highly charged 150 amino acid segment in the middle of the molecule, known as the spacer region, that separates the actin and myosin binding sites ${ }^{37}$. Although the function of this spacer is still not clear, the following function of $h$-caldesmon has been suggested $^{38}$ : The C-terminal region binds to actin and reversibly inhibits the contraction by inhibiting myosin ATPase activity, while the $\mathrm{N}$-terminus tethers the myosin filaments to the actin filaments. By cross-linking actin to myosin, it forms a non-cycling cross-bridge which contributes to the 'latch' state ${ }^{39}$ (see paragraph 2.3). In addition, the binding of h-caldesmon to tropomyosin potentiates the inhibiting effect on myosin ATPase activity, while the binding to $\mathrm{Ca}^{2+}$-calmodulin reverses the inhibitory effect ${ }^{36}$. Furthermore, caldesmon can be phosphorylated by ERK, PKC and several other kinases, which will also reverse the inhibitory effect on myosin ATPase activity ${ }^{40}$, probably by decreasing the actin-binding affinity of caldesmon. Although mice with a specific disruption of $h$-caldesmon have been generated, there are no data on the implication for smooth muscle contractility available yet ${ }^{41}$. Using an antisense oligonucleotide approach, Earley et al., however, showed that in resting vascular smooth muscle, active crossbridges are inhibited by caldesmon ${ }^{42}$. Thus, structurally caldesmon maintains the orderly arrangement of the myosin and actin filaments and functionally it can modulate contractile force development ${ }^{41}$ through inhibition of cross-bridge cycling.

\subsubsection{Calponin}

Calponin binds to many proteins including actin, myosin, tropomyosin and $\mathrm{CaM}^{43}$. There are three genetic isoforms expressed of which the basic (h1calponin) is the predominant isoform in smooth muscle. Calponin contains a prominent structural element at the $\mathrm{N}$-terminus referred to as the calponinhomology $(\mathrm{CH})$ domain. This domain has high homology with similar domains in a large group of proteins. Although it was previously reported to bind to actin, this remains controversial, since the $\mathrm{CH}$-domain alone is not sufficient for actin binding $^{44}$. Recent data suggest that the $\mathrm{CH}$ domain has a regulatory function ${ }^{45-47}$ whereas the 23-residue repeat sequences (also called calponin-like or CLIK 
repeats) at the C-terminus of calponin mediate the actin binding properties of calponin.

The interaction between calponin and actin results in a conformational change of both actin and calponin ${ }^{45,48,49}$ and through binding to actin, calponin has the capacity to inhibit the actin-activated Mg-ATPase activity of myosin in a $\mathrm{Ca}^{2+}$ regulated manner ${ }^{50}$. Calponin hereby slows the detachment of myosin from acti $^{51,52}$. The inhibition of the Mg-ATPase activity is mediated via an amino acid sequence (residues 146-171) that shows a high degree of structural homology to the inhibitory region on troponinl, indicating that calponin is one of the proteins substituting the troponin complex in smooth muscle ${ }^{53,54}$. The inhibitory action of calponin is, in contrast to caldesmon, however, not enhanced by binding to tropomyosin. Phosphorylation of calponin by either PKC or $\mathrm{Ca}^{2+} /$ calmodulindependent kinase $\|^{50}$, or binding of CaM disrupts the actin-calponin interaction which results in reduced inhibition of actomyosin ATPase and thus increased contraction $^{55}$.

Furthermore, calponin is involved in signal transduction processes that regulate SMC contraction. When calponin is phosphorylated by Rho-kinase, it translocates to the cell membrane, where it links ERK and PKC to the plasma membrane and activates them ${ }^{56-60}$. Activated ERK moves to the contractile filaments, phosphorylates caldesmon which induces contraction ${ }^{61}$.

Although mice without calponin are viable and reproductive, the contractile properties of SM-calponin deficient mice differ from wild-type mice ${ }^{62}$. Firstly, the shortening velocity of permeabilized smooth muscle strips of knockout mice is significantly increased because of enhanced cross-bridge cycling. In addition, $\alpha$-SMA levels are reduced by approximately $25-50 \%, S M-\alpha$-tropomyosin levels by $50 \%{ }^{62}$, and a slightly different $\mathrm{h}$-caldesmon isoform was expressed in calponin deficient mice ${ }^{62}$. Physiologically, the absence of calponin revealed a blunted $\alpha$-adrenergic response of peripheral vessels to sympathetic nervous activity $^{63}$. This was accompanied by an enhanced spontaneous baroreflex sensitivity, which was suggested to be a compensatory adaptation to the impairment of the $\alpha$-adrenergic response ${ }^{63}$. During exercise this resulted in higher fluctuations of the mean arterial pressure due to enhanced muscular vasodilatation ${ }^{64}$.

\subsubsection{SM22 $\alpha$}

SM22 $\alpha$ is a calponin-related, 201-amino acid SMC-specific protein ${ }^{65,66}$ also referred to as transgelin ${ }^{67}$. Three $\operatorname{SM} 22$ isoforms $(\alpha, \beta$, and $\gamma$ ) have been described $^{68,}{ }^{69}$, of which SM22 $\alpha$ is most abundantly expressed. During embryogenesis SM $22 \alpha$ is transiently expressed in cardiac and skeletal muscle lineages. In adult mammals its expression is, however, restricted to visceral and vascular smooth muscle ${ }^{66,70}$. 
SM22 $\alpha$ has sequence homology with calponin and contains one amino terminal $\mathrm{CH}$ domain and one calponin-like carboxyterminal repeat but lacks the troponinlike domain. It has been suggested to be involved in contraction of SMC by interactions with tropomyosin and actin filaments ${ }^{71,72}$. Based on co-localization with $\alpha$-SMA filaments ${ }^{73}$ and on co-sedimentation experiments, $\mathrm{Fu}$ et al. suggested that $S M 22 \alpha$ binds to actin with multiple regions within the $\mathrm{COOH}$ domain and they claim that this does affect SMC contraction ${ }^{71}$. However, smooth muscle of SM22 $\alpha$ deficient mice revealed no altered contractile phenotype ${ }^{74}$. This may be due to functional redundancy by the closely related calponin, the structurally similar SM22 $\beta$ protein or the paralog SM22 $\alpha$ homolog ${ }^{75,76}$. Moreover, the performance of the vessels was not tested under stress conditions. When contractile responses were subsequently measured in isolated mesenteric resistance arteries of SM $22 \alpha$ deficient mice, they showed, indeed, a $40 \%$ decreased contractility. In addition, $\alpha$-SMA content was 10-25\% lower in all vessel types of knock-out versus wild-type mice ${ }^{77}$. Calponin levels however were not altered and calponin did not compensate for the loss of function due to $\mathrm{SM} 22 \alpha$ deficiency ${ }^{77}$. Electron micrographs showed a subtle change in the actin filament distribution in SMCs, indicating that SM22 $\alpha$ is indeed involved in the organization of distribution of actin filaments in $\mathrm{SMCs}^{74}$. Also, in atherosclerotic plaques of SM22a deficient mice, SMCs showed more proliferation which may involve the reorganization of the actin cytoskeleton ${ }^{71,74,}$ 77,78 . In addition, Je et al. showed that aortas of SM22 $\alpha$-deficient mice displayed an almost three-fold increase in expression of SM22 $\beta$, while they did not find changes in actin, caldesmon, desmin or calponin. Furthermore, they provided evidence that SM22a is involved in $\mathrm{Ca}^{2+}$-independent vascular smooth muscle contraction, probably involving ERK-dependent signalling ${ }^{79}$.

\subsubsection{Telokin}

Telokin (also called kinase-related protein) is a small (17 kDa) cytoplasmic protein, transcribed from the mylk1 gene and is, as such, identical to the Cterminal part of MLCK. Telokin is expressed exclusively in smooth muscle cells ${ }^{80}$ where it stabilizes myosin filaments ${ }^{81}$ and promotes myosin polymerization, inducing filament extension ${ }^{82,}{ }^{83}$. However, its influence on myosin phosphorylation appear to be physiologically more significant ${ }^{84}$. The mechanism by which telokin acts is unclear, but several theories have been suggested, including a direct competition for myosin between MLCK and telokin ${ }^{85}$, and increased MRLC dephosphorylation ${ }^{86}$. There are also reports claiming that telokin directly inhibits $M L C K^{87,88}$. Through these actions telokin is an important protein in smooth muscle relaxation induced by elevated levels of cyclic guanosine monophosphate (CGMP) and activation of PKG and PKA (see 
paragraph 2.6). In this way, telokin induces calcium desensitization (see paragraph 2.4) of SMCs by enhancing the activity of MLCP ${ }^{84,89}$.

A recently generated telokin-deficient mouse model confirmed that telokin is involved in calcium desensitization. The telokin deficient mice had, compared with wild-type mice, decreased MLCP activity resulting in a higher level of MRLC phosphorylation ${ }^{90}$. This was most obvious in phasic smooth muscle. The SMCs of the mice contained normal myosin filaments, showing that telokin is not necessary for myosin filament formation and stability. In conclusion the mouse data indicate that the primary role for telokin is to modulate force by increasing MLCP activity and that this effect is further potentiated through phosphorylation by CGMP in telokin-rich (phasic) smooth muscle.

The summarized reports, in particular the mouse targeting studies, show that actin and myosin are the essential parts of the contractile machinery and that filament-associated proteins are not essential for smooth muscle function. However, without the associated proteins the actin-myosin interaction is not efficient and poorly controlled. The various mouse models have made clear that the associated proteins are necessary for full potential of smooth muscle contractility and that they play a role in smooth muscle contraction regulation. They contribute to various aspects of the contraction process, ranging from maintaining structure to calcium handling. However, some characteristics of smooth muscle contraction can not be explained by the already discovered functions of the described proteins. It therefore likely that either additional roles of the established regulatory proteins or new functions of other proteins, like for instance smoothelins, will be discovered to contribute to smooth muscle contraction.

\section{Smooth muscle contraction}

\subsection{Initiation of contraction}

Smooth muscle cell contraction can be triggered by activation of serpentine receptors, changes in membrane potential by action potentials or by activation of stretch-dependent ion channels. In response to this variety of stimuli the intracellular $\mathrm{Ca}^{2+}$ concentration increases by $\mathrm{Ca}^{2+}$ release from intracellular stores (sarcoplasmic reticulum) and by entry from the extracellular space through $\mathrm{Ca}^{2+}$ channels. In the cell $\mathrm{Ca}^{2+}$ binds to calmodulin (CaM), forming the $\mathrm{Ca}^{2+}$-calmodulin complex. This binding induces a conformational change, exposing sites that can interact with target proteins such as MLCK. The subsequent phosphorylation and activation of the $20 \mathrm{kDa}$ MRLC at serine19 induces the molecular interaction of the myosin complex with actin and starts 
cross-bridge cycling ${ }^{91}$. The sliding of overlapping, interdigitated actin and myosin filaments results in shortening of the contractile apparatus and generates force. However, force can also be generated by a mechanism that is independent of changes in $\mathrm{Ca}^{2+}$ concentration, which is referred to as $\mathrm{Ca}^{2+}$ sensitization ${ }^{4}$ (see section 2.4).

\subsection{Contraction types}

Vertebrate smooth muscle is functionally diverse, and characterized by different patterns of contraction. Smooth muscle contraction patterns are often divided into phasic or tonic contraction. Phasic smooth muscle, such as in the gastrointestinal tract, generates rapid cycles of rhythmic shortening and expansion with a fast maximum velocity, has a high actomyosin ATPase activity, but maintains tone poorly. On the other hand tonic smooth muscles, such as in blood vessels, have slower shortening velocities, low actomyosin ATPase activity, but are able to maintain contraction for a prolonged period of time with little energy expenditure ${ }^{17,92}$. The prolonged contraction at relatively small costs is one of the most remarkable characteristics of smooth muscle contraction. The difference between these two types of contraction is not only the consequence of differences in the contractile machinery, such as splice variants of myosin heavy chain ${ }^{23,93}$, variations in acidity of the light chain $(\mathrm{MLC} 17)^{94}$ and concentration of caldesmon and telokin ${ }^{95}$, but also of differences in kinetics of the regulatory systems ${ }^{96}$ and in signaling pathways producing different $\mathrm{Ca}^{2+}$ transients. In phasic smooth muscle a large global rise in $\mathrm{Ca}^{2+}$ underlies contraction, whereas in tonic smooth muscle latch-state and $\mathrm{Ca}^{2+}$-sensitization dominate contraction regulation ${ }^{96-99}$.

\subsection{Cross-bridge cycling}

The cross-bridge cycle model describes the interaction between myosin and actin as a series of coupled biochemical, biophysical and mechanical events. The sequence of the cross-bridge cycle is the same for all myosins, but between the different isoforms the relative rates of the individual steps are altered. The cycle starts from a state without ATP, the so-called rigor-state. The binding of ATP to either a resting myosin head, or a head bound to actin results in rapid dissociation from actin. ATP is subsequently hydrolyzed to adenosine diphosphate (ADP) and inorganic phosphate ( $\mathrm{Pi})$, which both remain tightly bound to the myosin head. The energy released by the hydrolysis of ATP remains within the structure of the myosin-ADP-Pi complex and causes a major conformational change of myosin and primes it for the power stroke ${ }^{100}$. MyosinADP-Pi has a significantly higher affinity for actin than myosin-ATP. This implies 
that the myosin-ADP-Pi complex will bind rapidly and reversibly to actin, if an actin site is within reach ${ }^{101}$. Once myosin binds to actin, the myosin complex opens and $\mathrm{Pi}$ is dissociated from the complex which provides the energy for the reverse conformational change: the power stroke ${ }^{102}$. In smooth muscle crossbridges do not necessarily cycle simultaneously. Both number and cycling rate of cross-bridges, determining the contractile force, are tightly regulated ${ }^{103}$.

\subsection{Contraction regulation}

Smooth muscle contractile activity is primarily determined by phosphorylation of the MRLC by MLCK and dephosphorylation by $M L C P^{3,4}$. For years attention has been focused on $\mathrm{Ca}^{2+}$-dependent activation of MLCK, that catalyses MRLC phosphorylation at Ser19, thereby increasing myosin MgATPase activity and subsequently contraction. This process has for long been considered the most prominent regulatory step in contraction regulation (for review: Gallagher et al. $\left.{ }^{104}\right)$. More recently, the focus has moved towards the action of MLCP and Rhomediated inhibition of MLCP activity ${ }^{105,106}$. MLCP removes the phosphate group to promote smooth muscle relaxation. The MPLC holoenzyme consists of three subunits: a $38 \mathrm{kDa}$ catalytic subunit responsible for MRLC dephosphorylation, a $20 \mathrm{kDa}$ small regulatory subunit and a $110 \mathrm{kDa}$ regulatory myosinbinding/targeting subunit (referred to as MYPT1). Phosphorylation of MYPT1 reduces the myosin binding and the enzymatic activity of MLCP and thus indirectly promotes contraction ${ }^{107,108}$.

This process is mostly referred to as ' $\mathrm{Ca}^{2+}$ sensitization'. Two signaling pathways have been described to lead to $\mathrm{Ca}^{2+}$ sensitization, both of them not completely mapped. In the first pathway MLC phosphatase is activated by the small $G$ protein RhoA and its downstream target Rho kinase (ROK). RhoA is a GTPase ${ }^{109}$ that can be activated by numerous $G$-protein coupled receptors ${ }^{110}$. For activating ROK, RhoA has to translocate from the cytoplasm, where it is kept inactive by Rho-GDP dissociation inhibitor (RhoGDI), to the plasma membrane. This requires active guanine nucleotide exchange factors (GEFs), which catalyze the transition of RhoA-GDP to RhoA-GTP. Binding of GTP-RhoA to ROK leads to autophosphorylation, a conformational change, and activation of ROK, which subsequently phosphorylates the MYPT1-unit of MLCP.

In addition to the RhoA/ROK pathway, phospholipase $C(P L C)$ activity can affect MRLC phosphorylation. PLC can be activated by agonists such as norepinephrine, angiotensin II, and endothelin, that bind to G-protein coupled receptors. PLC catalyzes the formation of two second messengers, inositol triphosphate $\left(\mathrm{IP}_{3}\right)$ and diacylglycerol (DAG). The binding of $\mathrm{IP}_{3}$ to receptors on the sarcoplasmic reticulum results in the release of $\mathrm{Ca}^{2+}$ into the cytosol. DAG, along with $\mathrm{Ca}^{2+}$, activates protein kinase $\mathrm{C}$ (PKC). In smooth muscle several 
tissue-specific isozymes of PKC have been found. PKC regulates MRLC phosphorylation by activating the MLCP inhibitor CPI-17 through phosphorylation of Thr38 ${ }^{111}$. This phosphorylation increases after agonist stimulation ${ }^{112}$ resulting in contraction without a change in $\mathrm{Ca}^{2+}$ concentration.

Other factors, such as ZIP kinase and integrin-linked kinase (ILK), appear on the one hand to be involved in the regulation of MLCP, while on the other hand they function as $\mathrm{Ca}^{2+}$-independent $\mathrm{MLCKs}^{113-115}$ (Figure 1.1). A recent study of Dimopoulos et al. suggests that the $\mathrm{Ca}^{2+}$ dependent phosphorylation of MLCP via the $I_{3} / D A G$ pathway induces the fast initial phase of contraction whereas the RhoA pathway sustains the following slow, prolonged contraction ${ }^{97}$. Amongst others, these results show again that the magnitude of changes in intracellular $\mathrm{Ca}^{2+}$ is not necessarily directly related to the force developed. Thus, under certain conditions, submaximal levels of $\mathrm{Ca}^{2+}$ are sufficient for maximal contraction as long as MLCP is sufficiently phosphorylated: $\mathrm{Ca}^{2+}$ sensitization. On the other hand, $\mathrm{Ca}^{2+}$ desensitization is in most cases the result of inhibitory effects on MLCK by for instance action of telokin ${ }^{89,110}$. Also the $\mathrm{Ca}^{2+}$-dependent phosphorylation of MLCK by CaM kinase $\|$ decreases $\mathrm{Ca}^{2+}$ sensitivity ${ }^{116}$. Inhibition of CaM kinase II, however results in inhibition of smooth muscle contractility ${ }^{117,118}$, probably via a MAPK-induced activation of MLCK ${ }^{117}$.

In addition to the signaling pathways, data accumulated over the last five years have shown a transcriptional input in contraction regulation. Transcription factors such as CREB, c-fos and NFAT are activated via $\mathrm{Ca}^{2+}$ dependent signaling pathways and influence contraction regulation by modulating the expression of proteins involved in contraction and SMC phenotype ${ }^{119,}{ }^{120}$. Although the last decade considerable progress has been made in the understanding of the regulation of contraction, the pathways are still incompletely resolved.

\subsection{Latch}

For contraction to occur, an increase in intracellular $\mathrm{Ca}^{2+}$ concentration is necessary. However, during sustained (tonic) smooth muscle contractions, after an initial $\mathrm{Ca}^{2+}$ peak, $\mathrm{Ca}^{2+}$ levels decrease approximately $30 \%$, while contraction remains stable. This phenomenon, unique and characteristic of smooth muscle, is called the 'latch state' or 'latch'. Latch has been defined as a mechanism by which force is maintained without proportional phosphorylation and with reduced cross-bridge turnover rates ${ }^{121}$. Latch, therefore, contributes to reduced ATP consumption ${ }^{121}$ creating a highly economical tonic smooth muscle contraction. 


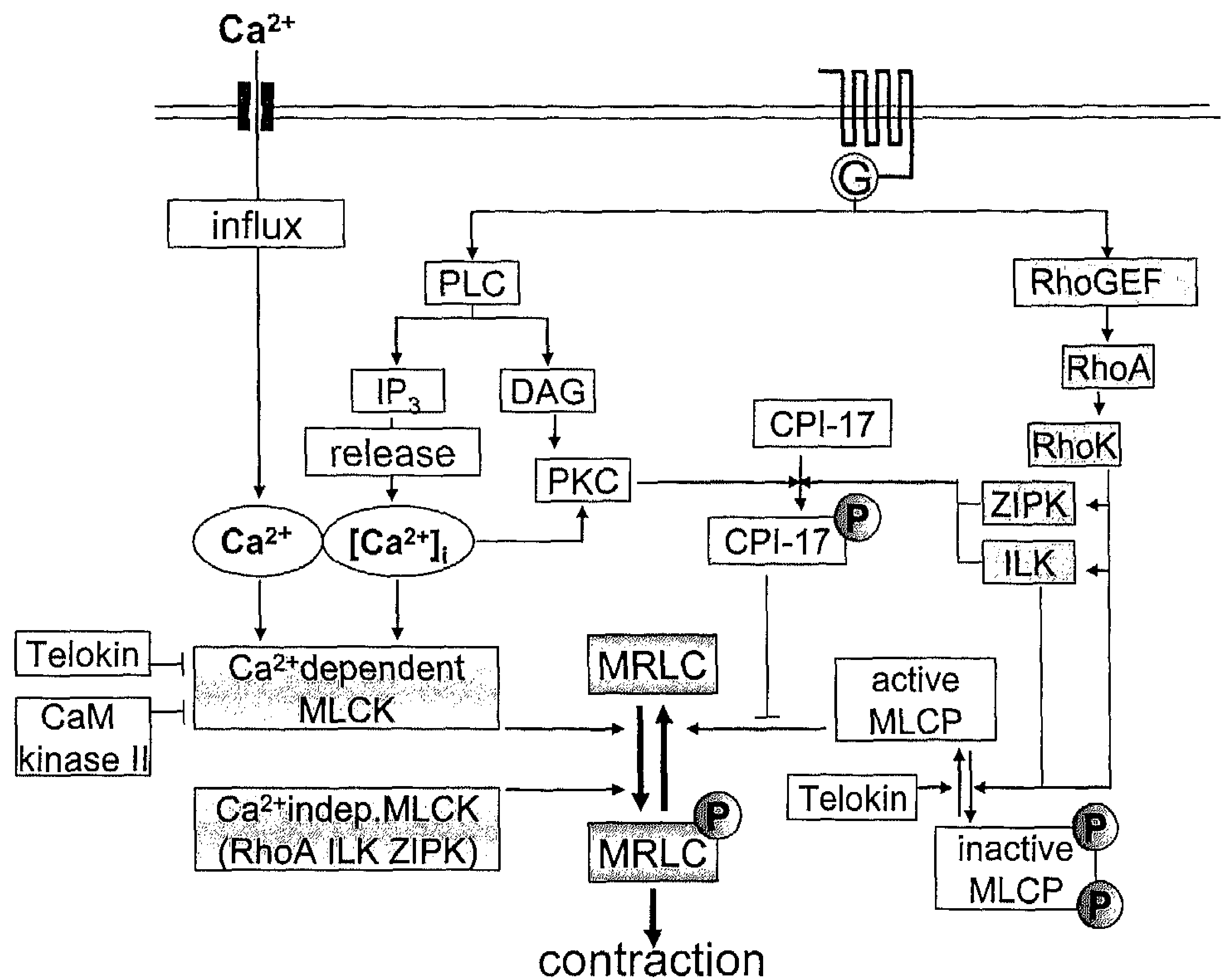

Figure 1.1 Schematic overview of signaling pathways involved in smooth muscle contraction regulation.

In 1988 Hai and Murphy proposed a model to explain the latch state ${ }^{122}$. They postulated that phosphorylation of MRLC is obligatory for cross-bridge attachment and that dephosphorylation of an attached cross-bridge reduces its detachment rate. They assumed that $\mathrm{Ca}^{2+}$-dependent MRLC phosphorylation is sufficient to explain contraction and that MLCP activity is constitutive. This, however, was not tenable, since relaxing agents like nitric oxide relax smooth muscle without changes in cross-bridge phosphorylation ${ }^{123,124}$ (see paragraph 2.6). Recently, the model has been modified by including MLCP regulation, 'cooperativity' and the presence of two populations of cross-bridges with variable or alternating cycle rates ${ }^{125,126}$.

Changes in velocity or force are also regulated by the other major component of the contractile system, the thin filaments. As described in part 1 of this introduction, thin filament associated proteins, such as caldesmon and calponin, also play a role in determining the rates of MLCP (de)phosphorylation, via their actomyosin ATPase inhibiting properties. Moreover, deficiency of these proteins 
results in altered contraction of smooth muscle ${ }^{41,63,127-129}$. In addition, recent research in bladder smooth muscle suggests that an increased content of thin filament associated proteins alters the contractile and cytoskeletal structure of SMCs and their contraction characteristics ${ }^{130-132}$. Also, smooth muscle myosins, independent of their phosphorylation status, can be activated by 'turned-on' thin filaments ${ }^{32,133-136 .}$

\subsection{Relaxation}

Smooth muscle relaxation is caused by either by removal of the contractile stimulus, or by direct action of a compound that inhibits the contractile mechanism. Regardless, relaxation requires both return of intracellular $\mathrm{Ca}^{2+}$ to resting levels and increased MLCP activity. Relaxant vasoactive compounds, such as NO and prostaglandins, stimulate synthesis of cyclic guanosine monophosphate (cGMP) and cyclic adenosine monophosphate (cAMP) by guanylate and adenylate cyclase in smooth muscle. The degradation of these cyclic compounds is regulated by phosphodiesterases (PDEs) ${ }^{137}$. They activate cGMP-dependent (PKG) and CAMP-dependent kinases (PKA), which act on various targets to regulate $\mathrm{Ca}^{2+}$ mobilization and induce relaxation ${ }^{138,139}$. PKG and/or PKA 1) inhibit $\mathrm{IP}_{3}$-dependent $\mathrm{Ca} 2+$ release, 2) stimulate $\mathrm{Ca}^{2+}$-uptake via SERCA in the sarcoplasmic membrane, 3) stimulate efflux from the cells by $\mathrm{Ca}^{2+}$ ATPase pumps in the plasmalemmal and sarcoplasmic membranes, 4) inhibit $\mathrm{Ca}^{2+}$ channel activity, and 5) stimulate $\mathrm{K}+$-channel activity causing membrane hyperpolarization and a reduction in $\mathrm{Ca}^{2+}$ influx via voltage dependent $\mathrm{Ca}^{2+}$ channels (this last point is reviewed by Tanaka et al. ${ }^{140}$ ). The integrated activities of PKG and PKA all affect $\mathrm{Ca}^{2+}$ mobilization and thus the fast/initial contraction of SMC. Both PKA and PKG can also induce relaxation of sustained contraction by acting on targets downstream of $\mathrm{Ca}^{2+}$ mobilization. By inhibiting $\mathrm{Ca}^{2+}-\mathrm{CaM}-$ dependent activation of MLCK and by activating MLCP via telokin, they can decrease MRLC phosphorylation ${ }^{84,141}$. In addition, during the $\mathrm{Ca}^{2+}$-independent sustained phase of contraction, both kinases can lower MRLC phosphorylation by inhibiting RhoA and blocking phosphorylation of MYPT1 ${ }^{142}$.

Other mechanisms that have been reported to relax smooth muscle are lowering of the sensitivity of MLCK for $\mathrm{Ca}^{2+}$ by CaM dependent protein kinase II and phosphorylation of HSP20 ${ }^{143,}{ }^{144}$. In conclusion, most if not all pathways leading to smooth muscle relaxation eventually converge on dephosphorylation of MRLC.

Although the source of the relaxing substances or the pathways involved may be different between vascular and visceral smooth muscle, the effector pathways in both cell types are similar. 
The summarized data show the complexity of the smooth muscle contractile apparatus and its mode of action. We have described a number of components of the contractile apparatus, in particular the thin filament, and provided data for their role in regular contraction and smooth muscle peculiarities such as the latch state and $\mathrm{Ca}^{2+}$ sensitization. in the past decades, studies on smooth muscle contraction dealt largely with the working of the myosin complex and the signaling pathways that regulated its activity. Recently, however, it has become evident that contraction is not so much an interaction between an active myosin complex and passive thin filaments, as well that actin and myosin are equivalent players in this process. The difference between the two major complexes that make up the contractile apparatus lies in the way they are activated. Myosin action is regulated via phosphorylation of the several components of the myosin signaling pathways, eventually leading to the phosphorylation of MRLC. The action around actin appears to consist largely of making the thin filaments available for interaction with the myosin heads. This is achieved by removal or binding of actin-associated proteins such as tropomyosin and calponin. A number of these proteins are also found in striated muscle, but there are also proteins that are smooth muscle-specific. These proteins, amongst which recently discovered ones such as HSP2O and smoothelin, may determine the smooth muscle characteristic contraction pattern. 


\section{References}

1. Bond $M$, Somlyo AV. Dense bodies and actin polarity in vertebrate smooth muscle. $J$ Cell Biol. Nov 1982;95(2 Pt 1):403-413.

2. Draeger $A, A m o s ~ W B$, Ikebe $M$, et al. The cytoskeletal and contractile apparatus of smooth muscle: contraction bands and segmentation of the contractile elements. $J$ Cell Biol. Dec 1990;111(6 Pt 1):2463-2473.

3. Hirano $\mathrm{K}$, Kanaide $\mathrm{H}$, Abe $\mathrm{S}$, et al. Temporal changes in the calcium-force relation during histamine-induced contractions of strips of the coronary artery of the pig. $\mathrm{Br} J$ Pharmacol. Jan 1991;102(1):27-34.

4. Somlyo AP, Somlyo AV. Signal transduction and regulation in smooth muscle. Nature. Nov 17 1994;372(6503):231-236.

5. Pollard TD, Cooper JA. Actin and actin-binding proteins. A critical evaluation of mechanisms and functions. Annu Rev Biochem. 1986;55:987-1035.

6. Carlier MF. Actin: protein structure and filament dynamics. J Biol Chem. Jan 5 1991;266(1):1-4.

7. Korn ED, Carlier MF, Pantaloni D. Actin polymerization and ATP hydrolysis. Science. 1987;238:638-644.

8. Rubenstein PA. The functional importance of multiple actin isoforms. BioEssays. 1990;12(7):309-315.

9. North AJ, Gimona M, Lando Z, et al. Actin isoform compartments in chicken gizzard smooth muscle cells. J Cell Sci. Mar 1994;107 ( Pt 3):445-455.

10. Vanderkerckhove J, Weber K. At least six different actins are expressed in a higher mamal: an analysis based on the amino acid sequense of the amino terminal tryptic peptide. J. Mol. Biol. 1978;126:783-802.

11. Herman IM. Actin isoforms. Cur. Opin. Cell Biol. 1993;5:48-55.

12. Ruzicka DL, Schwartz RJ. Sequential activation of alpha-actin genes during avian cardiogenesis: vascular smooth muscle alpha-actin gene transcripts mark the onset of cardiomyocyte differentiation. J Cell Biol. Dec 1988;107(6 Pt 2):2575-2586.

13. Skalli O, Vandekerckhove J, Gabbiani G. Actin-isoform pattern as a marker of normal or pathological smooth-muscle and fibroblastic tissues. Differentiation. $1987 ; 33(3): 232-238$.

14. Ausma J, Litjens $\mathrm{N}$, Lenders $\mathrm{MH}$, et al. Time course of atrial fibrillation-induced cellular structural remodeling in atria of the goat. J Mol Cell Cardiol. Dec 2001;33(12):20832094.

15. Schildmeyer LA, Braun R, Taffet $G$, et al. Impaired vascular contractility and blood pressure homeostasis in the smooth muscle alpha-actin null mouse. FASEB J. 2000;14(14):2213-2220.

16. Hinz B, Gabbiani G, Chaponnier C. The NH2-terminal peptide of alpha-smooth muscle actin inhibits force generation by the myofibroblast in vitro and in vivo. J Cell Biol. May 13 2002;157(4):657-663.

17. Babu GJ, Warshaw DM, Periasamy M. Smooth muscle myosin heavy chain isoforms and their role in muscle physiology. Microsc Res Tech. Sep 15 2000;50(6):532-540.

18. Trybus KM. Regulation of smooth muscle myosin. Cell Motil Cytoskeleton. 1991;18(2):81-85.

19. Kamm KE, Stull JT. The function of myosin and myosin light chain kinase phosphorylation in smooth muscle. Annu Rev Pharmacol Toxicol. 1985;25:593-620. 
20. Quevillon-Cheruel S, Foucault G, Desmadril M, et al. Role of the C-terminal extremities of the smooth muscle myosin heavy chains: implication for assembly properties. FEBS Lett. Jul 9 1999;454(3):303-306.

21. Rovner AS, Fagnant PM, Lowey $S$, et al. The carboxyl-terminal isoforms of smooth muscle myosin heavy chain determine thick filament assembly properties. J Cell Biol. Jan 7 2002;156(1):113-123.

22. Lauzon AM, Tyska MJ, Rovner AS, et al. A 7-amino-acid insert in the heavy chain nucleotide binding loop alters the kinetics of smooth muscle myosin in the laser trap. $J$ Muscle Res Cell Motil. Nov 1998;19(8):825-837.

23. Babu GJ, Loukianov E, Loukianova $T$, et al. Loss of SM-B myosin affects muscle shortening velocity and maximal force development. Nat Cell Biol. Nov 2001;3(11):1025-1029.

24. Martin AF, Bhatti S, Pyne-Geithman GJ, et al. Expression and function of COOHterminal myosin heavy chain isoforms in mouse smooth muscle. Am J Physiol Cell Physiol. Jul 2007;293(1):C238-245.

25. Morano I, Chai GX, Baltas LG, et al. Smooth-muscle contraction without smoothmuscle myosin. Nat Cell Biol. Jun 2000;2(6):371-375.

26. Kuro-o $M$, Nagai $R$, Nakahara $K$, et al. cDNA cloning of a myosin heavy chain isoform in embryonic smooth muscle and its expression during vascular development and in arteriosclerosis. J Biol Chem. Feb 25 1991;266(6):3768-3773.

27. Lofgren $M$, Ekblad $E$, Morano I, et al. Nonmuscle Myosin motor of smooth muscle. $J$ Gen Physiol. Apr 2003;121(4):301-310.

28. Spudich JA, Watt S. The regulation of rabbit skeletal muscle contraction. I. Biochemical studies of the interaction of the tropomyosin-troponin complex with actin and the proteolytic fragments of myosin. J Biol Chem. Aug 10 1971;246(15):4866-4871.

29. Lehrer SS. The regulatory switch of the muscle thin filament: $\mathrm{Ca}^{2+}$ or myosin heads? J Muscle Res Cell Motil. Jun 1994;15(3):232-236.

30. Gordon AM, Homsher E, Regnier M. Regulation of contraction in striated muscle. Physiol Rev. Apr 2000;80(2):853-924.

31. Somlyo AV, Goldman YE, Fujimori $T$, et al. Cross-bridge kinetics, cooperativity, and negatively strained cross-bridges in vertebrate smooth muscle. A laser-flash photolysis study. J Gen Physiol. Feb 1988;91(2):165-192.

32. Haeberle JR. Thin-filament linked regulation of smooth muscle myosin. J Muscle Res Cell Motil. May 1999;20(4):363-370.

33. Sobieszek A, Small JV. Effect of muscle and non-muscle tropomyosins in reconstituted skeletal muscle actomyosin. Eur J Biochem. Sep 1 1981;118(3):533-539.

34. Smith $\mathrm{CW}$, Pritchard $\mathrm{K}$, Marston SB. The mechanism of $\mathrm{Ca}^{2+}$ regulation of vascular smooth muscle thin filaments by caldesmon and calmodulin. $J$ Biol Chem. Jan 5 1987;262(1):116-122.

35. Chalovich JM, Cornelius P, Benson CE. Caldesmon inhibits skeletal actomyosin subfragment-1 ATPase activity and the binding of myosin subfragment-1 to actin. J Biol Chem. Apr 25 1987;262(12):5711-5716.

36. Huber PA. Caldesmon. Int J Biochem Cell Biol. Aug-Sep 1997;29(8-9):1047-1051.

37. Wang $C L$, Chalovich JM, Graceffa $P$, et al. A long helix from the central region of smooth muscle caldesmon. J Biol Chem. Jul 25 1991;266(21):13958-13963.

38. Wang CL. Caldesmon and smooth-muscle regulation. Cell Biochem Biophys. 2001;35(3):275-288. 
39. Wang $\mathrm{Z}$, Jiang $\mathrm{H}$, Yang $\mathrm{ZQ}$, et al. Both $\mathrm{N}$-terminal myosin-binding and C-terminal actinbinding sites on smooth muscle caldesmon are required for caldesmon-mediated inhibition of actin filament velocity. Proc Natl Acad Sci U 5 A. Oct 28 1997;94(22):11899-11904.

40. Huang R, Li L, Guo H, et al. Caldesmon binding to actin is regulated by calmodulin and phosphorylation via different mechanisms. Biochemistry. Mar 11 2003;42(9):25132523.

41. Guo H, Wang CL. Specific disruption of smooth muscle caldesmon expression in mice. Biochem Biophys Res Commun. May 20 2005;330(4):1132-1137.

42. Earley JJ, Su X, Moreland RS. Caldesmon inhibits active crossbridges in unstimulated vascular smooth muscle: an antisense oligodeoxynucleotide approach. Circ Res. Sep 21 1998;83(6):661-667.

43. Szymanski PT. Calponin ( $\mathrm{CaP}$ ) as a latch-bridge protein--a new concept in regulation of contractility in smooth muscles. J Muscle Res Cell Motil. 2004;25(1):7-19.

44. Gimona $M$, Mital $R$. The single $\mathrm{CH}$ domain of calponin is neither sufficient nor necessary for F-actin binding. J. Cell Sci. 1998;111(Pt 13):1813-1821.

45. Leinweber $B$, Tang JX, Stafford WF, et al. Calponin interaction with alpha-actinin-actin: evidence for a structural role for calponin. Biophys J. Dec 1999;77(6):3208-3217.

46. Mezgueldi $M$, Mendre $C$, Calas $B$, et al. Characterization of the regulatory domain of gizzard calponin. Interactions of the 145-163 region with F-actin, calcium-binding proteins, and tropomyosin. J Biol Chem. Apr 14 1995;270(15):8867-8876.

47. Galkin VE, Orlova A, Fattoum A, et al. The $\mathrm{CH}$-domain of calponin does not determine the modes of calponin binding to F-actin. J Mol Biol. Jun 2 2006;359(2):478-485.

48. Bartegi A, Roustan C, Kassab R, et al. Fluorescence studies of the carboxyl-terminal domain of smooth muscle calponin effects of F-actin and salts. Eur J Biochem. Jun 1999;262(2):335-341.

49. Borovikov Yu S, Horiuchi KY, Avrova SV, et al. Modulation of actin conformation and inhibition of actin filament velocity by calponin. Biochemistry. Oct 29 1996;35(43):13849-13857.

50. Winder SJ, Walsh MP. Smooth muscle calponin. Inhibition of actomyosin MgATPase and regulation by phosphorylation. J Biol Chem. Jun 15 1990;265(17):10148-10155.

51. Obara K, Szymanski PT, Tao T, et al. Effects of calponin on isometric force and shortening velocity in permeabilized taenia coli smooth muscle. Am J Physiol. Feb 1996;270(2 Pt 1):C481-487.

52. Winder SJ, Allen BG, Clement-Chomienne O, et al. Regulation of smooth muscle actinmyosin interaction and force by calponin. Acta Physiol Scand. Dec 1998;164(4):415426.

53. Takahashi K, Hiwada K, Kokubu T. Isolation and characterization of a 34,000-dalton calmodulin- and F-actin-binding protein from chicken gizzard smooth muscle. Biochem Biophys Res Commun. Nov 26 1986;141(1):20-26.

54. Takahashi K, Hiwada K, Kokubu T. Vascular smooth muscle calponin. A novel troponin T-like protein. Hypertension. Jun 1988;11(6 Pt 2):620-626.

55. Winder SJ, Walsh MP, Vasulka $C$, et al. Calponin-calmodulin interaction: properties and effects on smooth and skeletal muscle actin binding and actomyosin ATPases. Biochemistry. Dec 7 1993;32(48):13327-13333. 
56. Je HD, Gangopadhyay SS, Ashworth TD, et al. Calponin is required for agonist-induced signal transduction--evidence from an antisense approach in ferret smooth muscle. $J$. Physiol. 2001;537(Pt 2):567-577.

57. Kaneko T, Amano M, Maeda A, et al. Identification of calponin as a novel substrate of Rho-kinase. Biochem Biophys Res Commun. Jun 24 2000;273(1):110-116.

58. Leinweber B, Parissenti AM, Gallant $C$, et al. Regulation of protein kinase $C$ by the cytoskeletal protein calponin. J Biol Chem. Dec 22 2000;275(51):40329-40336.

59. Menice CB, Hulvershorn J, Adam LP, et al. Calponin and mitogen-activated protein kinase signaling in differentiated vascular smooth muscle. I Biol Chem. Oct 3 1997;272(40):25157-25161.

60. Sohn UD, Cao W, Tang DC, et al. Myosin light chain kinase- and PKC-dependent contraction of LES and esophageal smooth muscle. Am J Physiol Gastrointest Liver Physiol. Aug 2001;281(2):G467-478.

61. Dessy $C$, Kim I, Sougnez $\mathrm{CL}$, et al. A role for MAP kinase in differentiated smooth muscle contraction evoked by alpha-adrenoceptor stimulation. Am J Physiol. Oct 1998;275(4 Pt 1):C1081-1086.

62. Matthew JD, Khromov AS, MCDuffie MJ, et al. Contractile properties and proteins of smooth muscles of a calponin knockout mouse. J. Physiol. 2000;529 Pt 3:811-824.

63. Masuki S, Takeoka M, Taniguchi S, et al. Enhanced baroreflex sensitivity in free-moving calponin knockout mice. Am J Physiol Heart Circ Physiol. Mar 2003;284(3):H939-946.

64. Masuki S, Takeoka $M$, Taniguchi $S$, et al. Impaired arterial pressure regulation during exercise due to enhanced muscular vasodilatation in calponin knockout mice. $J$ Physiol. Nov 15 2003;553(Pt 1):203-212.

65. Nishida W, Kitami $Y$, Hiwada K. cDNA cloning and mRNA expression of calponin and SM22 in rat aorta smooth muscle cells. Gene. Aug 25 1993;130(2):297-302.

66. Solway J, Seltzer J, Samaha FF, et al. Structure and expression of a smooth muscle cellspecific gene, SM22 alpha. J Biol Chem. Jun 2 1995;270(22):13460-13469.

67. Lawson D, Harrison M, Shapland C. Fibroblast transgelin and smooth muscle SM22alpha are the same protein, the expression of which is down-regulated in many cell lines. Cell Motil Cytoskeleton. 1997;38(3):250-257.

68. Lees-Miller JP, Heeley DH, Smillie LB. An abundant and novel protein of $22 \mathrm{kDa}$ (SM22) is widely distributed in smooth muscles. Purification from bovine aorta. Biochem J. Jun 15 1987;244(3):705-709.

69. Lees-Miller JP, Heeley DH, Smillie LB, et al. Isolation and characterization of an abundant and novel 22-kDa protein (SM22) from chicken gizzard smooth muscle. J Biol Chem. Mar 5 1987;262(7):2988-2993.

70. Li L, Miano JM, Cserjesi P, et al. SM22 alpha, a marker of adult smooth muscle, is expressed in multiple myogenic lineages during embryogenesis. Circ. Res. 1996;78(2):188-195.

71. Fu Y, Liu HW, Forsythe SM, et al. Mutagenesis analysis of human SM22: characterization of actin binding. J. Appl. Physiol. 2000;89(5):1985-1990.

72. Kobayashi R, Kubota T, Hidaka H. Purification, characterization, and partial sequence analysis of a new $25-\mathrm{kDa}$ actin-binding protein from bovine aorta: a SM22 homolog. Biochem Biophys Res Commun. Feb 15 1994;198(3):1275-1280.

73. Small JV, Gimona M. The cytoskeleton of the vertebrate smooth muscle cell. Acta Physiol Scand. Dec 1998;164(4):341-348. 
74. Zhang JC, Kim S, Helmke BP, et al. Analysis of SM22alpha-deficient mice reveals unanticipated insights into smooth muscle cell differentiation and function. Mol. Cell. Biol. 2001;21(4):1336-1344.

75. Stanier P, Abu-Hayyeh S, Murdoch JN, et al. Paralogous sm22alpha (Tagln) genes map to mouse chromosomes 1 and 9: further evidence for a paralogous relationship. Genomics. Jul 1 1998;51(1):144-147.

76. Zhang JC, Helmke BP, Shum A, et al. SM22beta encodes a lineage-restricted cytoskeletal protein with a unique developmentally regulated pattern of expression. Mech Dev. Jul 2002;115(1-2):161-166.

77. Zeidan A, Sward K, Nordstrom I, et al. Ablation of SM22alpha decreases contractility and actin contents of mouse vascular smooth muscle. FEBS Lett. Mar 26 2004;562(13):141-146.

78. Feil 5, Hofmann F, Feil R. SM22alpha modulates vascular smooth muscle cell phenotype during atherogenesis. Circ Res. Apr 16 2004;94(7):863-865.

79. Je HD, Sohn UD. SM22alpha is required for agonist-induced regulation of contractility: evidence from SM22alpha knockout mice. Mol Cells. Apr 30 2007;23(2):175-181.

80. Herring $B P$, Lyons $G E$, Hoggatt $A M$, et al. Telokin expression is restricted to smooth muscle tissues during mouse development. Am I Physiol Cell Physiol. Jan 2001;280(1):C12-21.

81. Shirinsky VP, Vorotnikov AV, Birukov KG, et al. A kinase-related protein stabilizes unphosphorylated smooth muscle myosin minifilaments in the presence of ATP. J Biol Chem. Aug 5 1993;268(22):16578-16583.

82. Komatsu S, Miyazaki $K$, Tuft RA, et al. Translocation of telokin by CGMP signaling in smooth muscle cells. Am J Physiol Cell Physiol. Sep 2002;283(3):C752-761.

83. Kudryashov DS, Vorotnikov AV, Dudnakova TV, et al. Smooth muscle myosin filament assembly under control of a kinase-related protein (KRP) and caldesmon. $J$ Muscle Res Cell Motil. 2002;23(4):341-351.

84. Wu X, Haystead TA, Nakamoto RK, et al. Acceleration of myosin light chain dephosphorylation and relaxation of smooth muscle by telokin. Synergism with cyclic nucleotide-activated kinase. J Biol Chem. May 1 1998;273(18):11362-11369.

85. Silver DL, Vorotnikov AV, Watterson DM, et al. Sites of interaction between kinaserelated protein and smooth muscle myosin. J Biol Chem. Oct 3 1997;272(40):2535325359.

86. Krymsky MA, Kudryashov DS, Shirinsky VP, et al. Phosphorylation of kinase-related protein (telokin) in tonic and phasic smooth muscles. I Muscle Res Cell Motil. 2001;22(5):425-437.

87. Nieznanski K, Sobieszek A. Telokin (kinase-related protein) modulates the oligomeric state of smooth-muscle myosin light-chain kinase and its interaction with myosin filaments. Biochem J. Feb 15 1997;322 (Pt 1):65-71.

88. Sobieszek A, Andruchov OY, Nieznanski K. Kinase-related protein (telokin) is phosphorylated by smooth-muscle myosin light-chain kinase and modulates the kinase activity. Biochem J. Dec 1 1997;328 (Pt 2):425-430.

89. Choudhury $\mathrm{N}$, Khromov AS, Somlyo AP, et al. Telokin mediates $\mathrm{Ca}^{2+}$-desensitization through activation of myosin phosphatase in phasic and tonic smooth muscle. $J$ Muscle Res Cell Motil. 2004;25(8):657-665. 
90. Khromov AS, Wang $\mathrm{H}$, Choudhury $\mathrm{N}$, et al. Smooth muscle of telokin-deficient mice exhibits increased sensitivity to $\mathrm{Ca}^{2+}$ and decreased cGMP-induced relaxation. Proc Natl Acad Sci U S A. Feb 14 2006;103(7):2440-2445.

91. Harnett KM, Biancani P. Calcium-dependent and calcium-independent contractions in smooth muscles. Am J Med. Aug 18 2003;115 Suppl 3A:24S-30S.

92. Horowitz A, Menice $C B$, Laporte $R$, et al. Mechanisms of smooth muscle contraction. Physiol Rev. Oct 1996;76(4):967-1003.

93. Kelley CA, Adelstein RS. Characterization of isoform diversity in smooth muscle myosin heavy chains. Can J Physiol Pharmacol. Nov 1994;72(11):1351-1360.

94. Nabeshima $Y$, Nabeshima $Y$, Nonomura $Y$, et al. Nonmuscle and smooth muscle myosin light chain mRNAs are generated from a single gene by the tissue-specific alternative RNA splicing. J Bio/ Chem. Aug 5 1987;262(22):10608-10612.

95. Szymanski PT, Chacko TK, Rovner AS, et al. Differences in contractile protein content and isoforms in phasic and tonic smooth muscles. Am J Physiol. Sep 1998;275(3 Pt 1):C684-692.

96. Horiuti K, Somlyo AV, Goldman YE, et al. Kinetics of contraction initiated by flash photolysis of caged adenosine triphosphate in tonic and phasic smooth muscles. J Gen Physiol. Oct 1989;94(4):769-781.

97. Dimopoulos GJ, Semba S, Kitazawa K, et al. $\mathrm{Ca}^{2+}$-dependent rapid $\mathrm{Ca}^{2+}$ sensitization of contraction in arterial smooth muscle. Circ Res. Jan 5 2007;100(1):121-129.

98. Hirano $\mathrm{K}$. Current topics in the regulatory mechanism underlying the $\mathrm{Ca}^{2+}$ sensitization of the contractile apparatus in vascular smooth muscle. J Pharmacol Sci. Jun 2007;104(2):109-115.

99. Wray S, Burdyga T, Noble K. Calcium signalling in smooth muscle. Cell Calcium. Sep-Oct 2005;38(3-4):397-407.

100. Geeves MA. The dynamics of actin and myosin association and the crossbridge model of muscle contraction. Biochem J. Feb 15 1991;274 ( Pt 1):1-14.

101. Geeves MA, Holmes KC. Structural mechanism of muscle contraction. Annu Rev Biochem. 1999;68:687-728.

102. Uyeda TQ, Abramson PD, Spudich JA. The neck region of the myosin motor domain acts as a lever arm to generate movement. Proc Natl Acad Sci U S A. Apr 30 1996;93(9):4459-4464.

103. Bitar KN. Function of gastrointestinal smooth muscle: from signaling to contractile proteins. Am J Med. Aug 18 2003;115 Suppl 3A:15S-23S.

104. Gallagher PJ, Herring BP, Stull JT. Myosin light chain kinases. J Muscle Res Cell Motil. Feb 1997;18(1):1-16.

105. Hirano $K$, Hirano $M$, Kanaide $H$. Regulation of myosin phosphorylation and myofilament $\mathrm{Ca}^{2+}$ sensitivity in vascular smooth muscle. J Smooth Muscle Res. Dec 2004;40(6):219-236.

106. Kimura $K$, Ito $M$, Amano $M$, et al. Regulation of myosin phosphatase by Rho and Rhoassociated kinase (Rho-kinase). Science. Jul 12 1996;273(5272):245-248.

107. Toth A, Kiss E, Gergely $P$, et al. Phosphorylation of MYPT1 by protein kinase $C$ attenuates interaction with PP1 catalytic subunit and the $20 \mathrm{kDa}$ light chain of myosin. FEBS Lett. Nov 3 2000;484(2):113-117.

108. Velasco G, Armstrong $C$, Morrice $N$, et al. Phosphorylation of the regulatory subunit of smooth muscle protein phosphatase $1 \mathrm{M}$ at Thr850 induces its dissociation from myosin. FEBS Lett. Sep 11 2002;527(1-3):101-104. 
109. Bishop AL, Hall A. Rho GTPases and their effector proteins. Biochem J. Jun 1 2000;348 Pt 2:241-255.

110. Somlyo AP, Somlyo AV. $\mathrm{Ca}^{2+}$ sensitivity of smooth muscle and nonmuscle myosin $\mathrm{Il}$ : modulated by $G$ proteins, kinases, and myosin phosphatase. Physiol Rev. Oct 2003;83(4):1325-1358.

111. Eto $M$, Ohmori $T$, Suzuki $M$, et al. A novel protein phosphatase-1 inhibitory protein potentiated by protein kinase $C$. Isolation from porcine aorta media and characterization. J Biochem (Tokyo). Dec 1995;118(6):1104-1107.

112. Kitazawa $T$, Eto $M$, Woodsome $T P$, et al. Agonists trigger $G$ protein-mediated activation of the $\mathrm{CPI}-17$ inhibitor phosphoprotein of myosin light chain phosphatase to enhance vascular smooth muscle contractility. J Biol Chem. Apr 7 2000;275(14):98979900.

113. Deng JT, Van Lierop JE, Sutherland $\mathrm{C}$, et al. $\mathrm{Ca}^{2+}$-independent smooth muscle contraction. a novel function for integrin-linked kinase. J Biol Chem. May 11 2001;276(19):16365-16373.

114. Endo A, Surks HK, Mochizuki S, et al. Identification and characterization of zipperinteracting protein kinase as the unique vascular smooth muscle myosin phosphataseassociated kinase. J Biol Chem. Oct $12004 ; 279(40): 42055-42061$.

115. Wilson DP, Sutherland C, Borman MA, et al. Integrin-linked kinase is responsible for $\mathrm{Ca}^{2+}$-independent myosin diphosphorylation and contraction of vascular smooth muscle. Biochem J. Dec 15 2005;392(Pt 3):641-648.

116. Tansey MG, Word RA, Hidaka $H$, et al. Phosphorylation of myosin light chain kinase by the multifunctional calmodulin-dependent protein kinase II in smooth muscle cells. J Biol Chem. Jun 25 1992;267(18):12511-12516.

117. Kim I, Je HD, Gallant $C$, et al. $\mathrm{Ca}^{2+}$-calmodulin-dependent protein kinase II-dependent activation of contractility in ferret aorta. J Physiol. Jul 15 2000;526 Pt 2:367-374.

118. Rokolya A, Singer HA. Inhibition of CaM kinase 11 activation and force maintenance by KN-93 in arterial smooth muscle. Am J Physiol Cell Physiol. Mar 2000;278(3):C537-545.

119. Barlow CA, Rose P, Pulver-Kaste RA, et al. Excitation-transcription coupling in smooth muscle. J Physiol. Jan 1 2006;570(Pt 1):59-64.

120. Wamhoff BR, Bowles DK, Owens GK. Excitation-transcription coupling in arterial smooth muscle. Circ Res. Apr 14 2006;98(7):868-878.

121. Dillon PF, Aksoy MO, Driska SP, et al. Myosin phosphorylation and the cross-bridge cycle in arterial smooth muscle. Science. Jan 30 1981;211(4481):495-497.

122. Hai CM, Murphy RA. Cross-bridge phosphorylation and regulation of latch state in smooth muscle. Am J Physiol. Jan 1988;254(1 Pt 1):C99-106.

123. Etter $E F$, Eto $M, W$ ardle $R L$, et al. Activation of myosin light chain phosphatase in intact arterial smooth muscle during nitric oxide-induced relaxation. I Biol Chem. Sep 14 2001;276(37):34681-34685.

124. McDaniel NL, Chen XL, Singer HA, et al. Nitrovasodilators relax arterial smooth muscle by decreasing $\left[\mathrm{Ca}^{2+}\right] \mathrm{i}$ and uncoupling stress from myosin phosphorylation. Am J Physiol. Aug 1992;263(2 Pt 1):C461-467.

125. Hai CM, Kim HR. An expanded latch-bridge model of protein kinase C-mediated smooth muscle contraction. J Appl Physiol. Apr 2005;98(4):1356-1365.

126. Murphy RA, Rembold CM. The latch-bridge hypothesis of smooth muscle contraction. Can J Physiol Pharmacol. Oct 2005;83(10):857-864. 
127. Babu GJ, Pyne GJ, Zhou Y, et al. Isoform switching from SM-B to SM-A myosin results in decreased contractility and altered expression of thin filament regulatory proteins. Am J Physiol Cell Physiol. Sep 2004;287(3):C723-729.

128. Fujishige A, Takahashi $K$, Tsuchiya $T$. Altered mechanical properties in smooth muscle of mice with a mutated calponin locus. Zoolog Sci. Feb 2002;19(2):167-174.

129. Takahashi K, Yoshimoto R, Fuchibe $K$, et al. Regulation of shortening velocity by calponin in intact contracting smooth muscles. Biochem Biophys Res Commun. Dec 9 2000;279(1):150-157.

130. Mannikarottu AS, Disanto ME, Zderic SA, et al. Altered expression of thin filamentassociated proteins in hypertrophied urinary bladder smooth muscle. Neurourol Urodyn. 2006;25(1):78-88.

131. Mannikarottu AS, Hypolite JA, Zderic SA, et al. Regional alterations in the expression of smooth muscle myosin isoforms in response to partial bladder outlet obstruction. $J$ Urol. Jan 2005;173(1):302-308.

132. Shukla AR, Nguyen $T$, Zheng $Y$, et al. Over expression of smooth muscle specific caldesmon by transfection and intermittent agonist induced contraction alters cellular morphology and restores differentiated smooth muscle phenotype. J Urol. May 2004;171(5):1949-1954.

133. Haeberle JR. Calponin decreases the rate of cross-bridge cycling and increases maximum force production by smooth muscle myosin in an in vitro motility assay. $J$ Biol Chem. Apr 29 1994;269(17):12424-12431.

134. Haeberle JR, Coolican SA, Evan A, et al. The effects of a calcium dependent protease on the ultrastructure and contractile mechanics of skinned uterine smooth muscle. $J$ Muscle Res Cell Motil. Jun 1985;6(3):347-363.

135. Haeberle JR, Hemric ME. Are actin filaments moving under unloaded conditions in the in vitro motility assay? Biophys J. Apr 1995;68(4 Suppl):306S-310S; discussion 31053115 .

136. Haeberle JR, Trybus KM, Hemric ME, et al. The effects of smooth muscle caldesmon on actin filament motility. J Biol Chem. Nov 15 1992;267(32):23001-23006.

137. Omori K, Kotera J. Overview of PDEs and their regulation. Circ Res. Feb 16 2007;100(3):309-327.

138. Carvajal JA, Germain AM, Huidobro-Toro JP, et al. Molecular mechanism of cGMP. mediated smooth muscle relaxation. J Cell Physiol. Sep 2000;184(3):409-420.

139. Lincoln TM, Cornwell TL. Intracellular cyclic GMP receptor proteins. Faseb J. Feb 1 1993;7(2):328-338.

140. Tanaka $Y$, Koike $K$, Toro L. MaxiK channel roles in blood vessel relaxations induced by endothelium-derived relaxing factors and their molecular mechanisms. I Smooth Muscle Res. Oct 2004;40(4-5):125-153.

141. MacDonald JA, Walker LA, Nakamoto RK, et al. Phosphorylation of telokin by cyclic nucleotide kinases and the identification of in vivo phosphorylation sites in smooth muscle. FEBS Lett. Aug 18 2000;479(3):83-88.

142. Wooldridge AA, MacDonald JA, Erdodi F, et al. Smooth muscle phosphatase is regulated in vivo by exclusion of phosphorylation of threonine 696 of MYPT1 by phosphorylation of Serine 695 in response to cyclic nucleotides. J Biol Chem. Aug 13 2004;279(33):34496-34504. 
143. Beall A, Bagwell D, Woodrum D, et al. The small heat shock-related protein, HSP2O, is phosphorylated on serine 16 during cyclic nucleotide-dependent relaxation. J Biol Chem. Apr 16 1999;274(16):11344-11351.

144. Rembold CM, Foster DB, Strauss JD, et al. CGMP-mediated phosphorylation of heat shock protein 20 may cause smooth muscle relaxation without myosin light chain dephosphorylation in swine carotid artery. J Physiol. May 1 2000;524 Pt 3:865-878.

145. Buxton IL. Regulation of uterine function: a biochemical conundrum in the regulation of smooth muscle relaxation. Mol Pharmacol. May 2004;65(5):1051-1059. 


\section{Chapter 2}

\section{Smoothelins}

van Eys GJ, Niessen PM, Rensen SS.

Based on Trends in Cardiovascular Medicine, 2007;17:26-30. 


\section{Introduction}

Associated with different functional properties, smooth muscle cells (SMCs) exist in a variety of phenotypes. Depending on the type, developmental stage and condition of the tissue, SMC phenotypes can vary from contractile to synthetic/proliferative. Classically, SMC phenotypic diversity has been described in morphological terms ${ }^{1}$. Characterization has been refined by the application of a number of phenotype-specific marker proteins. The phenotypic diversity observed in vitro has also been found in vivo, where SMCs display a large variation in phenotype amongst and even within tissues. Phenotypic flexibility is necessary for SMCs to cope with varying conditions in hollow organs. Switches in gene expression that modulate the phenotype direct the adaptations of SMCs. More than ten years ago, Gary Owens published a scheme positioning marker proteins along a differentiation axis, combining embryonic appearance with morphological characteristics ${ }^{2}$. Such a scheme supposes a direct relation between marker expression and SMC phenotype. Although this still is largely true, a more complex and detailed picture of SMC phenotypic modulation has become apparent, and is in part the result of new markers that have become available ${ }^{3}$. Smoothelins are recent additions to the set of SMC markers. This review summarizes their significance as phenotypic markers.

\section{Discovery of smoothelins}

Ten years ago, a monoclonal antibody (generated against chicken gizzard) was observed to react with a hitherto unknown component that was only found in smooth muscle tissue. Analysis of a panel of tissues showed that the antibody reacted with all smooth muscle tissues (visceral as well as vascular) of a large variety of vertebrates (human to fish). The antibody was used to select a cDNA from a human intestinal smooth muscle cDNA library. This cDNA coded for an unknown, $59 \mathrm{kDa}$ protein that was designated smoothelin. The gene was cloned, and it was shown that the last three exons of the gene shared homology with genes of members of the spectrin protein family, coding for a 'calponinhomology domain' (Figure 2.1). For other structural proteins it has been shown that this domain, in a tandem repeat, preferentially binds to actin ${ }^{4,5}$. The colocalization of $\alpha$-smooth muscle actin ( $\alpha$-SMA) and smoothelin, as demonstrated in primary smooth muscle cells ${ }^{6}$ (Figure 2.2 ), indicates that the smoothelin calponin homology domain is functional. Based on sequence comparison, Quensel et al. ${ }^{7}$ claimed that smoothelin contains troponin-like elements, but no physical implication was mentioned.

Meanwhile it was found that vascular tissues contain a larger smoothelin isoform (app. $110 \mathrm{kDa}$ ). The vascular smoothelin, designated smoothelin-B, 
includes the complete smoothelin found in the viscera, which was then redesignated smoothelin-A (Figure 2.1). Transcripts for both smoothelin-A and -B are generated from a single-copy gene on human chromosome 22 . Smoothelin$B$ is encoded by 21 exons, whereas smoothelin- $A$ transcription starts in the middle of exon 10. The two transcripts are generated from the gene by two physically separated promoters. Remarkably, expression of smoothelin-A is under control of an intra-genic promoter comprising several exons of smoothelin-B (Figure 2.1). The promoter of smoothelin-B is in a more conventional position directly upstream of the first exon ${ }^{8}$.

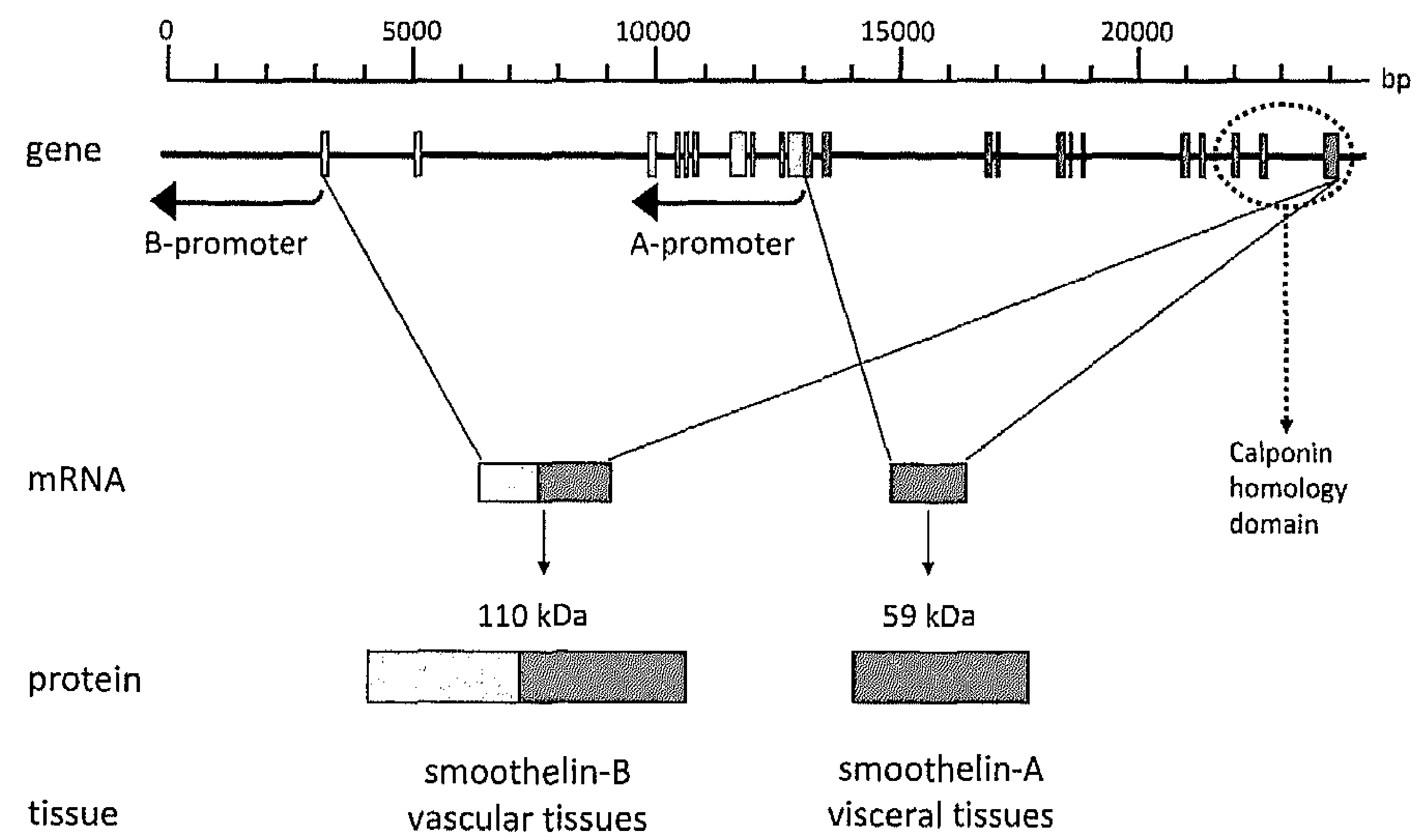

Figure 2.1 Gene structure and expression of smoothelins. Exon-intron organization of the human smoothelin gene is depicted. The dark gray boxes represent exons coding for smoothelin-A as well as smoothelin-B, the light gray boxes are smoothelin-B-specific. The promoters of both transcripts are indicated by arrows, whereas the calponin homology domain is indicated by a dotted line. Furthermore, the gene transcripts and final protein products are shown.

\section{Expression of smoothelins in vitro}

The contractile phenotype specificity of smoothelin expression became first apparent when SMCs were brought into culture. Smoothelin expression rapidly ceased, paralleling the shift towards a synthetic phenotype. The concentration of smoothelin-A mRNA of intestinal SMCs in culture fell within 12 hours to hardly detectable levels, although smoothelin protein remained present for several days ${ }^{9}$. Serum starvation or addition of compounds such as heparin results in the maintenance of detectable smoothelin- $B$ levels for a prolonged 
period ${ }^{6}$. So far, only few SMC systems have been described in which smoothelin synthesis can be induced ${ }^{10-12}$. However, in general, once smoothelin expression has ceased, it appears to be nearly impossible to re-express smoothelin protein in vitro. Nevertheless, several groups have found smoothelin transcripts in cultured SMCs by RT-PCR ${ }^{13-15}$.
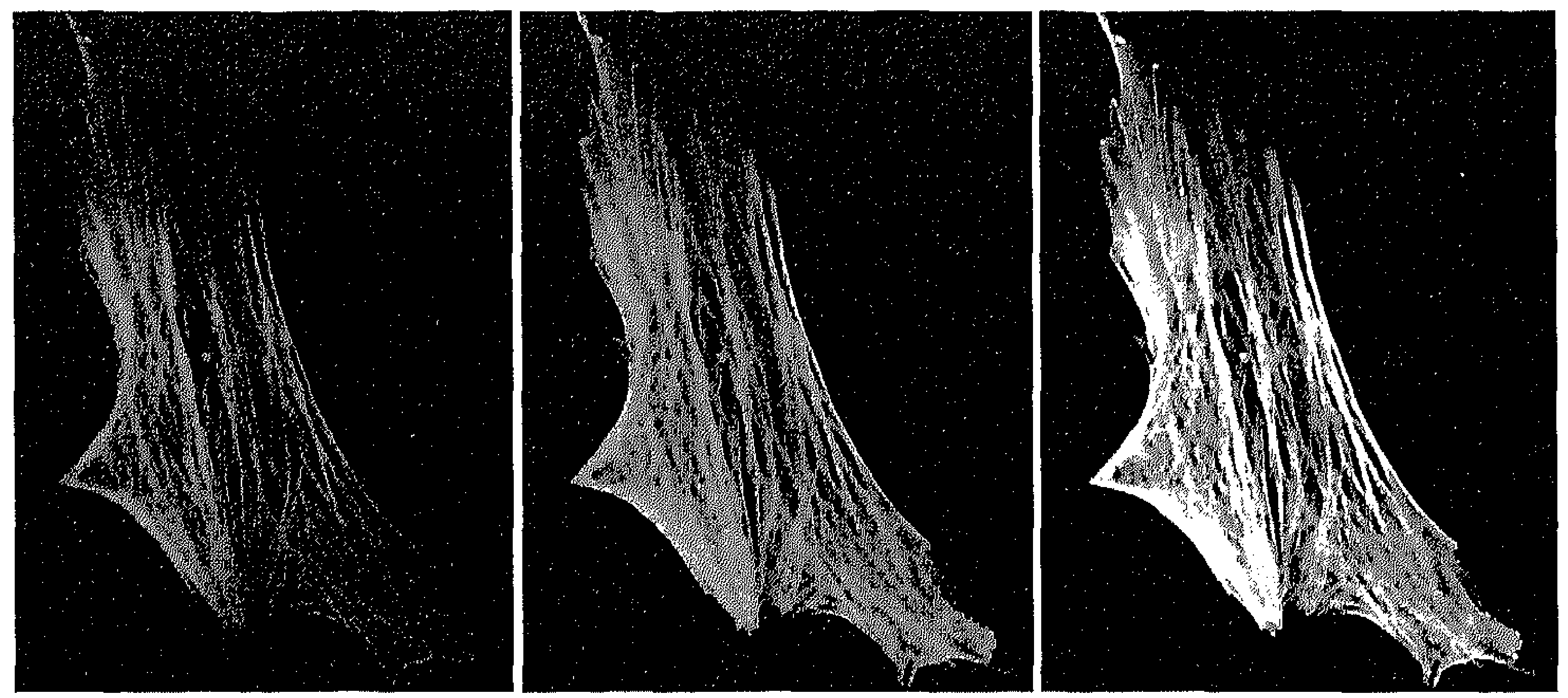

Figure 2.2 Colocalization of smoothelin and SM $\alpha$-actin in a porcine coronary artery SMC. Immunostaining with antibodies against smoothelin is shown in red (left panel) and against $\alpha$-SMA in green (middle panel). In the right panel, the two stainings are merged, demonstrating that smoothelin and $\alpha$-SMA colocalize. See front cover for color pictures.

\section{Embryonic expression of smoothelins}

Smoothelin expression in embryos differs from the pattern observed in adults. Abundant smoothelin expression is first observed in the heart and the somites ${ }^{16}$. Smoothelin expression in the heart and somites disappears in later stages of embryogenesis (Figure 2.3), although after birth remnants of smoothelin expression have been observed in the heart, in particular in the trabeculae ${ }^{16,17}$. The slightly larger embryonic heart isoform has been shown to be a smoothelinA variant that differs from the standard smoothelin-A by post-translational modification $^{16}$. In the second half of embryonic development, expression of smoothelins starts in the digestive tract and the vasculature. Surprisingly, it is the 'vascular' smoothelin-B that is found in the embryonic intestine. The Bisoform is replaced by smoothelin-A around birth ${ }^{16}$ (Figure 2.3). The physiological meaning of this switch is not clear but it may be related to the onset of peristalsis after birth. This is in line with smoothelin-A expression in the embryonic heart, since the heart is also subject to phasic contractions. Smoothelin-B, on the other hand, may operate in more tonic contractions as performed by mature vascular smooth muscle. 


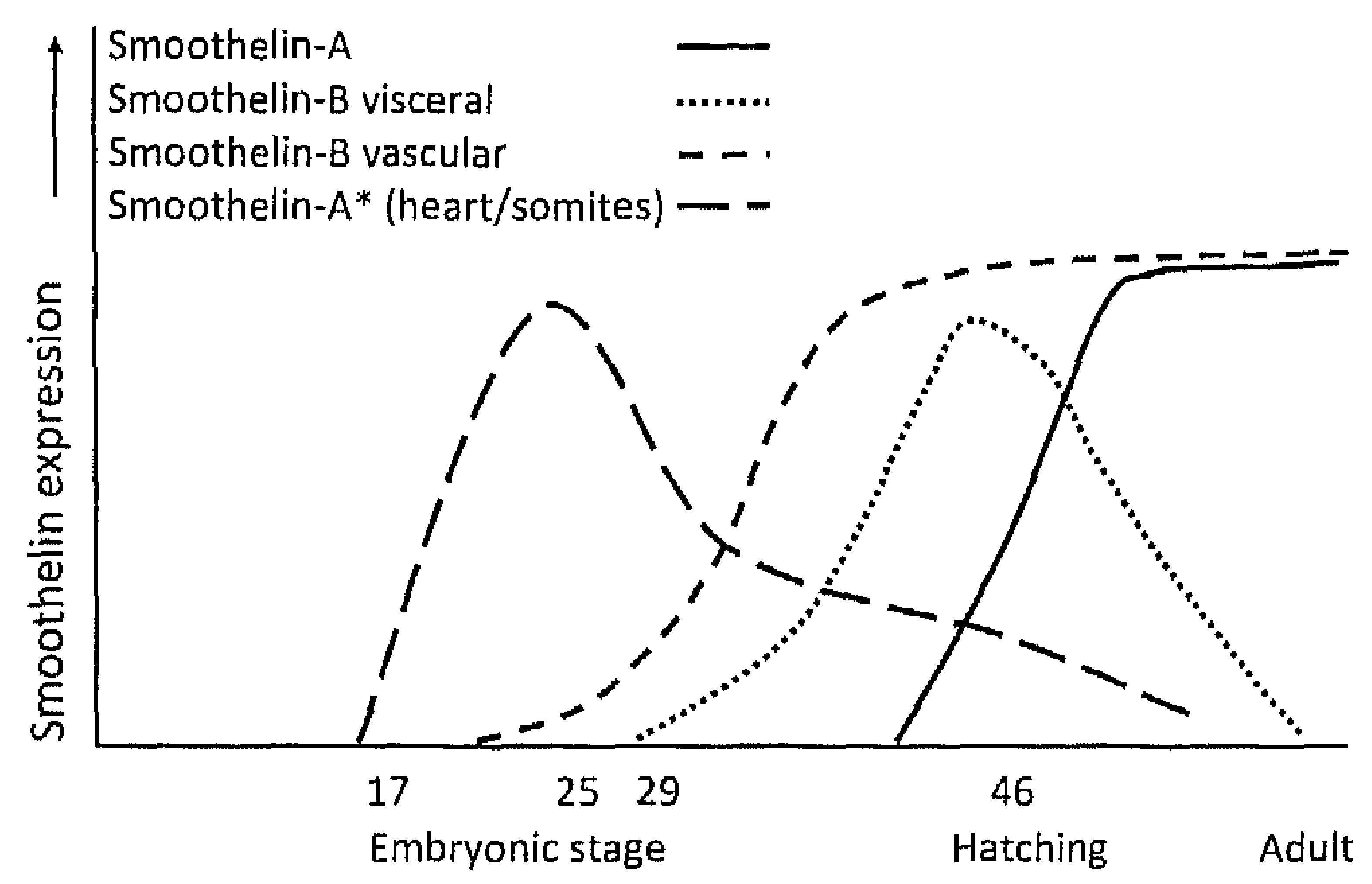

Figure 2.3 Schematic representation of the expression levels of the different smoothelin isoforms in various organs of the developing chicken embryo (based on De Ruiter et al. ${ }^{16}$ ). Although the physiological relevance of the isoform expression pattern is not clear, it may coincide with the type of contraction.

\section{Smoothelin as a marker of contractile SMCs in healthy and diseased tissue}

The phenotype specificity of smoothelins has been firmly established by different techniques (from immunohistochemistry to micro-arrays), and the use of smoothelin as a definitive marker of the SMC contractile phenotype, next to smooth muscle myosin heavy chain and SM $22 \alpha$, is now widely accepted. In fact, smoothelin is the only marker that differentiates between SMCs and myofibroblasts ${ }^{18,19}$.

In vascular tissues, the expression level of smoothelin-B is indicative of the type as well as the condition of the blood vessel. High levels are found in SMCs of arteries and relatively low expression in SMCs of veins. Not all vascular SMCs in arterial media express smoothelin. In elastic arteries, such as the aorta, the percentage of smoothelin-expressing SMCs is lower than in muscular arteries, such as the femoral artery ${ }^{19}$. In addition to these tissue-related differences, smoothelin concentration fluctuates with changing conditions. For example, van der Heijden et al., studying the uterine artery of mice during pregnancy, showed that fluctuations in smoothelin content of the media coincide with the remodeling of this artery and are inversely correlated to the expression of Ki67, a proliferation marker ${ }^{20}$. During pregnancy the murine uterine artery doubles in size to accommodate the increasing blood flow to the growing fetuses. The smoothelin concentration drops during the first half of pregnancy and starts to rise only after the vessel expansion starts to slow down. This and similar findings 
in other more pathology-related experimental set-ups (see below) indicate that the smoothelin concentration has to decrease to facilitate the remodeling process. Thus, smoothelin is a good marker to monitor SMC phenotypic shifts that occur during physiological vascular remodeling.

A number of vascular diseases are in part a process of pathological vascular remodeling and also in these cases smoothelin is increasingly used as a marker to evaluate the condition of the tissue. If the vessel wall is injured, it reacts by reinforcing the damaged area by proliferation and migration of SMCs into the intima, as seen in restenosis, or by formation of a fibrous cap, as seen in atherosclerosis. These processes are initiated by cytokines and growth factors that direct medial SMCs to proliferate. However, to start proliferation, the SMCS have to modulate towards a more synthetic phenotype, going through a series of events that include a shutdown of smoothelin expression. During restenosis, the smoothelin concentration in the SMCs of the affected area drops directly after angioplasty or stent placement ${ }^{18,21,22}$ (Figure 2.4). It stays low during migration and proliferation of the medial SMCS to the intima. When expansion of the SMCs ceases, they differentiate to a contractile phenotype, a process that is characterized by re-expression of smoothelin and smooth muscle myosin heavy chain. Work in pigs, rats and rabbits has shown that in this sequence of events smoothelin is the first marker to disappear after angioplasty and only returns after remodeling has been concluded ${ }^{18,21,22}$. This is in line with findings in human saphenous veins prepared for bypass surgery. These veins are tested to confirm their capability to handle the pressure produced by the ejecting heart. During this process smoothelin concentration drops by $60 \%{ }^{23}$. This may be one of the factors that facilitate the intimal proliferation that eventually leads to graft failure.

Another disease in which the phenotype-specific expression of smoothelin becomes manifest is atherosclerosis. In atherosclerotic lesions, in humans or in animal models, smoothelin expression decreases in the media directly below the affected area ${ }^{24,25}$. Here, too, smoothelin staining is inversely correlated with $\mathrm{Ki}-67$ staining. During plaque formation, SMCs proliferate and migrate from the affected media into the lumen of the blood vessel to form a neointima that caps the necrotic core. The neointima contains little smoothelin, while $\alpha$-SMA remains abundantly expressed ${ }^{25,26}$. However, in time, when the plaque becomes 'quiescent' and does no longer expand, smoothelin expression can be detected in SMCs of the cap ${ }^{19}$. Both in restenosis and in atherosclerotic plaques smoothelin expression is down-regulated in conjunction with smooth musclemyosin heavy chain and partly $\alpha-S M A$. However, down-regulation of smoothelin expression is usually more rapid and more uniform as compared to these other SMC contractile proteins. 

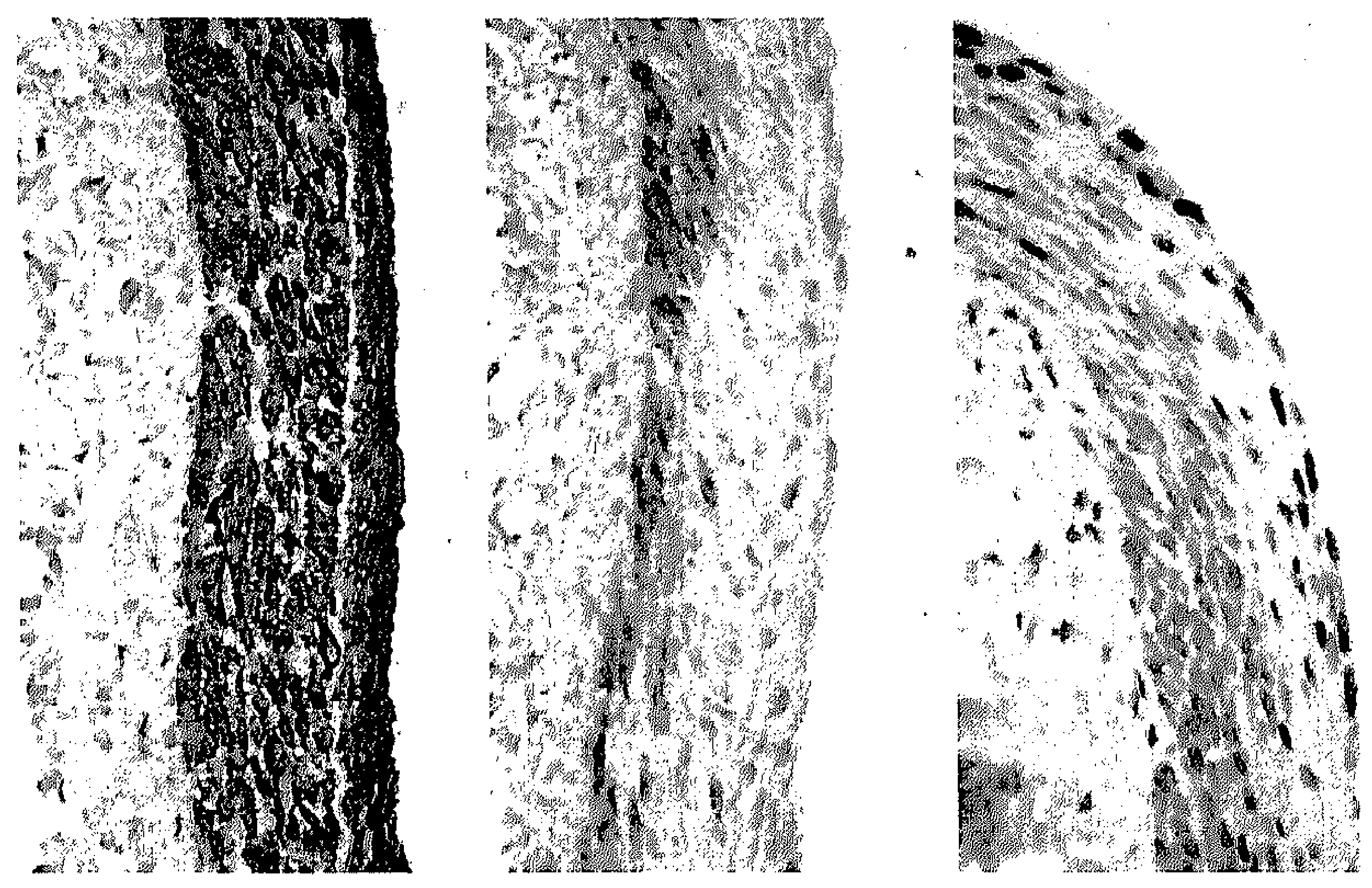

Figure 2.4 Smoothelin expression pattern in rabbit iliac arteries, 7 days after angioplasty (reprinted with permission from Maeng et al. ${ }^{18}$ ). Sections are stained for $\alpha$-SMA (left panel), smoothelin (middle panel), and a double staining for smoothelin in red and Ki-67 in brown (right panel). Note that the smoothelin staining is restricted to the deeper layers of the media, whereas proliferation, as indicated by $\mathrm{Ki}-67$, is found in the upper layers. See back cover for color pictures. 


\section{Aim of the thesis}

Although smoothelin has become one of the preferred markers to characterize the contractile phenotype of SMCs, knowledge about its function is limited. The co-localization with $\alpha$-SMA and its exclusive expression in contractile SMCs suggest that smoothelin is part of, or associated with, the contractile apparatus of SMCs. Although the unique features of SMC contraction are now better understood, not all of its properties can be explained on the basis of known contractile proteins and their regulators. The initial characterization of smoothelins was not sufficient to establish their possible role in SMC function. Therefore, the aim of the studies presented in this thesis was to investigate the function of smoothelins.

Using several in vitro approaches, we first determined if the co-localization of smoothelins with a-SMA actually resembled physical binding (chapter 3). In order to explain the tissue- and phenotype-specific expression of the smoothelins, the regulation of their expression pattern was examined next. Promoter regions for the expression of smoothelin-A were identified and the importance of specific transcriptional regulators and cis-elements in these regions for smoothelin isoform expression was assessed (chapter 4).

Functional characterization of smoothelins by in vitro techniques was impeded by the rapidly declining smoothelin levels in primary cultured SMCs. Therefore, functional studies on smoothelins required an in vivo approach. Two mouse models were generated, one deficient in the synthesis of both smoothelin isoforms (chapter 5), and one with functional smoothelin-A expression but smoothelin-B deficiency (chapter 6). The physiology and pathology of these mice was investigated and revealed a critical role for smoothelins in visceral as well as vascular smooth muscle contractile ability. To be able to position smoothelins in perspective to the contractile proteins, other smoothelin-binding proteins needed to be identified (chapter 7). The results obtained in these studies and their implications for the function of smoothelins in SMC contraction are discussed in chapter 8 . 


\section{References}

1. Chamley-Campbell J, Campbell GR, Ross R. The smooth muscle cell in culture. Physiol Rev. Jan 1979;59(1):1-61.

2. Owens GK. Regulation of differentiation of vascular smooth muscle cells. Physiol. Rev. 1995;75(3):487-517.

3. Owens GK, Kumar MS, Wamhoff BR. Molecular regulation of vascular smooth muscle cell differentiation in development and disease. Physiol Rev. Jul 2004;84(3):767-801.

4. Gimona $M$, Djinovic-Carugo $K$, Kranewitter $W J$, et al. Functional plasticity of $\mathrm{CH}$ domains. FEBS Lett. 2002;513(1):98-106.

5. Korenbaum E, Rivero F. Calponin homology domains at a glance. J Cell Sci. Sep 15 2002;115(Pt 18):3543-3545.

6. Christen $T$, Bochaton-Piallat ML, Neuville $P$, et al. Cultured porcine coronary artery smooth muscle cells. A new model with advanced differentiation. Circ. Res. 1999;85(1):99-107.

7. Quensel C, Kramer J, Cardoso $M C$, et al. Smoothelin contains a novel actin cytoskeleton localization sequence with similarity to troponin T. J. Cell. Biochem. 2002;85(2):403-409.

8. Rensen $S$, Thijssen V, De Vries $C$, et al. Expression of the smoothelin gene is mediated by alternative promoters. Cardiovasc. Res. 2002;55(4):850-863.

9. van der Loop FT, Schaart G, Timmer ED, et al. Smoothelin, a novel cytoskeletal protein specific for smooth muscle cells. J. Cell Biol. 1996;134(2):401-411.

10. van der Veer $E$, Nong $Z$, $O^{\prime}$ Neil $C$, et al. Pre-B-cell colony-enhancing factor regulates NADt-dependent protein deacetylase activity and promotes vascular smooth muscle cell maturation. Circ Res. Jul 8 2005;97(1):25-34.

11. Rodriguez LV, Alfonso Z, Zhang R, et al. Clonogenic multipotent stem cells in human adipose tissue differentiate into functional smooth muscle cells. Proc Natl Acad Sci U S A. Aug 8 2006;103(32):12167-12172.

12. Hao $H$, Ropraz $P$, Verin $V$, et al. Heterogeneity of smooth muscle cell populations cultured from pig coronary artery. Arterioscler Thromb Vasc Biol. Jul 1 2002;22(7):1093-1099.

13. Niu $Y, X \cup Y, Z$ Zhang $J$, et al. Proliferation and differentiation of prostatic stromal cells. BJU Int. Mar 2001;87(4):386-393.

14. Morrow D, Scheller A, Birney YA, et al. Notch-mediated CBF-1/RBP-J\{kappa\}dependent regulation of human vascular smooth muscle cell phenotype in vitro. Am $J$ Physiol Cell Physiol. Nov 2005;289(5):C1188-1196.

15. Yoshida T, Kawai-Kowase K, Owens GK. Forced expression of myocardin is not sufficient for induction of smooth muscle differentiation in multipotential embryonic cells. Arterioscler Thromb Vasc Biol. Sep 2004;24(9):1596-1601.

16. De Ruiter MC, Rensen SS, Coolen GP, et al. Smoothelin expression during chicken embryogenesis: Detection of an embryonic isoform. Dev. Dyn. 2001;221(4):460-463.

17. Johansson B, Eriksson A, Ramaekers $F$, et al. Smoothelin in adult and developing human arteries and myocardium. Histochem. Cell Biol. 1999;112(4):291-299.

18. Maeng $M$, Mertz $H$, Nielsen $S$, et al. Adventitial myofibroblasts play no major role in neointima formation after angioplasty. Scand Cardiovasc J. 2003;37(1):34-42.

19. van der Loop FT, Gabbiani G, Kohnen G, et al. Differentiation of smooth muscle cells in human blood vessels as defined by smoothelin, a novel marker for the contractile phenotype. Arterioscler. Thromb. Vasc. Biol. 1997;17(4):665-671. 


\section{Chapter 2}

20. van der Heijden OW, Essers YP, Simkens $L H$, et al. Aging blunts remodeling of the uterine artery during murine pregnancy. J Soc Gynecol Investig. Jul 2004;11(5):304310.

21. Christen $T$, Verin $V$, Bochaton-Piallat $M L$, et al. Mechanisms of neointima formation and remodeling in the porcine coronary artery. Circulation. 2001;103(6):882-888.

22. Bar $H$, Wende $P$, Watson $L$, et al. Smoothelin is an indicator of reversible phenotype modulation of smooth muscle cells in balloon-injured rat carotid arteries. Basic Res Cardiol. Jan 2002;97(1):9-16.

23. Johnson JL, van Eys GJ, Angelini GD, et al. Injury induces dedifferentiation of smooth muscle cells and increased matrix-degrading metalloproteinase activity in human saphenous vein. Arterioscler. Thromb. Vasc. Biol. 2001;21(7):1146-1151.

24. Verhamme P, Quarck $\mathrm{R}, \mathrm{Hao} H$, et al. Dietary cholesterol withdrawal reduces vascular inflammation and induces coronary plaque stabilization in miniature pigs. Cardiovasc Res. Oct 2002;56(1):135-144.

25. Tharp DL, Wamhoff BR, Turk JR, et al. Upregulation of intermediate-conductance $\mathrm{Ca}^{2+}$ activated $\mathrm{K}+$ channel (IKCa1) mediates phenotypic modulation of coronary smooth muscle. Am J Physiol Heart Circ Physiol. Jun 232006.

26. Hao H, Gabbiani G, Camenzind E, et al. Phenotypic modulation of intima and media smooth muscle cells in fatal cases of coronary artery lesion. Arterioscler Thromb Vasc Biol. Feb 2006;26(2):326-332. 


\section{Chapter 3}

\section{Biochemical evidence for interaction between smoothelin and filamentous actin}

Petra Niessen, Sophie Clément, Lionel Fontao, Christine Chaponnier, Birgit Teunissen, Sander Rensen, Guillaume van Eys and Giulio Gabbiani.

Experimental Cell Research, 2004;292(1):170-8. 


\begin{abstract}
The two major isoforms of smoothelin (A and B) contain a calponin homology (CH) domain, colocalize with $\alpha$-smooth muscle actin in stress fibers and are only expressed in contractile smooth muscle cells. Based on these findings, we hypothesized that smoothelins are involved in smooth muscle cell contraction, presumably via interaction with actin. The interaction between smoothelins and three different actin isoforms ( $\alpha$ - and $\gamma$-smooth muscle and $\alpha$-skeletal actin) was investigated using several in vitro assays. Smoothelin-B co-immunoprecipitated with $\alpha$-smooth muscle actin from pig aorta extracts. In rat embryonic fibroblasts, transfected smoothelins $-A$ and $-B$ associated with stress fibers. In vitro dot blot assays, in which immobilized actin was overlaid with radio-labeled smoothelin, showed binding of smoothelin-A to actin filaments, but not to monomeric $\mathrm{G}$-actin. A truncated smoothelin, containing the calponin homology domain, associated with stress fibers when transfected and bound to actin filaments in overlay, but to a lesser extent. ELISA results showed that the binding of smoothelin to actin has no significant isoform specificity. Our results indicate an interaction between smoothelin and actin filaments. Moreover, the calponin homology domain and its surrounding sequences appear to be sufficient to accomplish this interaction, although the presence of other domains is apparently necessary to facilitate and/or strengthen the binding to actin.
\end{abstract}


Biochemical evidence for interaction between smoothelin and filamentous actin

\section{Introduction}

Actin is a major component of the cytoskeleton in all eukaryotic cells and plays a fundamental role in a variety of dynamic cellular processes. The globular protein (G-actin) polymerizes into filaments (F-actin) to perform most of its biological functions ${ }^{1}$. Actin is encoded by a highly conserved gene family, which includes at least six different members in vertebrates. These isoactins ( $\alpha$-skeletal, $\alpha$-cardiac, $\alpha$-smooth muscle, $\gamma$-smooth muscle, non-muscle $\beta$ - and non-muscle $\gamma$-actin) display small differences in amino acid sequences ${ }^{2}$ and are expressed in a tissuespecific fashion that is conserved across species ${ }^{3-5}$. Actin isoforms cannot completely substitute each other ${ }^{4}$; in $\alpha$-smooth muscle actin ( $\alpha$-SMA) null mice, for example, $\alpha$-SMA is partially substituted by $\alpha$-skeletal actin $(\alpha-S K A)^{6}$, while in $\alpha$-cardiac actin ( $\alpha-C A)$ deficient mice, increased expression of $\alpha$-SMA and $\alpha$-SKA has been observed ${ }^{7}$. However, substitution and up-regulation of other actin isoforms in these mice are insufficient to maintain fully functional tissues, which results in, respectively, impaired vascular contractility and blood pressure homeostasis or even intrauterine death. High-level synthesis of exogenous actins leads to alterations in cell organization and morphology ${ }^{4}$. This indicates that the highly conserved actins are functionally specialized for the tissues in which they predominate.

Smoothelin is a structural protein with a distribution restricted to smooth muscle cells $(S M C s)^{8-10}$. In humans, two smoothelin isoforms have been characterized: smoothelin-A, a $59-\mathrm{kDa}$ protein predominantly expressed in visceral SMCs, and a larger $110-\mathrm{kDa}$ isoform, smoothelin-B, expressed in contractile vascular SMCs ${ }^{11}$. The smoothelins are encoded by a single copy gene, which consists of 21 exons and is located on human chromosome $22 q 12^{12}$. Their function and regulation are largely unknown. However, double-labeled immunofluorescence has shown that smoothelins colocalize with $\alpha$-SMA in human, porcine and chicken SMCs ${ }^{9,10,13}$. Moreover, a search for homologies at the protein level has revealed that both smoothelin isoforms contain, near their carboxy terminus, a calponin homology $(\mathrm{CH})$ domain with homology to the actin-binding domain (ABD) of members of the spectrin-superfamily ${ }^{9}$. Within this part of the gene, an alternative splice site is located, which generates three proteins of approximately the same size, but with different $\mathrm{CH}$ domains ${ }^{14,15}$. Smoothelin expression is limited to differentiated, contractile SMCs, and its concentration decreases rapidly during the early passages of cultured SMCs ${ }^{9}, 10$, ${ }^{13}$. Furthermore, a role for smoothelin in modulating SMC contraction has been suggested, since the presence of specific smoothelin isoforms in different muscle tissues correlated with the type of force the SMCs exert: smoothelin-A is expressed in pulsatile or cyclically contracting tissues, such as the early embryonic heart or the adult alimentary tract, while smoothelin-B is expressed 
in tonically contracting tissues, such as arterial blood vessels and the embryonic alimentary tract ${ }^{16}$. Taken together, these data suggest a role for smoothelin in contractile activity, possibly through interaction with actin. Defining this binding could constitute a first step in understanding the mechanism by which smoothelin influences actin action.

The present study deals with direct interactions between smoothelin and actin. Recently, it has been suggested that the $\mathrm{CH}$ domain of smoothelin is neither necessary nor sufficient for association with actin filaments ${ }^{17}$. Here we present evidence showing an interaction between smoothelin and the filaments of various actin isoforms and indicating that the $\mathrm{CH}$ domain is sufficient to constitute this binding, although the interaction is weaker than that of fulllength smoothelin.

\section{Materials and methods}

\section{Smoothelin fusion constructs}

pcDNA3-smoothelin-A was cloned as described in van der Loop et al. ${ }^{9}$. A Nterminal truncated smoothelin variant, called smoothelin- $B_{2311-3005}$, was made using the sequence-specific primers ' 5'-GGAATTCGGCAGTGGCAGCACCATG-3' (sense) and 5'-CGGGATCCTGCCACTGGCTGGCCATG-3' (antisense) containing, respectively, EcoRl and BamHI restriction sites. PCR cycles consisted of $45 \mathrm{~s}$ denaturation at $94^{\circ} \mathrm{C}, 45 \mathrm{~s}$ annealing at $55^{\circ} \mathrm{C}$, and 3 min extension at $72^{\circ} \mathrm{C}$ for 30 cycles. A pCDNA3 plasmid containing smoothelin-B CDNA ${ }^{11,14,15}$ was used as template for amplification. The acquired smoothelin sequence was inserted into pCDNA3-HA, a derivative of the eukaryotic expression vector pCDNA3 (Invitrogen AG, Basel, Switzerland) that contains an extra sequence $5^{\prime}$ of the multiple cloning site encoding the hemaglutinin (HA) tag. To obtain a gluthationS-transferase (GST)-smoothelin-A fusion protein, smoothelin-A CDNA was amplified by PCR using the pfu proofreading polymerase (Appligene Oncor, Tucson, AZ) with primers 5'-CGGGATCCAAGACCACATTCACCATC-3' (sense) and 5'-GGAATTCGACATTCT TGCCGCG-3' (antisense) containing, respectively, BamHI and EcoRI restriction sites, according to above PCR protocol. Amplified smoothelin-A was subsequently cloned into the pGex-2T vector (Amersham, Rahn AG, Zürich, Switzerland). The sequences of the generated plasmids were checked by sequencing with primers $T 7$ and Sp6. Schematic representations of the constructs are shown in Figure 3.1. 
Biochemical evidence for interaction between smoothelin and filamentous actin

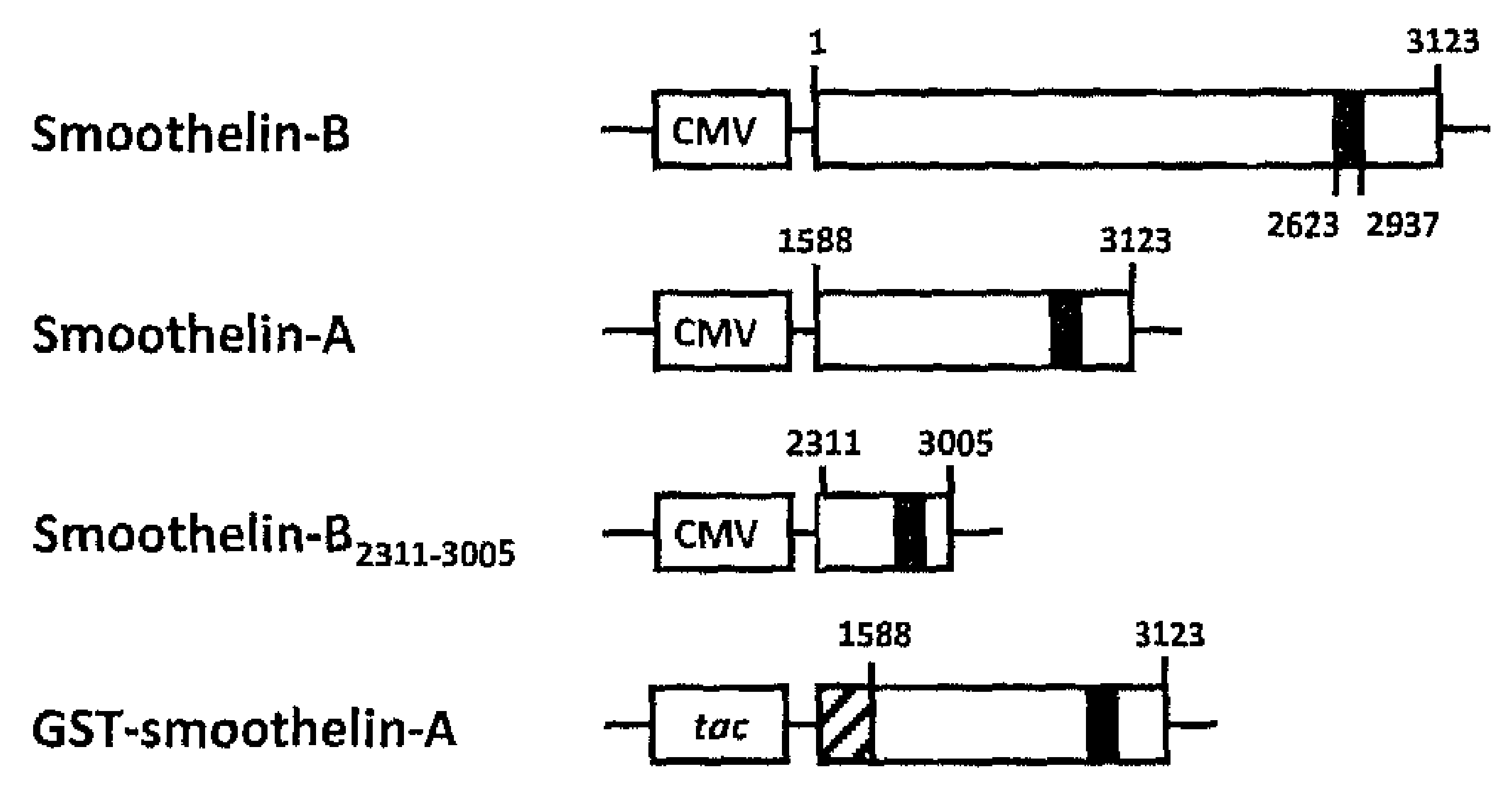

Figure 3.1 Schematic representation of the used constructs. Smoothelin- $B,-A$, and smoothelin$B_{2311-3005}$, were cloned into pcDNA3. Smoothelin- $B_{2311-3005}$ contains an $H A$ tag (grey box). Smoothelin-A was subcloned into pGEX-2T containing a tac promoter for chemically inducible, high-level expression, to obtain a gluthation-S-transferase (GST)-smoothelin-A fusion protein. The position of the $\mathrm{CH}$ domain is represented by the black box and the GST by a hatched box. Numbers correspond to base pair.

\section{Cell culture, transfection, and immunofluorescence microscopy}

Rat embryonic fibroblasts (REF52 cells) were grown in Dulbecco's Modified Eagle Medium (DMEM; Gibco-BRL, Life Technologies AG, Basel, Switzerland) supplemented with $100 \mathrm{U} / \mathrm{ml}$ penicillin, $100 \mu \mathrm{g} / \mathrm{ml}$ streptomycin, $2 \mathrm{mM} \mathrm{L-}$ glutamine, and $10 \%$ fetal calf serum (Hyclone, Logan, UT) at $37^{\circ} \mathrm{C}, 5 \% \mathrm{CO}_{2}$. Cells were transiently transfected with pcDNA3-smoothelin-A, pcDNA3-smoothelin-B, and pcDNA3-HA-smoothelin-B2311-3005, using FuGENE 6 Transfection Reagent (Roche Diagnostics AG, Rotkreuz, Switzerland) according to the manufacturer's instructions. Forty-eight hours after transfection, cells were washed twice with DMEM and fixed in 3\% paraformaldehyde in phosphate-buffered saline solution (PBS) for 10 min at RT, followed by three washes with PBS and permeabilization with $0.2 \%$ Triton X-100 in PBS for 2 min at RT. Subsequently, cells were stained with either a monoclonal anti-smoothelin antibody $R 4 A^{9}$, (undiluted) or the mouse monoclonal antibody 12CA5 (Santa Cruz Biotechnology Inc, Santa Cruz, CA, diluted 1:100 in PBS) against the hemaglutinin (HA)-epitope (YPYDVPDYA), combined with a polyclonal antibody reacting with both $\alpha$-smooth muscle and $\gamma$ actins (AL20 ${ }^{18}$ diluted 1:40 in PBS), for $30 \mathrm{~min}$ at RT. Anti-HA antibody was used to detect the truncated smoothelin (Smoo $B_{2311-3005}$ see Figure 3.1) containing the HA-tag but not the epitope for R4A. Samples were then incubated with TRITC-conjugated anti-mouse IgG1 (for R4A) or anti-mouse total IgG (for 12CA5) and fluorescein-labeled anti-rabbit antibody (all from Jackson ImmunoResearch Laboratories, West Grove, PA, and diluted 1:100 in PBS) for 30 min at RT. After washing in PBS, cells were mounted in polyvinyl alcohol $\left(\mathrm{PVA}^{19}: 50 \mathrm{mM}\right.$ Trisphosphate, $\mathrm{pH} 9.0,0.1 \%$ chlorobutanol, $20 \%$ polyvinyl alcohol, $0.5 \%$ phenol 
red, 20\% glycerol) and observed using a Zeiss Axiophot photomicroscope (Carl Zeiss, Oberkochen, Germany). Pictures were taken with a high sensibility color Axiocam camera (Zeiss) and printed with a digital Fujifilm Pictography 4000 printer (Fujifilm, Tokyo, Japan). To quantify the percentage of overlapping pixels, overlay images were analyzed by ImarisColoc software (Bitplane AG, Zürich, Switzerland).

\section{Co-immunoprecipitation}

For co-immunoprecipitation, a mouse monoclonal antibody against $\alpha$-SMA ( $\alpha$ $\mathrm{sm}^{20}{ }^{20}$ ) was covalently bound to aminolink beads (Aminolink ${ }^{\circledR}$ coupling gel, Pierce, Rockford, IL) according to the manufacturer's procedure. A tissue homogenate of the media of pig aorta was prepared in RIPA buffer $(10 \mathrm{mM}$ Tris, $150 \mathrm{mM} \mathrm{NaCl}, 0.5 \%$ Triton $X-100,0.1 \%$ sodium dodecyl sulfate [SDS], $1 \mathrm{mM}$ EDTA, pH 7.9) and clarified by centrifugation for $15 \mathrm{~min}$ at $13000 \mathrm{rpm}$ at $4^{\circ} \mathrm{C}$. Before co-immunoprecipitation, the tissue homogenate was diluted 10 times in RIPA buffer and precleared with $30 \% \mathrm{v} / \mathrm{V}$ aminolink beads for $2 \mathrm{~h}$ at $4^{\circ} \mathrm{C}$. Samples were centrifuged at $2000 \mathrm{rpm}$ for $1 \mathrm{~min}$ and supernatants collected. Precleared tissue homogenates were incubated with $30 \% \mathrm{v} / \mathrm{v}$ aminolink beads coupled with $\alpha-5 m 1$ antibody for $2 \mathrm{~h}$ at $4^{\circ} \mathrm{C}$. After three washes (10 min each) with RIPA buffer, the beads were resuspended in an equal volume of sample buffer $(62.5 \mathrm{mM}$ Tris-HCl, pH 6.8, 2\% SDS, 10\% glycerol, $50 \mathrm{mM}$ DTT, $0.01 \%$ bromophenol blue), boiled for $5 \mathrm{~min}$, and loaded on a 10\% SDS-PAGE gel ${ }^{21}$. After transferring the proteins onto a nitrocellulose membrane (Protran, BA85; Schleicher \& Schuell, Dassel, Germany ${ }^{22}$ ), the membrane was cut between the 64 and $40 \mathrm{kDa}$ marker bands and blocked for $1 \mathrm{~h}$ in 5\% milk powder in Trisbuffered saline solution (TBS: $10 \mathrm{mM}$ Tris, $154 \mathrm{mM} \mathrm{NaCl}, \mathrm{pH}$ 7.4). The upper part of the membrane was incubated with the monoclonal anti-smoothelin antibody (R4A diluted $1: 10$ in TBS containing 3\% BSA and $0.1 \%$ Triton $X-100$ ) and the lower part was incubated with AL20 (diluted 1:2000) for $1.5 \mathrm{~h}$ at RT. After three washes with TBS, the second incubation was performed with peroxidaseconjugated rabbit anti-mouse and goat anti-rabbit IgG (Jackson ImmunoResearch Laboratories) at a dilution of 1:20000 and 1:10000, respectively, in TBS containing $0.1 \%$ BSA and $0.1 \%$ Triton $X-100$. Peroxidase activity was developed using the enhanced chemiluminescence Western blotting system (Amersham) according to instructions of the manufacturer.

\section{In vitro binding assay}

Purification of $\alpha$-SMA from bovine aorta was carried out according to StrzeleckaGolaszewska et al. ${ }^{23}$. $\alpha$-SKA from rabbit skeletal muscle was purified by the method of Spudich and Watt ${ }^{24}$. Purified actin was dialyzed against G-actin buffer (G buffer: $2 \mathrm{mM}$ Tris- $-\mathrm{HCl}, 0.2 \mathrm{mM} \mathrm{CaCl}, 0.5 \mathrm{mM}$ ATP, $0.5 \mathrm{mM} \beta-$ 
Biochemical evidence for interaction between smoothelin and filamentous actin

mercaptoethanol, $\mathrm{pH} 7.8$ ) overnight at $4^{\circ} \mathrm{C}$, and protein concentration was determined by spectrophotometry at $290 \mathrm{~nm}$. Subsequently, actins were centrifuged in a Beckman Airfuge using an A-100 fixed-angle rotor (Beckman Instrument Co., Fullerton, $C A$ ) at 30 psi for $1 \mathrm{~h}$ to sediment auto-polymerized actin filaments. G-actin was allowed to polymerize at a concentration of $8 \mu \mathrm{M}$ for $30 \mathrm{~min}$ at RT by addition of $100 \mathrm{mM} \mathrm{KCl}$ and $2 \mathrm{mM} \mathrm{MgCl}$ (final concentration). Different amounts of both $\mathrm{G}$ - and F-actin $(1,2$, and $3 \mu \mathrm{g})$ were spotted on a nitrocellulose membrane using a Slot-blotter Minifold system

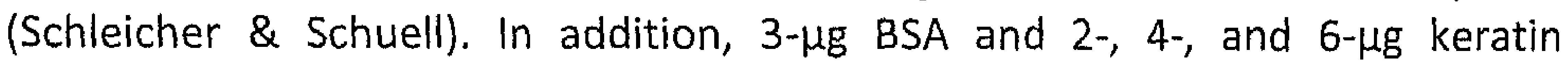
filaments K5/K14 (produced and purified as previously described ${ }^{25}$ ) were spotted. Membrane strips were stained for protein with 1\% amido-black in $15 \%$ acetic acid, $50 \%$ methanol, or incubated in Blocking Buffer ( $\mathrm{F}$ buffer: $100 \mathrm{mM}$ $\mathrm{KCl}, 2 \mathrm{mM} \mathrm{MgCl} 2$ in $\mathrm{G}$ buffer, supplemented with $1 \%$ heat-inactivated $\mathrm{BSA}$ ) for $4.5 \mathrm{~h}$ at RT and washed three times for $30 \mathrm{~min}$ in Washing Buffer ( $\mathrm{F}$ buffer supplemented with $0.2 \%$ heat-inactivated $\mathrm{BSA}) .{ }^{35} \mathrm{~S}$-methionine-labeled smoothelin-A and the truncated smoothelin were obtained by in vitro transcription-translation of pcDNA3-smoothelin-A, and pcDNA3-HA-smoothelin$B_{2311-3005}$ using the TNT ${ }^{\oplus}$ quick-coupled reticulocyte lysate system (Promega, Madison, WI). Nonincorporated radio-labeled amino acids were removed from the in vitro translation mixture using Centricon 10 filters (Millipore $A G$, Volketswil, Switzerland). The purified translation mixture was diluted into 4-ml Washing Buffer containing a protease inhibitor cocktail (complete ${ }^{\mathrm{TM}}$ EDTA-free protease inhibitor cocktail tablets; Roche Diagnostics $A G$ ) and incubated overnight at $4^{\circ} \mathrm{C}$ with the nitrocellulose strips. The strips were then washed in Washing Buffer, dried at $37^{\circ} \mathrm{C}$, and exposed $20 \mathrm{~h}$ at $-80^{\circ} \mathrm{C}$ to Biomax MR film (Kodak). In parallel, in vitro translated proteins were subjected to SDS-PAGE and visualized by autoradiography to verify their radio labeling. Because amido-black reacts differently with $\mathrm{G}$ - and $\mathrm{F}$-actin, we confirmed that equal quantities of $\mathrm{G}$ and $\mathrm{F}$-actin were spotted on the membrane strips by immunolabeling with the mouse monoclonal anti-actin antibody 1 C4 (Chemicon, Temecula, CA), which cross-reacts with all actin isoforms in both $G$ - and F-conformation with an equivalent affinity.

\section{Production and purification of GST-smoothelin-A}

Escherichia coli strain BL21 was transformed with the pGEX-2T-smoothelin-A plasmid. Colonies were tested for production efficiency of the recombinant GSTsmoothelin-A fusion protein by SDS-PAGE. The best producing clone was used to inoculate $2 \mathrm{YT}$ medium ( $16 \mathrm{~g} / \mathrm{l}$ tryptone, $10 \mathrm{~g} / \mathrm{l}$ yeast extract, $5 \mathrm{~g} / \mathrm{/} \mathrm{NaCl}, \mathrm{pH} 7.0)$ containing $100 \mu \mathrm{g} / \mathrm{ml}$ ampicillin, and cultures were grown overnight at $37^{\circ} \mathrm{C}$. The culture was then diluted 1:100 in $400 \mathrm{ml}$ fresh prewarmed medium, grown to an O.D. 600 of $0.6-0.8$ at $37^{\circ} \mathrm{C}$ and $250 \mathrm{rpm}$, and induced by the addition of isopropyl 
$\beta$-D-thiogalactopyranoside (IPTG) to $1 \mathrm{mM}$ for an additional $2 \mathrm{~h}$. Bacteria were harvested by centrifugation at $7000 \mathrm{rpm}$ for $10 \mathrm{~min}$, resuspended in 20-ml icecold PBS containing protease inhibitors (complete ${ }^{\mathrm{TM}}$ EDTA-free protease inhibitor cocktail tablets), and lysed by sonicating three times for $20 \mathrm{~s}$ at speed 8 on ice with a Sonifier ${ }^{\oplus}$ B-10 cell disrupter (Branson Sonic Power Company, Danbury, CT). After addition of $1 \%$ Triton $X-100$, the lysate was cleared by centrifugation at $9000 \mathrm{rpm}$ for $5 \mathrm{~min}$ at $4^{\circ} \mathrm{C}$. Resulting supernatant was loaded on a glutathione sepharose- $4 \mathrm{~B}$ column (Amersham). After washing the column, the GST-smoothelin-A was eluted in two steps to obtain a pure elution product: $10 \mathrm{mM}$ reduced glutathione (in $50 \mathrm{mM}$ Tris $-\mathrm{HCl}, \mathrm{pH} 8.0$ ) followed by $20 \mathrm{mM}$ reduced glutathione (in $100 \mathrm{mM}$ Tris $-\mathrm{HCl}, \mathrm{pH} 8.0,120 \mathrm{mM} \mathrm{NaCl}$ ). GST was used as negative control. Using the pGex-2T plasmid, it was produced and purified according to above described procedure. Pure GST was obtained by a singlestep elution with $10 \mathrm{mM}$ reduced glutathione (in $50 \mathrm{mM}$ Tris- $\mathrm{HCl}, \mathrm{pH}$ 8.0). The final elution products were dialyzed against $100 \mathrm{mM}$ Tris- $\mathrm{HCl}, 120 \mathrm{mM} \mathrm{NaCl}, \mathrm{pH}$ 8.0 , and protein concentration was estimated by the Bradford protein assay ${ }^{26}$ and SDS-PAGE analysis.

\section{ELISA}

Actin isoform specificity of smoothelin-A was tested in ELISA with $\alpha$-SMA, $\alpha$-SKA, and $\gamma$-smooth muscle actin ( $\gamma$-SMA). Chicken gizzard $\gamma$-SMA was purified as described by Strzelecka-Golaszewska et al. $^{27}$. All three actin isoforms were allowed to polymerize as described above. Polymerization efficiency of the actin isoforms was tested by sedimentation of F-actin at $30 \mathrm{psi}$ for $1 \mathrm{~h}$. Equivalent amounts of pellets and supernatants were analyzed on a $10 \%$ polyacrylamide gel. After staining with Coomassie blue, the gel was scanned (Arcus II; Agfa, Mortsel, Belgium), and the percentage of polymerized actin was quantified with the ImageQuant Program (Image Quant Analysis Version 3.3; Molecular Dynamics, Sunnyvale, CA). ELISA assay was performed using Reacti-Bind ${ }^{\text {TM }}$ glutathione-coated Clear strip plates (Pierce, Rockford, IL). After rinsing the strips with PBS containing $0.05 \%$ Tween 20, wells were incubated for $1 \mathrm{~h}$ with approximately $200 \mathrm{ng}$ GST-smoothelin-A or GST as a control and then blocked in presence of 1\% BSA in PBS for $1 \mathrm{~h}$. Different concentrations (0.6 [minimum of detection], 0.67, 0.77, 0.96, and $1.44 \mu \mathrm{M}$ ) of $\alpha$-SMA, $y$-SMA, and $\alpha$-SKA filaments, processed and quantified as described above, were allowed to bind in the presence of $0.5 \%$ gelatin and $0.5 \%$ Tween 20 . Actin was detected using the monoclonal 1C4 (diluted 1:400 in PBS), cross-reacting with all actin isoforms with similar reactivity, followed by a secondary peroxidase-conjugated affinity purified goat-anti-mouse IgG + IgM antibody (Jackson ImmunoResearch laboratories) diluted 1:500 in PBS containing 0.5\% BSA and 0.05\% Tween 20. As positive controls of GST and GST-smoothelin binding, an anti-GST antibody 
Biochemical evidence for interaction between smoothelin and filamentous actin

(Pharmacia Biotech AB, Uppsala, Sweden), diluted 1:1000 in PBS, was used followed by the secondary antibody peroxydase-conjugated donkey-anti-goat (Santa Cruz biotechnology). Peroxydase activity was developed with a substrate buffer containing $4.5 \mathrm{mM} \mathrm{5}$-aminosalicylic acid, $0.02 \% \mathrm{H}_{2} \mathrm{O}_{2}$ in PBS. Intensity of staining was quantified by measurement of the optical density at $570 \mathrm{~nm}$ with a umax kinetic microplate reader (Molecular Devices Corp., Sunnyvale, CA) and processed with software SOFTmax Pro (Molecular Devices Corp.). O.D.570 values were corrected for binding of actin to GST by deduction of background levels of GST binding and data were plotted according to the method of binding analysis by ELISA adapted by Yaoi et al. ${ }^{28}$.

\section{Statistical analysis}

ELISA results are shown as mean \pm SEM. Statistical analyses were performed using the SPSS 10 software. For statistical comparison, the results were analyzed by the nonparametric ANOVA test.

\section{Results}

\section{Smoothelin associates to stress fibers}

Transient expression of smoothelin cDNAs in REF52 cells, which contain no endogenous smoothelin, resulted in co-distribution of smoothelin and stress fibers. Using plasmids pcDNA3-smoothelin-B and pcDNA3-smoothelin-A (Figure 3.1), double-labeled immunofluorescence with anti-smoothelin (R4A) and antiactin (AL20) revealed that both smoothelin isoforms associated to stress fibers (Figure $3.2 \mathrm{~b}, \mathrm{e})$. To define the region that interacts with actin, a truncated sequence (pcDNA3-HA-smoothelin-B $\mathrm{B}_{2311-3005}$, Figure 3.1), containing the putative actin-binding site plus 104 amino acids upstream to the $\mathrm{CH}$ domain, was also transfected into REF52 cells. The truncated smoothelin similarly decorated actin stress fibers, although intensity of staining was weaker and filaments were less sharply defined after transfection with this construct (Figure 3.2h). At this stage, we cannot exclude that this difference in binding pattern could be because the immunofluorescent staining was performed with different antibodies (see Materials and methods).

Surprisingly, a nuclear staining could also be observed after transfection with the truncated smoothelin (Figure 3.2f), even though no nuclear translocation signal was found in the sequence of this part of the protein. Attempts to create stably transfected REF52 cells with smoothelin-A and -B were unsuccessful. It appeared as if the cells overexpressing smoothelins were unable to divide and disappeared gradually during consecutive passages (data not shown). 

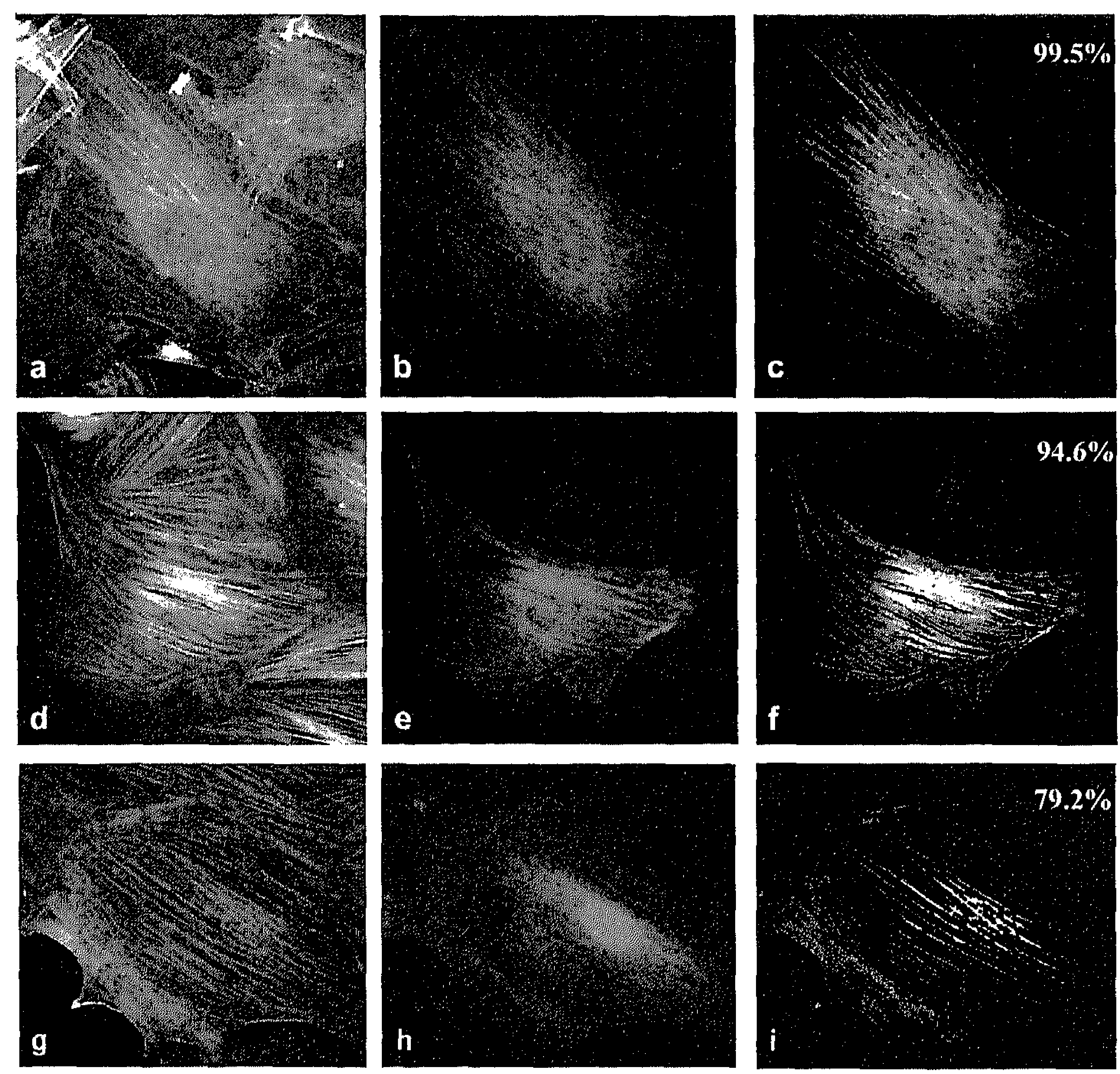

Figure 3.2 Transfection of rat embryonic fibroblasts (REF52 cells) with smoothelin- $A,-B$, and smoothelin- $B_{2311-3005}$. Smoothelin-A ( $\left.a-c\right)$, smoothelin-B ( $\left.d-f\right)$, and smoothelin- $B_{2311-3005}(g-i)$ were transfected into REF52 cells. Forty-eight hours after transfection, cells were stained with anti-actin antibody ( $a, d$, and $g$ ) combined with either anti-smoothelin (b and e) or anti-HA-tag ( $h$ ) antibodies. To estimate the percentage of co-distribution between actin and smoothelin, a "colocalization channel" was built using ImarisColoc software $(c, f$, and i). A false color (yellow) was applied to visualize the overlapping pixels (numbers at the right corner of images $c$, $f$, and $i$ correspond to the percentage of red overlapping the green pixels). Transfected smoothelin-A and -B associate to the stress fibers. The truncated smoothelin similarly decorated actin stress fibers, although intensity of staining was weaker and filaments were less sharply defined. See front cover for color pictures.

\section{Smoothelin-B co-immunoprecipitates with $\alpha$-smooth muscle actin}

Co-distribution of $\alpha$-SMA and smoothelin ${ }^{9,10,13}$ and the observation that both proteins co-purify in stringent conditions (data not shown) indicate that they belong to the same supramolecular structure. To confirm this, a coimmunoprecipitation assay of actin and smoothelin was performed. 
Biochemical evidence for interaction between smoothelin and filamentous actin

Immunoprecipitation was carried out on a tissue lysate from pig aorta in RIPA buffer, using both R4A and $\alpha$-sm 1 antibodies. Using $\alpha$-sm1, smoothelin-B coimmunoprecipitated with $\alpha$-SMA (Figure 3.3, lane 1). A negative control performed in the absence of the antibody showed no unspecific binding to the beads (Figure 3.3, lane 2). Thus, in a tissue lysate, smoothelin-B associates with $\alpha$-SMA. The reverse experiment in which actin should coprecipitate with smoothelin was not successful (data not shown), because the R4A antibody did not efficiently pull down smoothelin under the immunoprecipitation buffer conditions.

$\begin{array}{lll}1 & 2 & \\ & \text { Smoothelin-B } \\ & \text { Actin }\end{array}$

Figure 3.3 Co-immunoprecipitation of smoothelin-B with $\alpha$-smooth muscle actin. $\alpha$-SMA was immuno precipitated from a tissue homogenate of pig media with $\alpha-5 m 1$ in RIPA buffer. The upper part of the blot was stained with the anti-smoothelin antibody R4A and the lower part with the anti-actin antibody AL20. Smoothelin-B co-immunoprecipitates with $\alpha$-SMA (lane 1). A negative control performed in the absence of $\alpha-s m 1$ is shown in lane 2.

\section{Smoothelin binds to polymerized actin}

Smoothelin decorated actin stress fibers in cultured cells, suggesting that smoothelin interacts with filamentous actin. However, no biochemical evidence for direct binding has been established so far.

To investigate whether smoothelin can interact with G- and/or F-actin and preferentially with specific actin isoforms, we performed an in vitro overlay assay with radio-labeled smoothelin. As shown in Figure 3.4A, when equivalent amounts of filamentous (lane 1) and globular (lane 2) $\alpha$-SMA were spotted onto a nitrocellulose membrane, they displayed different reactivity with amido-black. Therefore, membranes were also stained with the anti-actin antibody 1C4, recognizing all actin isoforms independent of their polymerization state. As expected, this antibody showed the same level of staining for $F-$ and $G-\alpha-S M A$ (Figure 3.4A). Equivalent results were obtained with $F$ - and G- $\alpha$-SKA (data not shown). The immobilized proteins were overlaid with in vitro translated, radiolabeled smoothelin-A (Figure 3.4B, lane 1) or truncated smoothelin-A (Figure 3.4B, lane 2). Overlays were performed in $G$ as well as $F$ buffer, for both $G$ - and $F$-actin to rule out any effect of salt conditions on smoothelin conformation. Because all strips have been incubated separately with their own in vitro translation mixture, each signal was compared to its internal BSA control. 
Smoothelin-A did not bind to keratin filaments (Figure 3.4C, lane 2). However, it did bind efficiently to both $\alpha$-SMA and $\alpha$-SKA isoforms (Figure 3.4C, lane 2) but only in their filament forms (Figure 3.4C, no binding of smoothelin visible in lane 1). The truncated smoothelin also bound to the actin filaments but with a lower affinity (Figure 3.4C, lane 3), confirming the results of the transfection experiments.

A

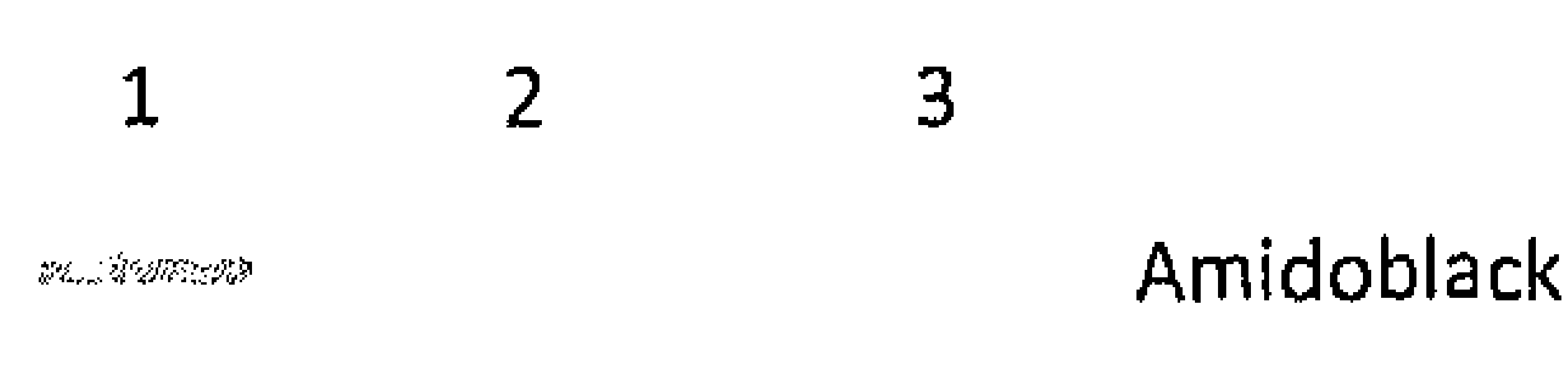

WB with anti-actin

B

12

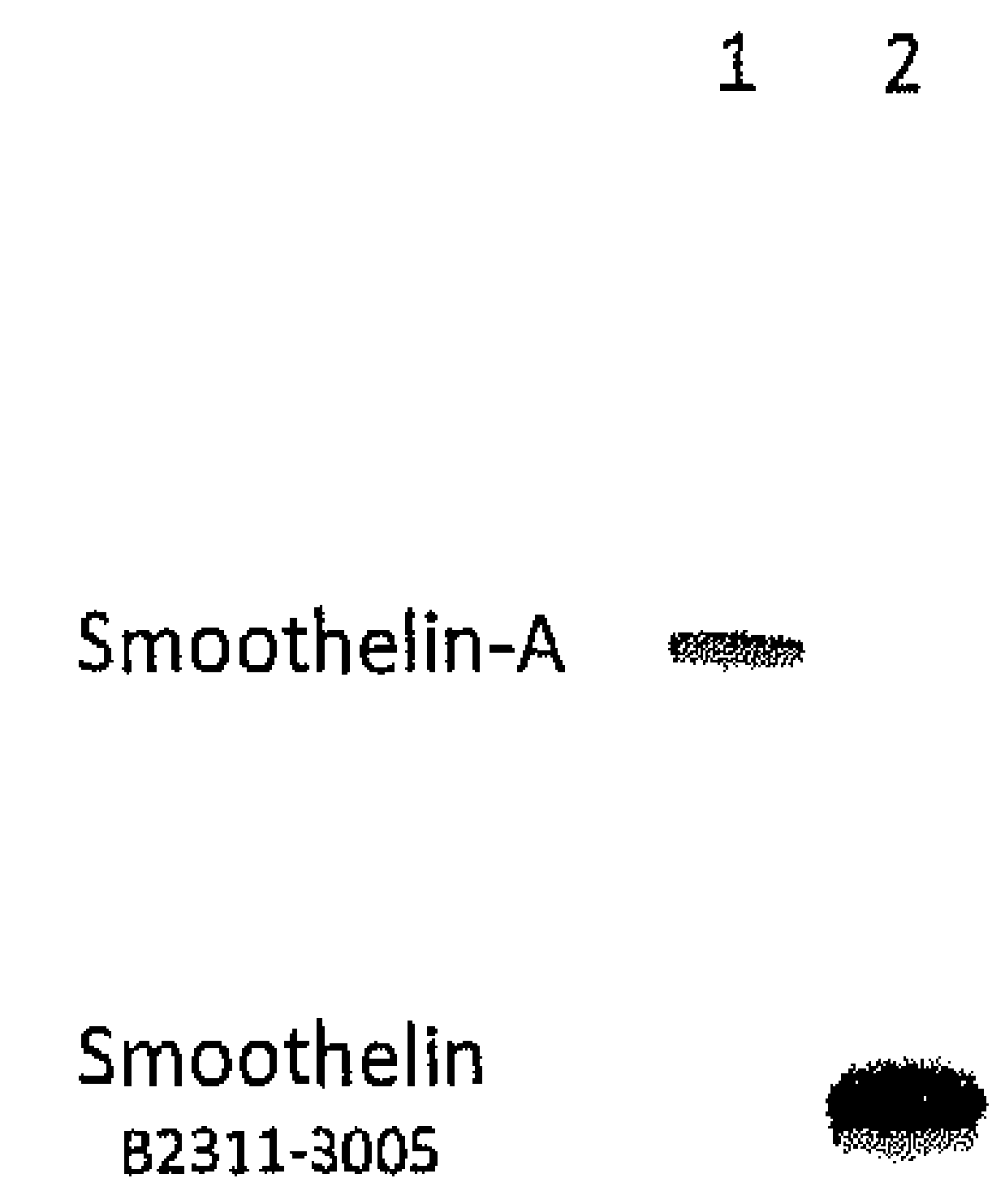

C

\begin{tabular}{|c|c|c|}
\hline & & 2 \\
\hline BSA & 3 & \\
\hline 1 & 1 & \\
\hline$\alpha-S M A$ & 2 & - \\
\hline & 3 & - \\
\hline & 1 & mamann \\
\hline$\alpha$-SKA & 2 & $m$ \\
\hline & 3 & $=$ \\
\hline & 2 & \\
\hline K5/K14 & 4 & \\
\hline
\end{tabular}

Figure 3.4 Dot blot overlay of actin with radio-labeled smoothelin. (A) Equivalent amounts $(3 \mu \mathrm{g})$ of filamentous (lane 1), globular $\alpha$-SMA (lane 2), and keratin filaments K4/K15 (lane 3) were spotted onto a nitrocellulose membrane and stained for protein with amido-black. Because of different reactivity of the proteins with amido-black, the membranes were stained with the antitotal-actin antibody 1C4. Spotted G-and F-actin showed the same amount of protein after staining. (B) Autoradiograph of SDS-PAGE of in vitro translated, radio-labeled smoothelin-A (lane 1) and smoothelin- $B_{2311-3005}$ (lane 2). (C) Autoradiograph of nitrocellulose membranes containing spotted BSA, $\alpha$-SMA, $\alpha$-SKA (both monomer, lane 1, and filament, lanes 2-3), and keratin filaments $\mathrm{K} 5 / \mathrm{K} 14$ (in a twofold higher concentration), which were incubated with the in vitro translated, radio-labeled smoothelin-A (lanes 1 and 2 ) and smoothelin- $B_{2311-3005}$ (lane 3). Smoothelin-A binds specifically to the actin filaments of both actin isoforms. Smoothelin- $B_{2311-3005}$ also binds to the actin filaments but with a lower affinity.

\section{Smoothelin-A binds to different actin isoforms}

The association of smoothelins with actin, as shown in the preceding experiments, could be mediated by other proteins. To test whether the interaction is direct, an ELISA was performed in presence of both purified actins and GST-smoothelin-A. As shown in Figure 3.5A and in accordance with previous work $^{29}$, all actin preparations were more than $95 \%$ pure. This assay likewise 
Biochemical evidence for interaction between smoothelin and filamentous actin

allowed us to compare actin isoform affinity to smoothelin. Equivalent amounts of $\alpha$-SMA, $\alpha$-SKA, and $\gamma$-SMA filaments (previously quantified by SDS-PAGE) were allowed to bind to GST-smoothelin coated strips (see Material and methods). Figure 3.5B shows that all three isoforms bound to smoothelin. In these standardized conditions, this binding was concentration dependent and saturable. Analysis, performed following the altered method of Scatchard plot for ELISA ${ }^{28}$, indicated that all three actin isoforms bound to smoothelin with similar affinities as shown by the nonsignificantly different slope values.

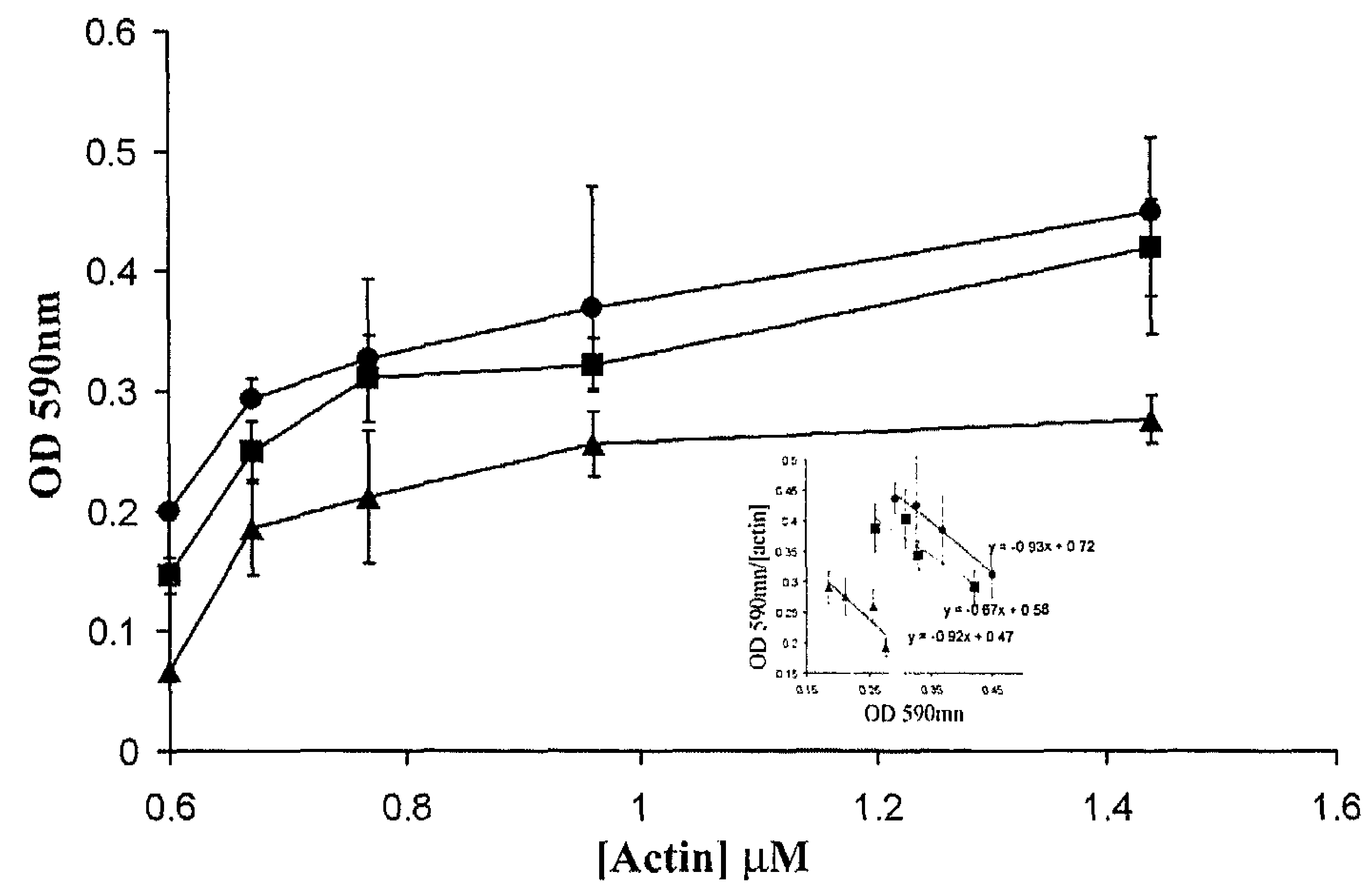

Figure 3.5 Binding of different actin isoforms to GST-smoothelin-A. (A) Coomassie blue staining reflecting the degree of purification of $\alpha$-SMA (lane 1), $\alpha$-SKA (lane 2), Y-SMA (lane 3), and GSTsmoothelin-A (lane 4). (B) The purified GST-smoothelin-A was immobilized on glutathione-coated strips and incubated with equivalent amounts of $\alpha-\operatorname{SMA}(\bullet), \alpha-\operatorname{SKA}(\boldsymbol{\bullet})$, and $\gamma-\operatorname{SMA}(\mathbf{A})$ filaments $(0.6-1.44 \mu \mathrm{M})$. Actin was detected using the monoclonal anti-actin antibody 1C4 followed by a peroxidase-conjugated anti-mouse $\mathrm{gG}$, and the absorbance was measured at $570 \mathrm{~nm}$. O.D. values were plotted against F-actin concentrations. Scatchard plots of the binding data are shown in the inset. Scale bars represent SEM, $n=3$ experiments. All three actin isoforms bind directly to smoothelin-A. 


\section{Discussion}

Both smoothelins contain near their carboxy terminus a single $\mathrm{CH}$ domain with homologies of $39-46 \%$ to the actin-binding domain ( $A B D$ ) of members of the spectrin superfamily. Also, both smoothelin isoforms have been found to colocalize with $\alpha$-SMA in primary porcine and human vascular SMCs ${ }^{10,13}$ and in transfected cells ${ }^{17}$. Although these data are indicative of a direct binding between actin and smoothelin, this has not yet been established. In the present work, we provide the first biochemical evidence that smoothelin binds to actin in vitro in the absence of any other proteins. This interaction appears to be rather strong as indicated by incubations carried out in the presence of detergents. Like other $\beta$-spectrin family members (e.g., $\alpha$-actinin, dystrophin), smoothelin binds to the filamentous form of actin, but not to G-actin. This allegedly excludes an involvement of smoothelin in the promotion or acceleration of actin polymerization; instead, smoothelin could have an effect on actin filament rigidity or actin bundle stabilization and thus be implicated in cell contraction, as previously suggested. Another possibility is that smoothelin mediates the interaction between actin filaments and other components of the cytoskeleton (see the review by McGough ${ }^{30}$ ). However, the observations that smoothelin, when transfected into COS7 cells, does not colocalize with intermediate filaments ${ }^{9}$ and that no binding of smoothelin to keratin filaments could be detected in our in vitro experiments tend to exclude intermediate filaments as a possible target.

The $\mathrm{CH}$ domain is a protein module of approximately 110 amino acids, which is found as a single copy in regulatory proteins and signal transduction proteins in muscle ${ }^{31}$. Two $\mathrm{CH}$ domains in tandem repeat $(\mathrm{CH} 1$ and $\mathrm{CH} 2)$ have been described to constitute an $A B D$ of members of protein families cross-linking actin filaments, forming meshworks or bundles ${ }^{30,32,33}$. These families include proteins such as $\beta$-spectrin, $\alpha$-actinin, dystrophin, utrophin, actin-binding protein 120 , fimbrin, and cortexillin. The two $\mathrm{CH}$ domains within an ABD appear to have different functions and affinities in terms of binding to actin ${ }^{34,35}$. $\mathrm{CH}_{2}$ domains have a weaker affinity for actin than $\mathrm{CH} 1$, as has been demonstrated for the $\mathrm{CH} 2$ domains of spectrin ${ }^{36}, \alpha$-actinin ${ }^{34}$, and utrophin ${ }^{37}$. Although both $\mathrm{CH}$ domains were previously considered to function as autonomous $\mathrm{ABDs}^{33,38}$, results that are more recent have cast doubts on this hypothesis ${ }^{39}$. Phylogenetic analysis of these domains shows that the $\mathrm{CH}$ domain of smoothelin is similar to the $\mathrm{CH} 2$ domains of other $\mathrm{ABD}$-containing proteins ${ }^{40}$. In addition, Quensel et al. ${ }^{17}$ argued that the $\mathrm{CH}$ domain of smoothelin is neither necessary nor sufficient for association with actin filaments.

As a first approach to investigate whether sequences near the $\mathrm{CH}$ domain have a role in its interaction with actin, as has been suggested for calponin ${ }^{41,42}$, we 
Biochemical evidence for interaction between smoothelin and filamentous actin

tested a truncated smoothelin containing the $\mathrm{CH}$ domain plus 104 additional amino acids. Our results indicate that this truncated protein can still mediate association with actin, although the binding appears to be weaker than that of full-length smoothelin-A. This observation suggests that other sequences located upstream of residue 698 may directly bind to actin or stabilize the interaction with actin filaments. The latter assumption is in agreement with recent data indicating that a region encompassing residues 535-682 has the ability to co-distribute with actin upon ectopic expression in NIH-3T3 fibroblasts ${ }^{17}$.

In spite of the high level of homology in amino acid composition between the actin isoforms, differences in binding with some actin-binding proteins have been found. For instance, profilin ${ }^{43,44}$ and thymosin $\beta 4^{45}$ have been shown to bind preferentially to $\beta$-cytoplasmic actin as compared to $\alpha$-SKA. Smoothelin isoforms are expressed, like actin isoforms, in a tissue-specific manner, suggesting that smoothelin could display different affinities to the different actin isoforms. However, our findings with both overlay and ELISA indicate that in vitro smoothelin-A is able to bind to various actin isoforms ( $\alpha$-SKA, $\alpha$-SMA, $\gamma$ SMA) with similar affinity. Nevertheless, we cannot exclude that another sequence present in the $\mathrm{N}$-terminal part of smoothelin-B could confer an actin isoform specificity to the vascular smoothelin. Another possibility could be that the ability of smoothelins to be recruited to actin filaments is regulated by different actin-binding proteins present in different tissues.

In conclusion, we have shown an interaction between F-actin and smoothelin. The putative actin-binding site ( $\mathrm{CH}$ domain) is an important player in the association, but other domains apparently facilitate and/or strengthen this binding. The following model is proposed: smoothelins interact directly with actin filaments with a low affinity in a $\mathrm{CH}$ domain-dependent manner. Sequences suggested by Quensel et al. ${ }^{17}$, located upstream to the $\mathrm{CH}$ domain, stabilize the association of smoothelin with actin by providing additional binding sites to actin or to yet unidentified actin-binding proteins.

\section{Acknowledgements}

This work was partially supported by a grant from the Netherlands Heart foundation (P.N.; 2000D019) and the Swiss National Science Foundation (grants n. 31-61336.00 and 31-68313.02).

We gratefully acknowledge Anita Hiltbrunner for actin purifications and E. Denkinger and J.-C. Rumbeli for photographic work. 


\section{References}

1. Korn ED, Carlier MF, Pantaloni D. Actin polymerization and ATP hydrolysis. Science. 1987;238:638-644.

2. Vanderkerckhove J, Weber K. At least six different actins are expressed in a higher mamal: an analysis based on the amino acid sequense of the amino terminal tryptic peptide. J. Mol. Biol. 1978;126:783-802.

3. Herman IM. Actin isoforms. Cur. Opin. Cell Biol. 1993;5:48-55.

4. Khaitlina SY. Functional specificity of actin isoforms. Int. Rev. Cytol. 2001;202:35-98.

5. Rubenstein PA. The functional importance of multiple actin isoforms. BioEssays. 1990;12(7):309-315.

6. Schildmeyer LA, Braun R, Taffet $G$, et al. Impaired vascular contractility and blood pressure homeostasis in the smooth muscle alpha-actin null mouse. FASEB $\mathrm{J}$. 2000;14(14):2213-2220.

7. Kumar A, Crawford K, Close $L$, et al. Rescue of cardiac alpha-actin-deficient mice by enteric smooth muscle gamma-actin. Proc. Natl. Acad. Sci. 1997;94(9):4406-4411.

8. van der Loop FT, Gabbiani G, Kohnen G, et al. Differentiation of smooth muscle cells in human blood vessels as defined by smoothelin, a novel marker for the contractile phenotype. Arterioscler. Thromb. Vasc. Biol. 1997;17(4):665-671.

9. van der Loop FT, Schaart G, Timmer ED, et al. Smoothelin, a novel cytoskeletal protein specific for smooth muscle cells. J. Cell Biol. 1996;134(2):401-411.

10. Van Eys GJ, Voller MC, Timmer ED, et al. Smoothelin expression characteristics: development of a smooth muscle cell in vitro system and identification of a vascular variant. Cell Struct. Funct. 1997;22(1):65-72.

11. van Eys GJJM, de Vries CJM, Rensen SSM, et al. Smoothelins: One gene, two proteins, three muscle cells types....so far. Vol 214. Dordrecht, Boston, London: Kluwer Acad. Publ.; 1999.

12. Engelen JJ, Esterling LE, Albrechts JC, et al. Assignment of the human gene for smoothelin (SMTN) to chromosome $22 q 12$ by fluorescence in situ hybridization and radiation hybrid mapping. Genomics. 1997;43(2):245-247.

13. Christen $T$, Bochaton-Piallat ML, Neuville $P$, et al. Cultured porcine coronary artery smooth muscle cells. A new model with advanced differentiation. Circ. Res. 1999;85(1):99-107.

14. Kramer J, Quensel C, Mending J, et al. Identification and characterization of novel smoothelin isoforms in vascular smooth muscle. J. Vasc. Res. 2001;38:120-132.

15. Rensen S, Thijssen V, De Vries $C$, et al. Expression of the smoothelin gene is mediated by alternative promoters. Cardiovasc. Res. 2002;55(4):850-863.

16. De Ruiter MC, Rensen SS, Coolen GP, et al. Smoothelin expression during chicken embryogenesis: Detection of an embryonic isoform. Dev. Dyn. 2001;221(4):460-463.

17. Quensel C, Kramer J, Cardoso MC, et al. Smoothelin contains a novel actin cytoskeleton localization sequence with similarity to troponin T. J. Cell. Biochem. 2002;85(2):403-409.

18. Chaponnier C, Gabbiani G. Gelsolin modulation in epithelial and stromal cells of mammary carcinoma. Am. J. Pathol. 1989;134(3):597-603.

19. Lennette DA. An improved mounting medium for immunofluorescence microscopy. Am. J. Clin. Pathol. 1978;69(6):647-648. 
Biochemical evidence for interaction between smoothelin and filamentous actin

20. Skalli O, Ropraz P, Trzeciak A, et al. A monoclonal antibody against alpha-smooth muscle actin: a new probe for smooth muscle differentiation. J. Cell Biol. 1986;103(6 Pt 2):2787-2796.

21. Laemmli UK. Cleavage of structural proteins during the assembly of the head of bacteriophage T4. Nature. 1970;227(259):680-685.

22. Towbin H, Staehelin T, Gordon J. Electrophoretic transfer of proteins from polyacrylamide gels to nitrocellulose sheets: procedure and some applications. Proc. Natl. Acad. Sci. 1979;76(9):4350-4354.

23. Strzelecka-Golaszewska $H$, Zmorzynski S, Mossakowska M. Bovine aorta actin. Development of an improved purification procedure and comparison of polymerization properties with actins from other types of muscle. Biochim. Biophys. Acta. 1985;828(1):13-21.

24. Spudich JA, Watt S. The regulation of rabbit skeletal muscle contraction. I. Biochemical studies of the interaction of the tropomyosin-troponin complex with actin and the proteolytic fragments of myosin. J. Biol. Chem. 1971;246(15):4866-4871.

25. Fontao L, Favre $B$, Riou $S$, et al. Interaction of the bullous pemphigoid antigen 1 (BP230) and desmoplakin with intermediate filaments is mediated by distinct sequences within their $\mathrm{COOH}$ terminus. Mol Biol Cell. May 2003;14(5):1978-1992.

26. Bradford MM. A rapid and sensitive method for the quantitation of microgram quantities of protein utilizing the principle of protein-dye binding. Anal. Biochem. 1976;72:248-254.

27. Strzelecka-Golaszewska H, Prochniewicz E, Nowak E, et al. Chicken-gizzard actin: polymerization and stability. Eur. J. Biochem. 1980;104(1):41-52.

28. Yaoi $K$, Kadotani $T$, Kuwana $H$, et al. Aminopeptidase $N$ from Bombyx mori as a candidate for the receptor of Bacillus thuringiensis Cry1Aa toxin. Eur. J. Biochem. 1997;246(3):652-657.

29. Mauss S, Chaponnier C, Just I, et al. ADP-ribosylation of actin isoforms by Clostridium botulinum $\mathrm{C} 2$ toxin and Clostridium perfringens iota toxin. Eur J Biochem. Nov 26 1990;194(1):237-241.

30. McGough A. F-actin-binding proteins. Curr. Opin. Struct. Biol. 1998;8(2):166-176.

31. Banuelos $S$, Saraste $M$, Carugo KD. Structural comparisons of calponin homology domains: implications for actin binding. Structure. 1998;6(11):1419-1431.

32. Hartwig JH. Actin-binding proteins 1: spectrin superfamily. Protein Profile. 1994;1(7):706-778.

33. Puius YA, Mahoney NM, Almo SC. The modular structure of actin-regulatory proteins. Curr. Opin. Cell Biol. 1998;10(1):23-34.

34. Way M, Pope B, Weeds AG. Evidence for functional homology in the F-actin binding domains of gelsolin and alpha-actinin: implications for the requirements of severing and capping. J. Cell Biol. 1992;119(4):835-842.

35. Winder SJ, Hemmings L, Maciver SK, et al. Utrophin actin binding domain: añalysis of actin binding and cellular targeting. J. Cell Sci. 1995;108(Pt 1):63-71.

36. Carugo KD, Banuelos S, Saraste M. Crystal structure of a calponin homology domain. Nat. Struc. Biol. 1997;4(3):175-179.

37. Keep NH, Norwood FL, Moores CA, et al. The 2.0 A structure of the second calponin homology domain from the actin-binding region of the dystrophin homologue utrophin. J. Mol. Biol. 1999;285(3):1257-1264. 
38. Castresana J, Saraste M. Does Vav bind to F-actin through a $\mathrm{CH}$ domain? FEBS Lett. 1995;374(2):149-151.

39. Gimona $M$, Winder SJ. Single calponin homology domains are not actin-binding domains. Curr. Biol. 1998;8(19):R674-675.

40. Olski TM, Noegel AA, Korenbaum E. Parvin, a $42 \mathrm{kDa}$ focal adhesion protein, related to the alpha-actinin superfamily. J. Cell Sci. 2001;114(Pt 3):525-538.

41. Corrado K, Mills PL, Chamberlain JS. Deletion analysis of the dystrophin-actin binding domain. FEBS Lett. 1994;344(2-3):255-260.

42. Gimona $M$, Mital $R$. The single $C H$ domain of calponin is neither sufficient nor necessary for F-actin binding. J. Cell Sci. 1998;111(Pt 13):1813-1821.

43. Larsson $\mathrm{H}$, Lindberg $\mathrm{U}$. The effect of divalent cations on the interaction between calf spleen profilin and different actins. Biochim. Biophys. Acta. 1988;953(1):95-105.

44. Ohshima $S$, Abe $H$, Obinata $T$. Isolation of profilin from embryonic chicken skeletal muscle and evaluation of its interaction with different actin isoforms. J. Biochem. 1989;105(6):855-857.

45. Weber A, Nachmias VT, Pennise CR, et al. Interaction of thymosin beta 4 with muscle and platelet actin: implications for actin sequestration in resting platelets. Biochemistry. 1992;31(27):6179-6185. 
Chapter 4

\section{Contribution of serum response factor and myocardin to transcriptional regulation of smoothelins}

Sander SM Rensen, Petra MG Niessen, Xiaochun Long, Pieter A Doevendans, Joseph M Miano, Guillaume JJM van Eys.

Cardiovascular Research, 2006;70(1):136-45. 
Chapter 4 
Contribution of SRF and myocardin to transcriptional regulation of smoothelins

\section{Introduction}

Smooth muscle cells (SMCs) are of key importance for the correct functioning of the vasculature. To perform well, these cells are equipped with a unique set of proteins involved in their contraction and relaxation. Many of these proteins are exclusively or predominantly expressed in contractile SMCs, including $\alpha$-smooth muscle actin ( $\alpha-S M A)$, smooth muscle myosin heavy chain isoforms (SM-MHC), SM22 $\alpha$, smooth muscle calponin (SM-calponin), and smoothelin-A and $-B^{1,2}$. During arterial remodeling, SMCs fulfill a role distinct from their contractile functions, which is aimed at restructuring or repairing to secure structural integrity. To accomplish this, they express a different set of proteins that allow proliferation, extracellular matrix (ECM) remodeling, and migration. Simultaneously, the expression of contractile proteins is downregulated. SMCs can shuttle between this so called synthetic phenotype and the contractile phenotype, a process referred to as phenotypic modulation ${ }^{2}$. During modulation towards the synthetic phenotype, expression of different contractile proteins does not diminish uniformly. Synthetic SMCs still express considerable amounts of $\alpha$-SMA, SM22 $\alpha$, and SM-calponin. Expression of SM-MHC and smoothelins, however, is rapidly lost in modulating $\mathrm{SMCs}^{3-7}$. Therefore, SM-MHC and smoothelins are widely used markers of the contractile SMC phenotype.

In recent years, many studies have been performed to elucidate the mechanisms by which SMCs regulate the expression of proteins that are associated with the contractile phenotype. It has become clear that many ciselements contribute to promoter activity of these genes, but one specific element, the CArG box, has been shown to be of critical importance for their expression $^{8-10}$. This element, with the sequence $C C(A / T 6) G G$, is recognized by the serum response factor (SRF), a transcription factor of the MCM1-AgamousDeficiens-Serum response factor (MADS) box family ${ }^{11}$. Because SRF is widely expressed and not regulated in a SMC phenotype-specific way, it has long remained unclear how this factor would be able to direct expression of genes specifically in contractile SMCs. Recently, myocardin has been identified as an SRF cofactor with higher levels in contractile SMCs than in synthetic SMCs ${ }^{12,13}$. Myocardin is a member of the SAP (SAF-A/B, Acinus, PIAS) family of transcriptional regulators which strongly enhances transcription of most $S M C$ contractile genes ${ }^{13-16}$. However, overexpression of myocardin in either embryonic stem cells or the SMC progenitor line A404 does not activate transcription of smoothelin- $B^{17}$, and there have been no studies on a possible activation of the smoothelin-A promoter by myocardin.

Expression of the smoothelin-A and -B transcripts has previously been shown to be mediated by two promoters separated by $10 \mathrm{~kb}$ in the human smoothelin 
gene $^{18}$. The promoter upstream of exon 1 directs expression of smoothelin-B mRNA in vascular SMCs, whereas an intragenic promoter located upstream of exon 10 regulates smoothelin-A expression in both vascular and visceral SMCs. As with several other SMC marker gene promoters, CArG boxes are found in both human smoothelin promoter regions ${ }^{19}$.

Since the presence of a promoter inside a gene's coding sequences is unusual, the first aim of the current study was to confirm the genuineness of the intragenic smoothelin-A promoter in the context of another species. Next, we set out to determine the functional importance of SRF binding to the two conserved CArG boxes that are present in the intragenic smoothelin-A promoter. The third aim was to assess the ability of myocardin to activate the smoothelin-A and smoothelin-B promoters in vascular SMCs.

We show that intragenic smoothelin-A promoter activity is partly dependent on CArG boxes, although their role is not as dominant as in other SMC-specific genes associated with the contractile phenotype. The activity of the smoothelin$B$ promoter is higher than smoothelin-A promoter activity, but not augmented by myocardin. Collectively, these findings suggest that distinct circuits of transcriptional control exist for smoothelin-A and smoothelin-B, and that nonCArG-dependent pathways predominate in the control of smoothelin expression.

\section{Materials and methods}

\section{Cell culture}

Pulmonary artery smooth muscle cells of the rat (PAC1) $)^{20,21}$ were cultured in Dulbecco's modified essential medium supplemented with $10 \%$ fetal calf serum, $50 \mu \mathrm{g} / \mathrm{ml}$ gentamicin and $200 \mu \mathrm{M}$ L-glutamine (Life technologies, Paisley, UK). The effect of low serum concentrations on smoothelin expression levels was determined by culturing PAC1 cells for three days in medium containing $5 \%$ or $2,5 \%$ serum.

\section{Construction of plasmids}

A mouse smoothelin-A promoter fragment was obtained by PCR amplification of a cosmid containing the mouse smoothelin gene ${ }^{19}$, using the primers: FW $5^{\prime}$ GCCTTCCTTATGGAGGTGTG-3', RV 5'-CCCAAGCTTCTGGCTCCCCAGTGCCAAC-3', and Pfu Taq DNA polymerase (Stratagene, La Jolla, CA). PCR parameters were $94^{\circ} \mathrm{C}$ for $5 \mathrm{~min}$, followed by $35 \mathrm{cycles}$ of $94^{\circ} \mathrm{C}$ for $30 \mathrm{sec}, 58^{\circ} \mathrm{C}$ for $30 \mathrm{sec}, 72^{\circ} \mathrm{C}$ for $1 \mathrm{~min}$, and a final step of $72^{\circ} \mathrm{C}$ for $5 \mathrm{~min}$. PCR products were cloned into pGEM-T 
Contribution of SRF and myocardin to transcriptional regulation of smoothelins

Easy (Promega, Madison, $\mathrm{WI}$ ) and sequence-verified. Promoter fragments were subcloned into the luciferase reporter vector $\mathrm{PGL3}$-basic using restriction enzymes Pvull-HindIII (M-851 A) and Xhol-HindIII (M-1560 A), as indicated in figure $4.2 \mathrm{a}$. These fragments extend to $+58 \mathrm{bp}$ relative to the smoothelin- $A$ transcription start site ${ }^{19}$. Construction of $\alpha-S M A \quad(-195 \mathrm{bp})$ and human smoothelin-B promoter reporter plasmids $(H-1616$ B) has been described before $^{18,21}$.

To determine whether the two CArG boxes of the human smoothelin-A promoter contribute to its transcriptional activity, they were mutated in the context of the reporter plasmid previously described to be active in $P A C 1^{18}$. This $\mathrm{H}-1613$ A plasmid was subjected to site-directed mutagenesis employing a high fidelity Pfu DNA polymerase (Stratagene). The proximal $C C(A / T)$ sequence of each CArG box was mutated to GTC (see Figure 4.3b), which is known to abrogate binding of $\mathrm{SRF}^{9}$. The resulting plasmids are referred to as CArGFmut, CArGNmut and CArGNFmut to indicate mutation of either the distal CArG-far box (Fmut), the proximal CArG-near box (Nmut), or mutation of both (NFmut). The mutated plasmids were verified by sequencing.

\section{Transient transfections and luciferase assays}

$1.5 \times 10^{5}$ PAC1 cells per well were seeded in 12-well plates and allowed to attach overnight. The next day, $2 \mu \mathrm{g}$ of reporter plasmid were transfected into the 60-70\% confluent cells using Fugene-6 transfection reagent (Roche, Brussels, Belgium) according to the provided instructions. A renilla reporter gene was included to normalize luciferase activity. To test the effects of myocardin expression on smoothelin-A and smoothelin-B promoter activity, cotransfection of a pCMV-Tag $2 B$ vector carrying rat myocardin CDNA was performed. In these experiments, control cells were transfected with equivalent amounts of backbone vector without insert. After 48 hours, analysis of luciferase expression in cell lysates was performed using a dual luciferase assay system (Promega) in a Biocounter M1500 luminometer (Lumac, Landgraaf, The Netherlands) or an AutoLumat LB 953 luminometer (EG\&G Berthold, Gaithersburg, MD). All transfections were done in quadruplicate and repeated in three or more independent experiments.

\section{Quantitative polymerase chain reaction (Q-PCR)}

$3 \times 10^{5}$ cells were seeded into 6 -well plates and allowed to attach overnight. The next day, $1 \mu \mathrm{g}$ of pCMV-Tag 2B vector carrying rat myocardin CDNA or $1 \mu \mathrm{g}$ of empty vector was transfected into the cells using Fugene- 6 transfection reagent (Roche) according to the provided instructions. Two days after transfection, total RNA was extracted using Tri reagent (Sigma-Aldrich, Zwijndrecht, The Netherlands) according to the manufacturer's instructions. Reverse 
transcription was performed using $1 \mu \mathrm{g}$ of RNA in the iScript cDNA synthesis kit (Biorad, Hercules, CA). Quantitative real-time PCR was done using the MylQ System (Biorad) and the following primers: Smtn-A/B FW $5^{\prime}$ GGCTCGTCCACTCCAATG-3', Smtn-A/B RV 5'-GGATGAGGAAGAGGAAGAGG-3', Smtn-B FW 5'-TCGGAGTGCTGGTGAATAC-3', Smtn-B RV 5'-CCCTGTTTCTCTTCCTC TGG-3'. Smoothelin mRNA levels were compared to $\alpha$-SMA mRNA levels as determined by using the primer set $\alpha$-SMA FW $5^{\prime}$-AACTGGTATTGTGCTGGACTCT GG-3' and $\alpha$-SMA RV $5^{\prime}$ - CACGGACGATCTCACGCTCAG-3'. The cyclophilin transcript was used to normalize the amount and quality of the extracted RNA, using the following primer set: FW 5'-TTCCTCCTITCACAGAATTATTCCA-3', RV 5'CCACCAGTGCCATTATGG-3'.

\section{Nuclear extract preparation and electrophoretic mobility shift assays (EMSA)}

PAC1 nuclear extracts were prepared from cells grown to confluency in $100 \mathrm{~mm}$ dishes using a Nuclear Extract kit (ActiveMotif, Rixensart, Belgium) and stored at $-80^{\circ} \mathrm{C}$. Protein concentrations were measured by the BCA assay (Pierce, Rockford, IL).

Probes for EMSA were obtained by end-labeling HPLC-purified oligonucleotides corresponding to the CArG boxes of the human smoothelin-A promoter (SigmaGenosys, The Woodlands, TX). The oligonucleotides used are indicated in Figure $4.3 \mathrm{~b}$ (dashed lines), and extend from -881 to -911 (CArG-near) and -919 to -947 (CArG-far). In addition, the intronic CArG box $\left(I C_{1}\right)$ of the SM-calponin gene, which has previously been shown to strongly bind $\mathrm{SRF}^{9}$, was used to compare SRF-binding affinities. $3.5 \mathrm{pmol}$ of sense and antisense oligos were separately labeled using $10 \mu \mathrm{Ci}$ of $\left[\gamma^{32}\right.$ P]ATP (at $4000 \mathrm{Ci} / \mathrm{mmol}$ ) and T4 polynucleotide kinase (Promega). The labeled probes were mixed and annealed by slowly cooling to room temperature after heating to $70^{\circ} \mathrm{C}$. Unincorporated nucleotides and single-stranded oligos were removed by Sepharose G-50 spin columns (Amersham Biosciences, Piscataway, NJ). The labeling efficiency for the smoothelin probes was comparable, whereas labeling of the SM-calponin probe was 3-fold less. For competition experiments, unlabeled wild-type oligonucleotides or oligonucleotides mutated in the same way as the CArGFmut or CArGNmut reporter constructs (see Figure 4.3b) were used at 20-fold excess. Reaction mixtures for EMSA containing $5 \mu \mathrm{g}$ of nuclear extract and $4 \%$ glycerol, $1 \mathrm{mM} \mathrm{MgCl}, 0.5 \mathrm{mM} \mathrm{EDTA}, 0.5 \mathrm{mM} \mathrm{DTT}, 50 \mathrm{mM} \mathrm{NaCl}, 10 \mathrm{mM}$ Tris- $\mathrm{HCl}$ (pH 7.5), and $0.05 \mathrm{mg} / \mathrm{ml}$ poly $(\mathrm{dl}-\mathrm{dC})$ were incubated for $10 \mathrm{~min}$ on ice. Subsequently, approximately $45000 \mathrm{cpm}$ of labeled probe $\left(15000 \mathrm{cpm}\right.$ for $\left(\mathrm{I}_{1}\right)$ was added and incubated for an additional $20 \mathrm{~min}$ at room temperature. For supershifts, $1 \mu \mathrm{l}$ of SRF antibody (Santa Cruz sc-335) was added to indicated reactions followed by 15 min incubation at room temperature. The samples were loaded on a 
Contribution of SRF and myocardin to transcriptional regulation of smoothelins

nondenaturing 4\% 40:1 acrylamide/bisacrylamide gel which pre-ran for $15 \mathrm{~min}$ at $200 \mathrm{~V}$ prior to loading. Electrophoresis was carried out at $200 \mathrm{~V}$ for $25 \mathrm{~min}$, after which gels were vacuum dried and exposed to $x$-ray film at $-80^{\circ} \mathrm{C}$.

\section{Chromatin Immunoprecipitation Assay (ChIP)}

ChIP assays were conducted with a kit according to the manufacturer's instructions (EZ ChIP; Upstate Cell Signaling Solutions, Lake Placid, NY). Briefly, PAC1 SMC were grown to subconfluency, fixed in $1 \%$ formaldehyde for $10 \mathrm{~min}$ to crosslink nucleoprotein complexes and scraped in phosphate buffered saline containing protease inhibitor cocktail. Pelleted cells were then lysed and sonicated 20 times at 10 second pulses using a Vibra Cell Sonicator (VC 130 PB; Sonics, Newton, CT) at 30\% maximum output. Sheared DNA-protein complexes were immunoprecipitated with $2 \mu \mathrm{g}$ anti-SRF (sc-335, Santa Cruz) or normal rabbit $\lg G$ as a control. Enriched DNA was then linearly amplified by PCR with primers flanking both CArG elements in the smoothelin-A promoter (FW primer, 5'-TGCCTACTCATCGGCAATTCTCCT-3' and RV primer, 5'- TGGGTTCTGATGCTTCTC TAGCCT-3').

\section{Statistical analysis}

All data are reported as mean \pm standard error of the mean and analyzed by one-way ANOVA, followed by Bonferroni's multiple comparison test. Values of $P<0.05$ are considered statistically significant.

\section{Results}

\section{Smoothelin mRNA expression in PAC1 SMCs}

To investigate endogenous expression of smoothelins by PAC1 SMCs, we performed Q-PCR and compared expression levels of smoothelins to those of $\alpha$ SMA. PAC1 cells expressed low levels of both smoothelin-A and smoothelin-B transcripts. Compared to $\alpha-S M A$, the most abundant protein in SMCs comprising $\sim 40 \%$ of the total protein content, smoothelin-A levels were $44,3 \pm$ 0,9 times lower and smoothelin-B levels were 50,9 $\pm 1,0$ times lower (Figure 4.1a). This shows that smoothelins are endogenously expressed in PAC1 cells and validates the use of these cells for functional analyses of smoothelin promoter activity.

Since serum concentrations have been reported to affect expression levels of smooth muscle specific markers, we examined the responsiveness of smoothelin transcript levels to reduced serum concentrations in the medium. Variations in serum concentrations ranging from $10 \%$ to $2,5 \%$ had no significant 
effect on the expression of either smoothelin-A or smoothelin-B, although there was a trend towards higher smoothelin-A expression with lower serum concentrations (Figure 4.1b).

A

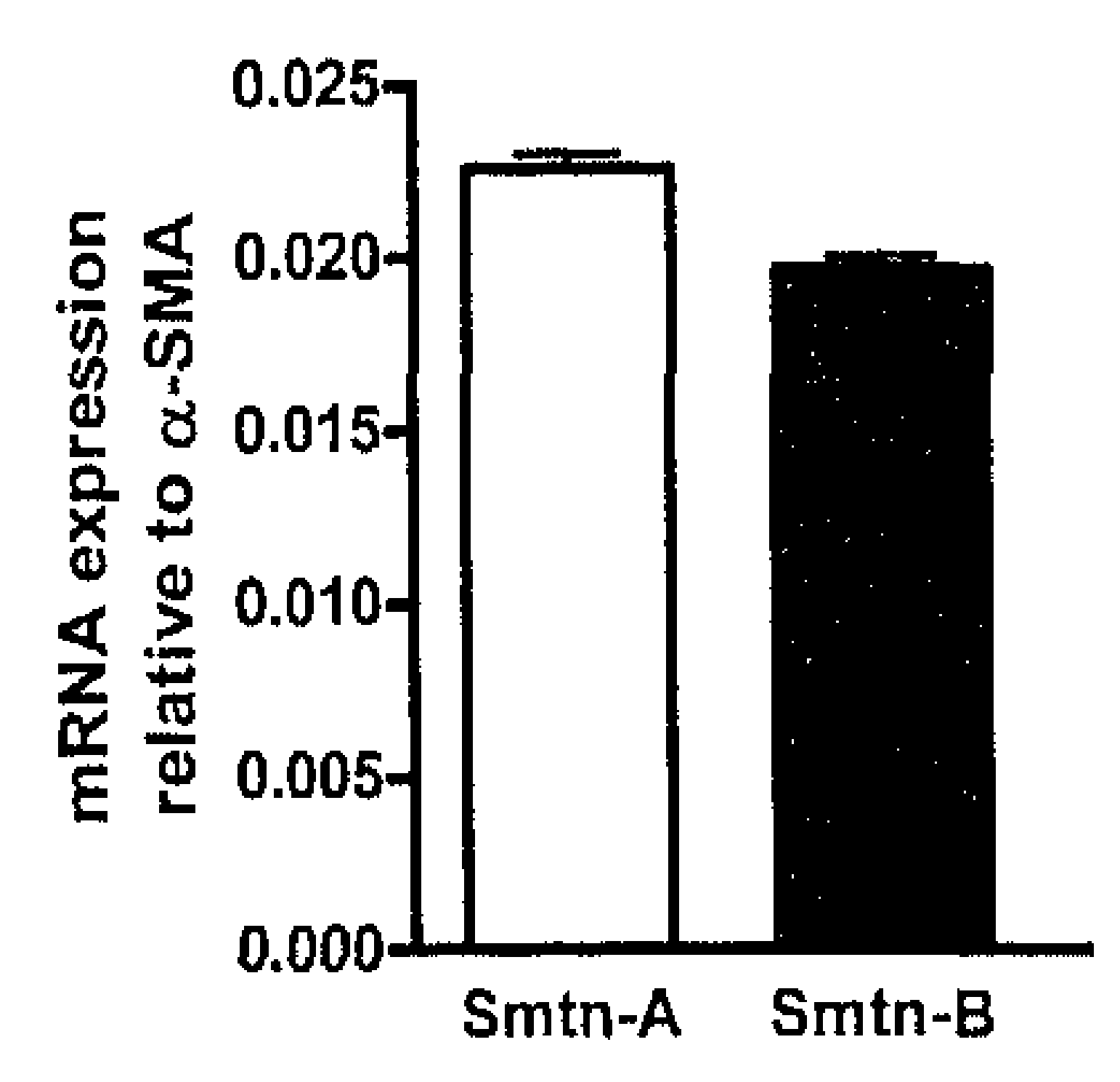

B

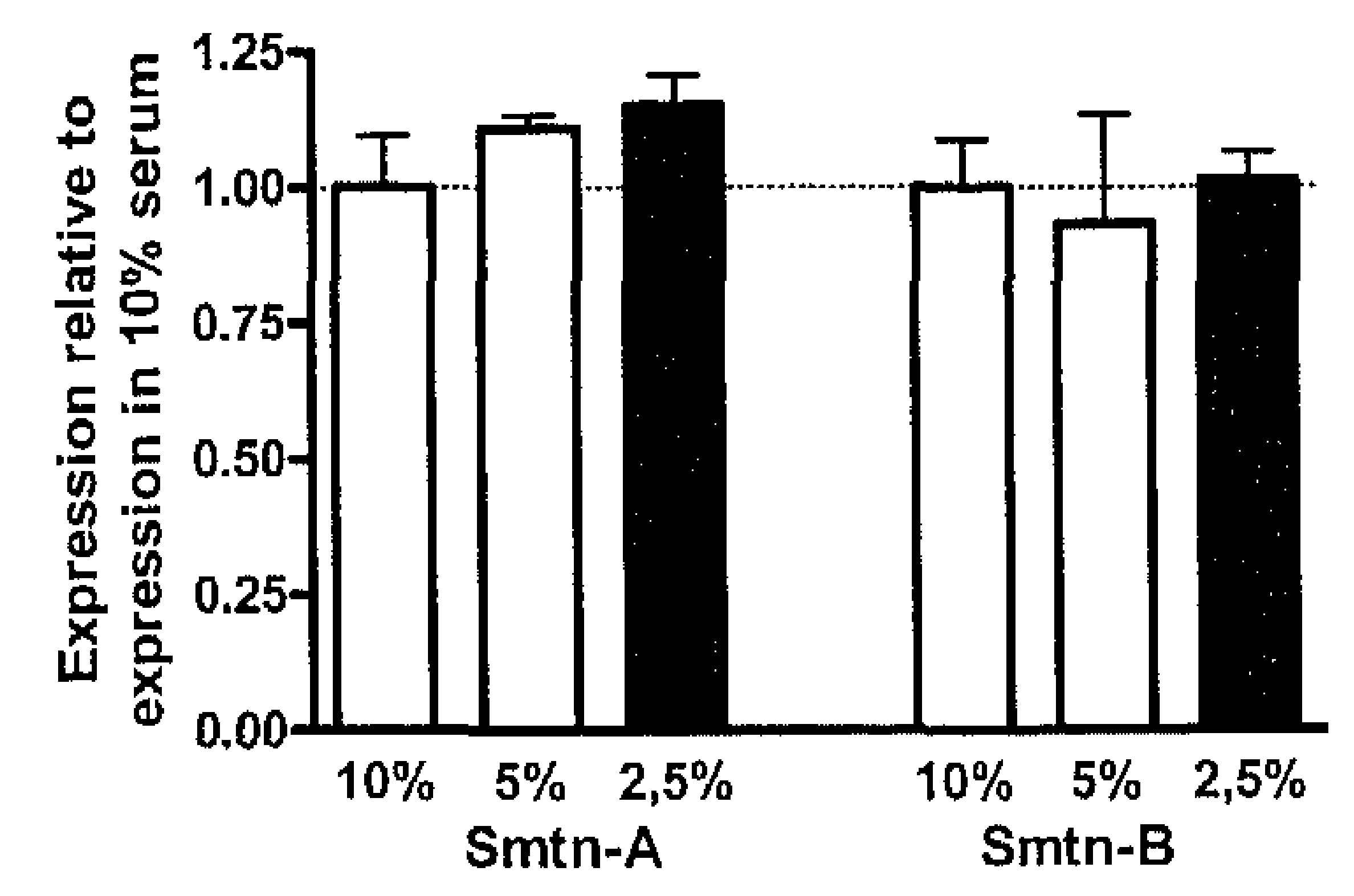

Figure 4.1 A) Expression of smoothelin-A and smoothelin-B mRNA in PAC1 SMCs. Expression levels were assayed by Q-PCR and normalized to $\alpha$-SMA expression. PAC1 cells express both smoothelin isoforms at the mRNA level. B) No significant effect of serum concentration on smoothelin-A and smoothelin-B mRNA expression in PAC1 cells. Expression levels were assayed by Q-PCR and normalized to expression at $10 \%$ serum.

\section{Functional analysis of the mouse smoothelin-A promoter}

To confirm that the intragenic $5^{\prime}$ upstream region of the smoothelin-A transcription start site can activate transcription in SMCs, we constructed a reporter plasmid carrying $1560 \mathrm{bp}$ of the putative mouse promoter $(\mathrm{M}-1560 \mathrm{~A})$, and transfected it into PAC1 SMCs. A sixteen-fold induction of transcription compared to a promoterless construct was found, showing that this region, which is comparable to the previously tested human construct ${ }^{18}$, indeed can act as a promoter in vitro (Figure 4.2b). Interestingly, a smaller construct containing $851 \mathrm{bp}$ of the promoter (M-851 A) was not able to drive transcription in PAC1 SMCs. Activities of a -1616 bp human smoothelin-B promoter fragment $(\mathrm{H}-1616$ B) and a $\alpha$-SMA promoter fragment of $195 \mathrm{bp}$ were approximately six-fold and three-fold higher in PAC1 cells compared to the previously tested human -1613 bp smoothelin-A promoter fragment ( $\mathrm{H}-1613 \mathrm{~A})$. 
Contribution of SRF and myocardin to transcriptional regulation of smoothelins

A

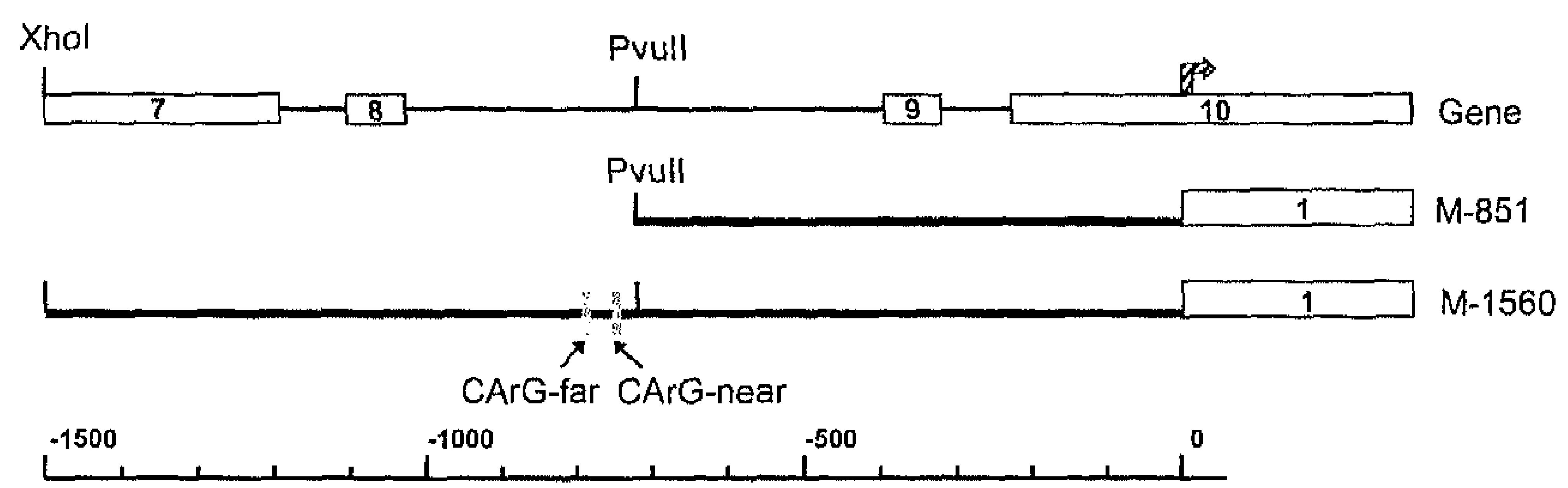

B

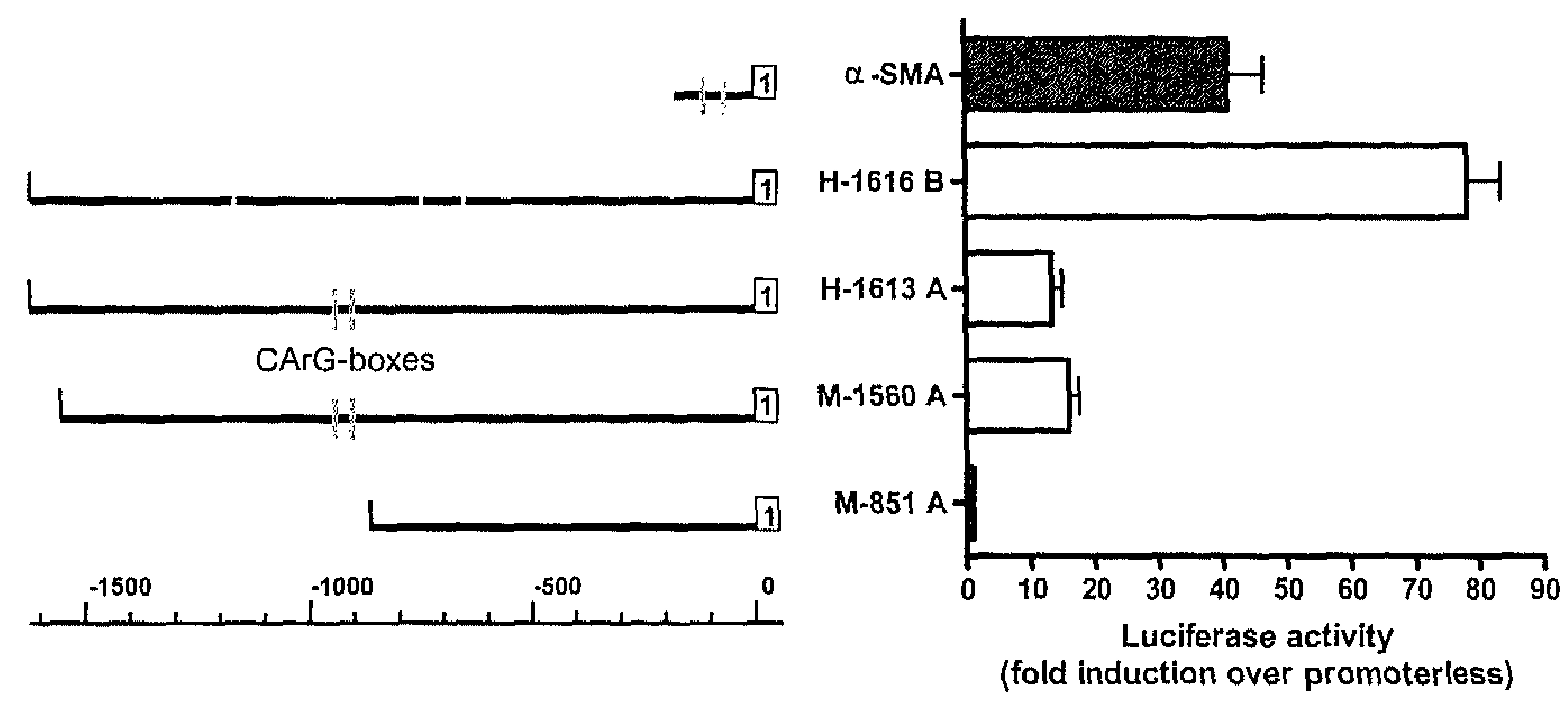

Figure 4.2 A) Schematic representation of mouse smoothelin-A promoter constructs. The upper line represents the smoothelin gene structure, exons are indicated by white boxes and numbered. The shaded arrow indicates the transcription start site of smoothelin-A, which resides inside exon 10 of smoothelin-B. The lower line shows the scale in bp. The CArG boxes are depicted as grey boxes. B) Comparison of activity of mouse smoothelin-A promoter fragments ( $M-1560$ A \& M-851 A) with human smoothelin-A ( $\mathrm{H}-1613 \mathrm{~A})$, human smoothelin-B $(\mathrm{H}-1616 \mathrm{~B})$ and $\alpha$-SMA promoters. Activity of the smoothelin-B construct is higher than activity of the smoothelin-A constructs. The active region in the mouse smoothelin-A promoter is located between -1560 and -851 nucleotides. Conserved CArG boxes are depicted as grey boxes, non-conserved CArG boxes as shaded grey boxes. The first exons of each gene are shown as white boxes.

\section{Functional significance of CArG boxes in the human smoothelin-A and $-B$ promoter}

Sequence comparisons between human, mouse, and rat showed that the three CArG boxes in the human smoothelin-B promoter were not conserved across species (Genbank accession numbers: human AC005005; mouse AF132449; rat Ensembl gene ID: ENSRNOG00000019451). In contrast, the two CArG-boxes in the human smoothelin-A promoter and their surrounding sequences are highly conserved (Figure 4.3a). A 111 bp region in intron 8 of the smoothelin gene 
containing the CArG boxes shows $86.5 \%$ homology. The $60 \mathrm{bp}$ core of this region has only 7 mismatches between mouse, human, and rat. The CArG boxes themselves are completely conserved, including a $G$ substitution in the core of both CArG-far and CArG-near. The region between the CArG boxes, spanning 27 $\mathrm{bp}$, shows only two non-conserved nucleotides between the three species. The 5 'flanking sequence of CArG-far is conserved for three nucleotides, like the $3^{\prime}$ flanking sequence of CArG-near. The high degree of homology indicated that the CArG boxes of the smoothelin-A promoter might be of functional significance.

To investigate the contribution of the CArG boxes to the transcriptional activity of the human smoothelin-A promoter, we introduced mutations in each element separately and in both elements simultaneously, and assessed activity of the mutated constructs in PAC1 cells (Figure 4.3b). The introduced mutations are known to abolish SRF-binding to these cis-elements, rendering them inactive $^{9}$. In comparison with the wild-type construct, mutation of the CArGnear box (CArGNmut) caused a mild but significant reduction of transcriptional activity of $15 \% \quad(P=0.02)$. Mutation of CArG-far (CArGFmut) did not affect promoter activity significantly. In contrast, mutation of both CArG boxes simultaneously (CArGNFmut) reduced activity significantly by $32 \%$ compared to the wild type construct $(P<0.01)$.

Surprisingly, co-transfection of wild type human smoothelin-A promoter fragments with constitutively active SRF (SRF-VP16) activated the promoter only slightly in PAC1 SMCs (statistically insignificant; data not shown). Similarly, human smoothelin-B promoter activity was not induced by constitutively active SRF.

\section{SRF interaction with smoothelin-A promoter CArG boxes}

The relatively mild effect of the CArG box mutations on smoothelin-A promoter activity and the minimal activation of the promoter by SRF-VP16 led us to determine if SRF was able to bind to the smoothelin-A CArG boxes. To this end, we performed electrophoretic mobility shift assays (EMSAs) using PAC1 nuclear extracts and individual double stranded oligonucleotides containing either smoothelin-A CArG box and at least 6 bp of flanking sequence on each side. This revealed several specific nucleoprotein complexes with shifted mobility for both smoothelin-A probes (Figure 4.4a), which were competed by unlabeled wildtype probe, but not by unlabeled mutant probe. The presence of SRF in one of these complexes was demonstrated by supershift experiments. SRF bound both smoothelin-A CArG probes, although binding to CArG-near was much stronger. However, in comparison to the $\mathrm{IC}_{1} \mathrm{CArG}$ box of the SM-calponin gene which binds SRF strongly ${ }^{9}$, even the smoothelin CArG-near bound SRF weakly. In addition, the $I C_{1}$ CArG box experiment showed only one specific shifted band, 
Contribution of SRF and myocardin to transcriptional regulation of smoothelins

representing the SRF-containing nucleoprotein complex. In contrast, both smoothelin-A CArG box regions bound additional proteins that are smaller than SRF and likely represent distinct transcription factors.

A Smoothelin-A CArG boxes

prope CArG-far

probe: CArG-near

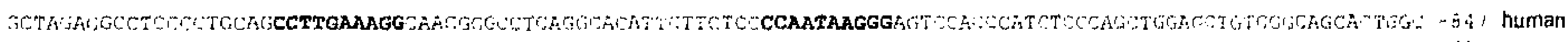

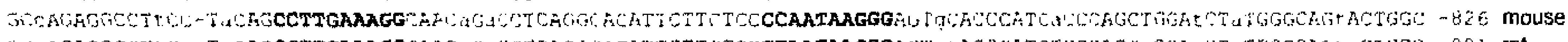

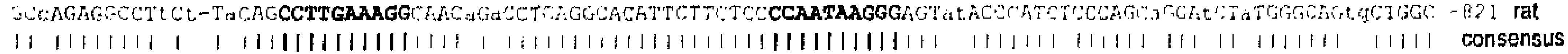

Smoothelin-B CArG boxes

CArG-3 CArG-2

CArG-1

TCCTAAATGG

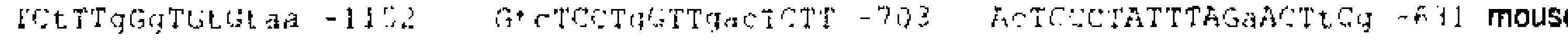

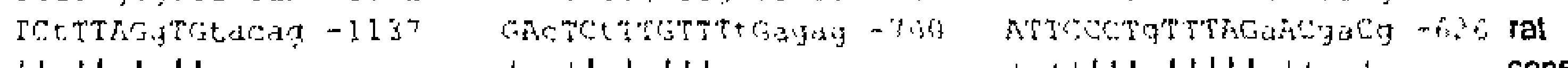

$1111111 \quad 111111$ consensus

B

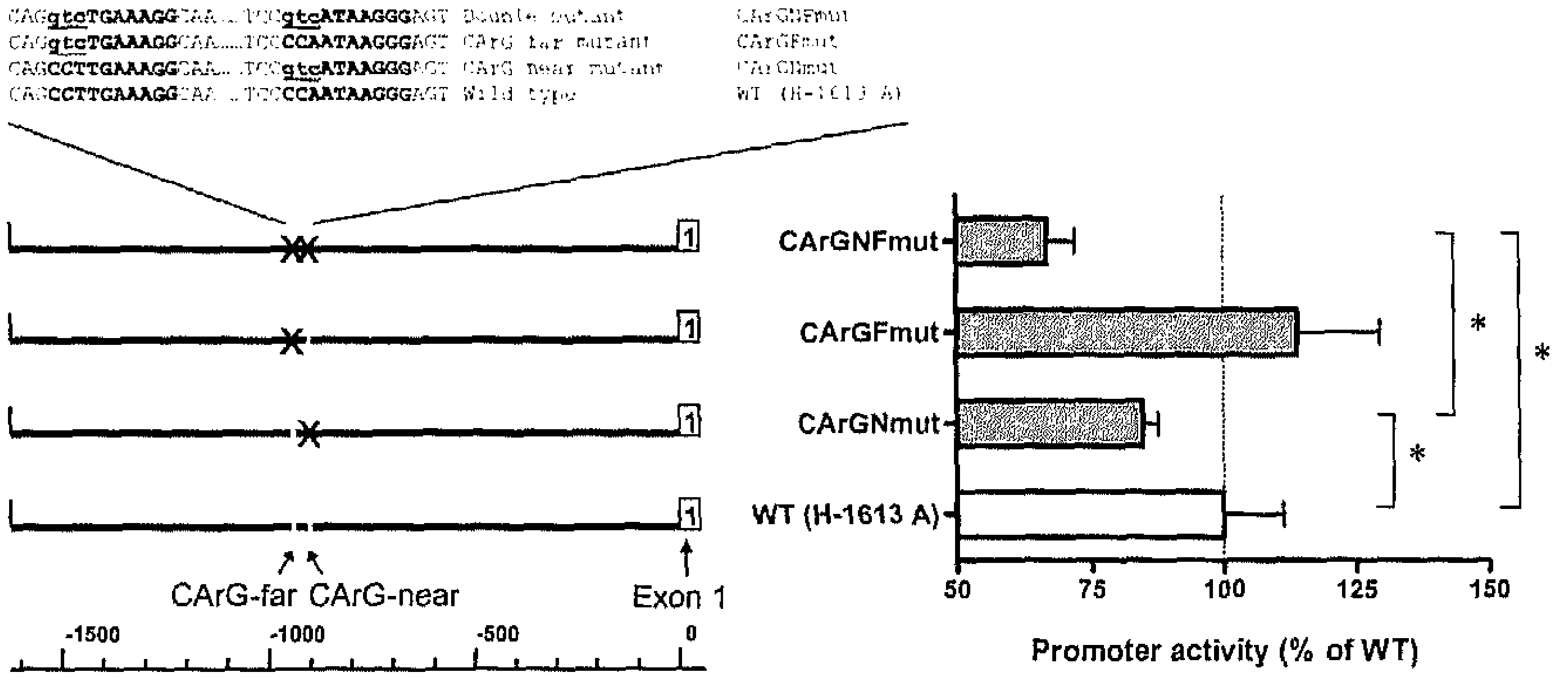

Figure 4.3 A) Sequence comparison of CArG box-containing regions in the smoothelin-A and smoothelin-B promoters of human, mouse and rat. Non-conserved nucleotides are indicated by small case letters. The CArG boxes are shown in bold. Dashes below the sequence indicate conserved nucleotides. Dashed lines indicate probes used for EMSA experiments. The numbers indicate the location of the sequence relative to the respective transcription start sites. B) Effect of CArG box mutations on the activity of the human smoothelin-A promoter construct $\mathrm{H}-1613 \mathrm{~A}$. Mutation of the proximal CArG-near box caused a significant reduction in smoothelin-A promoter activity. Mutation of both CArG boxes simultaneously caused a further decrease. Statistically significant differences are indicated by an asterisk. The sequence of CArG mutations introduced into the human smoothelin-A promoter reporter construct are shown. CArG boxes are shown in bold, mutations are underlined and in small case.

To determine whether SRF is bound to the smoothelin-A promoter CArGs in their native genomic context, we performed ChIP assays in PAC1 SMC. The results in Figure $4.4 \mathrm{~b}$ show enrichment for DNA containing the smoothelin-A promoter CArGs when nucleoprotein complexes are immunoprecipitated with SRF antibody. In contrast, little detectable DNA is seen when nucleoprotein 
complexes are immunoprecipitated with a control IgG. Note that because the CArG boxes are only $27 \mathrm{bp}$ apart from one another, the ChIP assay cannot discriminate relative binding of SRF to each individual CArG element. Nevertheless, these data are congruent with EMSA and show that SRF binds to one or both of the smoothelin-A CArGs in vivo.

A

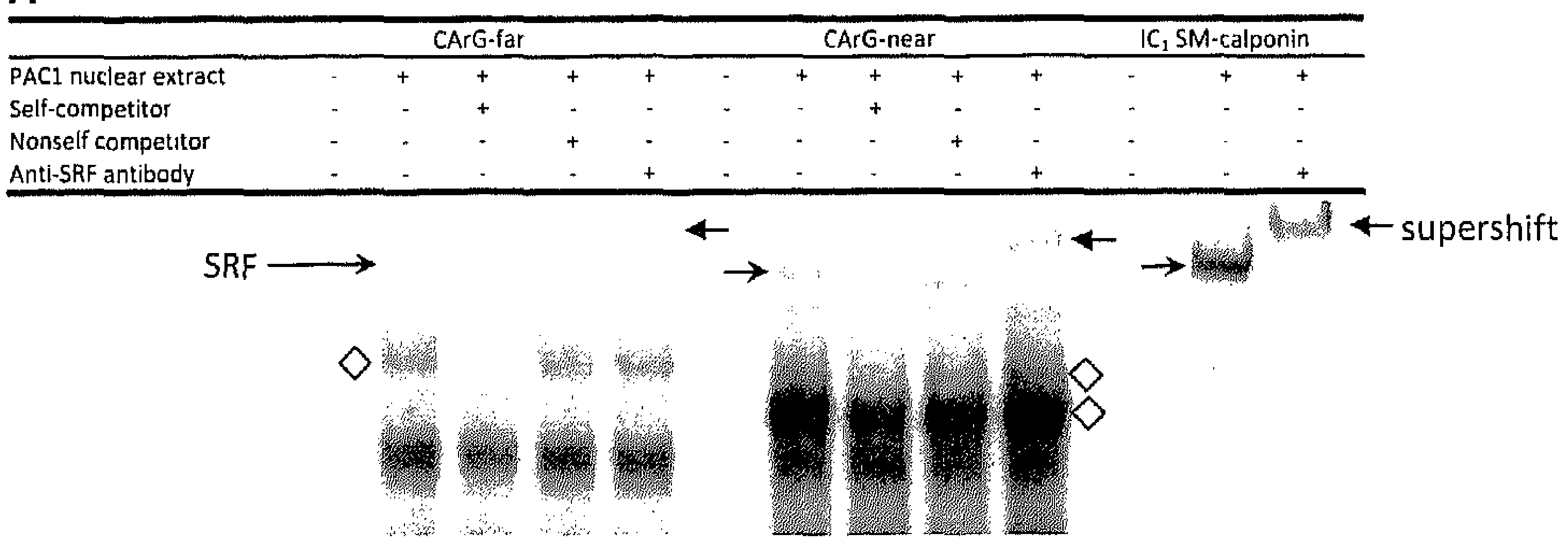

B

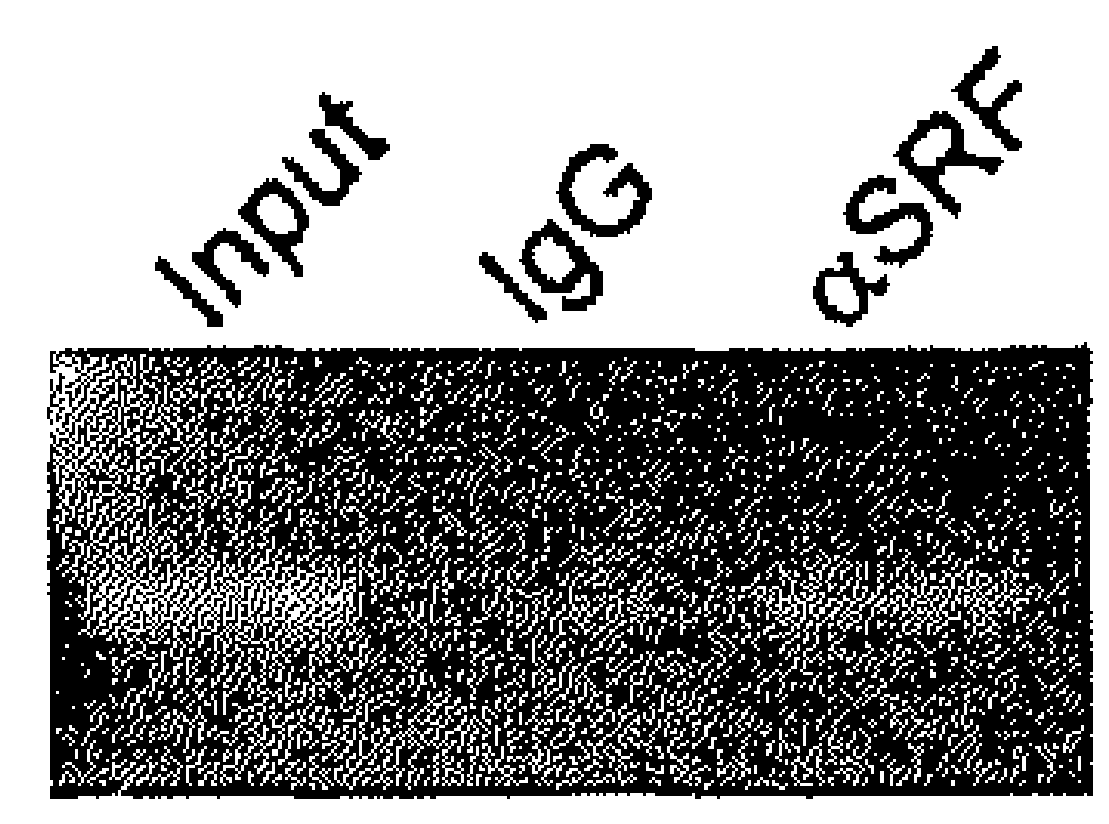

Figure 4.4 A) Electrophoretic mobility shift assay of smoothelin-A CArG-far and CArG-near boxes and of the intronic SM-calponin CArG box $\left(I C_{1} S M\right.$-calponin). Both smoothelin-A CArG boxes bound several nucleoprotein complexes, including a SRF-containing complex. Supershifted complexes are indicated by a left pointing arrow, SRF bound to CArG boxes is indicated by a right pointing arrow, additional specific complexes binding the smoothelin-A CArG boxes are indicated by diamonds. B) ChIP assay results showing an enriched PCR product from PAC1 SMC nucleoprotein encompassing SRF and the tandem smoothelin-A CArG boxes following immunoprecipitation with antibody to SRF ( $\alpha$ SRF). Control IgG shows little to no PCR product. The input lane represents genomic DNA prior to immunoprecipitation.

\section{Activation of the smoothelin-A promoter by myocardin in a CArG-near dependent manner}

To assess the ability of myocardin to transactivate the smoothelin-A promoter, we performed transient reporter assays using either the wild-type promoter or the promoter with single or double CArG box mutations. Myocardin increased wild-type promoter activity 2.5 -fold (Figure 4.5 a). Mutation of CArG-near greatly 
Contribution of SRF and myocardin to transcriptional regulation of smoothelins

reduced the potential of myocardin to activate transcription (1.6-fold versus 2.5 -fold induction). In contrast, mutation of CArG-far did not affect myocardin transactivation significantly (2.7-fold versus 2.5 -fold induction). Upon mutation of both CArG boxes, the ability of myocardin to activate transcription was completely lost. Smoothelin-B promoter activity was augmented by myocardin, but to a lesser extent than smoothelin-A. Similar to previous reports, $\alpha$-SMA promoter activity was highly stimulated by myocardin (17.1-fold induction).

To determine if myocardin also increased endogenous expression of smoothelins in PAC1 cells, we transfected a myocardin expression plasmid into PAC1 SMCs and analyzed smoothelin mRNA levels by Q-PCR. In line with the results above, myocardin overexpression increased endogenous smoothelin-A expression, although the increase was small. In contrast, smoothelin-B mRNA levels did not increase after myocardin overexpression (Figure 4.5b).

A
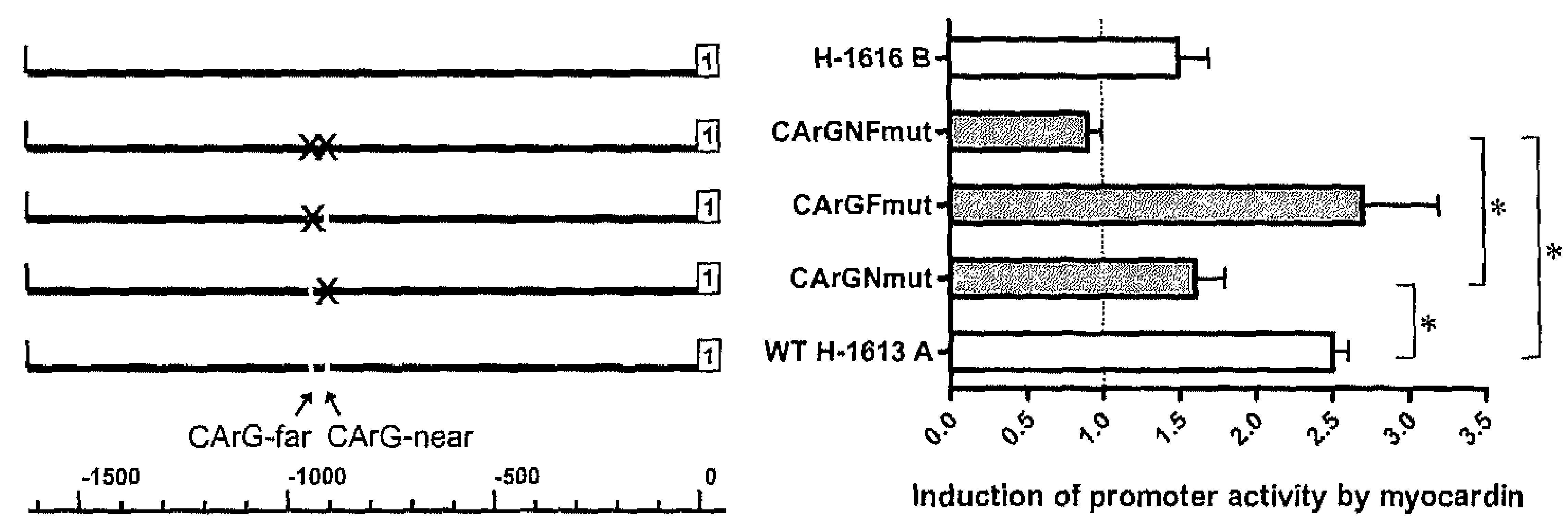

Induction of promoter activity by myocardin

B

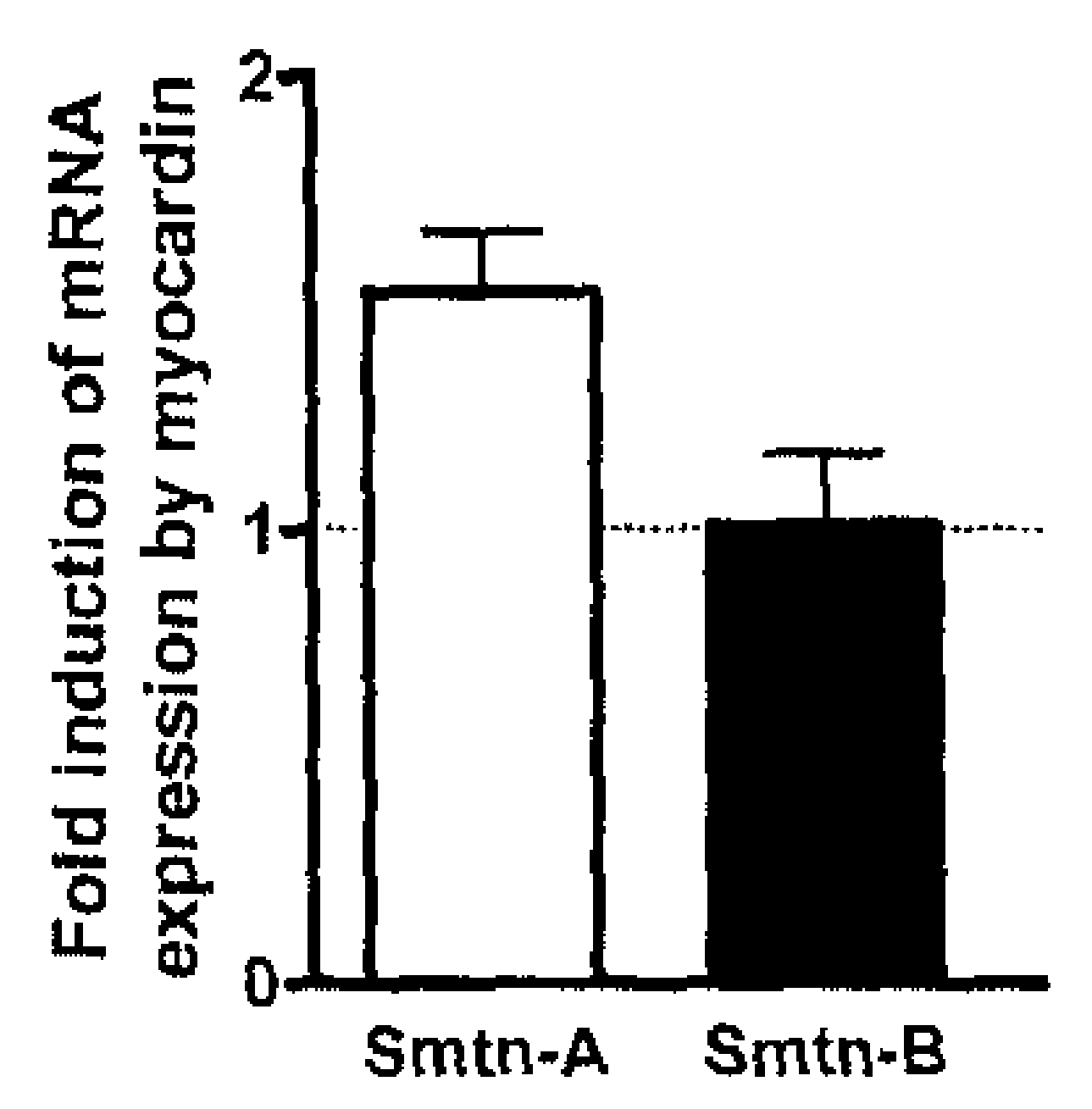

Figure 4.5 A) Effect of myocardin overexpression on wild type (WT H-1613 A) and mutated (CArGNF; CArG-F; CArG-N) human smoothelin-A and smoothelin-B (H-1616 B) promoter activity. The ability of myocardin to increase smoothelin-A promoter activity is reduced when SRF cannot bind CArG-near. Aberration of SRF-binding to both CArG-boxes causes a further decrease in promoter activity. Conserved CArG boxes are indicated by grey boxes. The first exons of each transcript are shown as white boxes. Statistically significant differences are indicated by an asterisk. B) Effect of myocardin overexpression on endogenous expression of smoothelins in PAC1 cells. Transfection with myocardin increased endogenous smoothelin-A expression, but did not affect smoothelin-B mRNA levels. 


\section{Discussion}

SMC differentiation is monitored by marker genes whose expression is restricted to SMCs and representative of a given stage of differentiation. In recent years, it has become clear that studies on the regulation of marker gene expression can direct us to those cis-elements and trans-factors that are important for SMC differentiation itself. The recurring theme in this type of studies is the critical role of SRF-binding to one or more CArG elements in the promoters of SMC marker genes ${ }^{11,22}$. Many of these genes are downregulated when SMCs modulate towards a synthetic phenotype. The extent of downregulation is however quite variable between the different markers. The gene that seems to be most responsive to conditions promoting the synthetic phenotype is the smoothelin gene ${ }^{4,23}$. Elucidation of mechanisms that regulate the expression of this gene is therefore likely to contribute to the understanding of regulators of the contractile SMC phenotype.

Like several other genes whose expression is restricted to SMCs, the smoothelin gene generates several transcripts. Unlike these other genes, this is the result of a dual promoter system, instead of alternative splicing. An intragenic promoter fragment which resides in a region where several exons of smoothelin-B are located can drive transcription of the smaller smoothelin-A mRNA in humans ${ }^{18}$. Data presented in this study confirm and extend these results by showing that although smoothelin-B promoter activity was higher, a smoothelin-A promoter construct derived from the mouse smoothelin gene was consistently active in PAC1 SMCs. Of note, a Smad-binding cis-element in the first exon of the SM $22 \alpha$ gene was recently demonstrated to contribute to $S M 22 \alpha$ expression ${ }^{24}$, showing that exonic and regulating functions of the same sequence are not mutually exclusive.

The previously analyzed human smoothelin-A promoter fragment contained two conserved CArG elements in close proximity in an intronic region ${ }^{19}$. In this study, the functional significance of these elements has been tested. We show that the CArG boxes in the smoothelin-A promoter contribute to, but are not fully responsible for smoothelin-A promoter activity. This is in marked contrast to the promoters of other SMC restricted genes with paired CArG boxes like $\alpha$-SMA and SM22 $\alpha$, which show $80 \%$ reduction of activity when either of their CArG boxes are mutated ${ }^{25}, 26$. The discrepancy of these findings may be explained by the differential organization of the CArG elements between these genes, for CArG spacing and phasing have a major impact on promoter activity ${ }^{27}$. The distance between the CArG boxes in the $\alpha$-SMA and SM22 $\alpha$ genes is 40 and 113 bp respectively, as compared to the smoothelin-A CArGs which are only $27 \mathrm{bp}$ apart. This may lead to different binding potential of SRF or SRF-cofactors. Apart from this, particularly the smoothelin CArG-far has a relatively low affinity for 
Contribution of SRF and myocardin to transcriptional regulation of smoothelins

SRF in EMSA experiments. CArG-near has a higher SRF-binding potential, which is in line with data on the affinity of SRF for CArG boxes with different G/C substitutions in the core indicating that a mutation at the last position of the AT core (CArG-near) is better tolerated than a mutation in the middle (CArG-far) ${ }^{11}$. Thus, it appears that CArG-near is the SRF-binding element that contributes most to smoothelin-A promoter activity. However, the additional reduction in promoter activity upon mutation of both $\mathrm{CArG}$ boxes compared to mutation of only CArG-near suggests that SRF binding to CArG-near may be required to facilitate SRF binding to CArG-far, as has been shown for the skeletal actin promoter $^{28}$.

In the gel shift experiments, additional nucleoprotein complexes with either smoothelin-A CArG box were formed that could not be supershifted by our SRF antibody. Since these complexes were smaller than the SRF-containing complex, this may indicate that distinct proteins unrelated to SRF bind these sequences. Alternatively, they may represent SRF-cofactor complexes of unknown nature, in which the cofactor masks the epitope recognized by our SRF antibody. Another possibility would be that an alternative isoform of SRF is involved ${ }^{29}$, which is not recognized by the SRF antibody we employed. Regardless, the ChIP data show that SRF also binds one or both smoothelin-A CArG boxes in vivo, supporting the gel shift data and indicating a role for SRF in smoothelin-A promoter regulation.

Taken together, the results show that although SRF binding to the smoothelin-A CArG boxes is functional, this is not essential for smoothelin-A promoter activity. This suggests that the transcriptional activation of smoothelin-A, which is associated with the advanced contractile SMC phenotype, requires additional factors.

Several studies have documented the important roles of transforming growth factor- $\beta$ (TGF- $\beta$ ) and various E-box binding transcription factors like GATAfactors and upstream stimulatory factors (USF)- 1 and -2 in transcriptional regulation of other smooth muscle specific markers ${ }^{2,24,30-33}$. The active region in the mouse smoothelin-A promoter, which is located between -1560 and -851 nucleotides, contains three conserved putative USF-binding sites but no TGF- $\beta$ control elements or Smad-binding elements ${ }^{19}$. Thus, further research may be directed towards a possible contribution of USF-1/USF-2 to regulation of smoothelin-A promoter activity.

In view of the recently suggested model in which myocardin specifically enhances transcription of genes containing two CArG boxes ${ }^{16}$, we tested the ability of myocardin to increase transcription of smoothelin-A and $-B$. Smoothelin-B promoter activity was only marginally induced by myocardin, consistent with previous studies ${ }^{17}$. This is in line with the fact that the three 


\section{Chapter 4}

CArG elements in the human smoothelin-B promoter have not been conserved across species. In contrast, myocardin did activate the smoothelin-A promoter, albeit to a much lesser extent than the $\alpha$-SMA promoter. In agreement with the data on SRF binding, CArG-near but not CArG-far appeared to be important for smoothelin-A promoter activation by myocardin. Myocardin activity was completely lost when both CArGs were mutated, confirming that the smoothelin-A CArG boxes are functional. Similar results were obtained in a study of the $\alpha$-SMA promoter, although mutation of only CArG-far severely impaired promoter activation by myocardin ${ }^{15}$. This suggests that activation of promoters in SMCs by myocardin is not absolutely dependent on two functional CArG motifs, but rather that one intact CArG element is sufficient. However, myocardin transactivation of the smoothelin-A promoter in PAC1 cells is much weaker than observed for other SMC genes ${ }^{13}$, probably because the smoothelinA CArG boxes do not bind SRF very efficiently. Thus, the hypothesized mechanism in which myocardin transactivational activity is only fully revealed after bridging of two CArG-bound SRF molecules is consistent with the present data ${ }^{16}$.

It appears that other factors distinct from SRF or its coactivators are needed for full activation of the smoothelin promoters. This may explain the difference in the extent of downregulation of smoothelins versus other, SRF-dependent, contractile SMC genes in synthetic SMCs. Also, the possibility that the stronger upstream smoothelin-B promoter is required for full exploitation of the smoothelin-A promoter can not be ruled out, and would provide a novel contribution to the complex ways in which expression of SMC genes is regulated.

\section{Acknowledgements}

This work was supported by National Institutes of Health Grant HL-62572 (J.M.) and by grant D97.167 (S.R.) from the Netherlands Heart Foundation. 
Contribution of SRF and myocardin to transcriptional regulation of smoothelins

\section{References}

1. Miano JM. Mammalian smooth muscle differentiation: origins, markers and transcriptional control. Results Probl Cell Differ. 2002;38:39-59.

2. Owens GK, Kumar MS, Wamhoff BR. Molecular regulation of vascular smooth muscle cell differentiation in development and disease. Physiol Rev. 2004;84:767-801.

3. van der Loop FT, Schaart G, Timmer ED, Ramaekers FC, van Eys GJ. Smoothelin, a novel cytoskeletal protein specific for smooth muscle cells. J Cell Biol. 1996;134:401-411.

4. Christen $T$, Bochaton-Piallat ML, Neuville P, Rensen S, Redard M, van Eys G, Gabbiani G. Cultured porcine coronary artery smooth muscle cells. A new model with advanced differentiation. Circ Res. 1999;85:99-107.

5. Bar H, Wende P, Watson L, Denger S, van Eys G, Kreuzer J, Jahn L. Smoothelin is an indicator of reversible phenotype modulation of smooth muscle cells in ballooninjured rat carotid arteries. Basic Res Cardiol. 2002;97:9-16.

6. Aikawa $M$, Sivam PN, Kuro-o $M$, Kimura K, Nakahara K, Takewaki S, Ueda $M$, Yamaguchi $H$, Yazaki $Y$, Periasamy $M$, et al. Human smooth muscle myosin heavy chain isoforms as molecular markers for vascular development and atherosclerosis. Circ Res. 1993;73:1000-1012.

7. Miano JM, Cserjesi P, Ligon KL, Periasamy $M$, Olson EN. Smooth muscle myosin heavy chain exclusively marks the smooth muscle lineage during mouse embryogenesis. Circ Res. 1994;75:803-812.

8. Manabe I, Owens GK. CArG elements control smooth muscle subtype-specific expression of smooth muscle myosin in vivo. J Clin Invest. 2001;107:823-834.

9. Miano JM, Carlson MJ, Spencer JA, Misra RP. Serum response factor-dependent regulation of the smooth muscle calponin gene. J Biol Chem. 2000;275:9814-9822.

10. Mack CP, Owens GK. Regulation of smooth muscle alpha-actin expression in vivo is dependent on CArG elements within the $5^{\prime}$ and first intron promoter regions. Circ Res. 1999;84:852-861.

11. Miano JM. Serum response factor: toggling between disparate programs of gene expression. J Mol Cell Cardiol. 2003;35:577-593.

12. Wang D, Chang PS, Wang Z, Sutherland L, Richardson JA, Small E, Krieg PA, Olson EN. Activation of cardiac gene expression by myocardin, a transcriptional cofactor for serum response factor. Cell. 2001;105:851-862.

13. Chen J, Kitchen CM, Streb JW, Miano JM. Myocardin: a component of a molecular switch for smooth muscle differentiation. J Mol Cell Cardiol. 2002;34:1345-1356.

14. Du KL, Ip HS, Li J, Chen M, Dandre F, Yu W, Lu MM, Owens GK, Parmacek MS. Myocardin is a critical serum response factor cofactor in the transcriptional program regulating smooth muscle cell differentiation. Mol Cell Biol. 2003;23:2425-2437.

15. Yoshida T, Sinha S, Dandre F, Wamhoff BR, Hoofnagle MH, Kremer BE, Wang DZ, Olson EN, Owens GK. Myocardin is a key regulator of CArG-dependent transcription of multiple smooth muscle marker genes. Circ Res. 2003;92:856-864.

16. Wang Z, Wang DZ, Pipes GC, Olson EN. Myocardin is a master regulator of smooth muscle gene expression. Proc Natl Acad Sci U S A. 2003;100:7129-7134.

17. Yoshida T, Kawai-Kowase K, Owens GK. Forced expression of myocardin is not sufficient for induction of smooth muscle differentiation in multipotential embryonic cells. Arterioscler Thromb Vasc Biol. 2004;24:1596-1601. 
18. Rensen S, Thijssen V, De Vries C, Doevendans P, Detera-Wadleigh S, Van Eys G. Expression of the smoothelin gene is mediated by alternative promoters. Cardiovasc Res. 2002;55:850.

19. Rensen S, Merkx G, Doevendans P, Geurts Van Kessel A, van Eys G. Structure and chromosome location of Smtn, the mouse smoothelin gene. Cytogenet Cell Genet. 2000;89:225-229.

20. Rothman A, Kulik TJ, Taubman MB, Berk BC, Smith CW, Nadal-Ginard B. Development and characterization of a cloned rat pulmonary arterial smooth muscle cell line that maintains differentiated properties through multiple subcultures. Circulation. 1992;86:1977-1986.

21. Firulli $A B$, Han D, Kelly-Roloff L, Koteliansky VE, Schwartz SM, Olson EN, Miano JM. A comparative molecular analysis of four rat smooth muscle cell lines. In Vitro Cell Dev Biol Anim. 1998;34:217-226.

22. Kumar MS, Owens GK. Combinatorial control of smooth muscle-specific gene expression. Arterioscler Thromb Vasc Biol. 2003;23:737-747.

23. van der Loop FT, Gabbiani G, Kohnen G, Ramaekers FC, van Eys GJ. Differentiation of smooth muscle cells in human blood vessels as defined by smoothelin, a novel marker for the contractile phenotype. Arterioscler Thromb Vasc Biol. 1997;17:665-671.

24. Chen S, Kulik M, Lechleider RJ. Smad proteins regulate transcriptional induction of the SM22alpha gene by TGF-beta. Nucleic Acids Res. 2003;31:1302-1310.

25. Li L, Liu Z, Mercer B, Overbeek P, Olson EN. Evidence for serum response factormediated regulatory networks governing SM22alpha transcription in smooth, skeletal, and cardiac muscle cells. Dev Biol. 1997;187:311-321.

26. Shimizu RT, Blank RS, Jervis R, Lawrenz-Smith SC, Owens GK. The smooth muscle aipha-actin gene promoter is differentially regulated in smooth muscle versus nonsmooth muscle cells. J Biol Chem. 1995;270:7631-7643.

27. Mack CP, Thompson MM, Lawrenz-Smith S, Owens GK. Smooth muscle alpha-actin CArG elements coordinate formation of a smooth muscle cell-selective, serum response factor-containing activation complex. Circ Res. 2000;86:221-232.

28. Lee TC, Chow KL, Fang P, Schwartz RJ. Activation of skeletal alpha-actin gene transcription: the cooperative formation of serum response factor-binding complexes over positive cis-acting promoter serum response elements displaces a negativeacting nuclear factor enriched in replicating myoblasts and nonmyogenic cells. Mol Cell Biol. 1991;11:5090-5100.

29. Kemp PR, Metcalfe JC. Four isoforms of serum response factor that increase or inhibit smooth-muscle-specific promoter activity. Biochem J. 2000;345 Pt 3:445-451.

30. Johnson $A D$, Owens GK. Differential activation of the SMalphaA promoter in smooth vs. skeletal muscle cells by bHLH factors. Am J Physiol. 1999;276:C1420-1431.

31. Chen YH, Layne MD, Watanabe $M$, Yet SF, Perrella MA. Upstream stimulatory factors regulate aortic preferentially expressed gene- 1 expression in vascular smooth muscle cells. J Biol Chem. 2001;276:47658-47663.

32. Sellak H, Choi C, Browner N, Lincoln TM. Upstream stimulatory factors (USF-1/USF-2) regulate human CGMP-dependent protein kinase I gene expression in vascular smooth muscle cells. J Biol Chem. 2005;280:18425-18433.

33. Yin F, Herring BP. GATA-6 can act as a positive or negative regulator of smooth muscle-specific gene expression. J Biol Chem. 2005;280:4745-4752. 


\section{Chapter 5}

\section{Smoothelin-A is essential for functional intestinal smooth muscle contractility in mice}

Petra Niessen, Sander Rensen, Jan van Deursen, Joris De Man, Ann De Laet, Jean-Marie Vanderwinden, Thilo Wedel, Darren Baker, Pieter Doevendans, Marten Hofker, Marion Gijbels, Guillaume van Eys.

Gastroenterology, 2005;129(5):1592-601. 


\begin{abstract}
Background \& Aims: In patients with chronic intestinal pseudo-obstruction, intestinal motility is disturbed by either nervous or myogenic aberrations. The cause of the myogenic form is unknown, but it is likely to originate in the contractile apparatus of the smooth muscle cells. Smoothelins are actin-binding proteins that are abundantly expressed in visceral (smoothelin-A) and vascular (smoothelin-B) smooth muscle. Experimental data indicate a role for smoothelins in smooth muscle contraction. A smoothelin-deficient mouse model may help to establish the role of smoothelin-A in intestinal contraction and provide a model for myogenic chronic intestinal pseudo-obstruction.

Methods: We used gene targeting to investigate the function of smoothelin-A in intestinal tissues. By deletion of exons 18, 19 and 20 from the smoothelin gene, the expression of both smoothelin isoforms was disrupted. The effects of the deficiency were evaluated by pathological and physiological analyses.

Results: In smoothelin-A/B knockout mice, the intestine was fragile and less flexible compared with wild type littermates. The circular and longitudinal muscle layers of the intestine were hypertrophic. Deficiency of smoothelin-A led to irregular slow wave patterns and impaired contraction of intestinal smooth muscle, leading to hampered transport in vivo. This caused obstructions that provoked intestinal diverticulosis and occasionally intestinal rupture.

Conclusion: Smoothelin-A is essential for functional contractility of intestinal smooth muscle. Hampered intestinal transit in smoothelin-A/B knockout mice causes obstruction, starvation and ultimately premature death. The pathology of mice lacking smoothelin-A is reminiscent of that seen in patients with chronic intestinal pseudo-obstruction.
\end{abstract}


Smoothelin-A is essential for functional smooth muscle intestinal contractility

\section{Introduction}

The principal function of smooth muscle cells (SMCs) in the intestinal tract is to enable propulsion and mixing of food ${ }^{1}$, which improves digestion of complex molecules and absorption of nutrients. Coordinated contractions of the circular and longitudinal smooth muscle layers are responsible for peristalsis of the gastro-intestinal tract. Contractions of SMCs are slower than those of skeletal and cardiac myocytes, but are more sustained. Hence, the composition of the contractile apparatus of SMCs differs from that of the striated muscle cells. In both cell types, actin-myosin interactions are at the basis of contraction. The contraction of striated muscle is rather well understood and accessory proteins, such as troponins, are known to be part of the organization of the contractile apparatus and determine the mode of contraction ${ }^{2,3}$. The architecture and composition of contractile elements in SMCs is, however, still not fully understood. The contractile apparatus of SMCs is connected with the cytoskeleton via dense bodies. It consists of an actin-myosin axis complemented with structural muscle proteins, including $\alpha$-actinin and tropomyosin, and more smooth muscle-specific proteins such as calponin, caldesmon and smoothelin ${ }^{4,5}$. Based on their expression pattern, smoothelins have been described as proteins specific for fully differentiated smooth muscle. The two major isoforms are: smoothelin-A in visceral tissues such as the digestive tract, bladder, and prostate, and smoothelin-B in vascular tissues ${ }^{6,7}$. Both are only found in actively contracting smooth muscle tissues. Under pathological conditions with impaired function of smooth muscle, like aneurysms and restenosis, expression of smoothelins rapidly decreases ${ }^{8,9}$. In cultured SMCs, smoothelins co-localize with smooth muscle $\alpha$-actin ( $\alpha$-SMA) stress fibers ${ }^{8,10}$. Recently, we demonstrated in vitro that smoothelins can physically bind to $\alpha$-SMA under normal physiological conditions $^{11}$. These findings point towards a direct role of smoothelin in contraction.

If SMCs are brought into culture, smoothelin expression is rapidly downregulated $^{6,10}$, concomitant with their modulation towards a synthetic phenotype. This hampers in vitro investigations of the function of smoothelin in smooth muscle contraction. Therefore, assessment of the function of smoothelins in intestinal contractility requires an in vivo approach. Here, we report the interruption of the smoothelin gene in mice, leading to elimination of both smoothelin-A and $-B$. The smoothelin knockout mice $\left(S m t n-A / B^{-1}\right)$ show dysfunction of intestinal motility and contractility and die prematurely. The observed phenotype displays pathologies reminiscent of intestinal diverticulosis, chronic intestinal pseudo-obstruction (CIP) and hollow visceral myopathy in humans. 


\section{Materials and methods}

\section{Generation of Smtn-A/B/- and Smtn- $B^{\circ /-}$ mice}

To generate Smtn-A/B/ mice, we replaced part of exon 18 , exon 19 and exon 20 with a neomycin resistance gene under the control of the thymidine kinase promoter in reverse orientation (Figure 5.1A). The targeting vector contained the thymidine kinase gene for negative selection. After electroporation of the Pvull-linearized construct into mouse L129/Sv embryonic stem (ES) cells, we selected neomycin-resistant clones with G418 (Invitrogen, Carlsbad, California) and 1-[2-Deoxy]2-fluoro- $\beta$-D-arabinofurasonyl (Invitrogen). DNA from resistant clones was screened by Southern blotting after Pstl restriction digestion, using the $3^{\prime}$ probe indicated in Figure 5.1A. ES cells from two independent targeted clones were injected into $\mathrm{C} 57 \mathrm{Bl} / 6$ blastocysts and implanted into pseudopregnant $\mathrm{C} 57 \mathrm{Bl} / 6$ females. Mating of the resulting chimeric males to $\mathrm{C} 57 \mathrm{BI} / 6$ females led to germline transmission of the targeted allele as detected by Southern blotting (Figure 5.1B). Since the mice had a mixed background (L129/SV and C57BI/6), we used littermates as controls. In the food transit experiment we used age- and sex-matched controls. The generation of smoothelin-B knockout mice $\left(S m t n-B^{-1}\right)$ is described elsewhere (Rensen et al., in preparation). In these mice, exons 3 through 6 of the smoothelin gene are removed and smoothelin-B synthesis is absent whereas smoothelin-A synthesis is not affected. All animal studies were performed according to protocols approved by the Committee on Animal Experimentation of the University of Maastricht.

\section{Reverse transcriptase-polymerase chain reaction (RT-PCR)}

Total RNA was extracted from various tissues with Tri reagent (Sigma-Aldrich, Zwijndrecht, The Netherlands). Reverse transcription was performed using $1 \mu \mathrm{g}$ of RNA in the RevertAid First Strand CDNA synthesis kit (Fermentas, St. LeonRot, Germany). Expression of smoothelin mRNA in $S m t n-A / B^{-1}$ mice was investigated by RT-PCR using smoothelin-B specific primers $1 \mathrm{~F}$ 5'CCAGGGGGCAGTATGAAGAC- $3^{\prime}$ and 1R $5^{\prime}$-CGCAGGTGGTTGTAGAGCGA- $3^{\prime}$ and common smoothelin primers $2 \mathrm{~F}$ 5'-GAGGAGCGCAAGCTGATCA-3' and 2R 5'CTGCTGGTGCTGAGAAGGGT-3'. RT-PCR products were cloned and sequenced.

\section{Western blot}

Intestinal tissue homogenates $(n=5)$ were prepared in SET buffer $(0.25 \mathrm{~mol} / \mathrm{L}$ Sucrose, $0.01 \mathrm{~mol} / \mathrm{L}$ Tris- $\mathrm{HCl} \mathrm{pH} 7.4,2 \mathrm{mmol} / \mathrm{L}$ EDTA) supplemented with 1 $\mathrm{mmol} / \mathrm{L}$ PMSF. Protein concentration was measured by the BCA method (Pierce, Rockford, IL) and $15 \mu \mathrm{g}$ was loaded onto a 9\% SDS-PAGE gel. Proteins were 
blotted on PVDF membrane (Hybond-P, Amersham Biosciences) and blocked over night in phosphate buffered saline (PBS) containing $0.2 \%$ Tween- 20 and $5 \%$ Marvel at $4^{\circ} \mathrm{C}$. $\alpha$-SMA was detected using the monoclonal antibody $1 \mathrm{~A} 4$ (DAKO, Glostrup, Denmark) and a secondary rabbit-anti mouse antibody conjugated with horse reddish peroxidase (HRP) (DAKO). Smooth muscle myosin heavy chain (SM MHC) was detected with the rabbit polyclonal lgG bt-562 (Campro Scientific, Veenendaal, The Netherlands) followed by donkey-anti-rabbit-HRP (Jackson ImmunoResearch laboratories, Inc., West Grove, PA). Bands were visualized by enhanced chemiluminescence. Subsequently, signals were digitized and analyzed with Quantity One software (Bio-Rad Laboratories, Hercules, CA).

\section{Histology, immunohistochemistry and electron microscopy}

Organs from mice aged from 0 days to six months were fixed overnight in $3.7 \%$ formaldehyde in PBS, embedded in paraffin, sectioned and stained with haematoxylin and eosin. Sirius Red staining was performed for the detection of collagen.

Samples of intestine (and several other tissues) were snap-frozen in liquid nitrogen-pre-cooled isopentane and embedded in OCT Tissue Tek compound (Sakura, Chicago, IL). Cryostat sections were stained with biotinylated mouse monoclonal R4A specific for smoothelin ${ }^{12}$. The ABC-peroxidase kit (Vector Laboratories) was used for detection, followed by diaminobenzidine tetrahydrochloride-staining and haematoxylin counterstaining. Interstitial cells of Cajal (ICCs) were identified by antibody against c-kit (Santa Cruz Biotechnology Inc, Santa Cruz, CA $)^{13}$.

Full thickness biopsies from ileum were obtained from a patient with CIP. Agematched control specimens were obtained from patients with diseases unrelated to GI motility disorders. The use of human tissues was approved by the Medical Institutional Ethics Committee of the Faculty of Medicine, University of Luebeck, Germany. Tissues were processed as described by Vanderwinden et al. ${ }^{14}$.

For electron microscopy, tissues were fixed in $3 \%$ phosphate buffered glutaraldehyde for 24 hours and postfixed for 1 hour in $1 \%$ osmium tetroxide. Tissues were then dehydrated through a graded ethanol series and routinely embedded in Epon. Ultrathin sections were counterstained with uranyl acetate and lead citrate and examined in a Philips CM100 electron microscope (Philips, Eindhoven, The Netherlands).

\section{Whole gut transit time test}

To determine the intestinal function, a whole gut transit time test was used as previously described ${ }^{15}$. We injected $100 \mu$ of $6 \%$ carmine (Sigma-Aldrich C1022) in PBS (pH 7.0) into the stomachs of six Smtn-A/B $B^{+/+}, S m t n-A / B^{+/}$and $S m t n-A / B^{-/}$, 
and five $S m t n-B^{+/+}$and $S m t n-B^{-/}$mice and monitored faeces for the first appearance of red dye.

\section{Contrast radiography}

After sedation with $0.15 \mu \mathrm{L}$ Nembutal (Ceva Sante Animale BV, Maassluis, the Netherlands) by intraperitoneal injection, $0.3 \mathrm{~mL}$ barium sulfate suspension (polibar $1 \mathrm{~g} / \mathrm{mL}$, E-Z-EM Inc, NY, USA; diluted 1:4 with water) was injected into the stomachs of $2 \mathrm{Smtn}-A / B^{-/}$and $2 \mathrm{Smtn}-\mathrm{A} / \mathrm{B}^{+/+}$mice (12 weeks old). Progression through the gastro-intestinal tract was followed by continuous $X$ ray examination $(60 \mathrm{Kv}, 1,6 \mathrm{MA})$. Digital $\mathrm{X}$-ray images were taken every 10 minutes with a Philips Diagnost 1997 device (Philips Medical Systems, Best, the Netherlands).

\section{Intestinal contractility}

Intestinal contractility was studied on 4-6 weeks old mice ( $n=6$ for each group). Before anaesthetizing mice with diethyl ether, we fasted them for $24 \mathrm{~h}$ with free access to water. The small intestine of $S m t n-A B^{-1}$ and $S m t n-A B^{+/+}$littermates (and of Smtn-B- $B^{-/-}$and Smtn- $B^{+/+}$littermates) was removed and put in ice-cold aerated Krebs-Ringer solution. A $10 \mathrm{~cm}$ segment of the jejunum was opened along the longitudinal axis and the mucosa was removed. Longitudinal muscle strips of $6.0 \mathrm{~mm}$ of the jejunum were mounted in organ baths $(5 \mathrm{~mL})$ filled with Krebs-Ringer solution, maintained at $37{ }^{\circ} \mathrm{C}$ and aerated with a mixture of $5 \%$ $\mathrm{CO}_{2}$ and $95 \% \mathrm{O}_{2}$. The muscle strips were positioned between two platinum ring electrodes (distance $10 \mathrm{~mm}$; diameter of rings: $3 \mathrm{~mm}$ ) that are mounted on a Plexiglas rod. The lower end of the muscle strip was fixed and the other end of the muscle strip was connected to a strain gauge transducer (Scaime, France) for continuous recording of isometric tension. After an equilibration period of $30 \mathrm{~min}$ during which the strips were washed every $5 \mathrm{~min}$, the muscle strips were contracted with $0.1 \mu \mathrm{mol} / \mathrm{L}$ carbachol. After washout of carbachol, the strips were stretched (increments of $5 \mathrm{mN}$ ). After stabilization of the basal tone muscle strips were again contracted with $0.1 \mu \mathrm{mol} / \mathrm{L}$ carbachol. This procedure was repeated until the contraction to $0.1 \mu \mathrm{mol} / \mathrm{L}$ carbachol was maximal. This point was taken as the point of optimal length-tension relation ${ }^{16}$. Muscle strips were then allowed to equilibrate for $60 \mathrm{~min}$ before starting the experimentation. During the equilibration period, the muscle strips were washed every $15 \mathrm{~min}$ with Krebs-Ringer solution. The contractile effect of electrical field stimulation (EFS, $0.5-8 \mathrm{~Hz}, 40 \mathrm{~V}$, pulse width: $1 \mathrm{~ms}$, pulse train: 10 s), of enteric nerves, carbachol ( $1 \mathrm{nmol} / \mathrm{L}-1 \mu \mathrm{mol} / \mathrm{L}$ ), prostaglandin F2 $\alpha$ (PGF2 $\alpha$, $1 \mathrm{nmol} / \mathrm{L}-10 \mu \mathrm{mol} / \mathrm{L})$, substance-P $(0.1 \mathrm{nmol} / \mathrm{L}-100 \mathrm{nmol} / \mathrm{L})$, serotonin $(5 \mathrm{HT}$, $1 \mathrm{nmol} / \mathrm{L}-10 \mu \mathrm{mol} / \mathrm{L})$ and $\mathrm{KCl}(50 \mathrm{mmol} / \mathrm{L})$ was investigated. To block inhibitory responses to nitric oxide (NO), contractions were studied in the presence of $L$ - 
Smoothelin-A is essential for functional smooth muscle intestinal contractility

nitroarginine, a blocker of NO synthase. An adjacent jejunal segment was fixed in $4 \%$ formaldehyde for histological examination and determination of the cross sectional area (CSA). Contractions were normalized to the CSA of the longitudinal jejunal muscle layer.

\section{Intracellular recordings}

A standard microelectrode technique was used to record slow waves from the SMCs of the small intestine. Pieces of duodenum $(2 \mathrm{~cm}$ beyond the pyloric sphincter) from the same mice as used for the intestinal contractility studies were used. The segments were opened along the mesenteric border and the mucosa and submucosa were removed. A muscle strip $(15 \times 6 \mathrm{~mm})$ was then pinned, serosal side down, to the Sylgard floor (Dow Corning Europe, Belgium) of a recording chamber that was placed on the stage of an inverted microscope (Diaphot; Nikon, Tokyo, Japan). The tissue was continuously superfused (10 $\mathrm{mL} / \mathrm{min}$; temperature $36.5-37^{\circ} \mathrm{C}$ ) with oxygenated Krebs-Ringer solution.

Throughout the experiment, the L-type $\mathrm{Ca}^{2+}$ blocker nicardipine $(1 \mu \mathrm{mol} / \mathrm{L})$ (Sigma Chemical, St. Louis, MO) was present in the superfusion solution to reduce contraction of the intestinal smooth muscle ${ }^{17,18}$. Intracellular recordings of the SMCs were made with borosilicate glass microelectrodes $(1 \mathrm{~mm}$ outer diameter; Clarc Electromedical Instruments, Reading, UK) pulled on a P-97 Brown-Flaming micropipette puller (Sutter Instrument Co., Novato, CA). The electrodes were back filled with $1 \mathrm{~mol} / \mathrm{L} \mathrm{KCl}$ (resistance 50-70 M $\Omega$ ). The electrode was positioned by a micromanipulator (type Narishige MO388). Passive electrical events were measured with an Axoclamp 2A current-voltage amplifier (headstage HS-2 L, gain 0.1) connected to a Labmaster TL-1 DMA interface (Axon Instruments). The amplifier bridge circuit was balanced for each electrode before impalement, and capacitance was compensated for during injection of rectangular electrical current pulses $(-0.2 \mathrm{nA}, 7 \mathrm{~ms})$ through the microelectrode. After amplification and low-pass filtering $(3 \mathrm{kHz})$, the signal was digitized at a sample rate of $5 \mathrm{kHz}$ and stored on PC using the pClamp 6.0.2 software (Axon Instruments).

\section{Morphometric analyses}

To determine the CSA of the longitudinal and circular muscle layer of the jejunum, cross sections were stained with haematoxylin/eosin. Images were captured using a Zeiss Axioscope (Zeiss, Göttingen, Germany) and a standard CCD camera (Stemmer Imaging, Puchheim, Germany), and analyzed with Leica QWin image analysis software (Leica Microsystems, Cambridge, UK). To determine the number of nuclei of the longitudinal and circular muscle layers of these sections, two opposite angular segments $\left(15^{\circ}\right)$ of the intestinal wall were selected and counted manually. 


\section{Statistical analyses}

Statistical significance was calculated by repeated measures one-way ANOVA followed by Bonferroni's multiple comparison test, or two-tailed (paired) Student $t$ tests using Graphpad Prism software (version 4.0). Groups were considered significantly different when $P<0.05$. Values are expressed as mean \pm standard error of the mean (SEM).

\section{Results}

\section{Mouse model}

Smoothelin-A/B ${ }^{-1 /}$ mice were generated by removal of exons 18 through 20 (Figure 5.1A,B). These exons code for the calponin homology domain that is involved in actin binding ${ }^{11}$. The deletion resulted in smaller smoothelin transcripts with an intact reading frame, corresponding to variants with exons 16 or 17 spliced to exon 21 (Figure 5.1C). However, smoothelin protein could not be detected in smooth muscle tissues of $S m t n-A / B^{-/-}$mice using an antibody against an epitope upstream of the deletion (Figure 5.1D), indicating that the targeting resulted in a null-mutation. Western blot analyses revealed that $\alpha$ SMA was downregulated in intestines of $S m t n-A / B^{-1-}$ mice whereas SM MHC concentration was similar (Figure 5.1E).

Smtn- $A / B^{-/}$pups were born at the expected Mendelian ratio $\left(S m t n-A / B^{+/+} 30 \%\right.$; Smtn-A/B $\left.{ }^{+/-} 46 \% ; S m t n-A / B^{-/-} 24 \%, n=415\right)$. At birth, $S m t n-A / B^{-1-}$ mice had a size and weight comparable with their wild type littermates, but their postnatal growth was overtly retarded and surviving animals reached only approximately $80 \%$ of normal body weight. In the $S m t n-A / B^{-/-}$mice, a remarkable absence of visceral and subcutaneous fat was observed. About $50 \%$ of $S m t n-A / B^{-1}$ mice died before weaning at three weeks of age (Figure 5.1F). Smtn-A/B ${ }^{-1-}$ mice that developed into adulthood were infertile. In contrast, $S m t n-A / B^{+/-}$(and also $S m t n-B^{-/}$mice) had no overt abnormalities, were fertile and had a normal life span.

\section{Whole gut transit time, contractility and slow wave recordings}

Motility of the intestine was determined by functional assays. Carmine, a red dye, was injected into the stomach and stool was monitored. Despite a comparable length of the intestinal tract, the whole gut transit time of Smtn$A / B^{-1-}$ mice was about twice as long as that of wild type littermates (Figure 5.2A). $S m t^{-1 /} B^{-1}$ mice showed no increase in whole gut transit time (Figure 5.2A). Contrast radiography after loading barium sulfate into the stomach of $S m t n-A / B^{-/-}$ mice confirmed the slower food transport in $S m+n-A / B^{-/-}$mice and showed a 


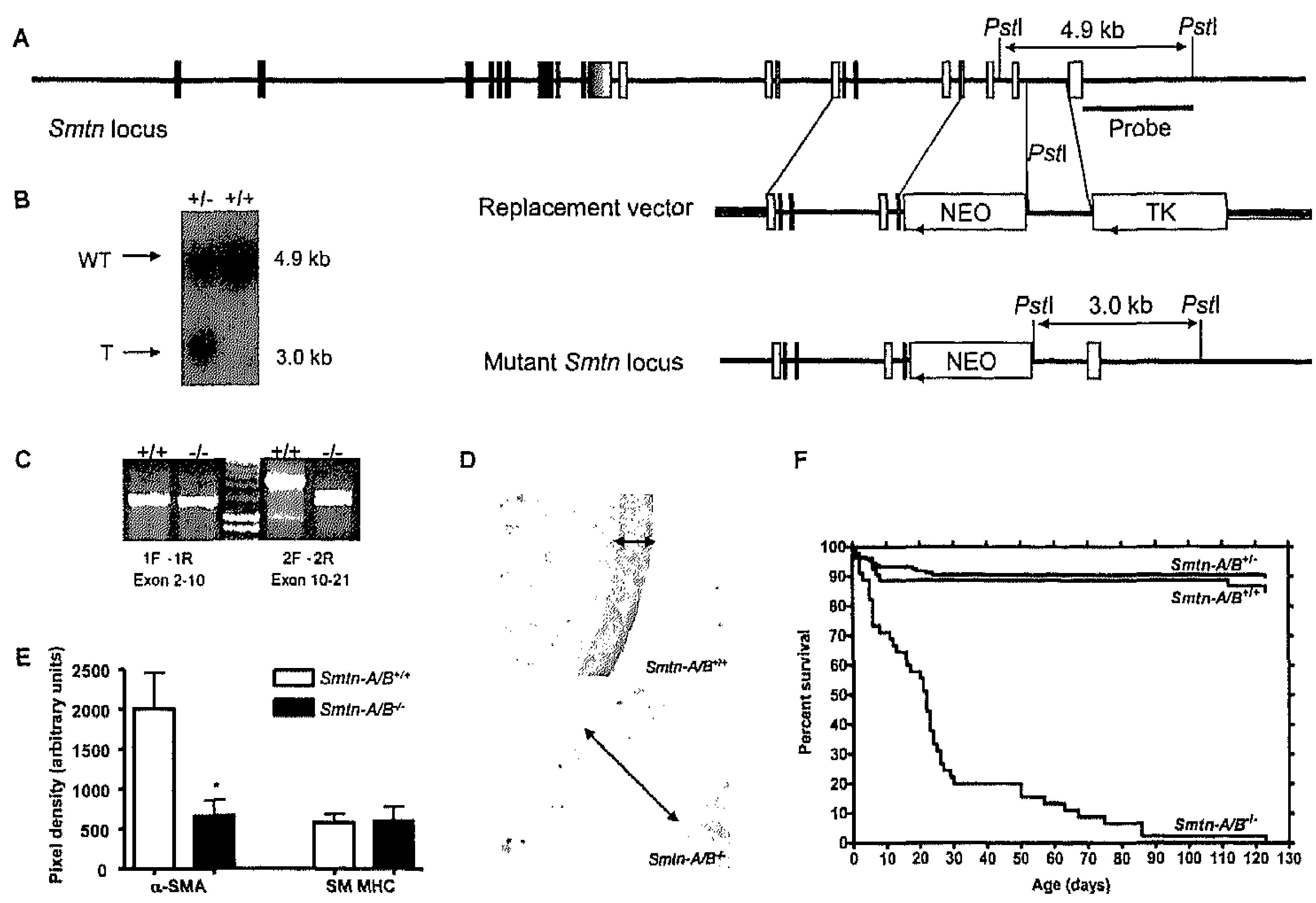

Figure 5.1 Smtn-A/B ${ }^{-1-}$ mice have a greatly reduced lifespan. (A) Schematic representation of the targeting strategy for the generation of $S m t n-A / B^{-1 /}$ mice. Top: Structure of the $S m t n$ gene. Black boxes indicate smoothelin-B exons, light grey boxes indicate exons common to smoothelin-A and $B$, white boxes represent targeted exons. Middle: $5 m t n-A / B^{-1}$ targeting vector containing neomycin resistance (NEO) and herpes simplex virus thymidine kinase (TK) genes, both transcribed in the reverse direction to that of the Smtn gene, as indicated by arrows. Bottom: Structure of the targeted $S \mathrm{mtn}$ allele and location of the probe used in Southern blot analyses after Pstl digestion. The distance between the Pstl sites in the wild type (top) and mutant (bottom) locus is shown. (B) Southern blot analyses of genomic DNA from wild type and targeted ES cells after Pstl digestion with the probe indicated in Figure 5.1A. The wild type Pstl fragment (WT) has a size of $4.9 \mathrm{~kb}$, whereas the mutant Pstl fragment (T) is $3.0 \mathrm{~kb}$. (C) RT-PCR analysis of RNA isolated from the colon shows that $S m t n-A / B^{-/}$mice express shorter smoothelin transcripts with exons 16 or 17 spliced to exon 21 (see Methods section for details). (D) Immunohistochemical stainings of jejunum reveal loss of smoothelin expression in $S m t n-A / B^{-\%}$ mice. The double-headed arrows indicate the thickness of the muscle layers (see also Figure 5.4). (E) Smooth muscle $\alpha$-actin $\left(\alpha\right.$-SMA) concentration is significantly lower in $S m t n-A / B^{-1}$ mice, whereas smooth muscle myosin (SM MHC) concentration does not differ ( $n=5)$. (F) Kaplan-Meyer survival curve of $S m t n-A / B^{+/+}, S m t n-A / B^{+/-}$and $S m t n-A / B^{-1 /}$ mice, showing that $50 \%$ of $S m t n-A / B^{-1-}$ mice die within three weeks after birth $(n=263)$.

greatly dilated proximal duodenum (Figure 5.2B), which was confirmed by macro- and microscopic observations. Twenty minutes after injection of barium sulfate, hardly any barium had passed the duodenum in Smtn-A/B $B^{-1}$ mice, whereas in $S m t n-A / B^{+/+}$mice barium had proceeded several centimeters into the jejunum. 
A

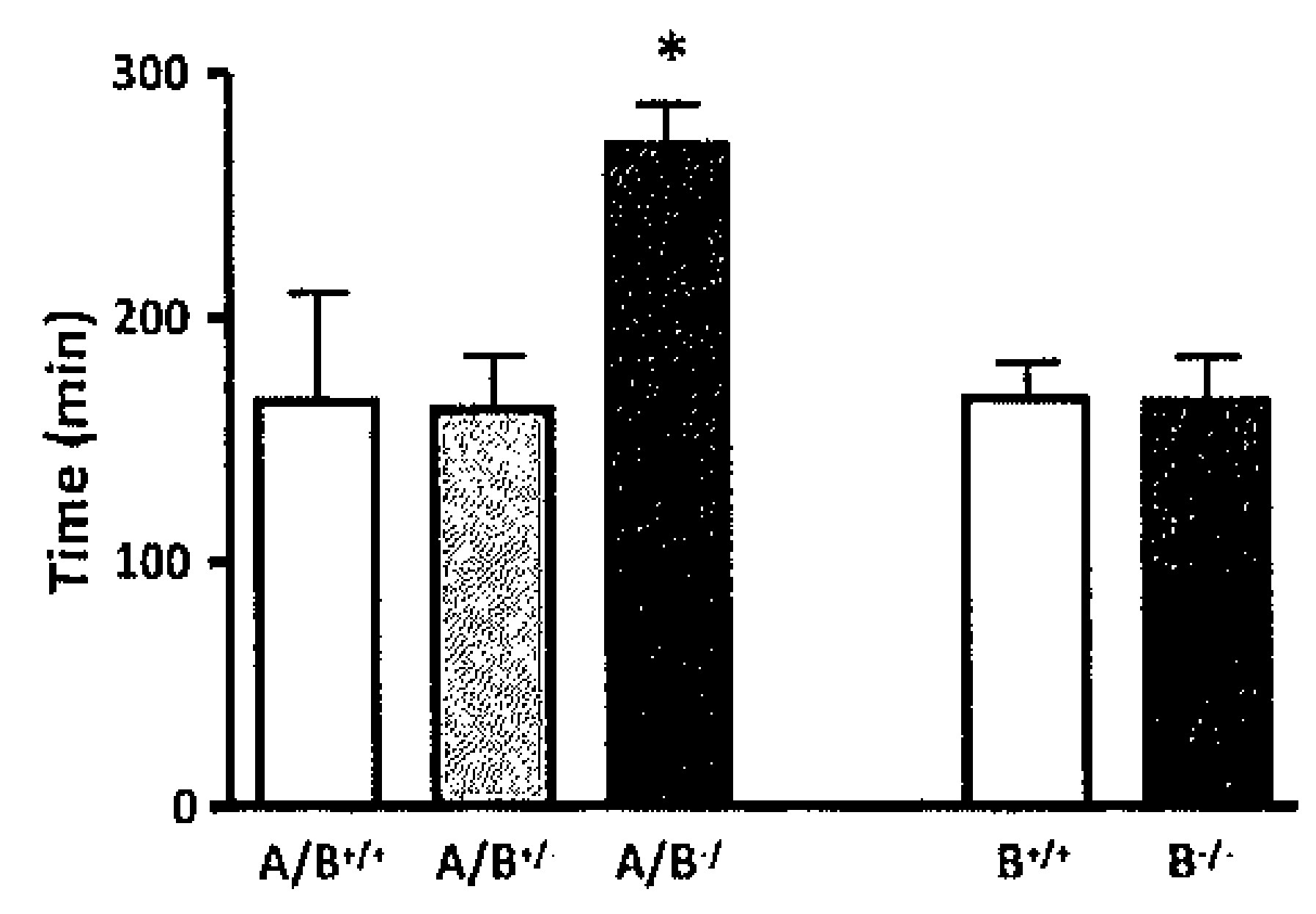

B

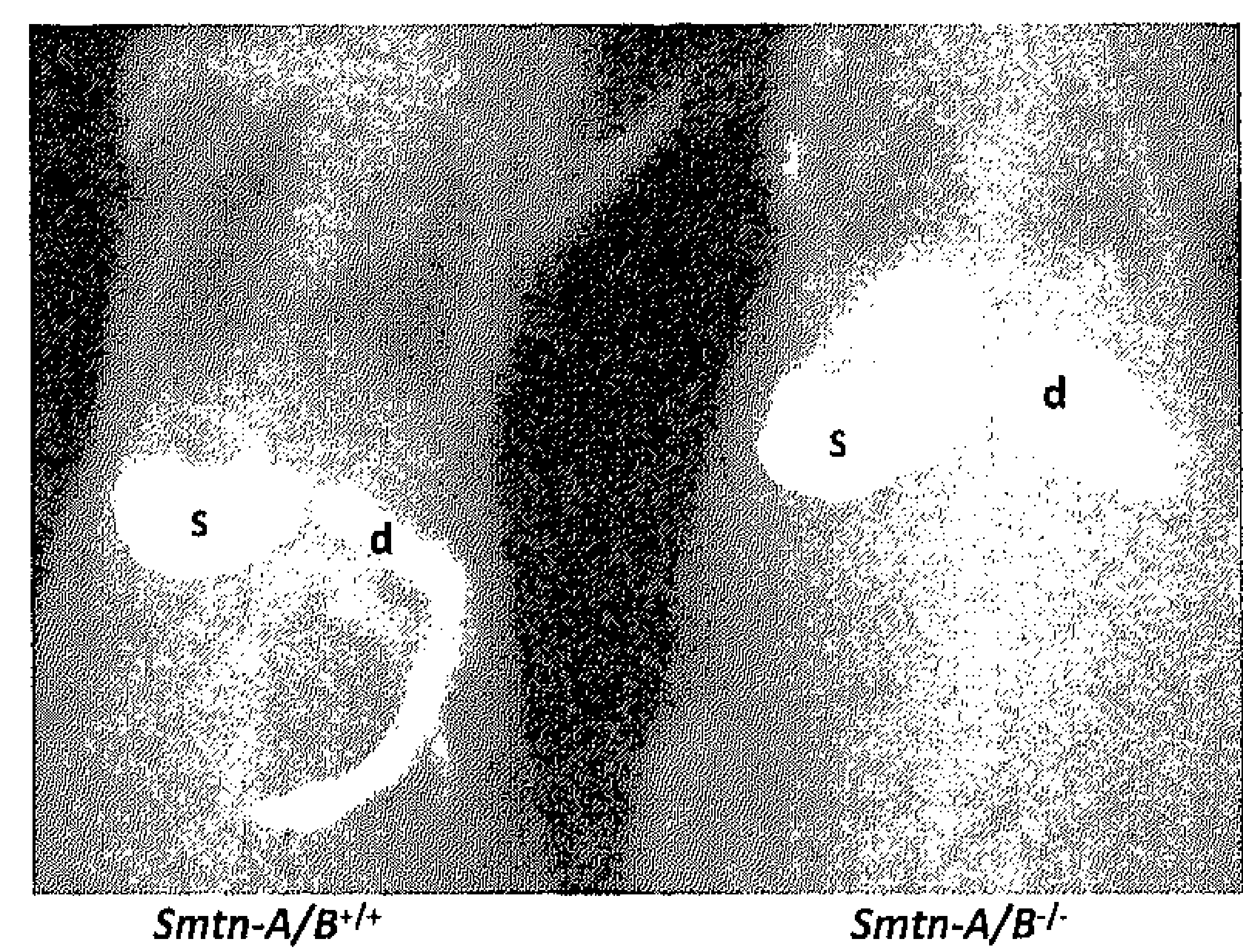

Figure 5.2 Whole gut transit time of $S m t n-A / B^{+/+}, S m t n-A / B^{+/}, S m t n-A / B^{-\%}, S m t n-B^{+/+}$and $S m t n-B^{-\%}$ mice. (A) Whole gut transit time of $S m t n-A / B^{-1}$ mice is doubled compared with $S m t n-A / B^{+/ t}, S m t n-$ $A / B^{+/ .}, 5 m t n-B^{+/+}$and $S m t n-B^{-\%}$ mice. $(P<0.05$ in repeated measures ANOVA followed by Bonferroni's multiple comparison tests). (B) Representative picture of contrast radiography of $S m t n-A / B^{+/+}$(left) and $S m t n-A / B^{-/}$(right). Picture was taken 20 minutes after injecting the barium sulfate solution into the stomach. The stomachs are indicated by $S, d$ indicates the duodenum. $S m t n-A / B^{-1}$ mice show a greatly dilated proximal duodenum and slower progression of food transport into the jejunum.

Isolated jejunal smooth muscle strips showed spontaneous spike activity in wild type, $S m t n-A / B^{-/-}$and $S m t n-B^{-/-}$mice. However, the amplitude and frequency of these spontaneous spikes were significantly lower in muscle strips of $S m t n-A / B^{-/}$ mice (amplitude: Smtn- $A / B^{+/+} 8.57 \pm 1.23, S m t n-A / B^{-/-} 2.44 \pm 0.39$; frequency: Smtn-A/B ${ }^{+/+} 43.09 \pm 1.04$, Smtn-A/B/ $\left.31.30 \pm 1.70\right)$. When subjected to several contractile agonists, the forces generated by these strips were in Smtn-A/B ${ }^{-/}$ mice at least four times smaller than in control mice (Figure 5.3A). Electrical stimulation of excitatory enteric nerves showed at least a five fold stronger contraction in wild type mice compared to $S m t n-A / B^{-1 /}$ mice (Figure 5.3A). Also, receptor-independent contractions to $\mathrm{KCl}$ as well as receptor-dependent contractions to carbachol, PGF2 $\alpha$, substance $P$ and serotonin, were significantly lower for $5 m t n-A / B^{-1-}$ mice (Figure 5.3A). In the same experimental set-up, contractility of jejunal strips of $S m t n-B^{-1}$ mice was comparable with $S m t n-B^{+/+}$ mice.

The slow waves measured in the SMCS of $S m t n-A / B^{-/}$mice were very irregular and variable, whereas, in $S m t n-A / B^{+/+}$littermates, regular slow waves were observed in all cells tested (Figure 5.3B,C,D). The amplitude of the slow waves in Smtn-A/B ${ }^{-1-}$ mice was significantly smaller $(10 \pm 1 \mathrm{mV})$ compared to $S m t n-A / B^{+/+}$ mice $(24 \pm 1 \mathrm{mV})$ and the frequency of the slow waves was significantly diminished in $S m t n-A / B^{-/-}$versus $S m t n-A / B^{+/+}$mice $(33.7 \pm 2.0$ cycles per minute 
versus $39.8 \pm 0.6$ cycles per minute). In addition, there was a much higher variability in frequency in $S m t n-A / B^{-1}$ (from 0 to 53 cycles per minute) compared with $S m t n-A / B^{+/+}$littermates (from 35 to 46 cycles per minute). In the same experimental set-up, the slow waves measured in the SMCs of Smtn-B ${ }^{-/}$mice did not differ from wild type mice.

A

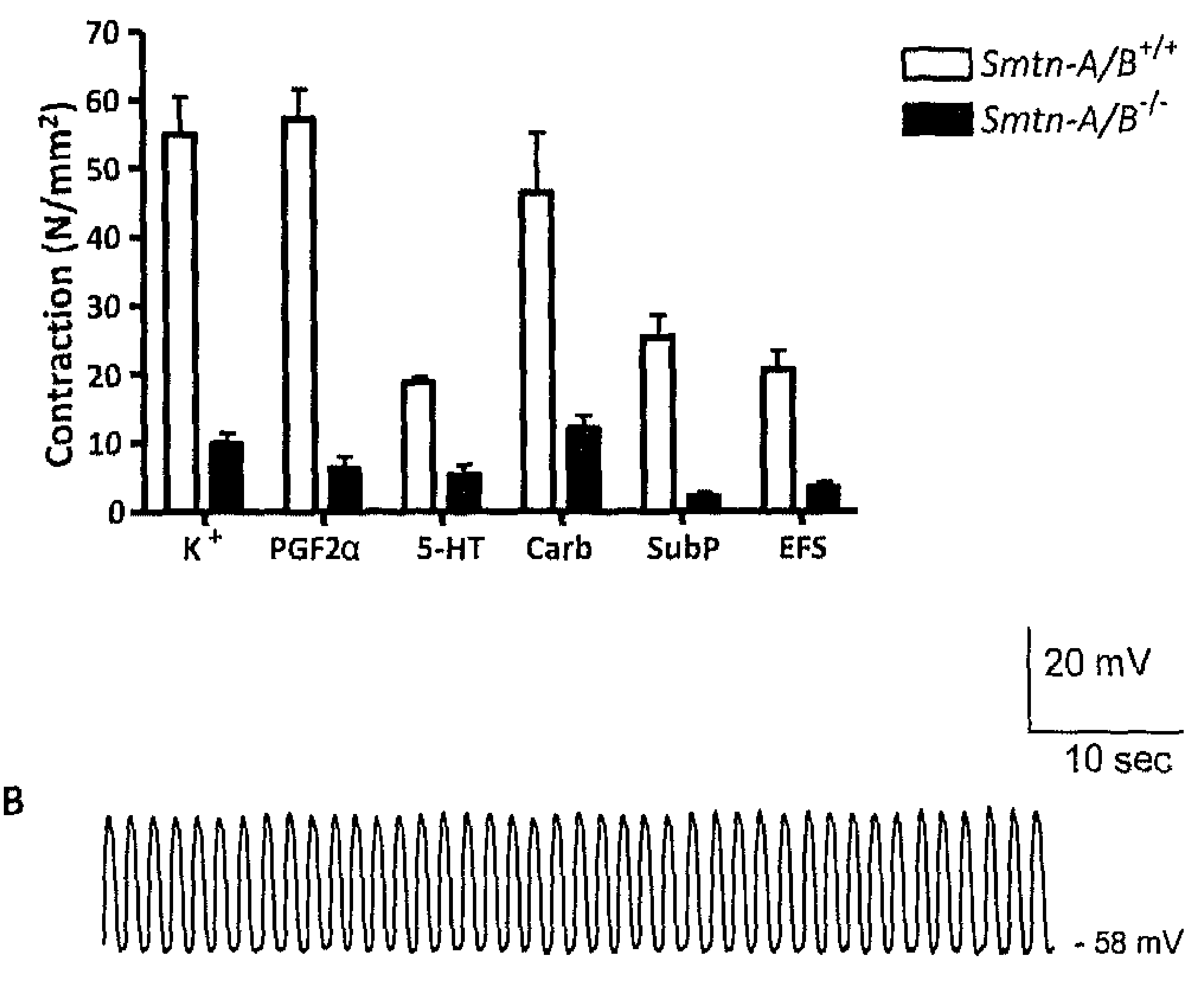

C

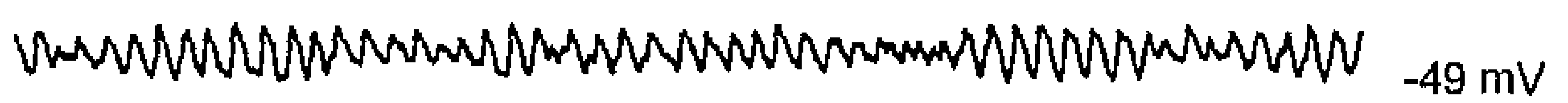

D

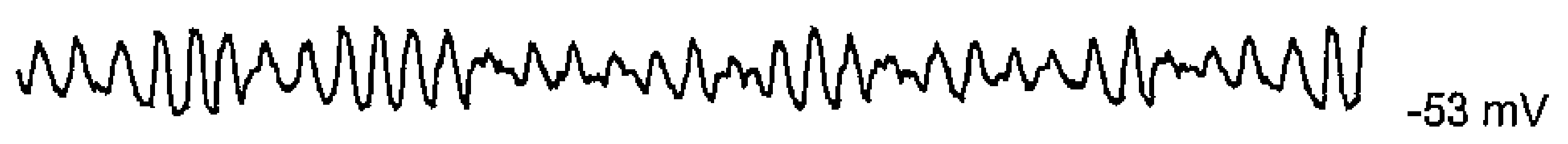

Figure 5.3 Intestinal smooth muscle of $S m t n-A / B^{-\%}$ mice shows reduced contractility and irregular slow wave patterns. (A) Maximal contractile responses to $\mathrm{KCl}\left(\mathrm{K}^{+}\right)$, prostaglandin $F 2 \alpha$ (PGF2 $\alpha$ ), serotonin (5-HT), carbachol (Carb), substance $P$ (SubP) and electrical field stimulation (EFS) are strongly reduced in jejunal longitudinal muscle strips from $S m t n-A / B^{-1-}$ mice. (B) Representative tracing of a slow wave measured in a small intestinal smooth muscle cell of an $S m t n-A / B^{+/+}$mouse. $(C, D)$ Two examples of slow waves measured in small intestinal smooth muscle cells of $5 \mathrm{mtn}-A / B^{-1}$ mice. The slow waves show lower and irregular amplitudes and a remarkable variability in frequency. 


\section{Pathology of the intestine}

To ascertain whether the intestinal contractile dysfunction of Smtn-A/B $B^{-1-}$ mice led to development of intestinal pathologies, we examined the morphology and histology of the digestive tract. No changes in the structure of the stomach were observed, while the structure of the intestine was compromised in $5 m t n-A / B^{-1}$ mice. The intestinal wall of $S m t n-A / B^{-/-}$mice was stiff and fragile. The duodenum was often dilated (see also Figure 5.2B) and the mass of the jejunal smooth muscle was significantly increased compared with wild type littermates (Table 5.1). The CSA of both longitudinal and circular muscle layers was approximately four-fold greater in $S m t n-A / B^{-/-}$mice than in wild type mice (Figure 5.4A,B), which could largely be attributed to SMC hypertrophy (Table 5.1). Nuclei as well as cytoplasm of the intestinal SMCs were larger in smoothelin deficient mice (Figure 5.4C,D; Figure 5.5). Extracellular matrix volume did not increase significantly as deduced from Sirius red staining and the distribution and appearance of the ICCs was normal (data not shown).

Table 5.1 Smtn-A/B-/- mice show jejunal smooth muscle hypertrophy.

\begin{tabular}{llll}
\hline & $S m+n-A / B^{+/+}(n=5)$ & $S m t n-A / B^{-/}(n=4)$ & P-value \\
\hline intestinal CSA* & $4,533 \pm 1,246$ & $7,582 \pm 1,780$ & $\mathrm{P}<0.05$ \\
intestinal muscle CSA* & $0,376 \pm 0,130$ & $1,684 \pm 0,381$ & $\mathrm{P}<0.001$ \\
muscle area / intestinal area & $9 \% \pm 3 \%$ & $23 \% \pm 3 \%$ & $\mathrm{P}<0.001$ \\
nuclei longitudinal muscle** & $71 \pm 12$ & $81 \pm 20$ & $\mathrm{NS}$ \\
nuclei circular muscle** & $51 \pm 13$ & $79 \pm 15$ & $\mathrm{P}<0.05$ \\
\hline
\end{tabular}

*) in $\mathrm{mm}^{2}$

$\left.{ }^{* *}\right)$ number of nuclei per $10 \%$ of the intestinal circumference

Electron microscopy showed subtle differences in the ultrastructural organization of the intestinal SMCs. In Smtn-A/B ${ }^{-1-}$ mice, the distribution of mitochondria and dense bodies appeared to be less strictly organized (Figure $5.5 \mathrm{~A}, \mathrm{~B})$. In addition, the micropinocytotic vesicles that are characteristic of smooth muscle were common in Smtn-A/B ${ }^{+/+}$mice but almost absent in Smtn$A / B^{-1}$ mice (Figure 5.5C,D). Hypertrophy was less common and less extensive in the more distal part of the gut. Numerous diverticula were observed in all parts of the intestine with exception of the coecum (Figure 5.4E,F). The diverticula were predominantly located at the mesenteric side. In $50 \%$ of the $S m t n-A / B^{-1}$ mice, they were already present 24 hours after birth. The diverticula increased in number and size as the mice aged (Figure 5.4F). Inflammation of the diverticula and the mesentery was common, and perforations leading to sepsis and death were observed (Figure 5.4G). 


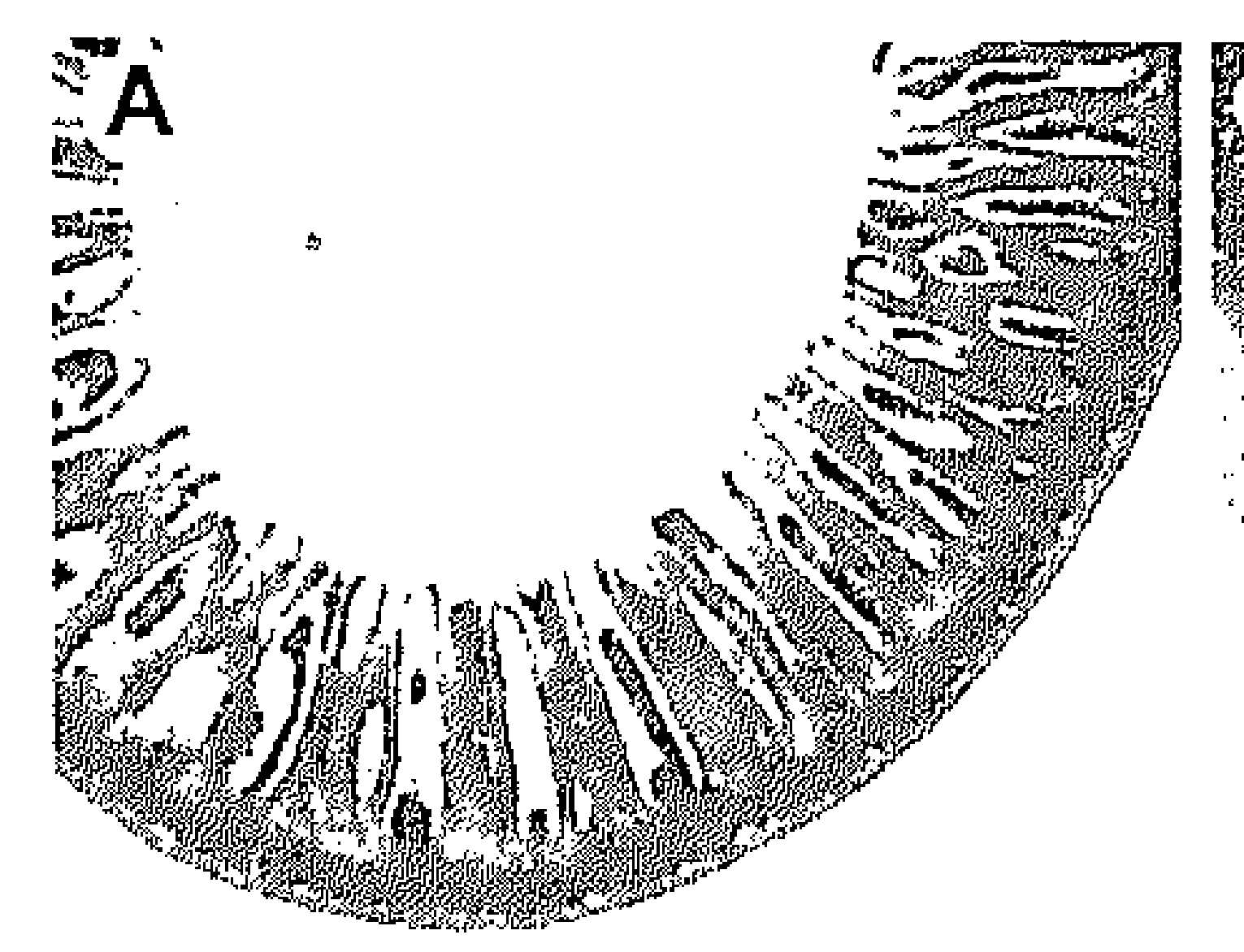

C

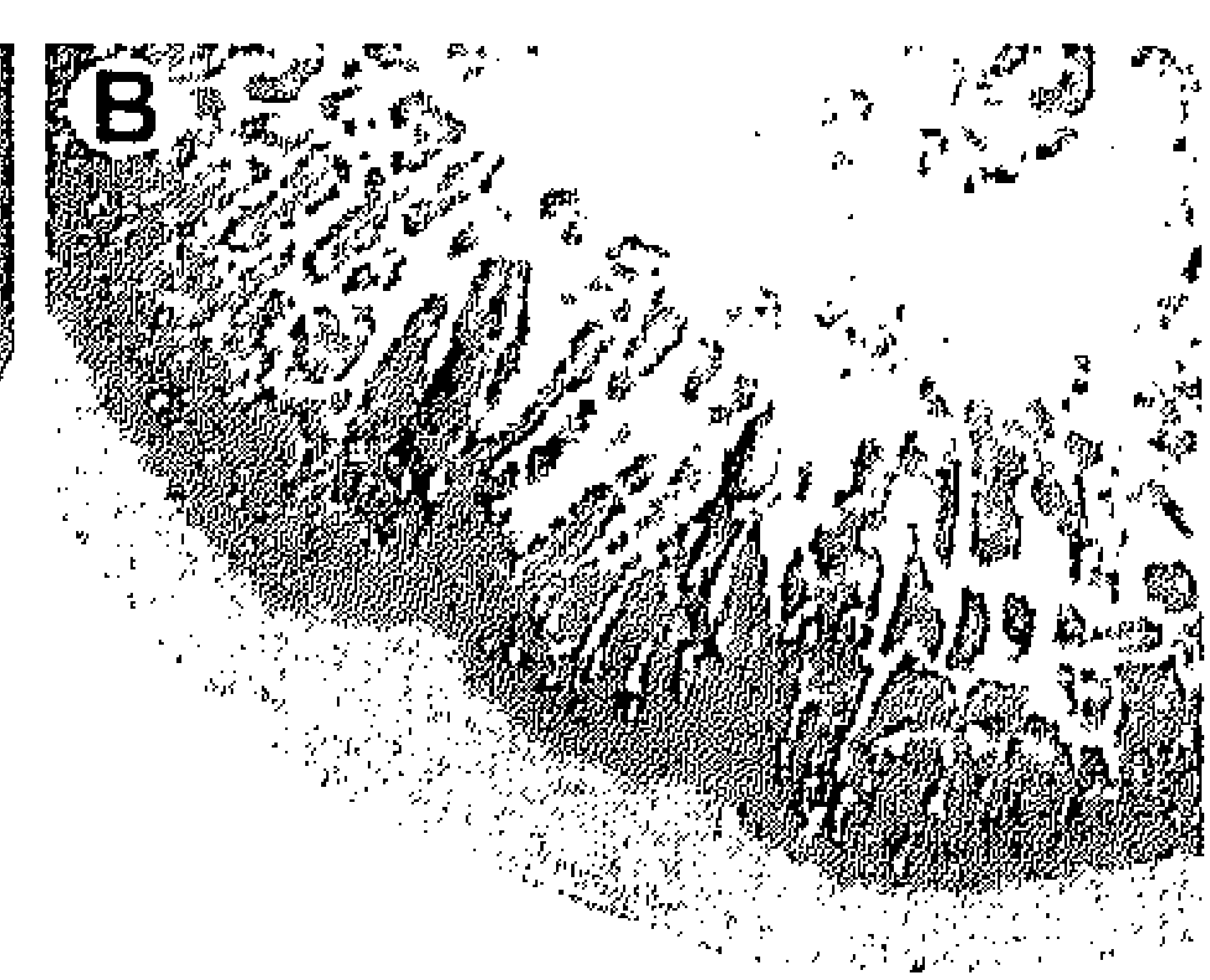

D
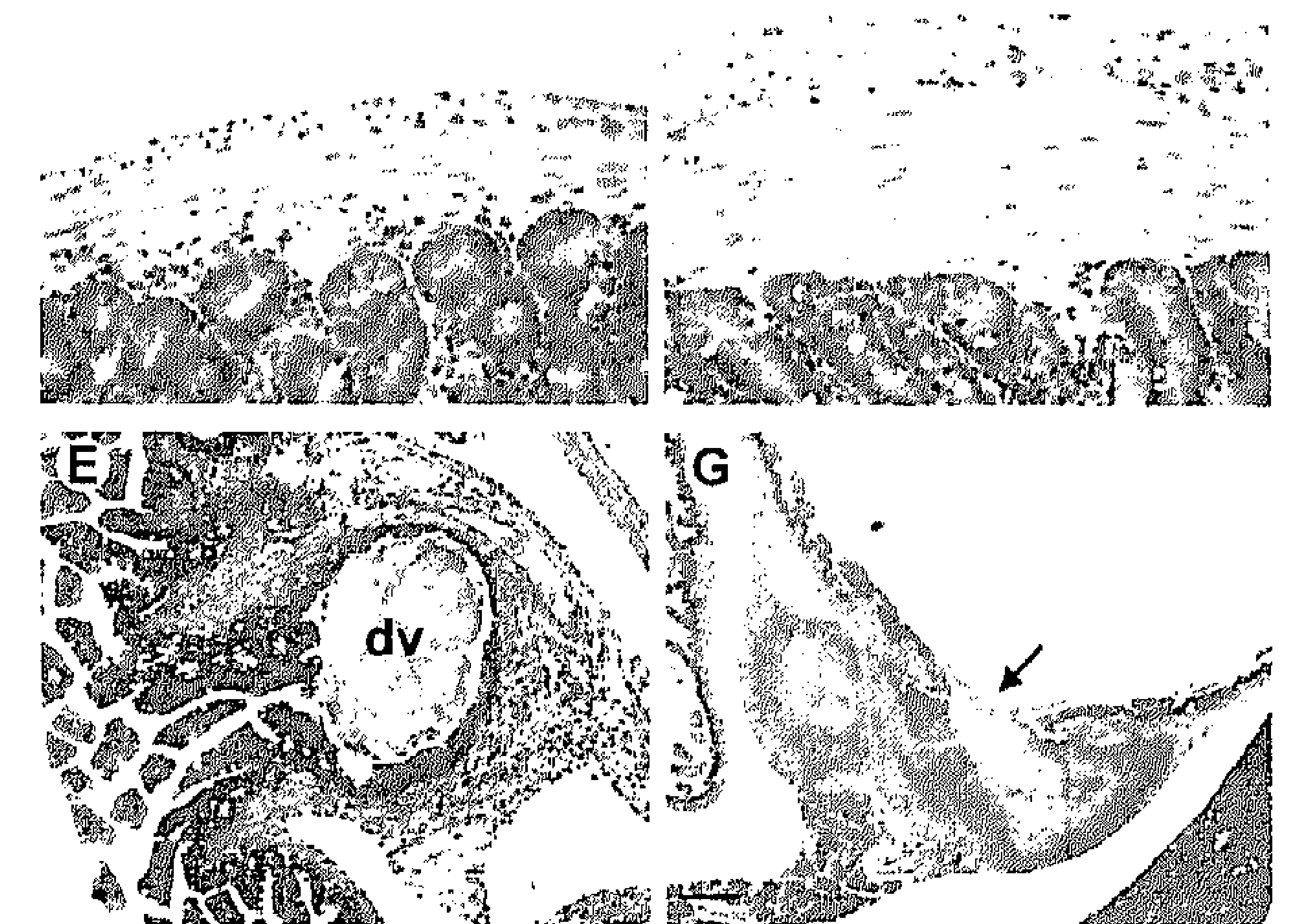

$\mathbf{F}$

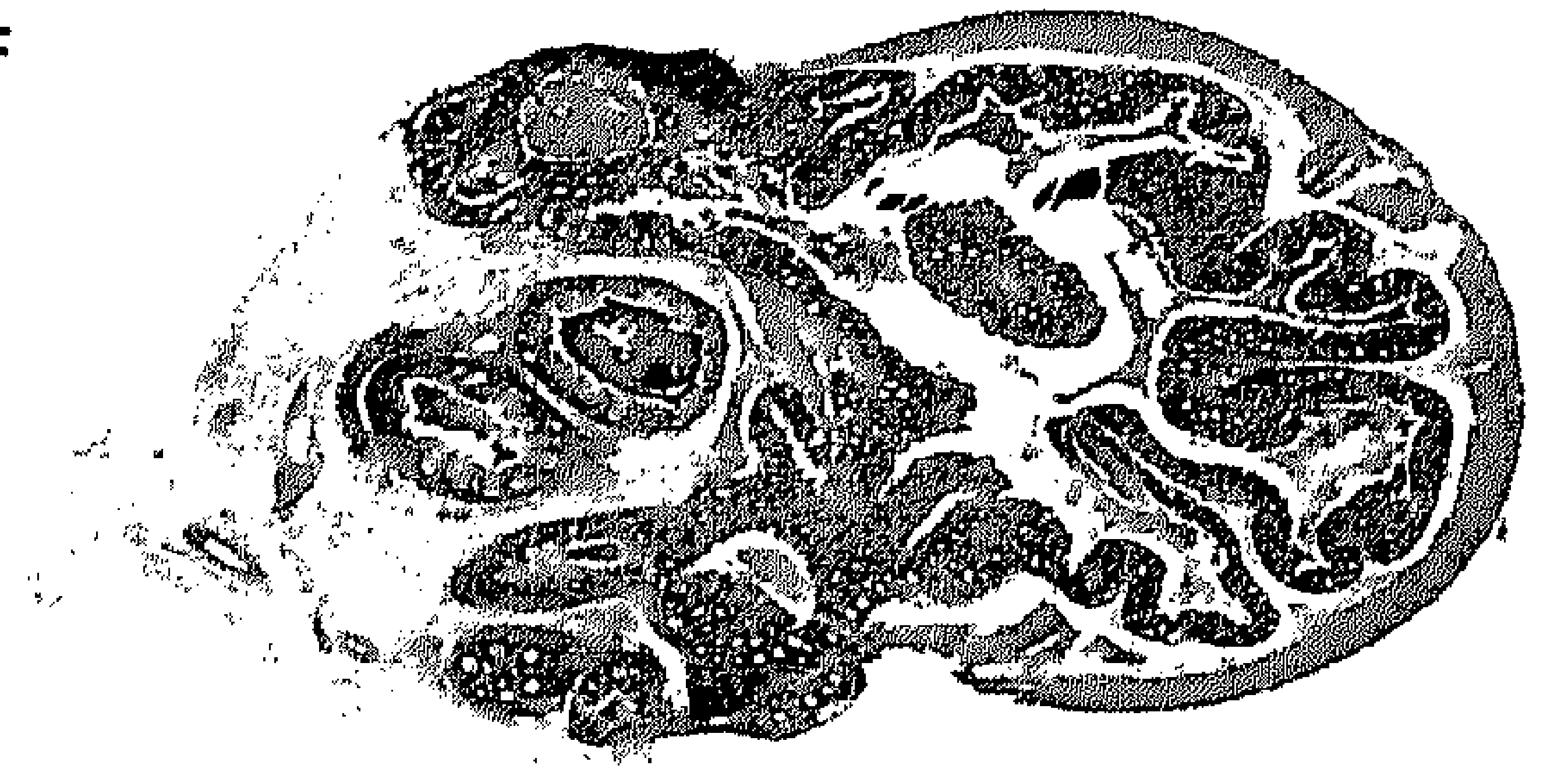

Figure 5.4 Smtn-A/B ${ }^{-1}$ mice develop lethal pathologies in the digestive tract. $(A, B)$ Cross-sections of jejuna of eight weeks old $S m t n-A / B^{+/+}(A)$ and $S m t n-A / B^{-\%}(B)$ littermates, showing irregular villi and profound hypertrophy of both circular and longitudinal smooth muscle layers in the Smtn$A / B^{--}$mouse. $(C, D) H E$ staining of jejuna of eight weeks old $S m t n-A / B^{+/+}(C)$ and $S m t n-A / B^{-1}$ (D) littermates, showing hypertrophy of SMCs in the $S m t n-A / B^{-/}$mouse. (E) A small diverticulum (indicated by $\mathrm{dv}$ ) of the jejunum of a ten days old $S m \mathrm{tn}-A / B^{-1}$ mouse, still surrounded by smooth muscle. (F) Cross-section of a colon of a 21 weeks old $S m t n-A / B^{-1}$ mouse showing typical severe diverticulosis. Little or no tunica muscularis is present on the side where the diverticula are observed, whereas the opposing side shows smooth muscle hypertrophy. (G) Perforation (indicated by the arrow) of a colonic diverticulum of a ten days old $S m t n-A / B^{-1-}$ mouse. Leakage of intestinal material has caused the development of a large abscess in the abdominal cavity. 
In addition, the intestinal villi in the affected areas were irregular and atrophic, which is probably a consequence of the disturbed motility and may be due to inflammation of the affected areas. The absence of fat deposition in $5 m t n-A / B^{-1}$ mice may be the consequence of diminished absorption due to the deteriorated structure of the villi. Inspection of the intestine of Smtn-B ${ }^{-1}$ mice did not reveal any abnormalities. Also, these mice had normal fat disposition, indicating sufficient food adsorption from the intestine. Furthermore, there are no morphological changes in the intestinal vasculature of both $5 m t n-A / B^{-1}$ and Smtn- $B^{-1-}$ mice at this age.

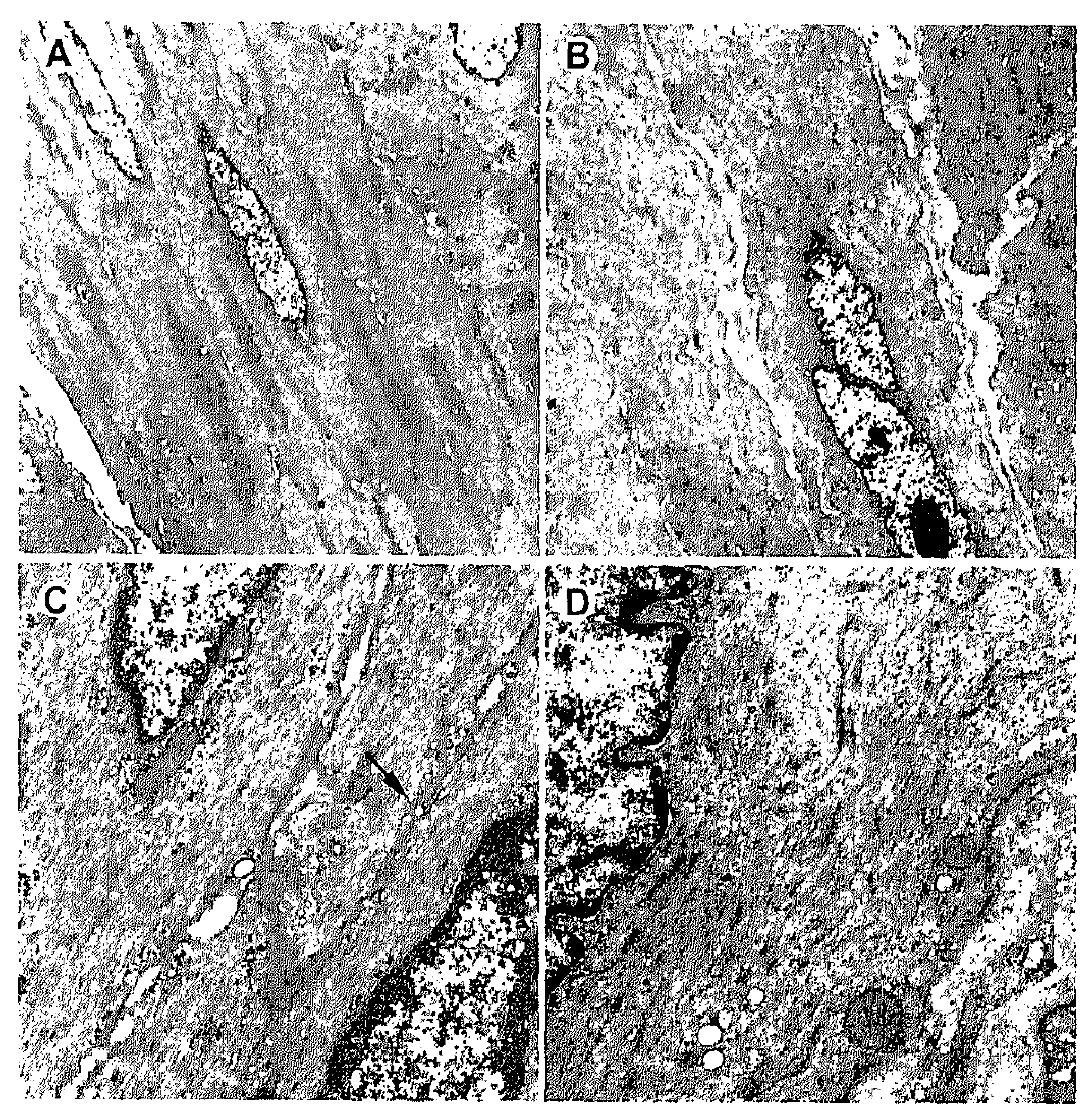

Figure 5.5 Differences in size and ultrastructure of intestinal SMCs in $S m t n-A / B^{-/-}$versus $S m t n-$ $A / B^{+/+}$mice. Electronmicrograph images of $5 m t n-A / B^{+/+}(A, C)$ and $5 m t n-A / B^{-/-}(B, D)$ mice show differences in cell size, thickness of the intercellular basal lamina and the distribution of the mitochondria $(A, B ; 2200 x)$. At larger magnification $(C, D ; 21.000 x)$ micropinocytotic vesicles (arrow) are apparent in Smtn-A/B $B^{+/+}$SMCs. 


\section{Smoothelin expression in intestine of CIP patients}

Since the phenotype of the $S m t n-A / B^{-1-}$ mice shares many aspects of the pathology seen in patients with CIP, we investigated the expression of smoothelin in intestines of those patients. In controls, smoothelin immunoreactivity stained all muscle layers uniformly, while, despite a normal morphology, lack of smoothelin was observed in the ileal circular muscle layer of a patient with CIP (Figure 5.6).
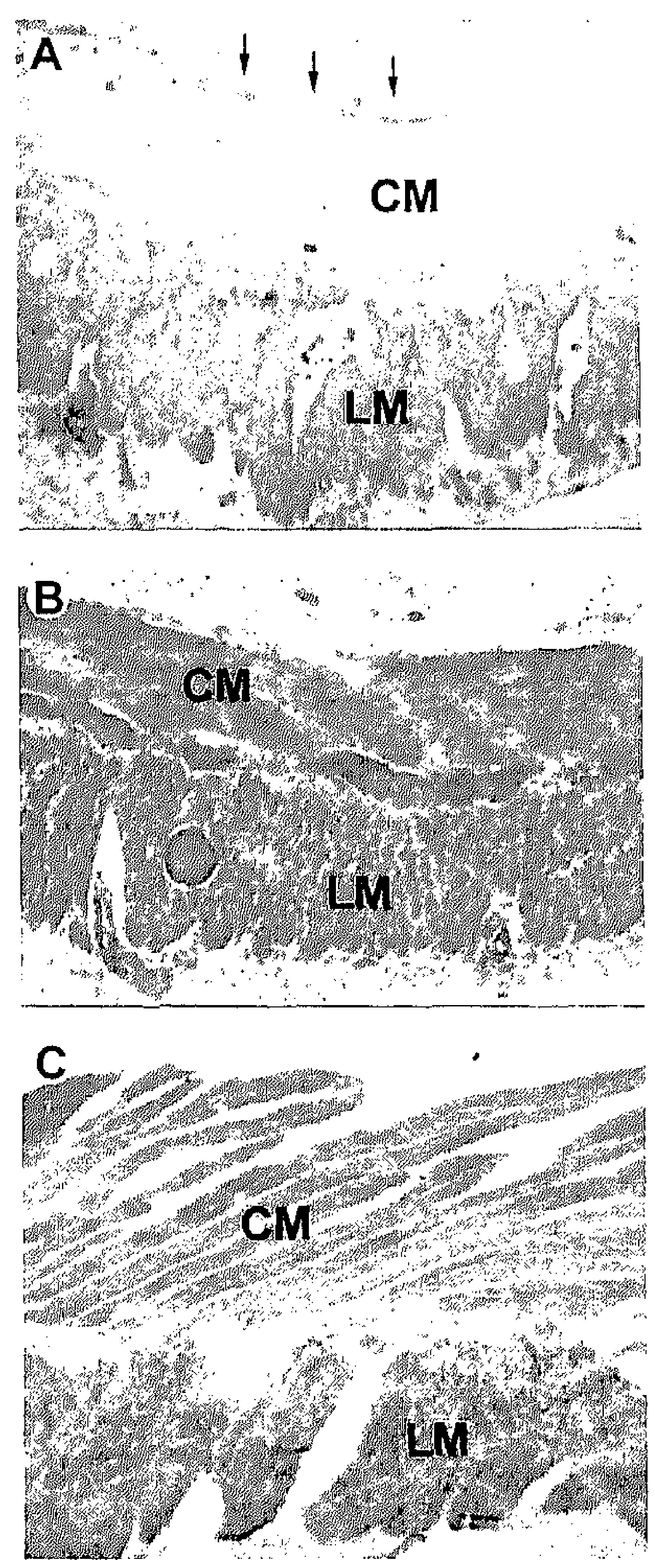

Figure 5.6 Absence of smoothelin in parts of the intestinal muscle layer of CIP patients. (A) Immunohistochemical staining of ileum obtained from a patient with CIP reveals absence of smoothelin in the circular smooth muscle layer (CM), except for the innermost border as indicated by arrows. (B) HE staining of an adjacent section from the same specimen showing normal morphology. (C) Immunohistochemical staining of control ileum shows a homogeneous distribution of smoothelin in both circular (CM) and longitudinal (LM) smooth muscle layers. 


\section{Discussion}

Digestive motility is a highly coordinated process, which enables mixing, propulsion and absorption of food by the digestive tract. Disturbances in intestinal motility can occur at different levels as a result of aberrations in the enteric nervous system, ICCS, and/or the contractility of smooth muscle cells. They all lead to impaired gastrointestinal propulsion. When no obvious lesions are obstructing intestinal transit, impaired food progress is often referred to as chronic intestinal pseudo-obstruction ${ }^{19}$ 20. Proper diagnosis and treatment of this rare and disabling disorder remain difficult, largely because the underlying pathology is poorly understood. Most attention has been paid to nervous system function in CIP, although smooth muscle myopathies appear to be responsible for the disease in approximately one third of the patients with congenital CIP, and in all cases of hollow visceral myopathy ${ }^{21,22}$. For the neuronal-based CIP, a few relevant mouse models have recently become available ${ }^{23}$. The myopathy-related CIP has obtained less attention and to the best of our knowledge, no animal model is available. We describe a mouse model that displays clinical manifestations similar to $\mathrm{ClP} /$ hollow visceral myopathy, caused by a mutation in the smoothelin gene. Moreover, we report on the absence of smoothelin in apparently unaffected intestine in CIP patients, providing evidence that smooth muscle dysfunction as a result of smoothelin deficiency might contribute to the development of this disease in humans.

Smoothelin-A is a marker protein for visceral $S M C S^{6,10}$. Analysis of intestinal muscle strips showed that inactivation of the smoothelin gene results in a decrease in contractile potential of intestinal SMCs. Smtn-A/B ${ }^{-1-}$-derived muscle strips displayed a four times lower contractile force per unit muscle mass as control mice, independent of the used agonists and concentration. In contrast, contractility of intestinal smooth muscle strips of $S m+n-B^{-1}$ mice was similar to wild type mice (data not shown). These results show that smoothelin-A is the functional smoothelin isoform in intestinal tissues and that this protein is a key component in the contractile machinery of intestinal smooth muscle. The exact role of smoothelin-A in smooth muscle contraction remains to be elucidated. However, the reduced response to non-receptor mediated as well as receptormediated excitation indicates that smoothelin-A must be closely associated to the primary components of the contractile apparatus. In addition, the recently shown direct physical interaction of smoothelin with $\alpha-S M A^{11}$ as well as the observed downregulation of $\alpha$-SMA in intestines of Smtn-A/B ${ }^{-\%}$ mice, indicate a cooperation of these two proteins ${ }^{11}$.

Intriguing, is the observed disturbance of the slow waves in SMCs of Smtn-A/B. mice, which correlates well with the disturbed spontaneous activity of smooth 
Smoothelin-A is essential for functional smooth muscle intestinal contractility

muscle strips. Slow waves are generated by ICCS. ICCS do not contain smoothelin and both the number and distribution of these cells is normal in Smtn-A/B $B^{\%}$ mice. Therefore, the loss of regularity must be due to changes in the interaction between ICCS and SMCs or in the characteristics of SMCs (as found by electron microscopy), which interfere with a proper communication between these cells. Alternatively, changes in the spatial structure of the smooth muscle layers may break-up the ICC network. SMCs will then receive non-coordinated signals from several ICCs. The latter is in line with the analysis of the Smtn-A/Bslow waves, which can be considered to be the resultant of two or more independent slow waves (according to Fourier analysis, data not shown). Regardless, the lack of smoothelin results in structural changes in the smooth muscle that interferes with the slow wave generation, which in turn diminishes the regulation of peristalsis.

The lack of smoothelin-A and consequent reduced contractility in Smtn-A/B ${ }^{-1}$ mice has significant consequences for the intestinal performance. The retarded passage of the carmine bolus demonstrated that whole gut transit time was approximately doubled. This was confirmed by contrast radiography that showed the transit in the intestine of $5 m t n-A / B^{-1 /}$ mice to be much slower compared with $S m t n-A / B^{+/+}$littermates. Furthermore, the $X$-ray pictures show that the duodenum of Smtn-A/B $B^{-/-}$mice is dilated, which may be the result of chronic pseudo-obstruction in the small intestine. This deduction is supported by the hypertrophy of the smooth muscle in the intestinal wall, the deterioration of the intestinal mucosa and villi, and the numerous diverticula found in the intestine of Smtn-A/B $B^{-1-}$ mice. The four-fold increased muscular CSA in $S m t n-A / B^{-1}$ mice is likely to be an adaptive response to increased workload (as the result of the diminished contractility) of this pulsatively contracting muscle. Similar hypertrophy has been described for segments of the gut upstream of an obstruction ${ }^{24}$ and has also been extensively documented for other muscle types under increased workload such as the cardiac muscle $e^{25-27}$. The diverticula, that are already found in very young mice and that are increasing in number and size with age, point towards an increasing transverse pressure on the wall caused by the retarded food transport. The increased wall thickness decreases the flexibility of the intestinal wall. As a result, the pressure provokes herniation of mucosa and submucosa through the intestinal muscular wall at the mesenteric side, which is weaker because of the entering of mesenteric blood vessels and nerves ${ }^{28}$. Thus, diverticulosis in $S m t n-A / B^{-1 /}$ mice most likely results from a loss of intestinal SMC contractile performance in combination with increased wall rigidity. Smtn-A/B $B^{-1}$ mice with a sick and apathetic behavior were shown to have extensive diverticulosis. Human intestinal diverticulosis is a rather common disease, affecting $30-50 \%$ of people 
over the age of 60 and causing strong and recurrent abdominal pain ${ }^{29}$. The premature death of $S m t n-A / B^{-1-}$ mice is most likely due to intestinal perforation or starvation caused by intestinal dysfunction and diverticulosis.

The presented study was focused on intestinal problems as a consequence of interruption of the smoothelin gene since the intestine was always affected. Investigations on other parts of the gastro-intestinal tract (esophagus, stomach) did not reveal aberrations. However, reduced function was found for other organs such as the urogenital system. In some animals, these pathologies occurred simultaneously, in others one or two of the organ systems were affected. We have no explanation for the variety in onset and type of pathology or for the fact that in the group of $S m t n-A / B^{-/}$mice with intestinal malfunction, some mice died at the first day after birth whereas others lived for months. However, similar variations are found in CIP and hollow visceral myopathy. Backcrossing on other mouse strains had no effect on this variation, which makes genomic diversity as the cause of the observed differences less likely. The physiological part of this study has been done with mice that survived for more than 5 weeks. As can be deduced from Figure 5.1F, this is a small group and therefore the results are obtained from mice that have a late onset of intestinal dysfunction.

In conclusion, we have shown that smoothelin-A deficiency causes a major decline in the contractile performance of intestinal smooth muscle. By showing that the reduction in contractility occurs independently of the signal transduction pathway activated, we have identified smoothelin-A as a structural protein that is crucial for normal intestinal smooth muscle contractility. Mutations in the Smtn gene or alterations in smoothelin-A levels may play an important role in the development of smooth muscle myopathies such as CIP or hollow visceral myopathy and intestinal diverticulosis.

\section{Acknowledgements}

We would like to thank Alfons Kroese, Roy Vliegen, Jean-Pierre Timmermans and Pierre-Paul van Bogaert for their collaboration. Expert technical assistance by our colleagues from the animal facility and by Hans Duimel, J. Ramesh Babu, Alexandra Oldenhof and Diane Fens is gratefully acknowledged. The support of Be Wieringa in the initial phase of this study is appreciated.

This work was supported by grants from the Netherlands Heart Foundation (97.167), Stichting De Gelderfonds, Stichting Simonsfonds, the Netherlands Organization for Scientific Research (NWO), Interuniversity Pole of Attraction (Grant number P5/20) of the Belgian Government, the Borne Bunge Foundation, the National Fund for Scientific Research (Belgium), the Foundation Médicale Reine Elisabeth and the Deutsche Forschungsgemeinschaft (DFG We2366/3-1). 


\section{References}

1. Kunze WA, Furness JB. The enteric nervous system and regulation of intestinal motility. Annu Rev Physiol 1999;61:117-42.

2. Herzog W, Ait-Haddou R. Considerations on muscle contraction. J Electromyogr Kinesiol 2002;12:425-33.

3. Gordon AM, Homsher E, Regnier M. Regulation of contraction in striated muscle. Physiol Rev 2000;80:853-924.

4. Owens GK, Kumar MS, Wamhoff BR. Molecular regulation of vascular smooth muscle cell differentiation in development and disease. Physiol Rev 2004;84:767801.

5. Szymanski PT. Calponin ( $\mathrm{CaP})$ as a latch-bridge protein--a new concept in regulation of contractility in smooth muscles. J Muscle Res Cell Motil 2004;25:719.

6. van Eys GJ, Voller MC, Timmer ED, Wehrens XH, Small JV, Schalken JA, Ramaekers FC, van der Loop FT. Smoothelin expression characteristics: development of a smooth muscle cell in vitro system and identification of a vascular variant. Cell Struct. Funct. 1997;22:65-72.

7. Rensen S, Thijssen V, De Vries C, Doevendans P, Detera-Wadleigh S, Van Eys G. Expression of the smoothelin gene is mediated by alternative promoters. Cardiovasc. Res. 2002; 55:850-863.

8. Christen $T$, Verin V, Bochaton-Piallat ML, Popowski Y, Ramaekers F, Debruyne P, Camenzind E, van Eys G, Gabbiani G. Mechanisms of neointima formation and remodeling in the porcine coronary artery. Circulation 2001;103:882-8.

9. van der Loop FT, Gabbiani G, Kohnen G, Ramaekers FC, van Eys GJ. Differentiation of smooth muscle cells in human blood vessels as defined by smoothelin, a novel marker for the contractile phenotype. Arterioscler. Thromb. Vasc. Biol. 1997; 17:665-71.

10. van der Loop FT, Schaart G, Timmer ED, Ramaekers FC, van Eys GJ. Smoothelin, a novel cytoskeletal protein specific for smooth muscle cells. J. Cell Biol. 1996;134:401-11.

11. Niessen P, Clement S, Fontao L, Chaponnier C, Teunissen B, Rensen S, van Eys G, Gabbiani $G$. Biochemical evidence for interaction between smoothelin and filamentous actin. Exp Cell Res 2004;292:170-8.

12. van der Heijden OW, Essers YP, Fazzi G, Peeters LL, De Mey JG, van Eys GJ. Uterine artery remodeling and reproductive performance are impaired in endothelial nitric oxide synthase-deficient mice. Biol Reprod 2005;72:1161-8.

13. Rumessen JJ, Vanderwinden JM. Interstitial cells in the musculature of the gastrointestinal tract: Cajal and beyond. Int Rev Cytol 2003;229:115-208.

14. Vanderwinden JM, Rumessen JJ, Liu H, Descamps D, De Laet MH, Vanderhaeghen JJ. Interstitial cells of Cajal in human colon and in Hirschsprung's disease. Gastroenterology 1996;111:901-10.

15. van der Zee $R$, Welling GW. A simple method to determine the transit time in mice. $Z$ Versuchstierkd 1983;25:233-7. 
16. Pelckmans PA, Boeckxstaens GE, Van Maercke YM, Herman AG, Verbeuren TJ. Acetylcholine is an indirect inhibitory transmitter in the canine ileocolonic junction. Eur J Pharmacol 1989;170:235-42.

17. Kunze WA, Bertrand PP, Furness JB, Bornstein JC. Influence of the mucosa on the excitability of myenteric neurons. Neuroscience 1997;76:619-34.

18. Brookes SJ, Ewart WR, Wingate DL. Intracellular recordings from myenteric neurones in the human colon. J Physiol 1987;390:305-18.

19. Smith VV, Milla PJ. Histological phenotypes of enteric smooth muscle disease causing functional intestinal obstruction in childhood. Histopathology 1997;31:112-22.

20. De Giorgio R, Sarnelli G, Corinaldesi R, Stanghellini V. Advances in our understanding of the pathology of chronic intestinal pseudo-obstruction. Gut 2004;53:1549-52.

21. Rodrigues CA, Shepherd NA, Lennard-Jones JE, Hawley PR, Thompson HH. Familial visceral myopathy: a family with at least six involved members. Gut 1989;30:128592.

22. Hyman PE, Bursch B, Sood M, Schwankovsky L, Cocjin J, Zeltzer LK. Visceral painassociated disability syndrome: a descriptive analysis. J Pediatr Gastroenterol Nutr 2002;35:663-8.

23. Kapur RP. Neuropathology of paediatric chronic intestinal pseudo-obstruction and related animal models. J Pathol 2001;194:277-88.

24. Geuna S, Cardillo S, Giacobini-Robecchi MG. Smooth muscle cell hypertrophy and hyperplasia in the partially obstructed gut of the rat: a quantitative evaluation. Acta Anat (Basel) 1998;163:69-74.

25. Sadoshima J, Izumo S. The cellular and molecular response of cardiac myocytes to mechanical stress. Annu Rev Physiol 1997;59:551-71.

26. Bell D, Kelso EJ, Argent CC, Lee GR, Allen AR, McDermott BJ. Temporal characteristics of cardiomyocyte hypertrophy in the spontaneously hypertensive rat. Cardiovasc Pathol 2004;13:71-8.

27. Anversa P, Ricci R, Olivetti G. Quantitative structural analysis of the myocardium during physiologic growth and induced cardiac hypertrophy: a review. I Am Coll Cardiol 1986;7:1140-9.

28. West $A B$, Losada $M$. The pathology of diverticulosis coli. J Clin Gastroenterol 2004;38:S11-6.

29. Stollman N, Raskin JB. Diverticular disease of the colon. Lancet 2004;363:631-9. 


\section{Chapter 6}

\section{Smoothelin-B deficiency results in reduced arterial contractility, hypertension, and cardiac hypertrophy in mice}

Sander S.M. Rensen, Petra M.G. Niessen, Jan M. van Deursen, Ben Janssen, Marion J. Gijbels, Edwin Heijman, Gustav J. Strijkers, Pieter A.F.M. Doevendans, Jo G.R. De Mey, Marten H. Hofker, Guillaume J.J.M. van Eys. 


\begin{abstract}
Background Smoothelins are actin-binding proteins that are abundantly expressed in healthy visceral (smoothelin-A) and vascular (smoothelin-B) smooth muscle. Their expression is strongly associated with the contractile phenotype of smooth muscle cells. Analysis of mice lacking both smoothelins $\left(S m t n-A / B^{-1}\right.$ mice) previously revealed a critical role for smoothelin-A in intestinal smooth muscle contraction. Here, we report on the generation and cardiovascular phenotype of mice lacking only smoothelin-B $\left(S m t n-B^{-1-}\right)$.

Methods and results Myograph studies revealed that the contractile capacity of the aorta and the femoral artery was strongly reduced in Smtn- $B^{-/}$mice, irrespective of the contractile agonist used to trigger contraction. Arteries from $S m t n-A / B^{-1-}$ compound mutant mice exhibited a very similar contractile deficit, demonstrating that smoothelin-B is the only functional smoothelin isoform in the vasculature. Smtn-B/ arteries had a normal architecture, and expressed normal levels of smooth muscle cell specific genes, including smooth muscle myosin heavy chain, $\alpha$-smooth muscle actin and smooth muscle-calponin.

Decreased contractility of Smtn-B ${ }^{-1-}$ blood vessels was accompanied by increased mean arterial pressure $(20 \mathrm{mmHg}$ ) and concomitant cardiac hypertrophy. MRI experiments revealed that cardiac function was not changed, whereas distension of the proximal aorta during the cardiac cycle was increased in Smtn$B^{-1-}$ mice, indicating that increased peripheral vascular resistance is responsible for the higher blood pressure in Smtn- $B^{-/}$mice.

Conclusions Collectively, our results identify smoothelin-B as a key determinant of arterial smooth muscle contractility and cardiovascular performance. Studies on mutations in the Smtn gene or alterations in smoothelin-B levels in connection to hypertension in humans are warranted.
\end{abstract}


Smoothelin-B deficiency results in reduced arterial contractility

\section{Introduction}

Hypertension is a common condition in Western countries, affecting approximately $27 \%$ of the people worldwide. It is a major risk factor for the development of life threatening conditions such as coronary heart disease and stroke. However, the cause of increased blood pressure is unknown in the majority of patients ${ }^{1}$. Smooth muscle contractility is one of the primary determinants of vascular resistance, thereby contributing significantly to the maintenance of a physiological blood pressure. Accordingly, molecular defects in the regulation or mechanics of smooth muscle contraction generally cause profound cardiovascular phenotypes. For example, $\alpha$-smooth muscle actin ( $\alpha$ SMA) knockout mice display impaired vascular contractility and reduced blood flow $^{2}$. Likewise, smooth muscle myosin heavy chain (SM-MHC)-B knockouts show a significant decrease in maximal shortening velocity of vascular smooth muscle $^{3}$ and smooth muscle (SM)-calponin deficient mice have impaired mean arterial pressure (MAP) regulation ${ }^{4}$.

Despite the importance of smooth muscle cell (SMC) contraction for the cardiovascular system, the contractile process itself is still incompletely understood. In particular the functions of regulatory proteins that are connected to the actin-myosin filaments in vascular SMCs remain poorly defined $d^{5}$.

Candidate thin filament regulatory proteins that have not been studied in this respect are the smoothelins, which are $\alpha$-SMA-binding proteins specifically and abundantly expressed in contractile $S \mathrm{MCs}^{6-9}$. They are encoded by a single copy gene that generates two major isoforms, both containing a troponin T-like domain ${ }^{10}$. The smaller smoothelin-A isoform is most prominently expressed in visceral SMCs. In contrast, the $110 \mathrm{kD}$ smoothelin-B, which comprises the smoothelin-A gene plus ten upstream exons, is only found in vascular SMCs ${ }^{11}$. Smoothelin-B expression is particularly high in muscular arteries, whereas expression in elastic arteries is modest ${ }^{7}$.

In recent years, smoothelin-B has been increasingly recognized as an excellent marker of the so-called contractile phenotype of SMCs. Indeed, loss of smoothelin-B expression reliably indicates the disappearance of the contractile $S M C$ phenotype in various vascular disorders ranging from aortic aneurysms to atherosclerosis and restenosis ${ }^{9,12-16}$.

Functional studies on smoothelins have been hampered by the rapid downregulation of their expression in vitro and their relative insolubility at physiological ionic concentrations ${ }^{6}$. Therefore, despite its relevance for the characterization of the contractile SMC phenotype, the function of smoothelin-B in the vascular SMC has remained elusive. Recently, however, we showed that 
smoothelin-A plays a crucial role in intestinal SMC contraction in mice ${ }^{17}$. Smtn$A / B^{-\%}$ mice, which lack both smoothelin isoforms, develop fatal intestinal problems due to drastically decreased SMC contractility. The severe impact of smoothelin-A deficiency on visceral smooth muscle contraction suggested that smoothelin-B might play an equivalent important role in vascular smooth muscle. To test this hypothesis, we have generated mice lacking only smoothelin-B $\left(S m t n-B^{-1}\right)$, and investigated their cardiovascular physiology. We report that smoothelin-B deficient mice show reduced arterial contractility, elevated MAP and cardiac hypertrophy.

\section{Methods}

\section{Generation of Smtn- $B^{-/}$mice}

To generate $S m+n-B^{-1-}$ mice, we targeted exons 3 through 7 with a neomycin gene under the control of the thymidine kinase promoter in reverse orientation (Figure 6.1a). The targeting vector contained a thymidine kinase gene for negative selection. After electroporation of the Pvull-linearized constructs into mouse L129/SV embryonic stem (ES) cells, we selected neomycin-resistant clones with G418 (Invitrogen, Carlsbad, California) and 1-[2-Deoxy]2-fluoro- $\beta$-Darabinofurasonyl (Invitrogen). DNA from resistant clones was screened by Southern blotting after Sacl restriction digestion using a $5^{\prime}$ probe as indicated in Figure 6.1a. ES cells from targeted clones were injected into C57BI/6 blastocysts and implanted into pseudopregnant $\mathrm{C} 57 \mathrm{Bl} / 6$ females. Mating of the resulting chimeric males to $\mathrm{C} 57 \mathrm{Bl} / 6$ females led to germline transmission of the targeted alleles as detected by Southern blotting (Figure 6.1b). Mice were further backcrossed at least five times on $\mathrm{C} 57 \mathrm{Bl} / 6$ background prior to initiation of experiments. Since the mice had a mixed background, we always used littermates for experimentation. Generation of $S m t n-A / B^{-/}$mice has been described before ${ }^{17}$. All animal experiments were approved by the University of Maastricht animal ethics committee.

\section{Quantitative reverse transcriptase-polymerase chain reaction (Q-PCR)}

Total RNA was extracted from jejunum, hearts, or from pooled aortas and femoral arteries from $S m t n-B^{+/+}$and $S m t n-B^{-/}$mice with Tri-reagent (SigmaAldrich, Zwijndrecht, The Netherlands). Reverse transcription was performed using the iscript cDNA synthesis kit (Biorad, Veenendaal, The Netherlands) and 0.5 or $1 \mu \mathrm{g}$ of RNA. Expression of several transcripts was investigated by Q-PCR using the ABIPrism7700 System (Perkin Elmer, Norwalk, Connecticut). Applied primers and probes are listed in table 6.1. The cyclophilin A transcript was used 
Smoothelin-B deficiency results in reduced arterial contractility

to normalize the amount and quality of the extracted RNA. Smtn- $B^{+/+}$expression levels were set at 1 .

Table 6.1 Sequence of primers and probes used for Q-PCR.

\begin{tabular}{lll} 
Gene & Forward Primer 5'-3' & Reverse Primer 5'-3' \\
\hline & & \\
CyclophilinA & TTCCTCCTTCACAGAATTATTCCA & CCGCCAGTGCCATTATGG \\
$\alpha$-SMA & ACGAACGCTTCCGCTGC & GATGCCCGCTGACTCCAT \\
SM-MHC & TGGCTAGCAGCTTGTCAGGAA & GCCTTGCGTACTCTATCACTCATG \\
SM-calponin & GAAGGCAGGAACATCATTGGA & CCTGCTGACTGGCAAACTTG \\
Smoothelin-A/B & GGCAACCAGAGAGCAGAATTG & CTGCTGGTGCTGAGAAGGGT \\
probe & \multicolumn{2}{c}{ TGGGATTGCGGGCACCCC } \\
Smoothelin-B & GAGGAGCGCAAGCTGATCA & GGCAGCCTTAATCTCCTGAGC \\
probe & & CTGCCATCCGCCGAGTGCG \\
ANF & CATCATGGGCTCCTTCTCCAT & TGTACACAGGATTTGGTCCAATATG \\
BNP & AGGACCAAGGCCTCACAAAA & TTGAGATATGTGTCACCTTGGATTT \\
\hline
\end{tabular}

\section{Histology and immunohistochemistry}

Organs from mice aged 2 months and 1 year were fixed in 3.7\% formaldehyde in phosphate buffered saline, embedded in paraffin, sectioned and stained with haematoxylin and eosin. Samples of aorta and femoral artery were snap-frozen and embedded in OCT Tissue Tek compound (Sakura, Chicago, IL). Cryostat sections were blocked with $5 \%$ normal donkey serum (Jackson ImmunoResearch, Soham, UK), stained with a polyclonal antibody raised against two smoothelin specific peptides (described below) and a secondary antibody donkey-anti-rabbit conjugated with FITC (Sigma-Aldrich).

Polyclonal antibody generation was performed by Eurogentec (Seraing, Belgium). Two rabbits were immunized with the smoothelin-B specific peptide KRFRAERQDNKENWL (smoothelin-B residues 52-66) and the peptide RQRKRDQRDKERERR, present in both smoothelin-A and in smoothelin-B (smoothelin-A residues 160-174, smoothelin-B residues 614-628). $5 \mathrm{mg}$ of the synthesized peptides were conjugated to keyhole limpet hemocyanin. The rabbits received three booster injections with a 14-day interval. Sera were tested on different tissues for cross-reactivity and smooth muscle specificity.

To determine the staining pattern of the extracellular matrix proteins collagen and elastin, paraffin embedded cross sections of arteries were stained with Sirius red and Lawson's solution. To evaluate $\alpha-S M A$ and SM-MHC expression, sections were incubated with anti- $\alpha$-SMA (DAKO, Glostrup, Denmark) or antiSM-MHC antibody (Biomedical Technologies, Stoughton, MASS), diluted 1:200 or $1: 40$, respectively. 


\section{Vascular contractility}

Contractility of the thoracic aorta $(n=5)$ and femoral artery $(n=6)$ was compared between 10 weeks old $S m t n-B^{-1}$ and $S m t n-B^{+/+}$littermates. For the contractility analyses of $S m t n-A / B^{-1}$ and $S m t n-A / B^{+/+}$littermates, mice of approximately 8 weeks old were used ( $n=7$ for both arteries). Isolated arteries were mounted in myograph organ baths as previously described ${ }^{18}$. We examined reactivity in response to $\mathrm{K}+(40 \mathrm{mmol} / \mathrm{L})$, the thromboxane A2 mimetic U-46619 (0.1-100 $\mathrm{nmol} / \mathrm{L})$ and the $\alpha_{1}$-adrenergic agonist phenylephrine $(0.1-30 \mu \mathrm{mol} / L)$, all obtained from Sigma-Aldrich. Contractile forces were corrected for vessel segment length and medial thickness and normalized to wild-type values.

\section{Hemodynamics}

Five months old male $S m+n-B^{+/+}$and $S m t n-B^{-/}$mice were instrumented with catheters as described before ${ }^{19}$ and conscious baseline MAP and heart rate (HR) were recorded for 30-60 minutes on three different days (days 3, 5 and 7 after surgery). Due to their physical condition and short lifespan, the hemodynamic parameters of $S m t n-A / B^{-/}$and $S m t n-A / B^{+/+}$mice were measured in six weeks old females under $1-2 \%$ isoflurane anesthesia via a catheter introduced into the right carotid artery $(n=5)$.

\section{Magnetic Resonance Imaging (MRI)}

MRI measurements were performed with a 6.3 Thorizontal-bore animal scanner (Bruker BioSpin, Ettlingen, Germany) and a $3 \mathrm{~cm}$ diameter birdcage RF coil (Rapid Biomedical, Rimpar, Germany). Eleven 8 months old male mice of each genotype were positioned supine in the MRI scanner with their front paws fixed on copper electrodes used for ECG triggering. During the experiments the mice were sedated using 1.5 vol\% isoflurane. Prospective CINE MRI scans were collected using a FLASH sequence ${ }^{20}$ with the following parameters: repetition time $7 \mathrm{~ms}$; echo time $2.3 \mathrm{~ms}$; field of view $3 \times 3 \mathrm{~cm}^{2}$; matrix $192 \times 192$; slice thickness $1 \mathrm{~mm}$; total acquisition time per slice $5 \mathrm{~min}$. The mice were scanned by acquiring short axis CINE images, covering the heart from apex to base. End diastolic volume (EDV), end systolic volume (ESV), stroke volume (SV), ejection fraction (EF) and left ventricular mass $\left(1.05 \mathrm{~g} / \mathrm{cm}^{3}\right)^{21}$ were calculated using a semi-automatic segmentation of the images with the FARM MRV CAAS software provided by Pie Medical Imaging (Maastricht, the Netherlands) ${ }^{22}$.

To determine the lumen motion of the descending thoracic aorta during the cardiac cycle, a modified FLASH sequence was used with an in-plane navigator echo ${ }^{22}$ with the following parameters: flip angle $30^{\circ}$; repetition time $5.4 \mathrm{~ms}$; echo time $2.98 \mathrm{~ms}$; field of view $2.5 \times 3 \mathrm{~cm}^{2}$; matrix $256 \times 192$; slice thickness 2 $\mathrm{mm}$; number of repetitions 700; total acquisition time approximately $12 \mathrm{~min}$. The whole thoracic aorta was placed within the slice, with the descending aorta 
perpendicular to the MRI readout direction. Cardiac triggering and respiratory gating were performed by analyzing the navigator echo data retrospectively and dividing the cardiac cycle into twenty time frames. Before analyzing the motion, all images were zero-filled to a matrix of $512 \times 512$ for enhancing the aorta lumen $^{23}$. The circumferential stretch of the descending aorta was manually measured at a fixed position (see Figure 6.5a) for seven $5 m t n-B^{+/+}$and five Smtn$B^{-/}$mice. From these data the relative circumferential stretch as function of time and the maximum widening were derived.

\section{Morphometric analyses}

To determine the radius and medial cross sectional area (CSA) of arteries, cross sections were stained with Lawson's solution. The CSA was defined as the area between the internal elastic lamina and the external elastic lamina ${ }^{24}$. To assess the volume of different parts of the heart, surface areas of two different crosssections of the heart were measured. Total CSA, left and right ventricular wall CSA, and left and right lumen area were measured. To determine the number of cardiomyocytes, three pictures were taken of each heart at different locations, and cell nuclei were counted manually. Images were captured using a Zeiss Axioscope (Zeiss, Göttingen, Germany) and a standard CCD camera (Stemmer Imaging, Puchheim, Germany), and analyzed with Leica QWin image analysis software (Leica Microsystems, Cambridge, UK).

\section{Statistical analysis}

Statistical significance was calculated by two-tailed paired Student's t-tests using Graphpad Prism software (v4.0). Results were considered significantly different when $P<0.05$. Values are expressed as mean \pm standard error of the mean (SEM).

\section{Results}

Smtn- $B^{\%}$ mice develop normally, expressing smoothelin-A but no intact smoothelin-B

To generate $S m t n-B^{-1-}$ mice, we replaced Smtn exons 3 through 7 by a neomycinresistance cassette (Figure 6.1a,b). This deletion disrupts the smoothelin-B gene, while leaving the smoothelin-A promoter intact ${ }^{25}$. Intercrosses of $S m t n-B^{+/-}$mice produced Smtn- $B^{-1}$ offspring at normal Mendelian frequency $\left(S m+n-B^{+/+}\right.$ $28 \%: 5 m t n-B^{+/-} 50 \%: 5 m t n-B^{-/} 22 \%, n=506$ ), indicating that loss of smoothelin-B does not interfere with embryonic survival. In contrast to $5 m t n-A / B^{\%}$ mice, which die rapidly after birth ${ }^{17}, 5 m t_{n}-B^{-/}$mice appeared normal, had no gross histological abnormalities in any organ as evaluated by an experienced animal pathologist, and their intestinal function was unaltered ${ }^{17}$. Q-PCR analyses showed absence of 
intact smoothelin-B transcripts in aorta, femoral artery and jejunum of $S m t n-B^{-1-}$ mice (Figure 6.1c). On the other hand, upregulation of either smoothelin-A or an interrupted smoothelin-B transcript still containing its $3^{\prime}$ smoothelin-A sequence was found in $S m t n-B^{-/-}$blood vessels (Figure 6.1c). However, smoothelins were not detectable in the aorta of $S m t n-B^{-/}$mice by immunohistological stainings with polyclonal antibodies recognizing both smoothelin-A and smoothelin-B (Figure 6.1d). Thus, $S m+n-B^{-/}$mice present with a null mutation in vascular tissue, and can be used to delineate the role of smoothelin-B in vascular smooth muscle function. As predicted, $S m+n-B^{--}$mice displayed normal smoothelin expression in visceral tissues (Figure 6.1c).

a

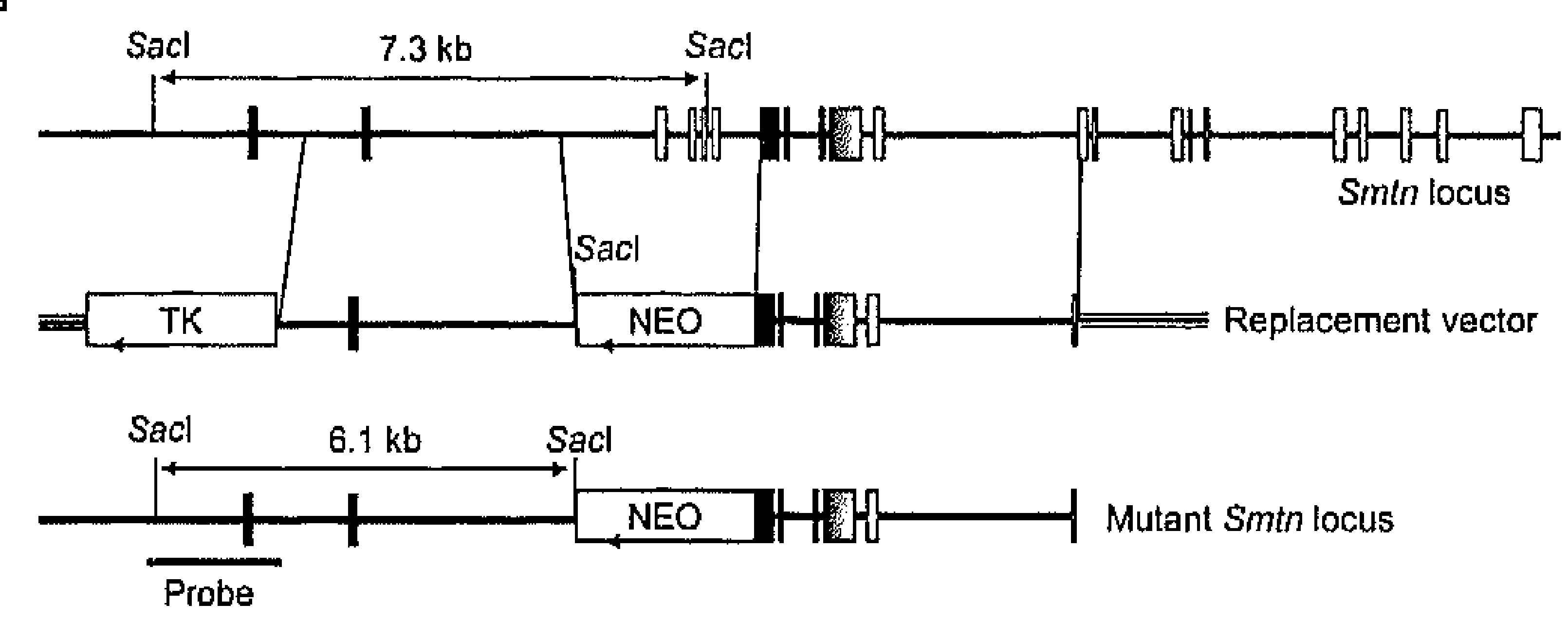

b

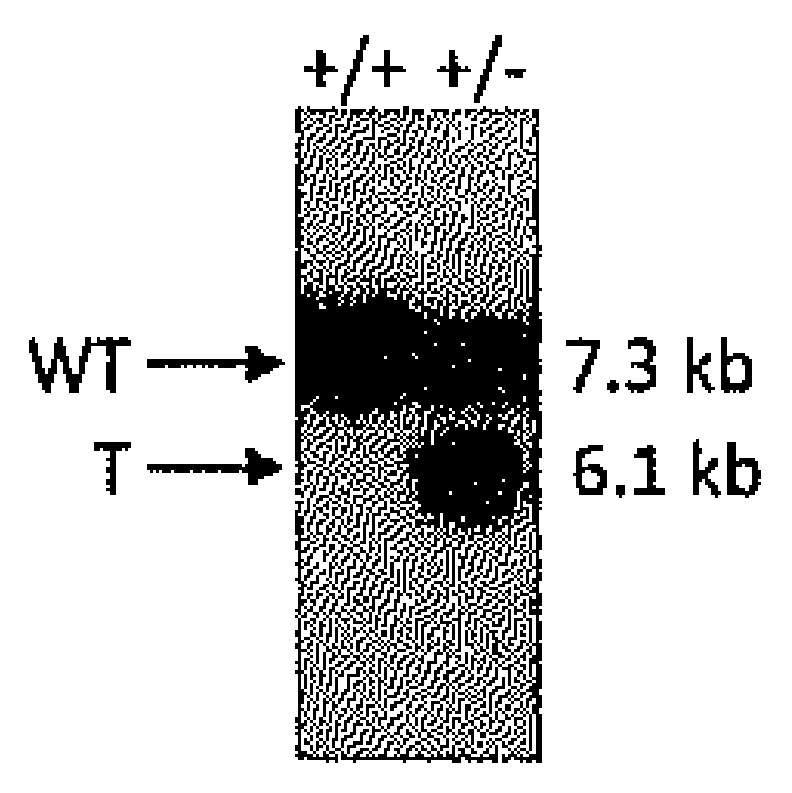

c

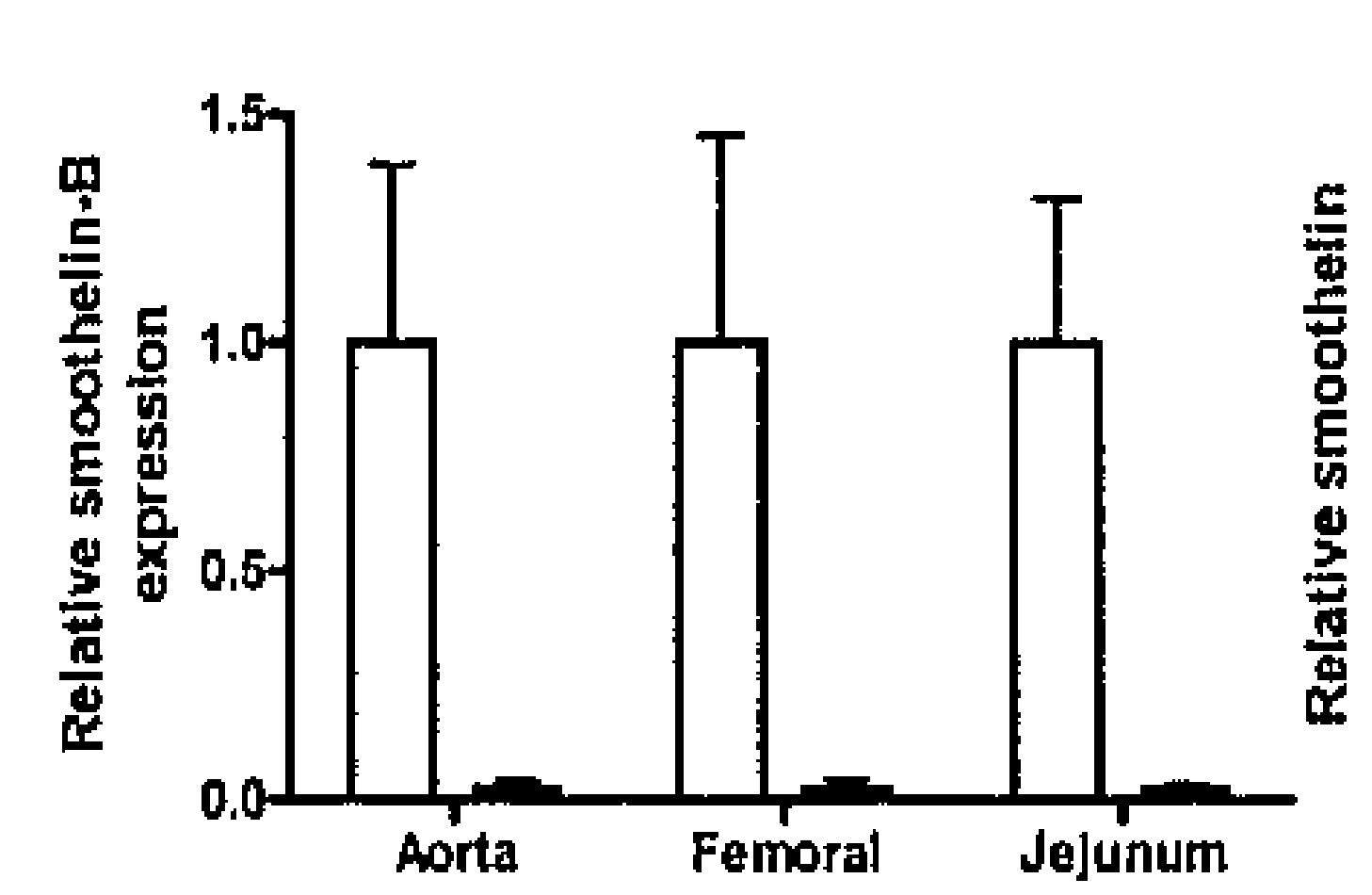

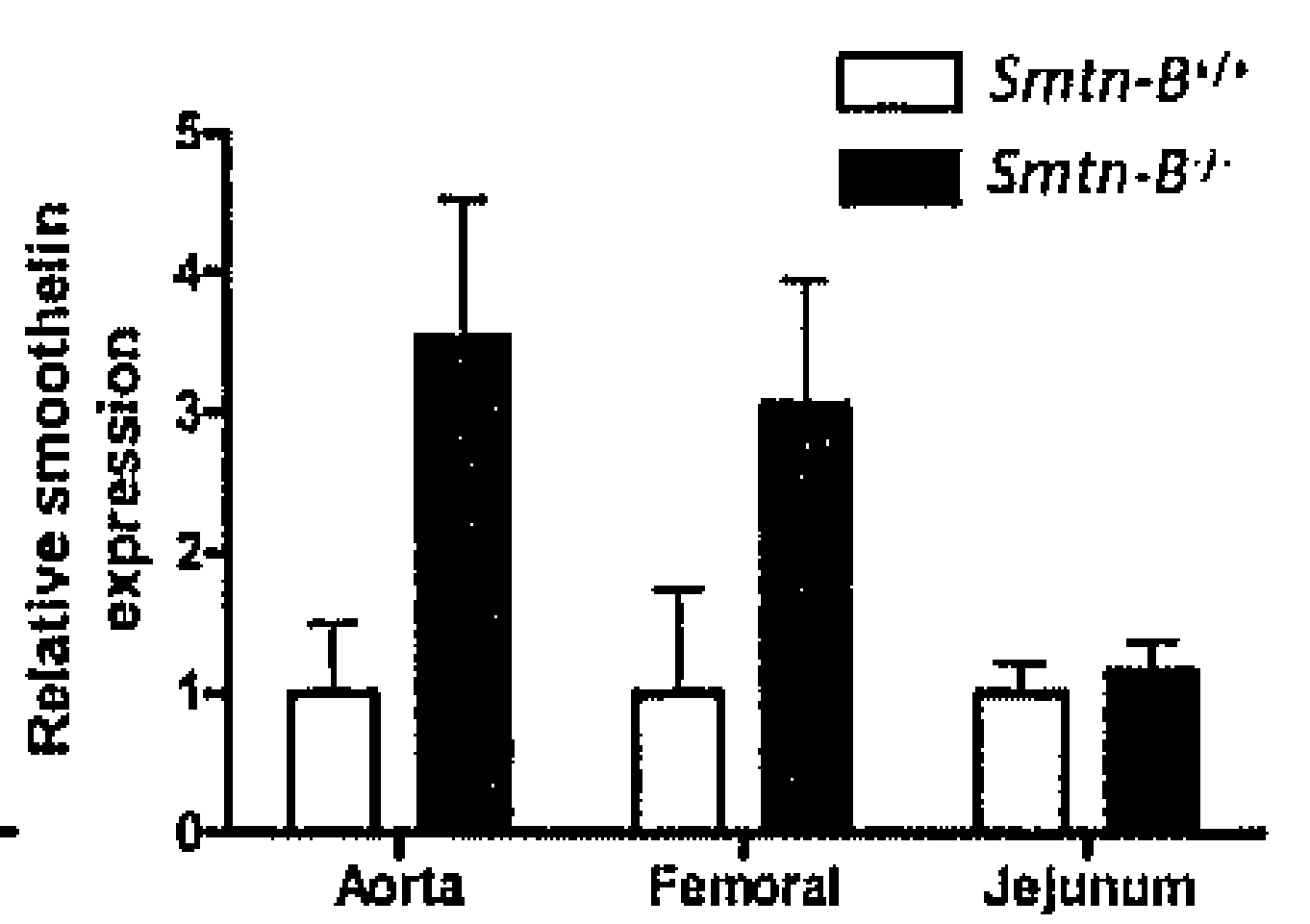

d

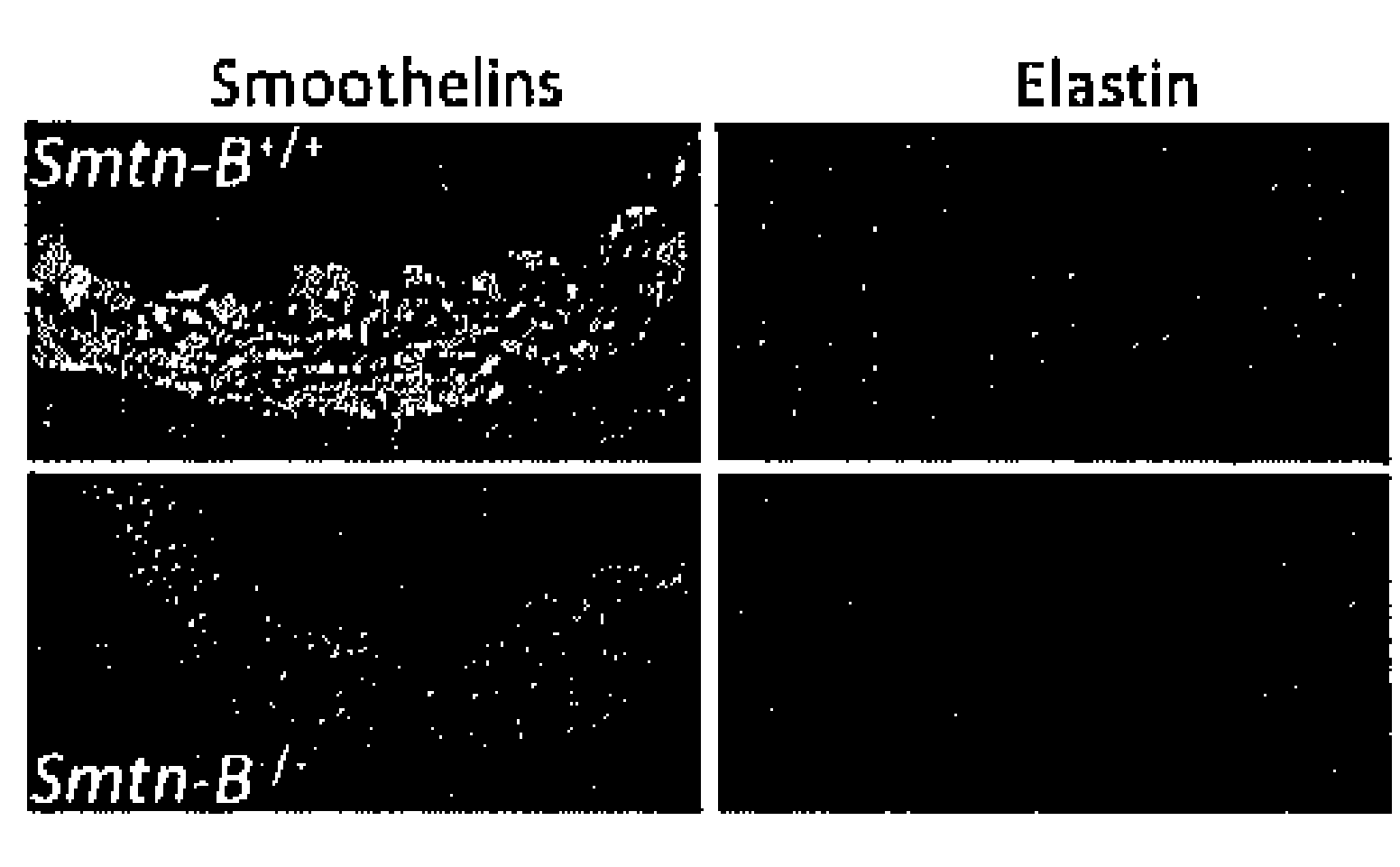

Figure 6.1 Targeting of the Smtn gene for the generation of mice lacking smoothelin-B in vascular smooth muscle. (a) Schematic representation of the targeting strategy. Top: Structure of the Smtn gene. Black boxes indicate smoothelin-B exons, light grey boxes indicate exons common to smoothelin-A and -B, white boxes represent targeted exons. Middle: Smtn-B ${ }^{\%}$ targeting vector containing neomycin resistance (NEO) and herpes simplex virus thymidine kinase (TK) genes, both transcribed in the reverse direction to that of the Smtn gene, as indicated by arrows. Bottom: Structure of the targeted Smtn allele and location of the probe used in Southern blot analyses after Sacl digestion. The distance between the Sacl sites in the wild type (top) and mutant (bottom) locus is shown. (b) Southern blot analyses of genomic DNA from wild type and targeted ES cells after Sacl digestion with the probe indicated in Figure 6.1a. The wild type Sacl fragment (WT) has a size of $7.3 \mathrm{~kb}$, whereas the mutant Sacl fragment (T) is $6.1 \mathrm{~kb}$. (c) Q-PCR analysis showing absent smoothelin-B expression in aorta, femoral artery, and jejunum of $S m t n-B^{-/-}$mice (left panel). Q-PCR experiments using primers and probes directed against the part that both smoothelins have in common revealed upregulated expression of either smoothelin-A or an interrupted smoothelin-B transcript in blood vessels, but not in jejunum (right panel). (d) Crosssections of aortas of $S m t n-B^{+/+}$and $S m t n-B^{-/-}$mice were stained for smoothelin-A and $-B$ (green; $400 x$ magnification). The cells between the autofluorescent elastic laminae do not stain, showing that smoothelins are not present in vascular SMCs of Smtn- $B^{-/}$mice. At the right panel autofluorescence of the elastic laminae is shown in red. See front cover for color pictures. 

Normal contractile gene expression and blood vessel structure in Smtn-B/-
mice

To study whether levels of important contractile smooth muscle specific genes were altered by the loss of smoothelin-B, we examined the expression of $\alpha$ SMA, SM-MHC, and SM-calponin in blood vessels by Q-PCR. The expression of these components of the SMC contractile machinery was not significantly changed at the RNA level (Figure 6.2a). In addition, both $\alpha$-SMA (Figure 6.2b) and SM-MHC (Rensen, unpublished data, 2007) proteins were readily detectable in medial SMCs of Smtn- $B^{-1}$ mice. Moreover, the femoral artery and the aorta of $S m t n-B^{-1-}$ mice appeared histologically normal and had an unaltered medial CSA and vessel radius in comparison with $S m t n-B^{+/+}$mice (CSA aorta: $0.086 \pm 0.004$ vs. $0.075 \pm 0.004 \mathrm{~mm}^{2}$; CSA femoral artery: $0.0107 \pm 0.0005$ vs. $0.0101 \pm 0.0005 \mathrm{~mm}^{2}$; radius aorta: $367 \pm 4$ vs. $349 \pm 10 \mu \mathrm{m}$; radius femoral artery: $145 \pm 5$ vs. $143 \pm 5 \mu \mathrm{m}$ for Smtn- $B^{+/+}$vs. Smtn- $B^{-/-}$mice, respectively). The staining patterns of the extracellular matrix proteins collagen and elastin were also normal in mice of both genotypes, showing regular arrangement of elastic fibers and laminae without fragmentation (Figure $6.2 c, d$ ). Hence, loss of smoothelin-B does not affect the expression of other major smooth muscle contractile proteins or blood vessel architecture.

\section{Severely compromised arterial contractile capacity in Smtn-B ${ }^{-/-}$mice}

To examine the effect of smoothelin-B deficiency on vascular smooth muscle function, we measured the contractility of the femoral artery and the thoracic aorta, which contain high and low amounts of smoothelin-B, respectively ${ }^{7}$. We applied several contractile agonists to isolated vessel segments in a myograph to assess the integrity of different signal transduction pathways that activate SMC contraction. Because sensitivities to the contractile stimuli did not differ significantly between genotypes, only differences between maximal responses will be discussed. The maximal contractile responses generated by femoral arteries of Smtn- $\mathrm{B}^{-1}$ mice were strongly decreased compared to control mice, during stimulation with either $\mathrm{K}+$, the thromboxane $\mathrm{A} 2$ mimetic $\mathrm{U} 46619$, or the $\alpha 1$-adrenergic agonist phenylephrine (Figure 6.3a). Contractility in response to phenylephrine was reduced by more than $50 \%$. Maximal contractile forces produced by aortas from $S m+n-B^{-/}$mice were also smaller than those of control mice, though the differences were less prominent than for the femoral arteries 
a
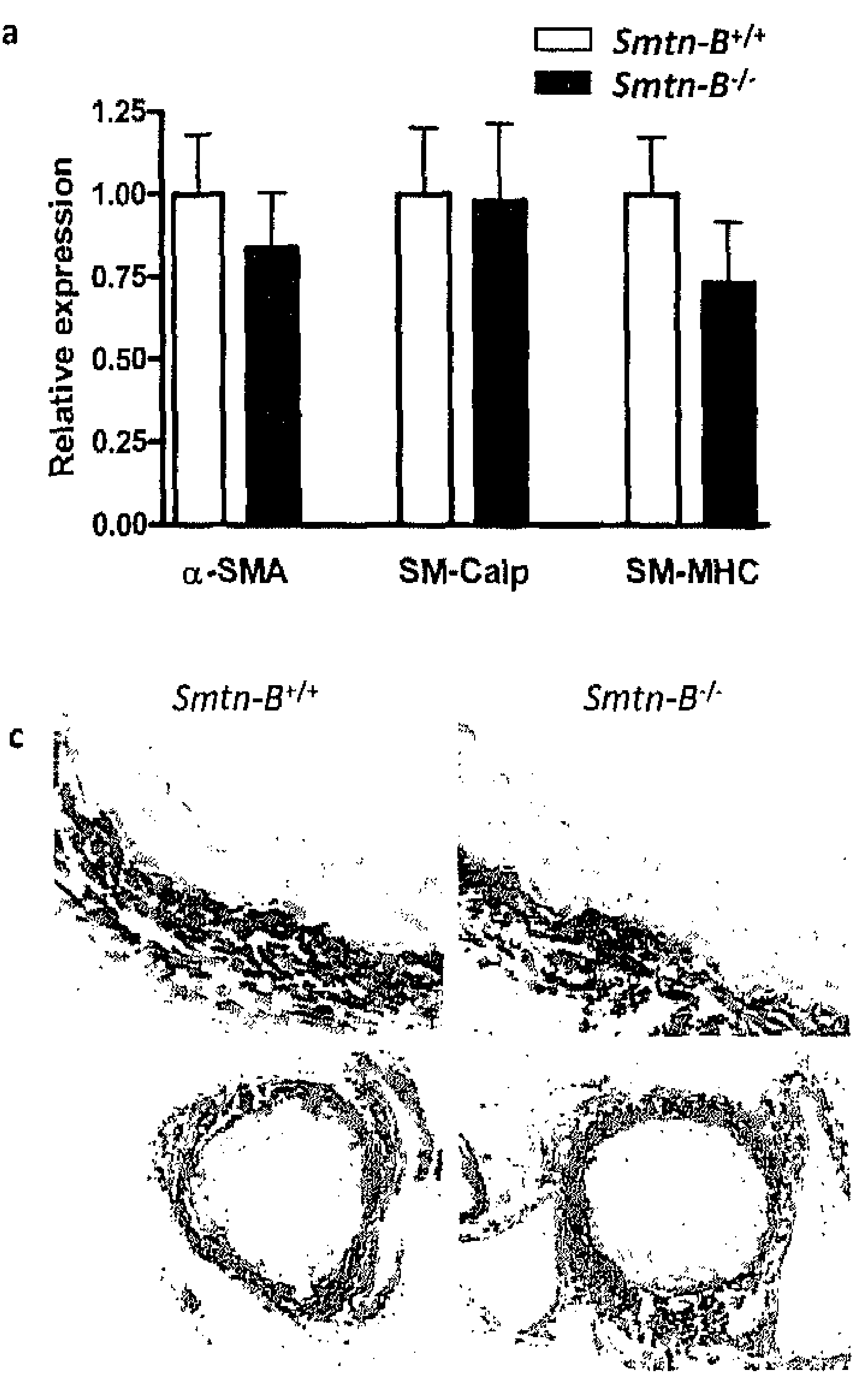
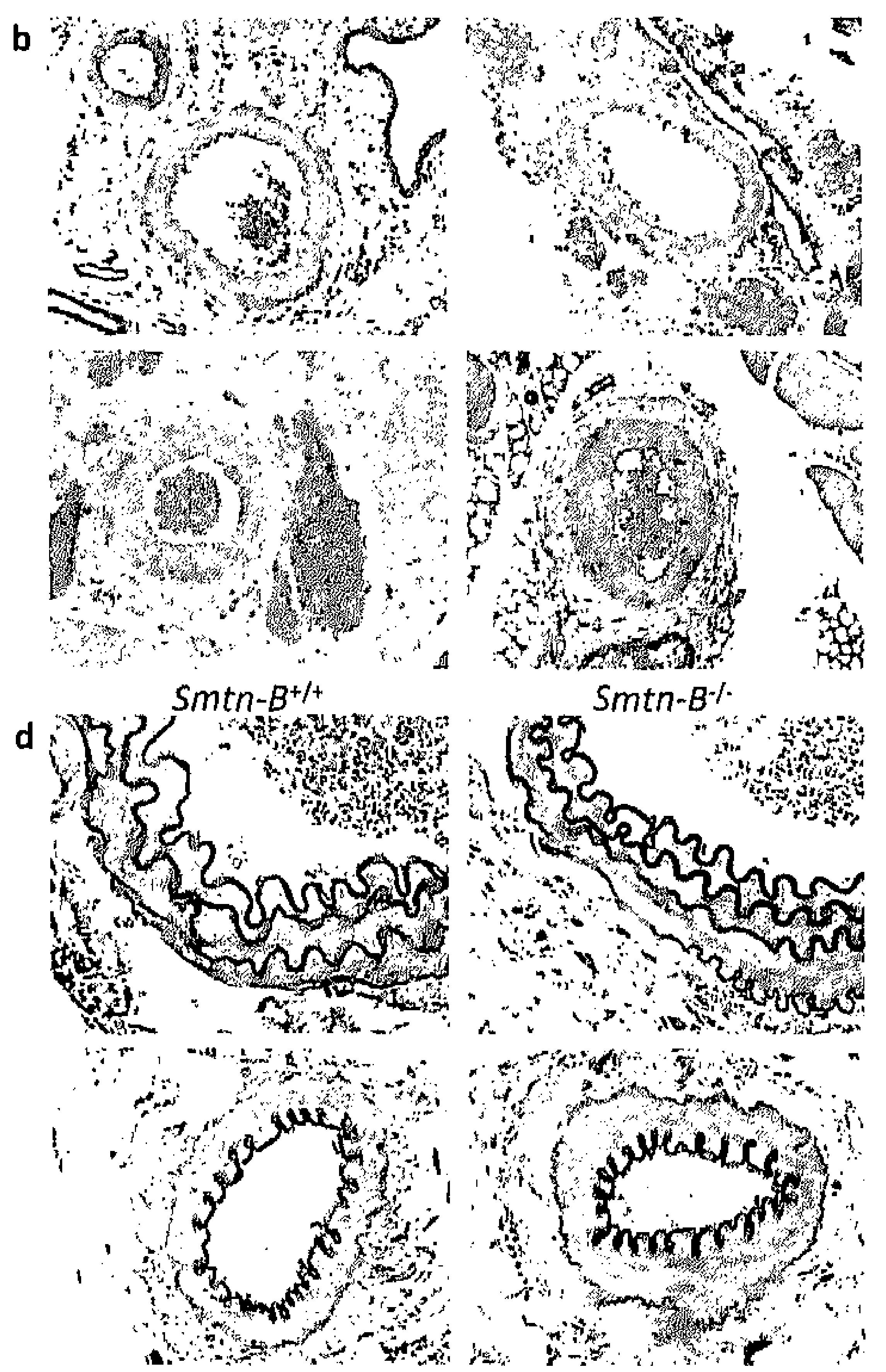

Figure 6.2 Normal contractile gene expression and arterial structure in $S m t n-B^{-1}$ mice. (a) Expression of $\alpha$-SMA, SM-MHC and SM-calponin was measured by Q-PCR. Levels were normalized to cyclophilin $A$ expression and $S m t n-B^{+/+}$levels were set at 1 . There was no significant change in expression levels between $S m t n-B^{+/ t}$ and $S m t n-B^{-1-}$ mice. (b) Representative immunohistochemical staining of $\alpha$-SMA in the aorta (upper panel) and femoral artery (lower panel) of $S m t n-B^{-1-}$ and $5 m t n-B^{+/+}$mice, showing no differences between the genotypes (magnification aorta 100x, femoral artery 200x). (c) Representative images of Sirius Red staining of the aorta (upper panel, 400x magnification) and femoral artery (lower panel, 200x magnification) of Smtn- $B^{-1-}$ and Smtn$B^{+/+}$mice, showing no major differences in collagen content or distribution. (d) Representative images of Lawson's elastin staining of the aorta (upper panel, 400x magnification) and femoral artery (lower panel, 200x magnification) of $S \mathrm{mtn}-B^{-\%}$ and $S \mathrm{mtn}-B^{+/+}$mice, showing regular elastic fibers in both genotypes. See back cover for color pictures.

and not significant (Figure $6.3 \mathrm{~b}$ ). This can probably be attributed to the lower smoothelin content of aortic $\mathrm{SMCs}^{7}$.

To investigate if a lack of smoothelin-A on top of smoothelin-B deficiency has an additional effect on vascular smooth muscle performance, we tested the same vasoactive compounds on arterial vessels isolated from $S m t n-A / B^{\%}$ mice. Of note, Smtn- $A / B^{-/}$mice had a decreased medial CSA of the thoracic aorta and femoral artery which was, however, proportional to their smaller body size ${ }^{17}$. 
The reduced smooth muscle volume was corrected for in the contractility analyses. Like Smtn-B ${ }^{-\%}$ vessels, femoral arteries of $S m t n-A / B^{-1}$ mice showed greatly reduced contractility, irrespective of the type of agonist used to trigger contraction (Figure 6.3c). The extent of the reduction was comparable to that observed in Smtn-B ${ }^{-1}$ vessels. Likewise, thoracic aortas of $5 m t n-A / B^{-1}$ mice displayed reduced maximal contractility in response to all stimuli tested and a more pronounced reduction of maximal responses to phenylephrine (Figure 6.3d). These data show that smoothelin-B is an important determinant of vascular contractility whereas smoothelin-A does not appear to play a significant role in the vascular system.

\section{Femoral artery}
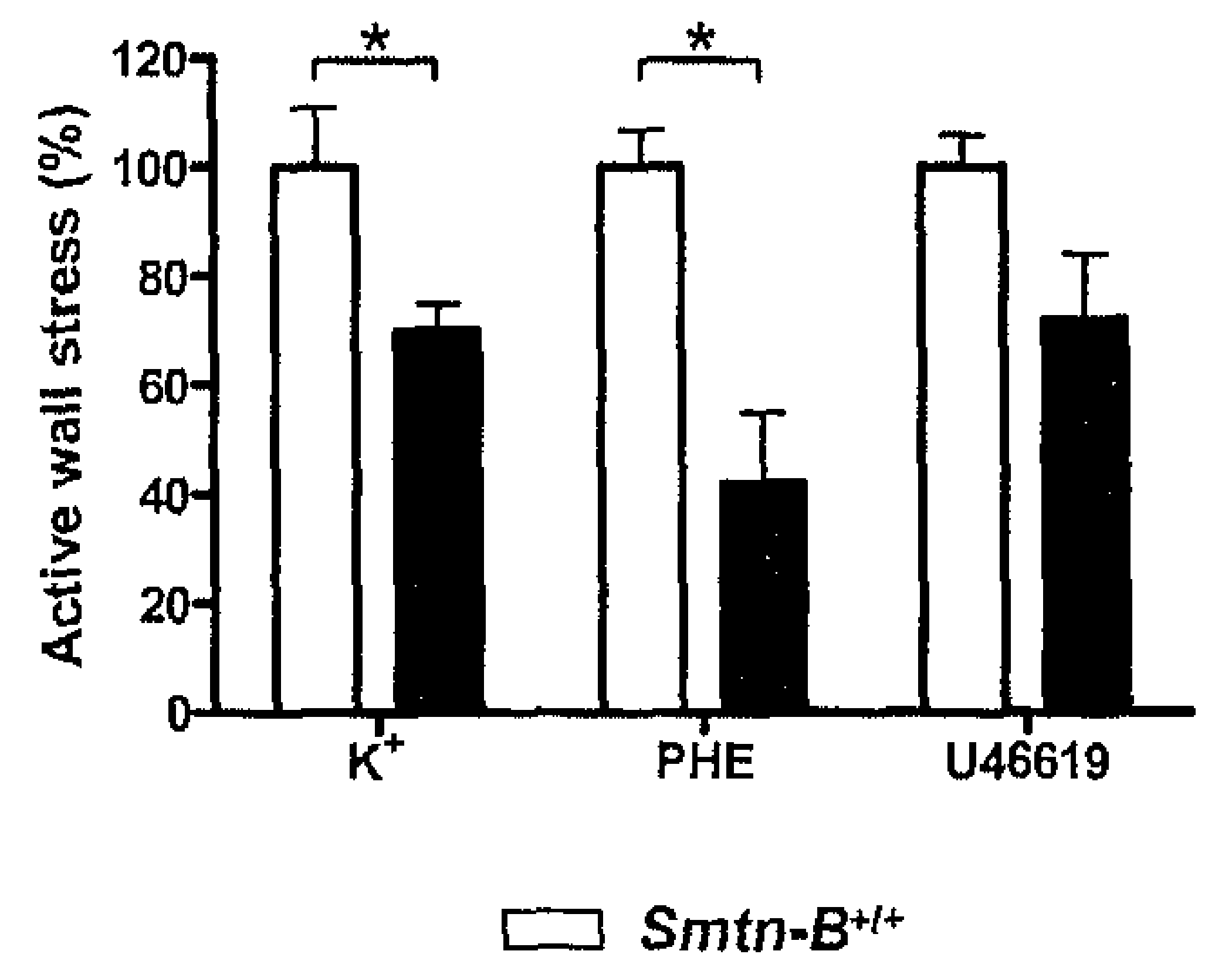

c

\section{Aorta}
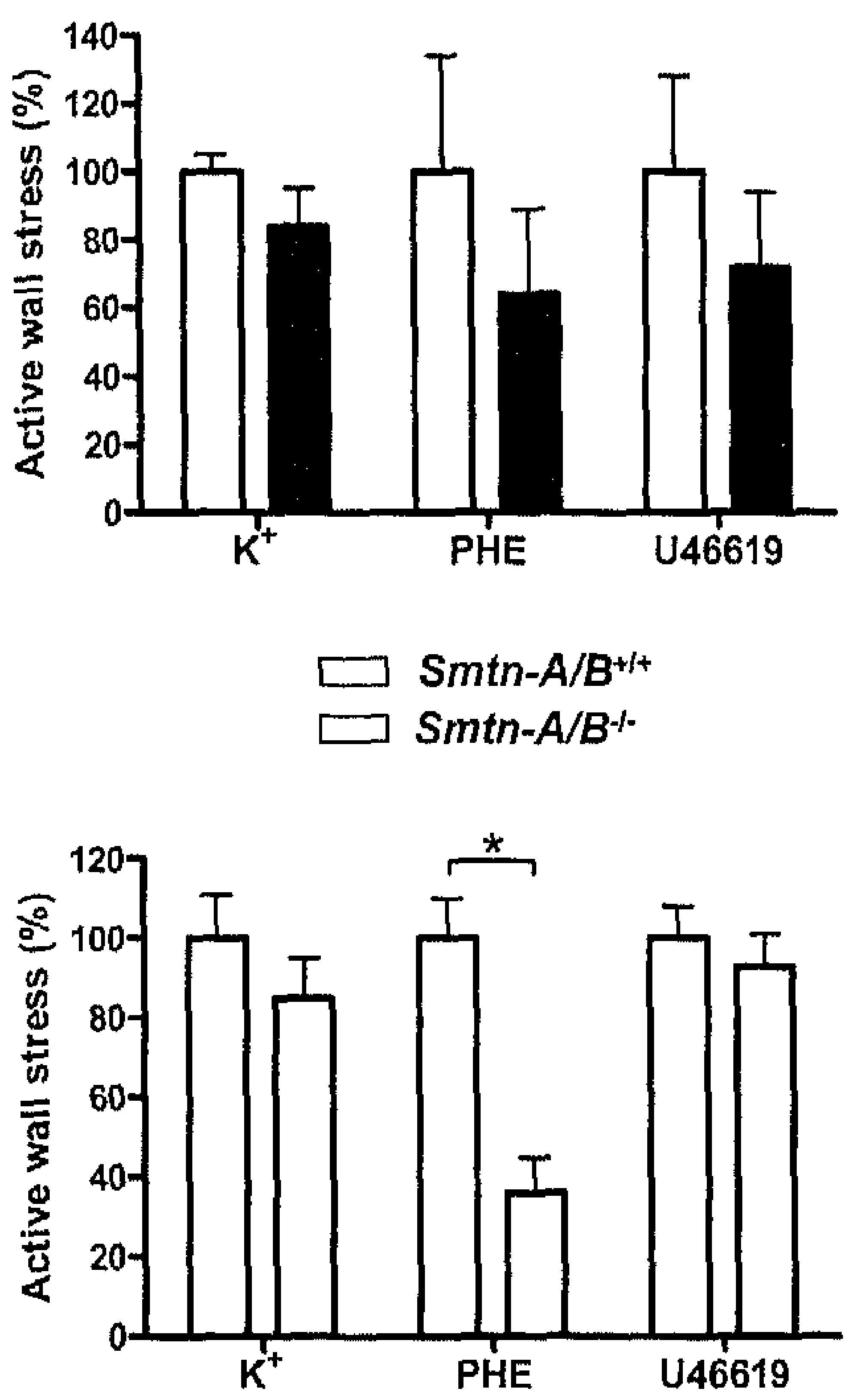

Figure 6.3 Decreased vascular smooth muscle contractility in $5 m t n-B^{-1-}$ and $S m t n-A / B^{\%}$ mice. Maximal contractile responses to $\mathrm{K}+$, phenylephrine (PHE) and $\mathrm{U} 46619$ of both femoral artery (a) and thoracic aorta (b) of $S m t n-B^{-1}$ mice were diminished (femoral artery: $K+p=0.03$; PHE $p<0.01$ ). A similar decrease was observed in $S m t n-A / B^{-1-}$ mice $(c, d)$ (femoral artery: $K+p<0.05$; PHE $p<0.01$; U46619 $p<0.05$; aorta: PHE: $p<0.01$ ). Force was normalized to wild-type values. Asterisks indicate statistically significant differences. 
Increased mean arterial pressure and cardiac hypertrophy in Smtn- $B^{-/-}$mice

The physiological consequences of the reduced arterial contractility in Smtn- $B^{-1-}$ mice were analyzed by measuring several hemodynamic parameters in conscious mice. Basal MAP was significantly higher in $S m t_{n}-B^{-1}$ mice than in control mice (approximately $20 \mathrm{mmHg}$, Figure 6.4a). In line with the elevated MAP, Smtn- $B^{-t}$ mice developed a significantly higher heart weight to body weight (HW/BW) ratio at the age of eight months (Figure 6.4b). Morphometric analysis of the hearts of these mice showed that both the left and the right ventricular wall were enlarged (left ventricle CSA $13.4 \pm 0.1 \mathrm{vs} .12 .9 \pm 0.1 \mathrm{~mm}^{2}$ and right ventricle CSA $5.4 \pm 0.6$ vs. $4.8 \pm 0.4 \mathrm{~mm}^{2}$ for $S m t n-B^{-/-}$vs. $S m t n-B^{+/+}$mice). The number of cardiomyocyte nuclei $/ \mathrm{mm}^{2}$ was similar $(79.8 \pm 3.0$ vs. $79.4 \pm 4.1$ for $S m t n-B^{-1-}$ vs. Smtn- $B^{+/+}$littermates), consistent with a hypertrophic response. To establish if the increased HW/BW ratio indeed reflected cardiac hypertrophy, we measured the expression of the cardiac hypertrophy markers atrial natriuretic factor (ANF) and brain natriuretic peptide (BNP) in the heart. RNA levels of both natriuretic peptides were elevated in $S m t n-B^{-1-}$ mice compared with $5 m t_{n}-B^{+/+}$littermates (Figure 6.4c). Increased MAP as well as higher $\mathrm{HW} / \mathrm{BW}$ ratio were also detected in $S m t n-A / B^{-1}$ mice at a young age of only six weeks (MAP: $95 \pm 5$ vs. $87 \pm 2 \mathrm{mmHg}$; HW/BW: $6.8 \pm 0.9$ vs. $5.8 \pm 0.4 \mathrm{mg} / \mathrm{g}$ for Smtn$A / B^{-1-}$ vs. Smtn-A/B $B^{+/+}$littermates). Collectively, these results show that smoothelin deficiency results in elevated blood pressure leading to cardiac hypertrophy.

\section{Normal cardiac function in Smtn- ${ }^{-1-}$ mice}

The elevated blood pressure in $5 m t_{n}-B^{-/}$mice must be due to an elevated cardiac output or increased peripheral resistance (or both). To assess these possibilities, cardiac function was analyzed in vivo by magnetic resonance imaging (MRI) experiments. The MRI data revealed that stroke volume, heart rate, cardiac output, end systolic volume and end diastolic volume were not significantly different between $S m t n-B^{-/}$and $S m t n-B^{+/+}$littermates, whereas the ejection fraction was slightly but significantly elevated in $5 m t_{n}-B^{-\%}$ mice (Table 6.2). The higher left ventricular mass of $S m t n-B^{-/}$mice was confirmed using MRI. Heart rate (HR) as measured by classical arterial catheters was also not significantly different between conscious $S m t n-B^{-/}$and $S m t n-B^{+/+}$mice $(657 \pm 14$ vs. $654 \pm 18$ beats $/ \mathrm{min}$ ) or between anaesthetized $S m t n-A / B^{-/-}$and $S m t n-A / B^{+/+}$ mice $(517 \pm 12$ vs. $468 \pm 23$ beats $/ \mathrm{min})$. Thus, cardiac function does not appear to be compromised in Smtn-B ${ }^{-/}$mice under normal conditions. Moreover, the higher MAP is not caused by increased cardiac output. 


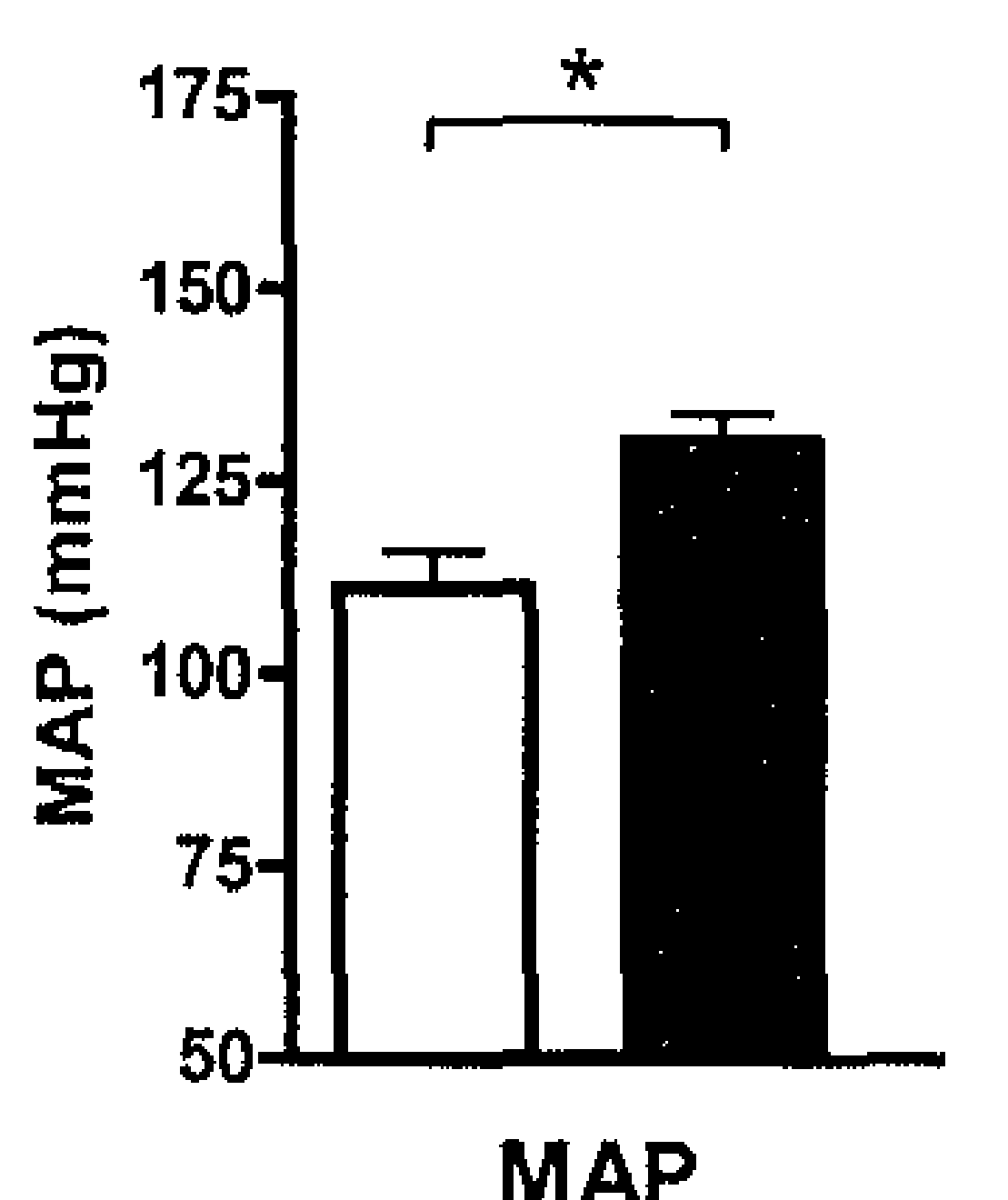

c

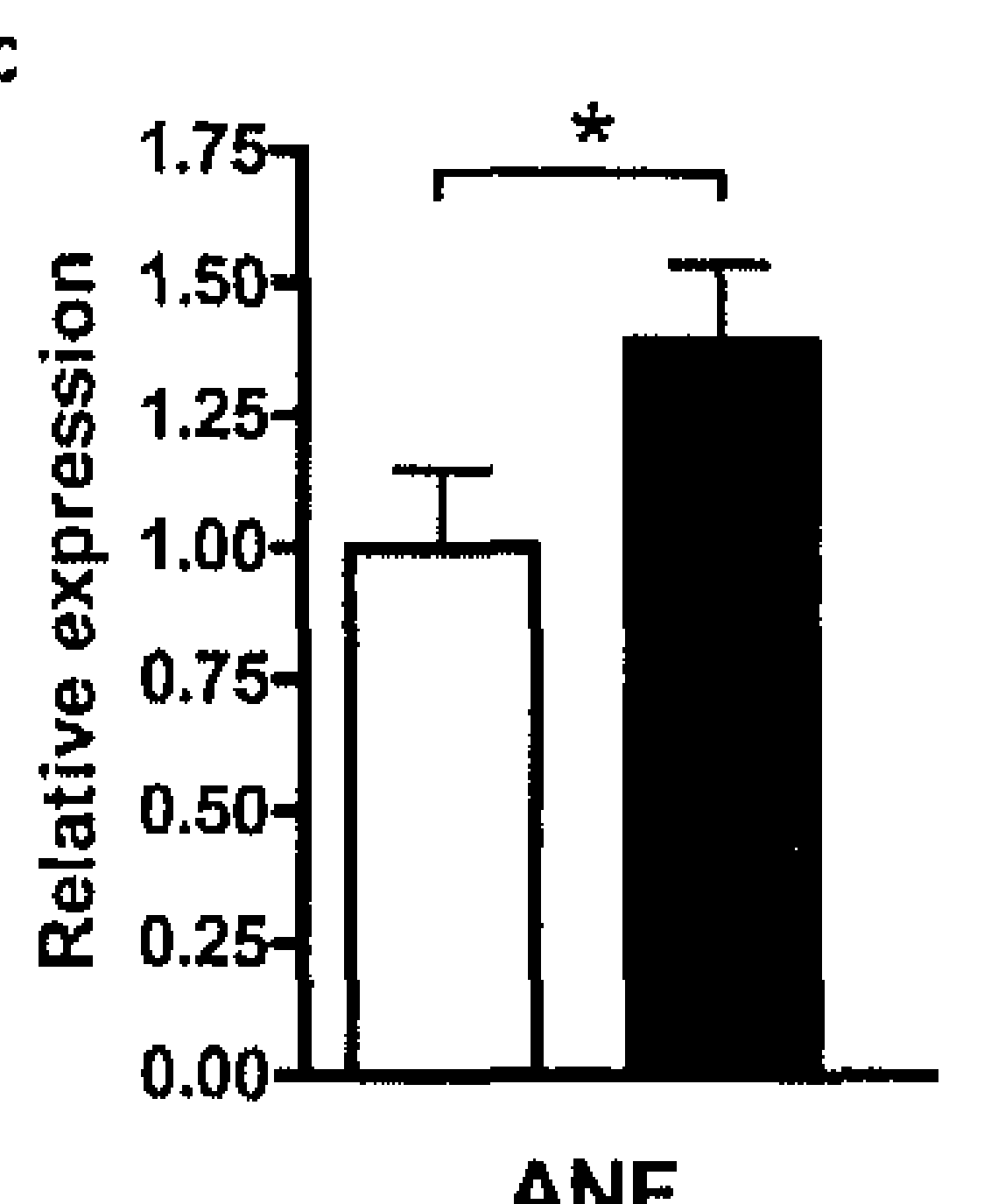

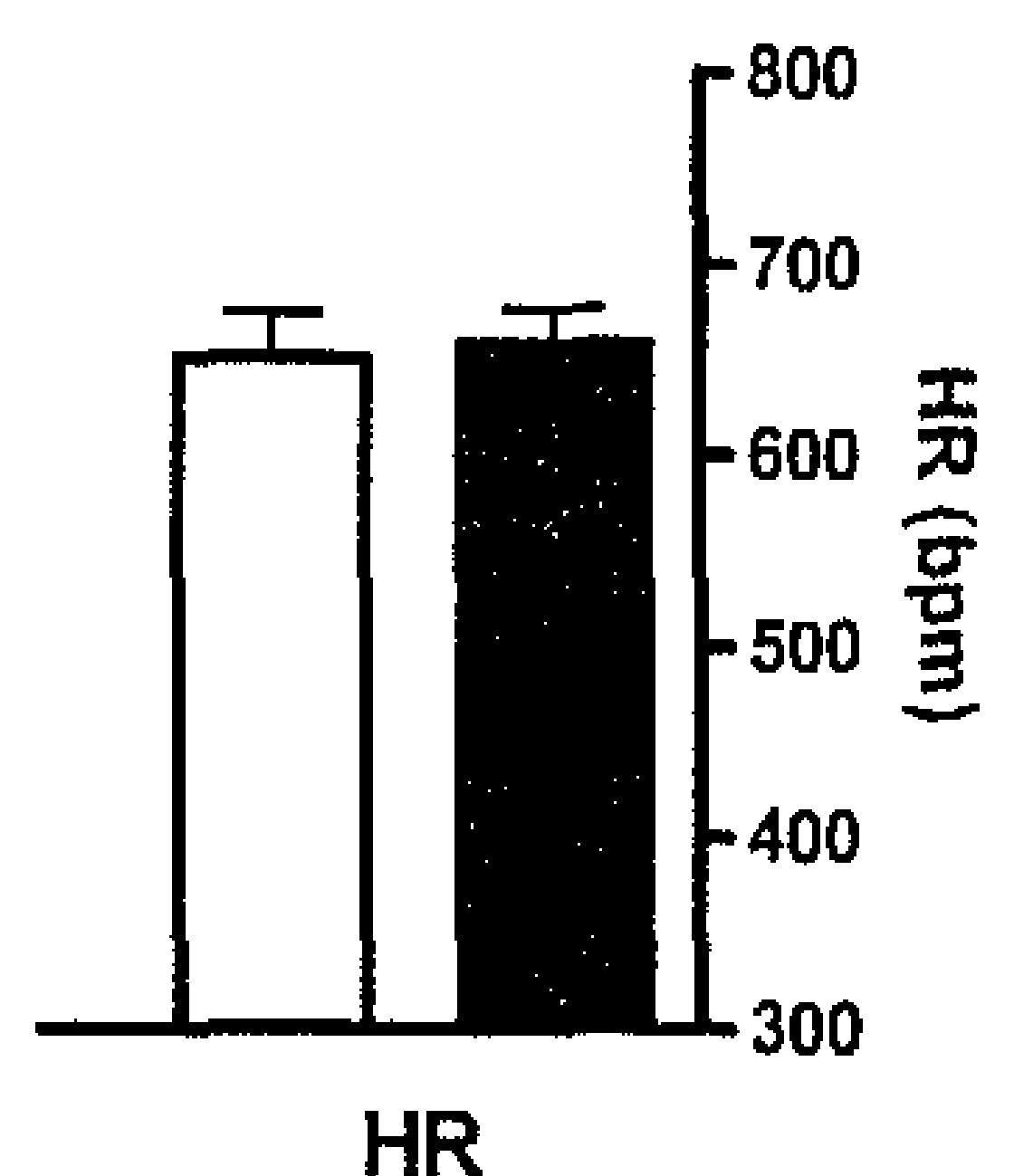

HR

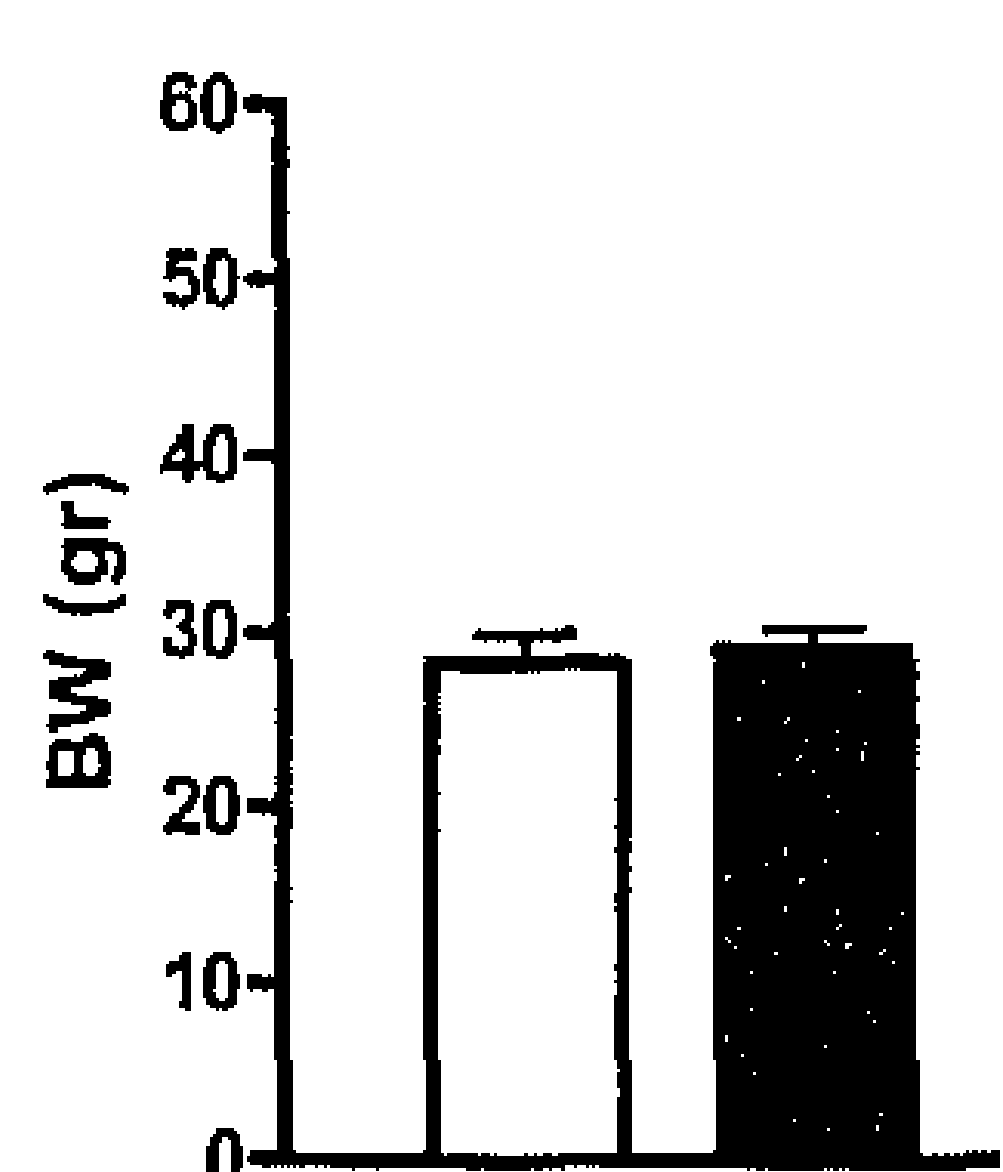

BW

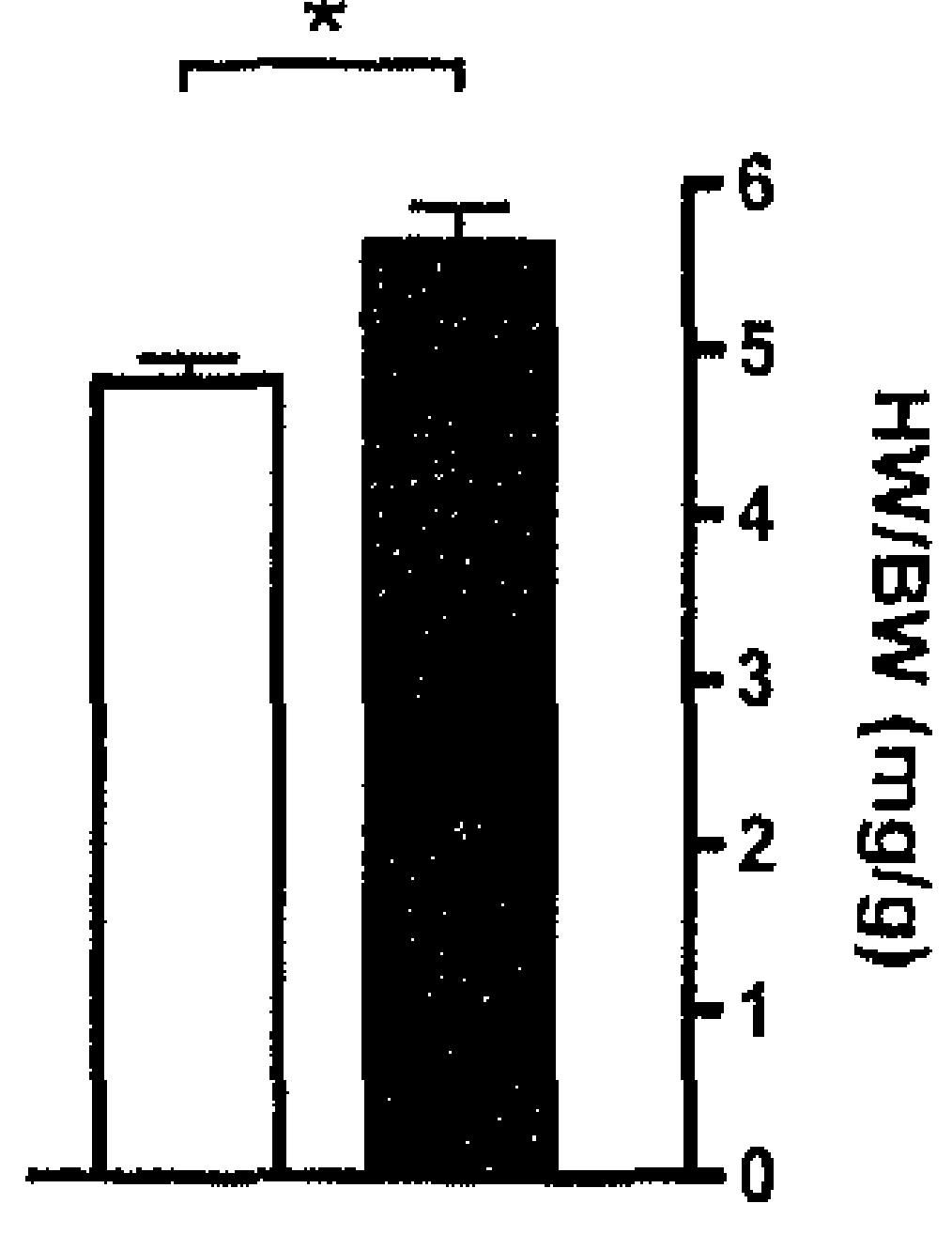

HW/BW

$\square S m t n-B^{+1+}$

Smtn-B $\%$

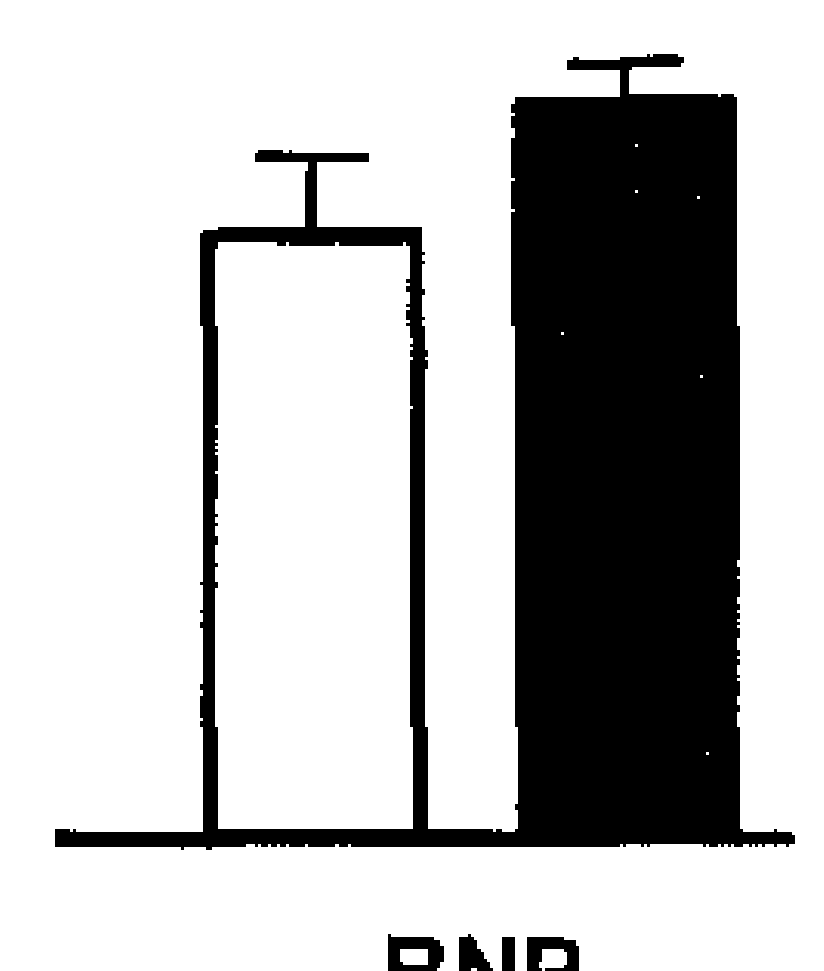

BNP

Figure 6.4 Smtn- $B^{-/-}$mice develop elevated blood pressure and cardiac hypertrophy. (a) $S m t n-B^{-1-}$ mice displayed elevated MAP compared with $S m t n-B^{+/+}$mice $(p=0.01)$. (b) Heart weight to body weight $(H W / B W)$ ratio was increased $(p<0.01)$, while BW was unaltered in $S m t n-B^{-1}$ mice. (c) Ventricular ANF and BNP levels as measured by $Q-P C R$ were elevated in $5 m t n-B^{-1}$ mice $(p=0.04$; $p=0.08$, respectively). Levels were normalized to cyclophilin $A$ expression and $S m t n-B^{+/+}$levels were set at 1 . Asterisks indicate statistically significant differences.

Table 6.2 Characteristics of cardiac function of $S m t n-B^{-/-}$and $S m t n-B^{+/+}$mice as measured by MRI.

\begin{tabular}{lll} 
Parameter & $S m t n-B^{-/-}$ & $S m t n-B^{+/+}$ \\
\hline & & \\
End diastolic volume $(\mu l)$ & $44 \pm 2.6$ & $47 \pm 2.1$ \\
End systolic volume $(\mu l)$ & $10 \pm 0.8$ & $13 \pm 1.2$ \\
Ejection fraction $(\%)$ & $76 \pm 1.1$ & $73 \pm 1.2 \quad(p=0.02)$ \\
Left ventricular mass $(\mathrm{mg})$ & $114 \pm 2.7$ & $101 \pm 4.5 \quad(p=0.02)$ \\
Stroke volume $(\mu l)$ & $34 \pm 2.0$ & $34 \pm 1.1$ \\
Heart rate $($ beats $/ \mathrm{min})$ & $521 \pm 11$ & $527 \pm 6$ \\
Cardiac output $(\mathrm{ml} / \mathrm{min})$ & $17.7 \pm 1.0$ & $18.1 \pm 0.7$ \\
\hline
\end{tabular}




\section{Increased distension of the proximal aorta in Smtn- $\mathrm{B}^{-/-}$mice}

Since cardiac output was not changed, increased total peripheral resistance had to be responsible for the elevated MAP of $5 m+n-B^{-1-}$ mice. Therefore, we next investigated the distension of the aorta during the cardiac cycle, which is an indicator of peripheral vascular resistance, by in vivo MRI analysis (Figure 6.5a). Indeed, the mean circumferential stretch of the aorta of $S m t n-B^{-/}$mice was higher throughout the cardiac cycle compared to $S m+n-B^{+/+}$mice (Figure $6.5 \mathrm{~b}$ ). The maximal distension was also larger for the $S m+n-B^{-1 /}$ mice compared with the $5 m t n-B^{+/+}$mice (Figure $6.5 \mathrm{c}$ ). Division of the maximal increase of the lumen diameter by the end-diastolic lumen diameter resulted in a maximal circumferential stretch of $39.8 \pm 6.3 \%$ for $S m t n-B^{-1-}$ mice versus $19.8 \pm 6.3 \%$ for $S m t n-B^{+/+}$mice $(p=0.01)$. Maximal distension was reached at approximately the same phase of the cardiac cycle in mice of each genotype. The lumen diameter of the thoracic aorta at the end-diastolic heart phase was $1.15 \pm 0.15$ versus $1.05 \pm 0.17 \mathrm{~mm}$ for the $5 m \mathrm{~m} n-B^{-1 /}$ and $S m t n-B^{+/+}$mice, respectively.

a

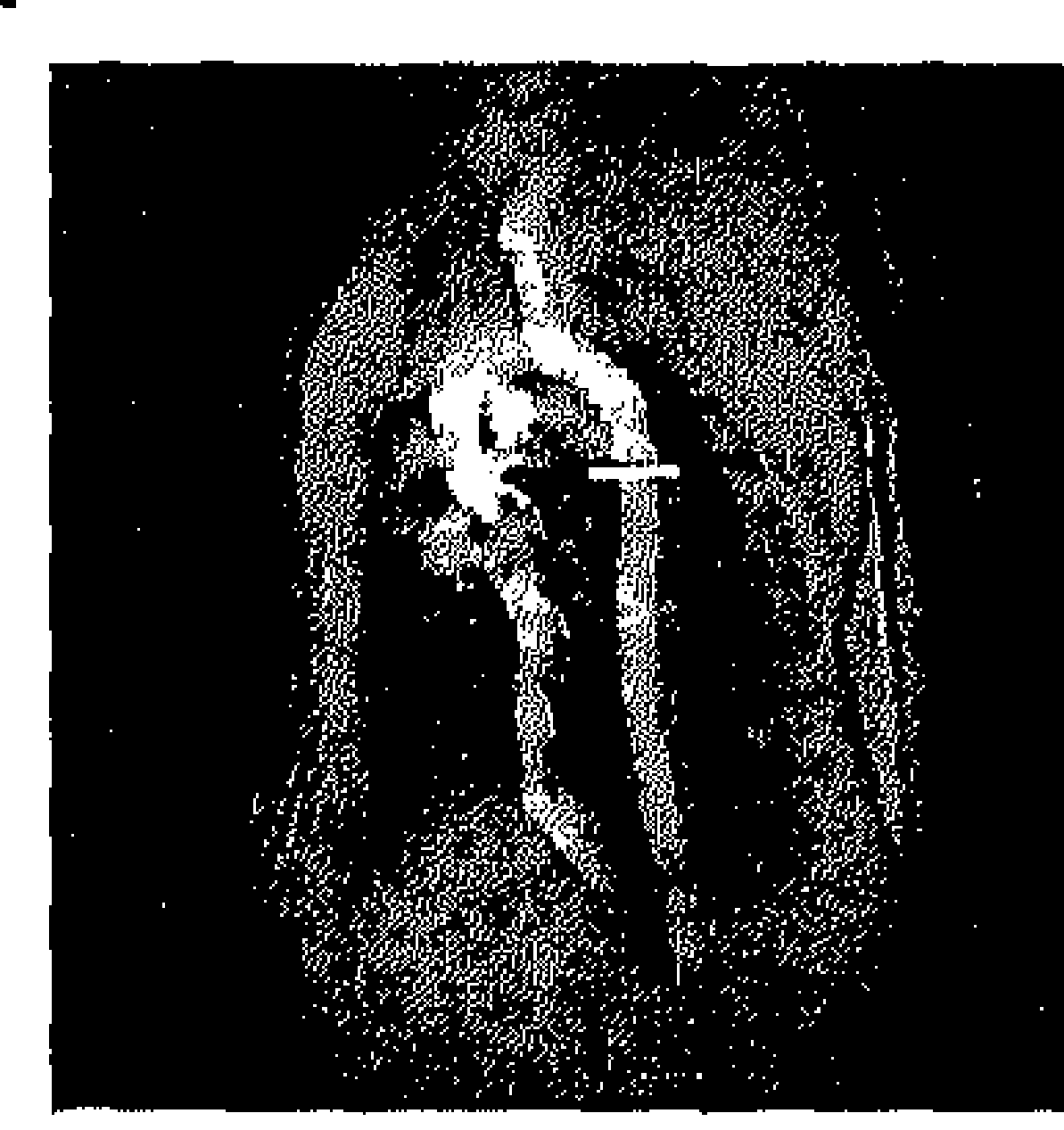

b

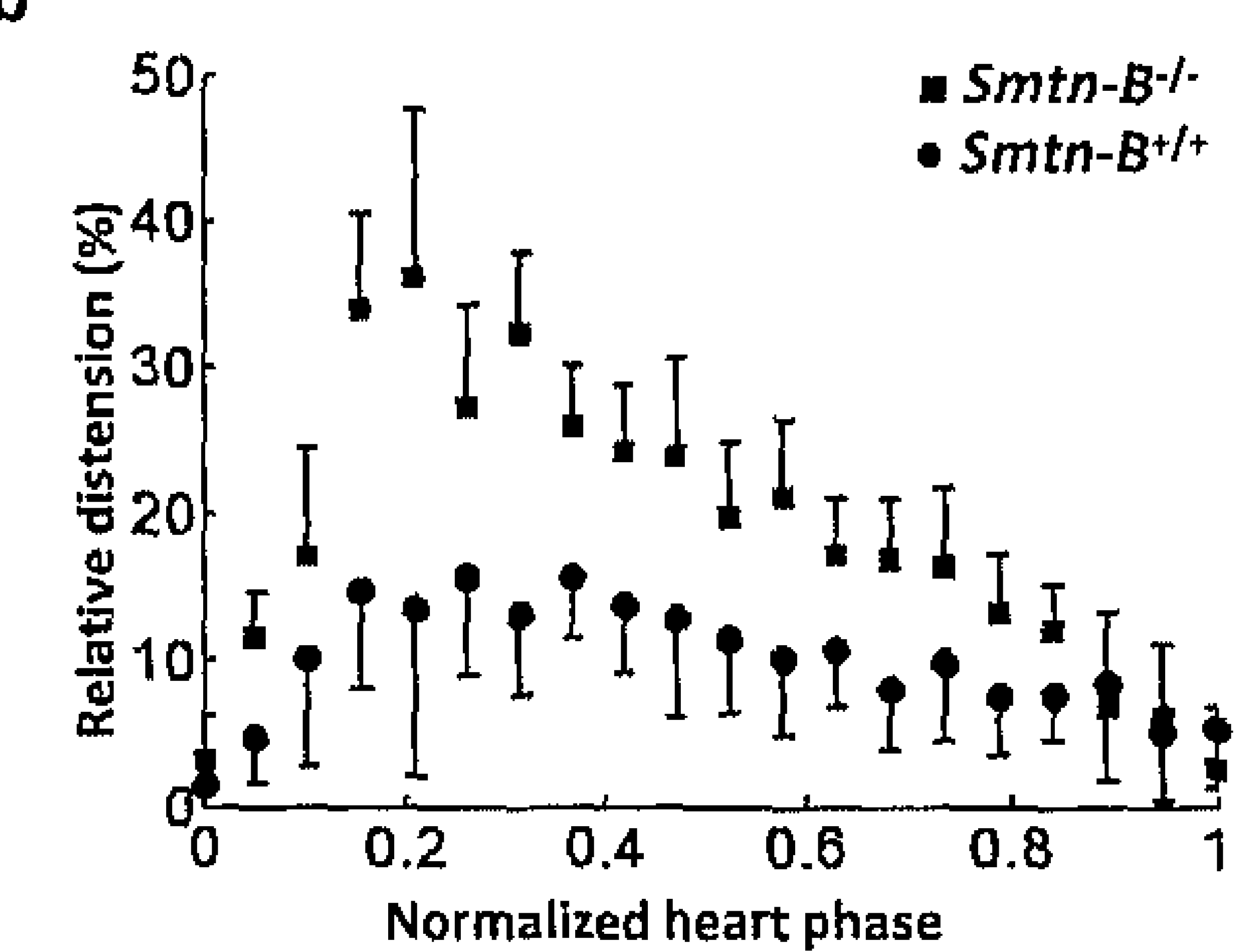

c

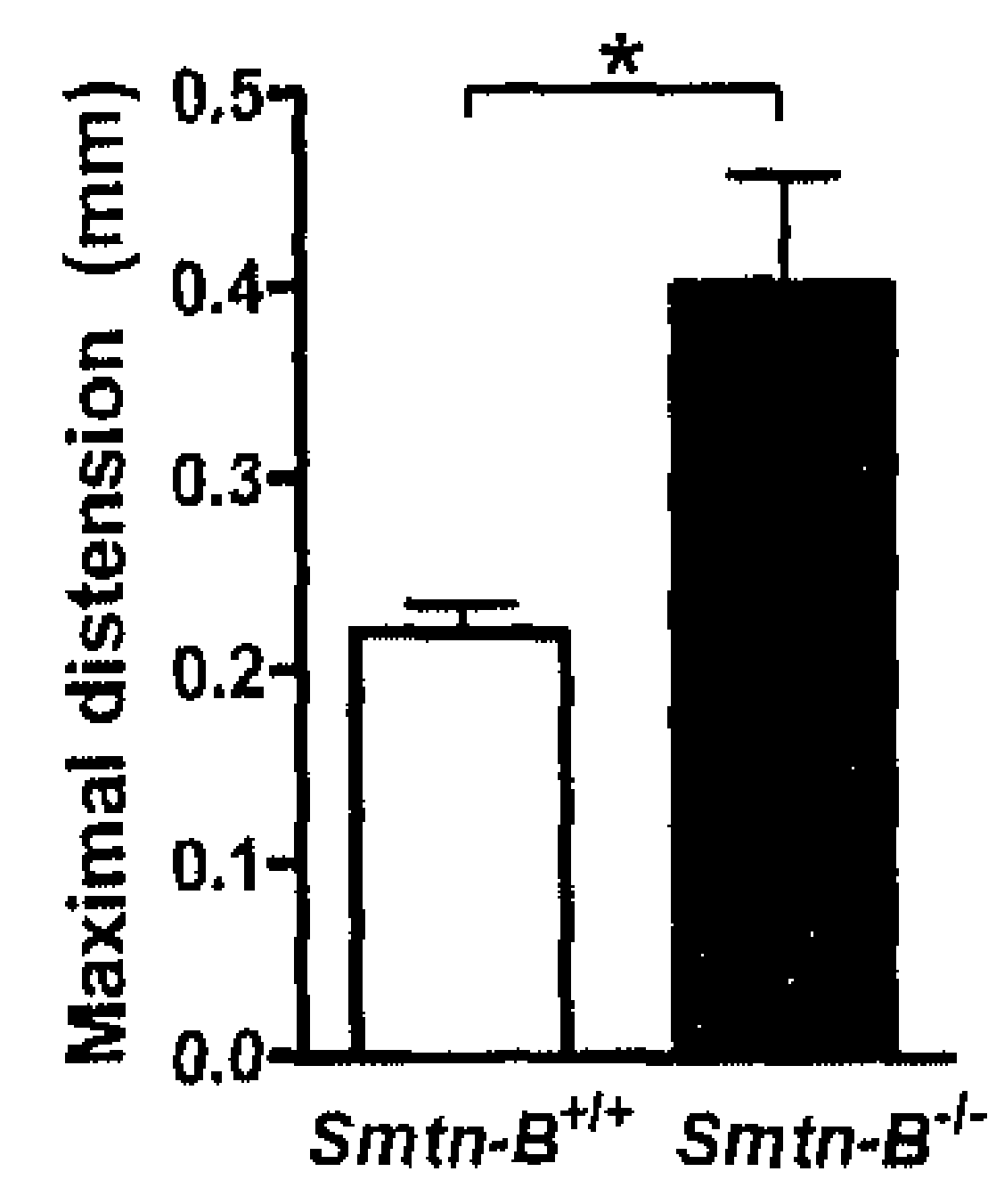

Figure 6.5 increased aortic distension in $S m t n-B^{-/ *}$ mice. MR image of the aorta of a $S m t n-B^{+/+}$ mouse at the end diastolic heart phase (a). The white line indicates the position of the lumen diameter measurement. Both mean circumferential stretch during the cardiac cycle (b) and maximal distension ( $c$ ) of the thoracic aorta were increased in $S m t n-B^{-1}$ mice (squares) compared to Smtn- $B^{+/+}$mice (dots), as determined by MRI analysis. The beginning of the systolic heart phase is represented by 0 , whereas 1 represents the end-diastolic phase. Asterisks indicate statistically significant differences.

\section{Discussion}

The present study was instigated by our recent demonstration that mice lacking both smoothelin isoforms display markedly reduced intestinal smooth muscle contraction $^{17}$. In line with this, we show here that loss of the vascular specific smoothelin-B protein leads to greatly diminished vascular contractile capacity. This is accompanied by elevated blood pressure and cardiac hypertrophy. In addition, aortic distension is significantly increased in smoothelin-B deficient 
mice. The data obtained in this study provide the first direct evidence that smoothelin-B is essential for vascular smooth muscle performance.

Reduced contractility of $5 m t_{n}-B^{-1}$ arteries was observed regardless of which signal transduction pathway was activated. Together with the binding of smoothelin- $B$ to the contractile filaments ${ }^{26}$, this non-selective reduction of contractility suggests that smoothelin-B plays a role at the core of the vascular SMC contractile machinery. The mechanism by which smoothelin-B affects smooth muscle contraction needs more study. It has been shown that the cardiovascular phenotype of other knockout mouse models of contractile SMC proteins may be explained by 1 ) downregulation of other proteins involved in SMC contraction, 2) upregulation of related proteins, or 3) expression of different alternatively spliced contractile proteins ${ }^{2,3,27,28}$. We have excluded the possibility that downregulation of the most important SMC contractile genes is responsible for the phenotype of $S m t_{n}-B^{-/}$mice. Also, smoothelin homologs are not detected by database searches, making it unlikely that upregulation of such proteins can compensate for the loss of smoothelin function. It cannot be ruled out, however, that changes in alternative splicing or organization of other contractile proteins occur in $S m+n-B^{-/}$animals.

An important determinant of the amount of contractile force in muscle contraction is the degree of cooperativity between multiple actomyosin crossbridges. Cooperativity in skeletal muscle is coordinated by tropomyosin and the troponin proteins ${ }^{29}$. However, troponins are not expressed in SMCs. Instead, smooth muscle tropomyosin interacts with $\mathrm{h}$-caldesmon and SM-calponin, which partly take over the role of troponins ${ }^{5}$. Importantly, smoothelins contain a 37 amino acid sequence that is similar to the tail domain of troponin $\mathrm{T}^{10}$. In skeletal muscle, this domain is not only required for troponin $T$ interaction with tropomyosin, but also involved in activation of actomyosin ATPase ${ }^{30}$. Thus, smoothelins might be part of a smooth muscle tropomyosin-troponin-like system. The diminished contractile potential of vascular smooth muscle of $S m t n-B^{-1-}$ may be due to a lack of cooperativity of contraction, which then would depend on a functional smoothelin-tropomyosin system.

The low expression of smoothelin-A in the vasculature previously led to the assumption that this smaller isoform is not important for vascular smooth muscle function. The current study provides the first evidence for this concept, since arterial contractility was shown to be reduced to the same extent in mice lacking both smoothelin-A and -B compared with mice lacking only smoothelin$B$. Thus, smoothelin-B is the only functional smoothelin isoform in vascular smooth muscle. In addition, on the basis of its strict contractile phenotypespecific expression, it was previously suggested that smoothelin-B might be involved in SMC differentiation. Nevertheless, there were no indications of SMC 
phenotype changes in $5 m+n-B^{-/}$mice such as decreased contractile gene expression or altered cell morphology.

The reduced contractile capacity of smoothelin-B deficient arteries ex vivo was accompanied by elevated blood pressure in $S m t n-B^{-1}$ mice. However, a reduced maximal contractile response does not necessarily manifest itself in the mean arterial pressure. Elevation of mean blood pressure may occur as a result of increased cardiac output, increased total peripheral resistance, or a combination of both. The MRI measurements in this study show that cardiac output in the $5 m t n-B^{-1-}$ mice is not changed. Therefore, the peripheral resistance of the vasculature must be affected by the mutation, which is conceivable considering the expression of smoothelin-B in the vessels. Indeed, the increased aortic distension despite similar cardiac stroke volume and similar aortic structure and size in Smtn-B $B^{-1}$ mice indicates increased resistance in the smaller parts of the vascular tree.

It is unlikely that the increased MAP is caused by overactivity of the autonomic nervous system, since heart rate did not differ between the genotypes. Nevertheless, changes in other neuro-humoral vasopressor systems that control blood pressure, or differences in the total number of vessels or the composition of their ECM might contribute to the altered MAP in Smtn- $B^{-/}$mice. Overall, the cardiovascular phenotype of $S m+n-B^{-1}$ mice bears similarity to that of patients with established hypertension. These, too, have a normal cardiac output with a hypertrophic heart, accompanied by increased peripheral resistance ${ }^{31}$.

In conclusion, the data in this study show that smoothelin-B deficiency causes a major decline in the contractile performance of vascular smooth muscle. Instead of merely reflecting the smooth muscle cell contractile phenotype, smoothelins appear to actively participate in the contractile process itself. Mutations in the Smtn gene or alterations in smoothelin levels may contribute to the development of hypertension and concomitant cardiac hypertrophy in humans.

\section{Acknowledgements}

We would like to thank Agnieszka Strzelecka and Jacques Debets for the hemodynamical measurements, and Gregorio Fazzi for the morphometric analysis. Technical assistance by our colleagues from the animal facility and by Darren Baker and Natascha Lie is gratefully acknowledged.

This work was supported by grants from the Netherlands Heart Foundation (97.167), Stichting De Gelderfonds, Stichting Simonsfonds, The Netherlands Organization for Scientific Research (NWO), the European Vascular Genomics Network, the EC-FP6-project DiMI, LSHB-CT-2005-512146, and the BSIK program 'Molecular Imaging of Ischemic Heart Disease' (BSIK03033). PN was supported by a Kootstra fellowship from the University of Maastricht. 


\section{References}

1. Cowley AW, Jr. The genetic dissection of essential hypertension. Nat Rev Genet. 2006;7:829-840.

2. Schildmeyer LA, Braun R, Taffet G, Debiasi M, Burns AE, Bradley A, Schwartz RJ. Impaired vascular contractility and blood pressure homeostasis in the smooth muscle alpha-actin null mouse. Faseb J. 2000;14:2213-2220.

3. Babu GJ, Loukianov E, Loukianova T, Pyne GJ, Huke S, Osol G, Low RB, Paul RJ, Periasamy $M$. Loss of SM-B myosin affects muscle shortening velocity and maximal force development. Nat Cell Biol. 2001;3:1025-1029.

4. Masuki S, Takeoka M, Taniguchi S, Yokoyama M, Nose H. Impaired arterial pressure regulation during exercise due to enhanced muscular vasodilatation in calponin knockout mice. J Physiol. 2003;553:203-212.

5. Morgan KG, Gangopadhyay SS. Cross-bridge regulation by thin filament-associated proteins. J App/ Physiol. 2001;91:953-962.

6. van der Loop FT, Schaart G, Timmer ED, Ramaekers FC, van Eys GJ. Smoothelin, a novel cytoskeletal protein specific for smooth muscle cells. J Cell Biol. 1996;134:401-411.

7. van der Loop FT, Gabbiani G, Kohnen G, Ramaekers FC, van Eys GJ. Differentiation of smooth muscle cells in human blood vessels as defined by smoothelin, a novel marker for the contractile phenotype. Arterioscler Thromb Vasc Biol. 1997;17:665-671.

8. Johnson JL, van Eys GJ, Angelini GD, George SJ. Injury induces dedifferentiation of smooth muscle cells and increased matrix-degrading metalloproteinase activity in human saphenous vein. Arterioscler Thromb Vasc Biol. 2001;21:1146-1151.

9. Christen $T$, Verin $V$, Bochaton-Piallat $M$, Popowski $Y$, Ramaekers $F$, Debruyne $P$, Camenzind $E$, van Eys $G$, Gabbiani $G$. Mechanisms of neointima formation and remodeling in the porcine coronary artery. Circulation. 2001;103:882-888.

10. Quensel C, Kramer J, Cardoso MC, Leonhardt H. Smoothelin contains a novel actin cytoskeleton localization sequence with similarity to troponin T. J Cell Biochem. 2002;85:403-409.

11. Rensen S, Thijssen V, De Vries C, Doevendans P, Detera-Wadleigh S, Van Eys G. Expression of the smoothelin gene is mediated by alternative promoters. Cardiovasc Res. 2002;55:850.

12. Bar H, Wende P, Watson L, Denger S, van Eys G, Kreuzer J, Jahn L. Smoothelin is an indicator of reversible phenotype modulation of smooth muscle cells in ballooninjured rat carotid arteries. Basic Res Cardiol. 2002;97:9-16.

13. Maeng $M$, Mertz $H$, Nielsen S, Van Eys GJ, Rasmussen K, Espersen GT. Adventitial myofibroblasts play no major role in neointima formation after angioplasty. Scand Cardiovasc J. 2003;37:34-42.

14. Verhamme P, Quarck R, Hao H, Knaapen M, Dymarkowski S, Bernar H, Van Cleemput J, Janssens S, Vermylen J, Gabbiani G, Kockx M, Holvoet P. Dietary cholesterol withdrawal reduces vascular inflammation and induces coronary plaque stabilization in miniature pigs. Cardiovasc Res. 2002;56:135-144.

15. Tharp DL, Wamhoff BR, Turk JR, Bowles DK. Upregulation of intermediateconductance $\mathrm{Ca}^{2+}$-activated $\mathrm{K}+$ channel (IKCa1) mediates phenotypic modulation of coronary smooth muscle. Am J Physiol Heart Circ Physiol. 2006;291:H2493-2503.

16. Hao $H$, Gabbiani $G$, Camenzind $E$, Bacchetta $M$, Virmani R, Bochaton-Piallat ML. Phenotypic modulation of intima and media smooth muscle cells in fatal cases of coronary artery lesion. Arterioscler Thromb Vasc Biol. 2006;26:326-332. 


\section{Chapter 6}

17. Niessen $P$, Rensen $S$, van Deursen J, De Man J, De Laet $A$, Vanderwinden JM, Wedel T, Baker D, Doevendans P, Hofker M, Gijbels M, van Eys G. Smoothelin-a is essential for functional intestinal smooth muscle contractility in mice. Gastroenterology. 2005;129:1592-1601.

18. Raat NJ, Wetzels GE, De Mey JG. Calcium-contraction relationship in rat mesenteric arterial smooth muscle. Effects of exogenous and neurogenic noradrenaline. Pflugers Arch. 1998;436:262-269.

19. Janssen BJ, Leenders PJ, Smits JF. Short-term and long-term blood pressure and heart rate variability in the mouse. Am J Physiol Regul Integr Comp Physiol. 2000;278:R215225.

20. Ruff J, Wiesmann F, Hiller KH, Voll S, von Kienlin M, Bauer WR, Rommel E, Neubauer S, Haase A. Magnetic resonance microimaging for noninvasive quantification of myocardial function and mass in the mouse. Magn Reson Med. 1998;40:43-48.

21. Franco F, Dubois SK, Peshock RM, Shohet RV. Magnetic resonance imaging accurately estimates LV mass in a transgenic mouse model of cardiac hypertrophy. Am J Physiol. 1998;274:H679-683.

22. Heijman E, de Graaf W, Niessen P, Nauerth A, van Eys G, de Graaf L, Nicolay K, Strijkers GJ. Comparison between prospective and retrospective triggering for mouse cardiac MRI. NMR Biomed. 2007;20:439-447.

23. Du YP, Parker DL, Davis WL, Cao G. Reduction of partial-volume artifacts with zerofilled interpolation in three-dimensional MR angiography. J Magn Reson Imaging. 1994;4:733-741.

24. Buus CL, Pourageaud F, Fazzi GE, Janssen G, Mulvany MJ, De Mey JG. Smooth muscle cell changes during flow-related remodeling of rat mesenteric resistance arteries. Circ Res. 2001;89:180-186.

25. Rensen SS, Niessen PM, Long X, Doevendans PA, Miano JM, van Eys GJ. Contribution of serum response factor and myocardin to transcriptional regulation of smoothelins. Cardiovasc Res. 2006;70:136-145.

26. Niessen P, Clement S, Fontao L, Chaponnier C, Teunissen B, Rensen S, van Eys G, Gabbiani G. Biochemical evidence for interaction between smoothelin and filamentous actin. Exp Cell Res. 2004;292:170-178.

27. Matthew JD, Khromov AS, McDuffie MJ, Somlyo AV, Somlyo AP, Taniguchi S, Takahashi $K$. Contractile properties and proteins of smooth muscles of a calponin knockout mouse. J Physiol. 2000;529 Pt 3:811-824.

28. Morano I, Chai GX, Baltas LG, Lamounier-Zepter V, Lutsch G, Kott M, Haase H, Bader M. Smooth-muscle contraction without smooth-muscle myosin. Nat Cell Biol. 2000;2:371-375.

29. Marston SB, Redwood CS. The essential role of tropomyosin in cooperative regulation of smooth muscle thin filament activity by caldesmon. J Biol Chem. 1993;268:1231712320.

30. Perry SV. Vertebrate tropomyosin: distribution, properties and function. J Muscle Res Cell Motil. 2001;22:5-49.

31. Mayet J, Hughes A. Cardiac and vascular pathophysiology in hypertension. Heart. 2003;89:1104-1109. 
Chapter 7

\section{Identification of novel smoothelin binding proteins}

Petra Niessen, Janneke Willems, Victor Thijssen, Guillaume van Eys. 


\begin{abstract}
Smoothelins are only expressed in contractile smooth muscle cells and they are increasingly used as marker proteins. Previously, it has been demonstrated that smoothelins co-localize with $\alpha$-smooth muscle actin and directly bind to actin filaments. Furthermore, smoothelin deficiency has been shown to result in impaired smooth muscle contractility. These findings indicate that smoothelins are part of the contractile apparatus of smooth muscle cells, although the way in which they exert their function remains unknown.

To address this issue, we determined which other proteins interact with smoothelin using the yeast two-hybrid system for smoothelin-A (predominantly found in visceral smooth muscle) and smoothelin-B (specific for vascular smooth muscle). Both screens identified a considerable number of candidates, several of which interacted with both smoothelin isoforms. Further analyses focused on galectin-1, a matri-cellular protein, and vimentin, a component of the cytoskeleton. The preliminary results imply smoothelins as potential intermediates between the contractile apparatus and structural cellular elements.
\end{abstract}


Identification of novel smoothelin binding proteins

\section{Introduction}

Since their discovery in 1996, several characteristics of smoothelins have been revealed ${ }^{1}$. Their expression in adults is only present in contractile smooth muscle cells $(S M C s)^{2-4}$. The two major isoforms, which are encoded by a single copy gene, have a tissue-specific expression pattern. Smoothelin-A, a $59 \mathrm{kDa}$ protein, is mainly found in visceral tissues such as the digestive tract, bladder, uterus and prostate. Smoothelin-B, a $110 \mathrm{kDa}$ protein, is only expressed in vascular tissues ${ }^{5}$. During vascular remodeling as well as under pathological conditions with impaired smooth muscle function, like in restenosis and aneurysms, expression of smoothelins rapidly decreases, either temporarily or definitive ${ }^{2,6-11}$. These characteristics have put smoothelins forward as widely used markers of the contractile smooth muscle phenotype.

Under physiological conditions, smoothelins have been shown to physically bind to $\alpha$-smooth muscle actin ( $\alpha$-SMA) filaments in vitro ${ }^{12}$. This was in agreement with earlier immunohistochemical findings showing co-localization of smoothelins and $\alpha$-SMA stress fibers in cultured SMCs, ${ }^{43}$. Mice deficient in both smoothelin isoforms develop severe intestinal problems due to drastically reduced smooth muscle contraction, resulting in lack of peristalsis and subsequent intestinal obstruction ${ }^{14}$. Smoothelin-B deficient $\left(S m t n-B^{1-}\right)$ mice display a less severe phenotype but develop hypertension and related cardiac hypertrophy ${ }^{15}$. Both mouse strains exhibit a considerable loss of smooth muscle contractile potential and hence impaired smooth muscle function. Together, these data indicate that smoothelins are part of the contractile apparatus of smooth muscle cells, although their exact function is still unknown.

To understand the decreased contractility in the absence of smoothelin in smooth muscle containing organs, additional smoothelin-binding or interacting proteins need to be identified. Furthermore, identification of possible differences in protein binding between smoothelin- $A$ and $-B$ might explain their differential expression and magnitude of impact on smooth muscle cell functioning. This chapter describes the application of the yeast two-hybrid method to identify proteins present in SMCs that bind to either smoothelin- $A$, smoothelin- $B$, or both. From the considerable number of binding proteins, the two most abundantly represented proteins, galectin-1 and vimentin, were selected for further study.

\section{Methods}

\section{Yeast two-hybrid screens}

Yeast two-hybrid screening was performed using the Matchmaker3 system (Clontech, Breda, The Netherlands) according to the manufacturers' instructions. In short, human smoothelin-A and -B cDNAs (NCBI accession 
numbers: smoothelin-A: Z49989; smoothelin-B: NM134270) were cloned into bait vector pGBKT-7 in frame with the GAL4 DNA-binding domain. Each construct was tested for absence of transcriptional activation and toxicity. A smooth muscle cDNA library was constructed with SMART III and CDS III oligo(dT) primers using total RNA isolated from human internal thoracic artery cells (HITB5), grown under serum-deprived conditions ${ }^{16}$. HITB5 cells are maturation competent and upon serum withdrawal they differentiate to the contractile phenotype and express both smoothelin-A and-B proteins ${ }^{17}$.

Previous to all screens the phenotype of yeast strain AH109 was verified. Smoothelin-A and -B were used in separate screens with the constructed library by co-transformation with the linearized prey vector (pGADT7), containing the GAL4 transcription activation domain. Following transformation, cells were incubated for 6 days at $30^{\circ} \mathrm{C}$ on selection plates lacking the amino acids histidine, leucine and tryptophane $(-H L T)$. Subsequently, colonies were transferred to more stringent selection plates lacking the amino acids histidine, arginine, leucine and tryptophane (-HALT). To exclude false positive interactions, this selection was performed four times. During the last two selection rounds $X$ $\alpha-G A L$ was added to the medium as an additional control for interaction. The inserted CDNAs of positive yeast colonies were PCR amplified using primers complementary to sequences flanking the insertion site of the pGADT7 plasmid. Amplified DNA fragments were sequenced using an automatic DNA-sequencer (AbiPrism377, Applied Biosystems, Nieuwerkerk aan de IJssel, The Netherlands). Obtained sequences were BLASTed against the human genome (www.ncbi.nlm.nih.gov/blast/). Finally, pGADT7 plasmids from 11 positive yeast colonies were isolated using CHROMA SPIN-1000 columns (Clontech) and amplified in E.Coli strain DH5 $\alpha$. After verification by sequencing the plasmid DNA was retransformed into yeast cells with either smoothelin-A or -B constructs and plated on -HALT medium to confirm positive interaction.

\section{Mapping of the galectin-1 binding domain}

Galectin-1 deletion constructs lacking respectively 8 and 26 amino acids at the C-terminus (Gal1-C $\Delta 8$ and Gal1-C $\Delta 26$ ) were PCR amplified from full length galectin-1 CDNA using specific primers flanked with restriction enzyme recognition sites (Ndel-gal1 Forward: AAACATATGATGGCTTGTGGTCTGG; gal1dC8-Xbal Reverse: AAATCTAGATGAAGTCACCGTCAGCTG; gal1dC26-Xbal Reverse: AAATCTAGAGGGAACTTGAATTCGTATC). PCR fragments were directionally cloned into the pGADT7 plasmid using the appropriate restriction enzymes. Full length galectin 3 CDNA was obtained by PCR amplification of CDNA from human umbilical vein endothelial cells.

Confirmation of interaction between smoothelin-A or $-B$ and galectin-1 or 3 or their derivatives was performed by targeted transformation of the specific 
Identification of novel smoothelin binding proteins

constructs using the small-scale yeast transformation protocol provided by the manufacturer (Clontech).

\section{Immunohistochemistry}

Hearts from wild-type $\left(\mathrm{Gal}_{-1} 1^{+/+}\right)$and galectin-1 deficient $\left(\mathrm{Gal}--^{-1 /}\right)^{18}$ were dissected, snap-frozen in liquid nitrogen and embedded in Tissue-Tek (Sakura, Zoeterwoude, Netherlands). Cryostat sections were fixed in ice-cold aceton/methanol (v/v: 50/50), dried and blocked with $10 \%$ normal goat serum. Smoothelin was stained using a rabbit polyclonal antiserum (see chapter 6) followed by goat-anti-rabbit conjugated with Texas Red (DAKO) in $5 \%$ normal goat serum. Sections were mounted in Vectashield (Vector, Burlingame, CA) containing DAPI.

\section{Quantitative reverse transcriptase-polymerase chain reaction (qRT-PCR)}

Total RNA was extracted from pooled aorta and femoral arteries from $6 \mathrm{Smtn}$ $B^{+/+}$and 6 Smtn- $B^{-/}$mice with Tri reagent (Sigma-Aldrich, Zwijndrecht, The Netherlands). Reverse transcription was performed using the iscript cDNA synthesis kit (Biorad, Veenendaal, The Netherlands) with $0.5 \mu \mathrm{g}$ of RNA. Expression of galectin-1, vimentin and cyclophilin $A$ was investigated by quantitative real-time PCR using the $A B I$ Prism 7700 System (Perkin Elmer, Norwalk, Connecticut). Applied primers are listed in table 7.1. The cyclophilin A transcript was used to normalize the amount and quality of the extracted RNA. Expression levels of $S m+n-B^{+/+}$mice were set at 1.

Table 7.1 Oligonucleotide sequence of primers used for qRT-PCR.

\begin{tabular}{lll}
\hline Gene & Forward Primer 5'-3' & Reverse Primer 5'-3' \\
\hline & & \\
Cyclophilin A & TTCCTCCTTCACAGAATTATTCCA & CCGCCAGTGCCATTATGG \\
Galectin-1 & CTCGGACGCCAAGAGCTT & CAATGGTGTTGGCGTCTCC \\
Vimentin & CACCCTGCAGTCATTCAGACA & GATTCCACTTTCCGTTCAAGGT \\
\hline
\end{tabular}

\section{Statistical analysis}

Statistical significance was calculated by Wilcoxon signed rank tests and twotailed paired Student's t-tests using Graphpad Prism software (version 4.0). Groups were considered significantly different when $P<0.05$. Values are expressed as mean \pm standard error of the mean (SEM). 


\section{Results}

\section{Yeast two-hybrid screens}

Screening for interaction with smoothelin-A resulted in 249 clones of which 115 clones survived 4 selection rounds on -HALT medium. Of these 115 clones, 93 could be sequenced and BLAST analysis revealed 25 different unidentified genes and 38 different genes with a known function. The genes identified more than ones are listed in table 7.2. Three genes were found several times, i.e. vimentin ( 9 times; $10 \%$ ), galectin-1 (9 times; $10 \%$ ) and collagen type 1 ( 8 times; $9 \%$ ). Eight genes were selected for further study, being: vimentin, collagen type 1 , tropomyosin-2, gremlin-1, galectin-1, laminin A/C, PDZ/LIM domain 7 and fibrillin-1. The plasmids of the 8 selected genes were isolated and transformed again together with smoothelin-A to confirm positive binding. The results are listed in table 7.3. Only vimentin, galectin-1, PDZ/LIM domain 7 and collagen type 1 remained positive for interaction with smoothelin-A.

Table 7.2 Genes identified more than once in the smoothelin-A screen.

Insert Times identified

$\begin{array}{lc}\text { Vimentin } & 10 \\ \text { Galectin-1 } & 9 \\ \text { Collagen type I } & 8 \\ \text { Metallothionein 2A } & 4 \\ \text { Bac clone RP11-33301 } & 2 \\ \text { CDNA DKFZp78111086 } & 2 \\ \text { CDNA DKFZp781N0678 } & 2 \\ \text { Glyceraldehyde-3-phosphate dehydrogenase } & 2 \\ \text { Guanin nucleotide binding protein } & 2 \\ \text { IMAGE: 4103475 } & 2 \\ \text { Keratin 18 } & 2 \\ \text { Similar to retinitis pigmentosa 9, homolog } & 2 \\ \text { Tropomyosin 2 } & 2\end{array}$

Screening for interaction with smoothelin-B resulted in 452 clones of which 124 clones survived 4 rounds of selection on -HALT medium. Of the 96 sequenced clones, 17 contained unidentified genes while 79 sequences were genes that had been described before. The genes most abundantly represented among the selected clones were galectin-1 (26 times; 27\%), IMAGE: 4103475 ( 5 times; 5\%) and ferritin ( 4 times; $4 \%$ ). The genes identified more than once are listed in table 7.4. In contrast to the smoothelin-A screen in which vimentin and collagen 
type 1 were among the most occurring genes, they only occurred twice in the smoothelin-B screen.

To compare smoothelin-A versus smoothelin-B binding and to verify both screens, the plasmids isolated from the 8 selected clones of the smoothelin-A screen were also retransformed together with smoothelin-B (table 7.3). This confirmed that 1) the smoothelin-B screen was valid, since the proteins that only showed up in the smoothelin-A screen did not bind to smoothelin-B and that 2) except for vimentin, all proteins showing binding with smoothelin-A did also bind to smoothelin-B.

Table 7.3 Screening results of targeted transformation for positive interaction with smoothelin- $A$ and $-\mathrm{B}$.

\begin{tabular}{|c|c|c|c|c|}
\hline \multirow[b]{2}{*}{ Insert } & \multicolumn{2}{|c|}{ Smoothelin-A } & \multicolumn{2}{|c|}{ Smoothelin-B } \\
\hline & Survival & $\mathrm{X}$-Gal staining & Survival & X-Gal staining \\
\hline Vimentin * & + & blue & $+/-$ & $*$ \\
\hline Galectin-1 * & + & blue & + & blue \\
\hline Gremlin $^{\#}$ & - & - & 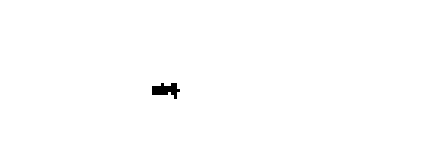 & - \\
\hline Collagen type $1 *$ & + & blue & + & blue \\
\hline PDZ+Lim domain 7 & + & blue & + & blue \\
\hline $\operatorname{Lamin} A / C^{\#}$ & - & - & - & - \\
\hline Fibrillin $\#$ & + & - & $+/-$ & - \\
\hline Tropomyosin-2 * & - & - & - & - \\
\hline
\end{tabular}

* Found in both smoothelin-A and -B screen

\# Found only in smoothelin-A screen

Table 7.4: Genes identified more than once in the smoothelin-B screen.

Insert $\quad$ Times identified

$\begin{array}{lc}\text { Galectin-1 } & 26 \\ \text { IMAGE: } 4103475 & 5 \\ \text { Ferritin heavy polypeptide 1 } & 4 \\ \text { Ribosomal protein S2 } & 4 \\ \text { Tropomyosin 2 } & 3 \\ \text { Collagen type 1 } & 2 \\ \text { High density lipoprotein binding protein } & 2 \\ \text { Metallothioneine 2A } & 2 \\ \text { Myosin light polypeptide 6 alkali } & 2 \\ \text { Ribosomal protein S3A } & 2 \\ \text { Small nuclear ribonucleoprotein polypeptide G } & 2 \\ \text { Ubiquitin C } & 2 \\ \text { Vimentin } & 2\end{array}$


Amino acids 88-109 of galectin-1 are required for interaction with smoothelins. Galectin-1 was the protein most abundantly present in both screens and showed interaction with both smoothelins. Next to full length galectin-1, also several $\mathrm{N}$-terminal truncated galectin-1 inserts were identified. The smallest binding galectin- 1 sequences from the smoothelin- $A$ and $-B$ screen comprised amino acids 74 to 136 and 88 to 136 respectively. To further define the nature of the binding and to position the possible binding site, deletion constructs lacking respectively 8 and 26 amino acids at the C-terminus (Gal1-C $\Delta 8$ and Gal1$C \Delta 26)$ were constructed. These constructs were tested for interaction with both smoothelin-A and -B. To rule out non-specific binding to the galectin family, galectin-3 was used as a negative control. Galectin 3 did not bind to either of the smoothelins, while both galectin-1 deletion constructs still showed interaction (figure 7.1). This narrowed the binding site to galectin-1 residues 88 109 (figure 7.1).

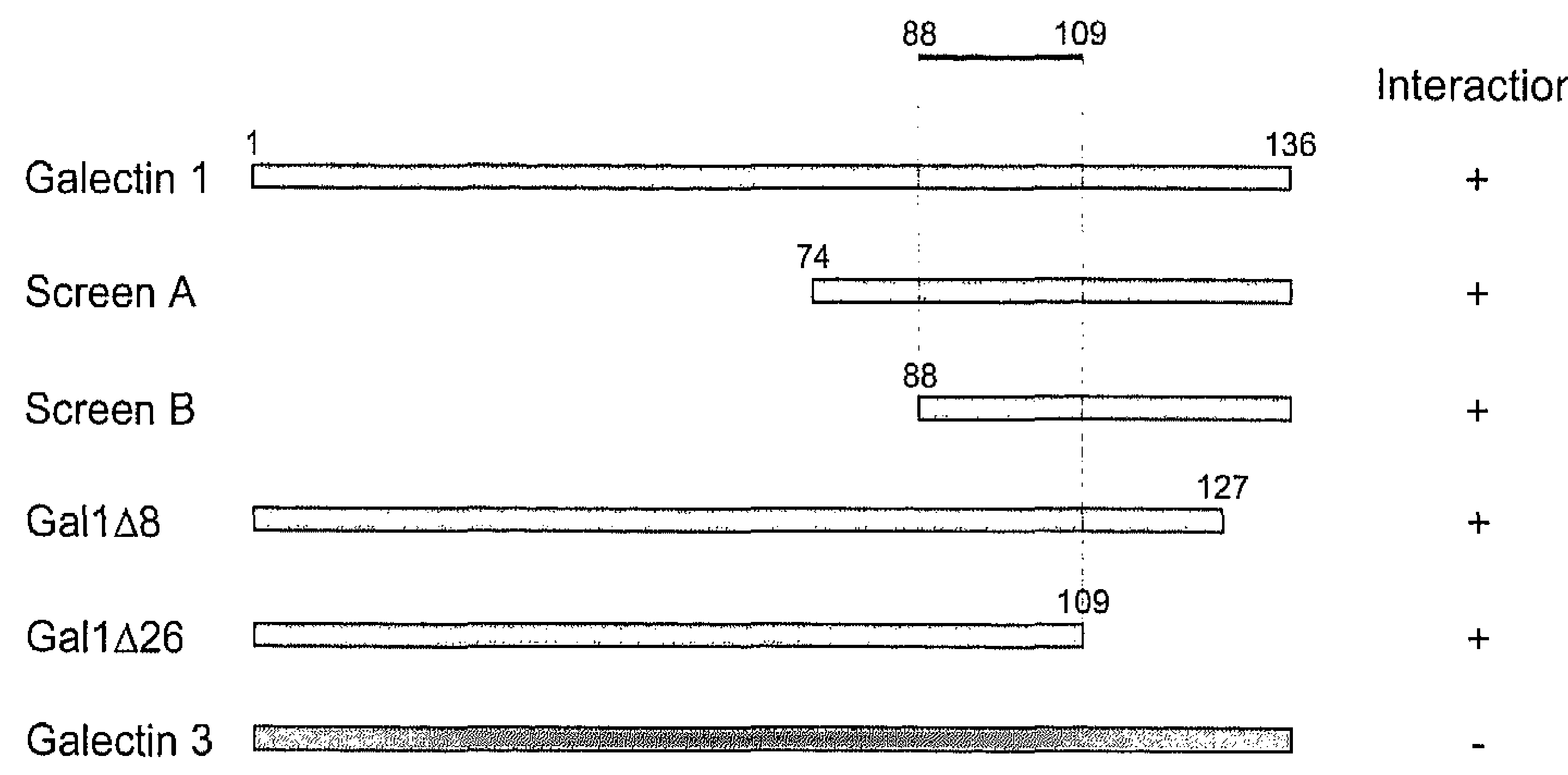

Figure 7.1 Mapping of the galectin-1 binding domain. Galectin-1 C-terminal deletion constructs (GAL1-C $\triangle 8$ and GAL1-CD26) narrowed the interaction binding site to amino acids 88-109. Galectin 3 , used as a negative control, did not interact.

Visualization of the three dimensional structure of galectin-1 residues 88-109 showed that these amino acids are located at a site accessible for interaction with other proteins (figure 7.2). 


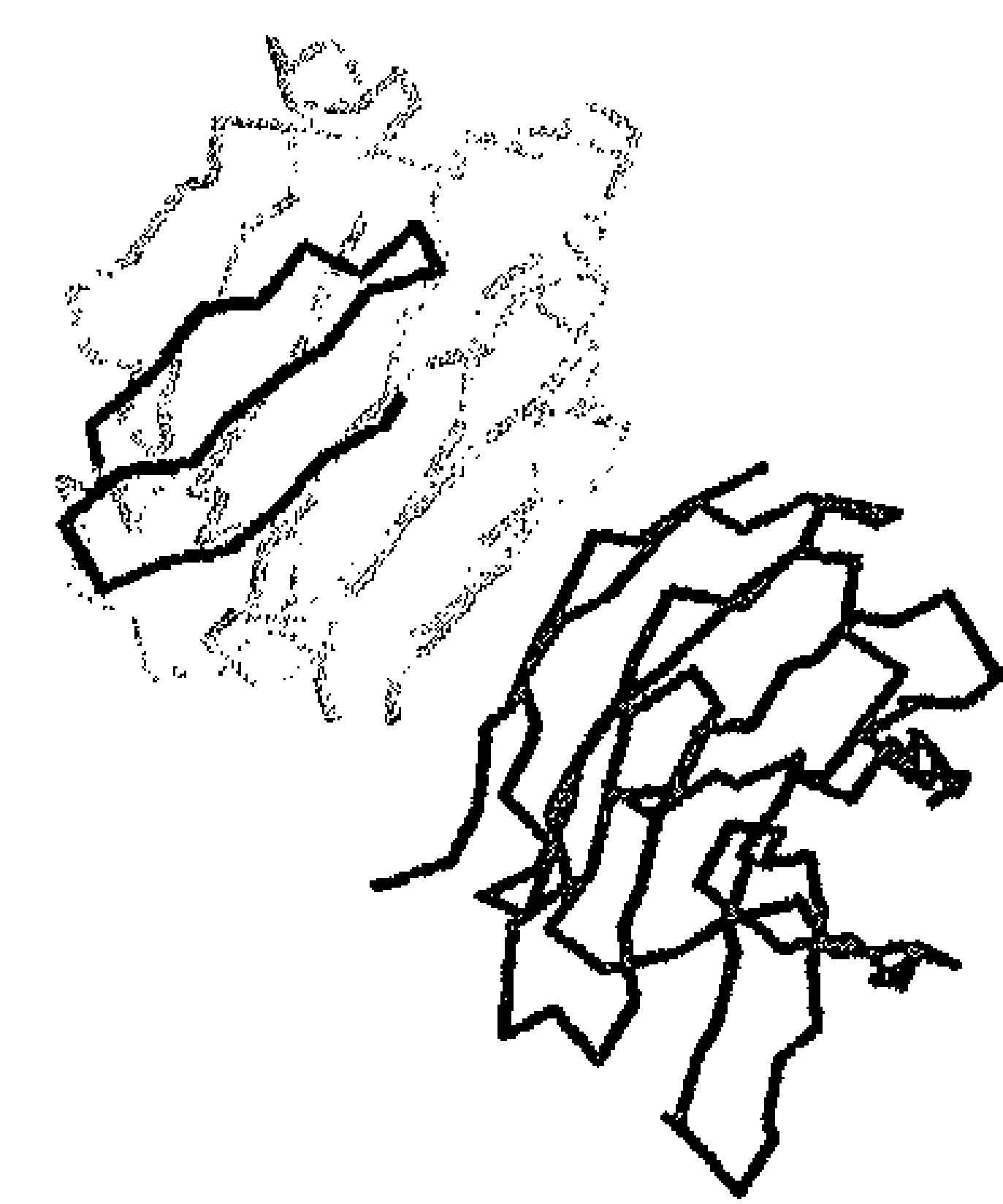

Figure 7.2 Three dimensional view of the galectin-1 tertiary protein structure showing both parts of the galectin-1 dimer in blue and purple respectively. Amino acids 88-109, shown in brown, are located at the outside of the protein. See back cover for color picture.

Galectin-1 and vimentin expression levels are not altered in the vasculature of smoothelin-B deficient mice.

Deficiency of smoothelin-B may affect the expression of interacting proteins. Therefore, we examined the expression levels of galectin-1 and vimentin in blood vessels of smoothelin-B deficient mice by quantitative RT-PCR analysis. The expression of these proteins was not significantly changed at the RNA level (figure 7.3). Also, smoothelin staining of hearts of $\mathrm{Gal}-1^{+/+}$and $\mathrm{Gal}-1^{1 /}$ mice revealed no difference in staining pattern or intensity in the smooth muscle cells of coronary arteries (figure 7.4).

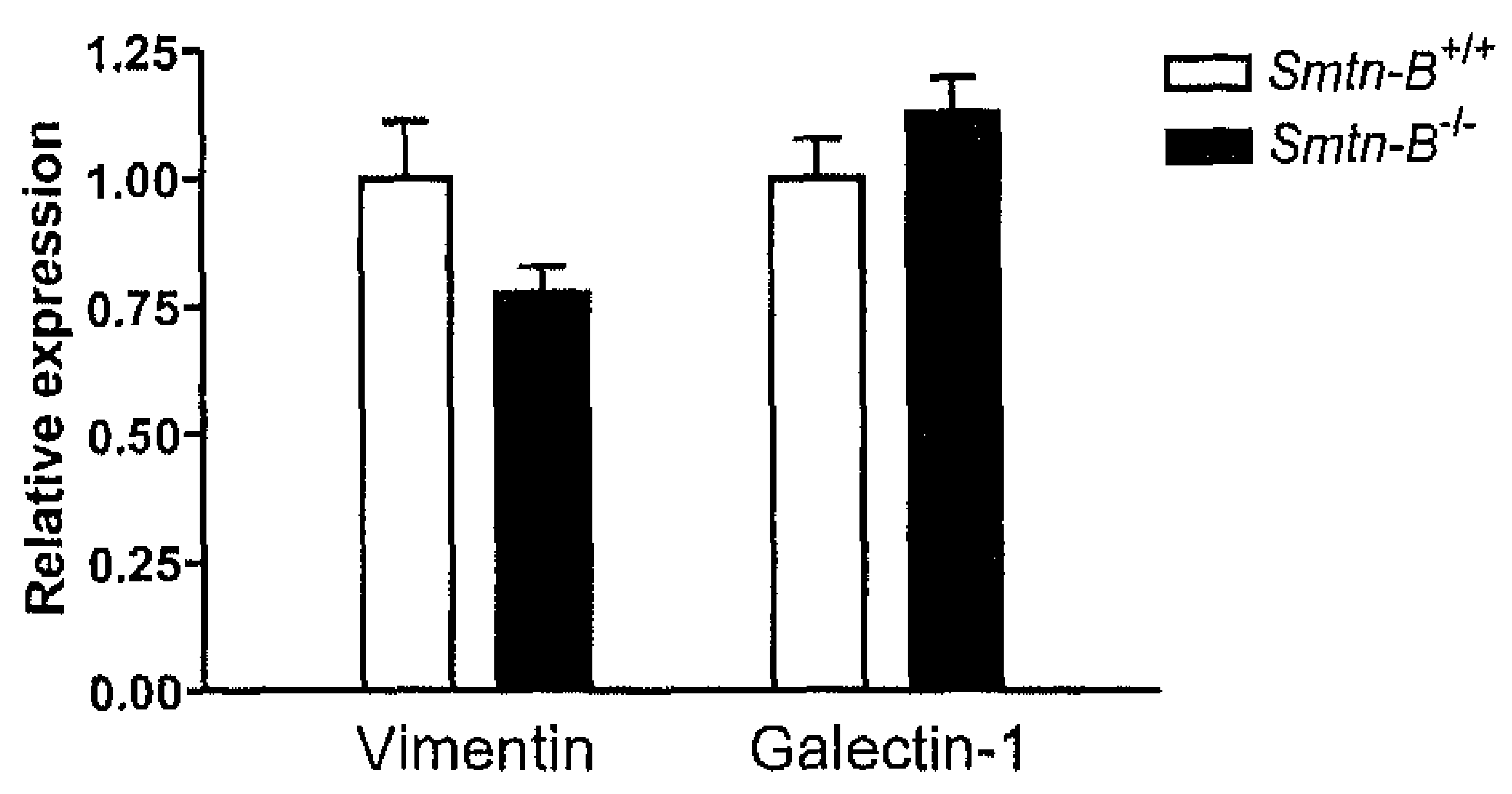

Figure 7.3 Expression of galectin-1 and vimentin was measured by quantitative RT-PCR. Levels were normalized for cyclophilin $A$ expression and $S m t n-B^{+/+}$levels were set at 1 . There was no significant change in expression levels between $S m t n-B^{+/+}$and $S m t n-B^{-1-}$ mice. 

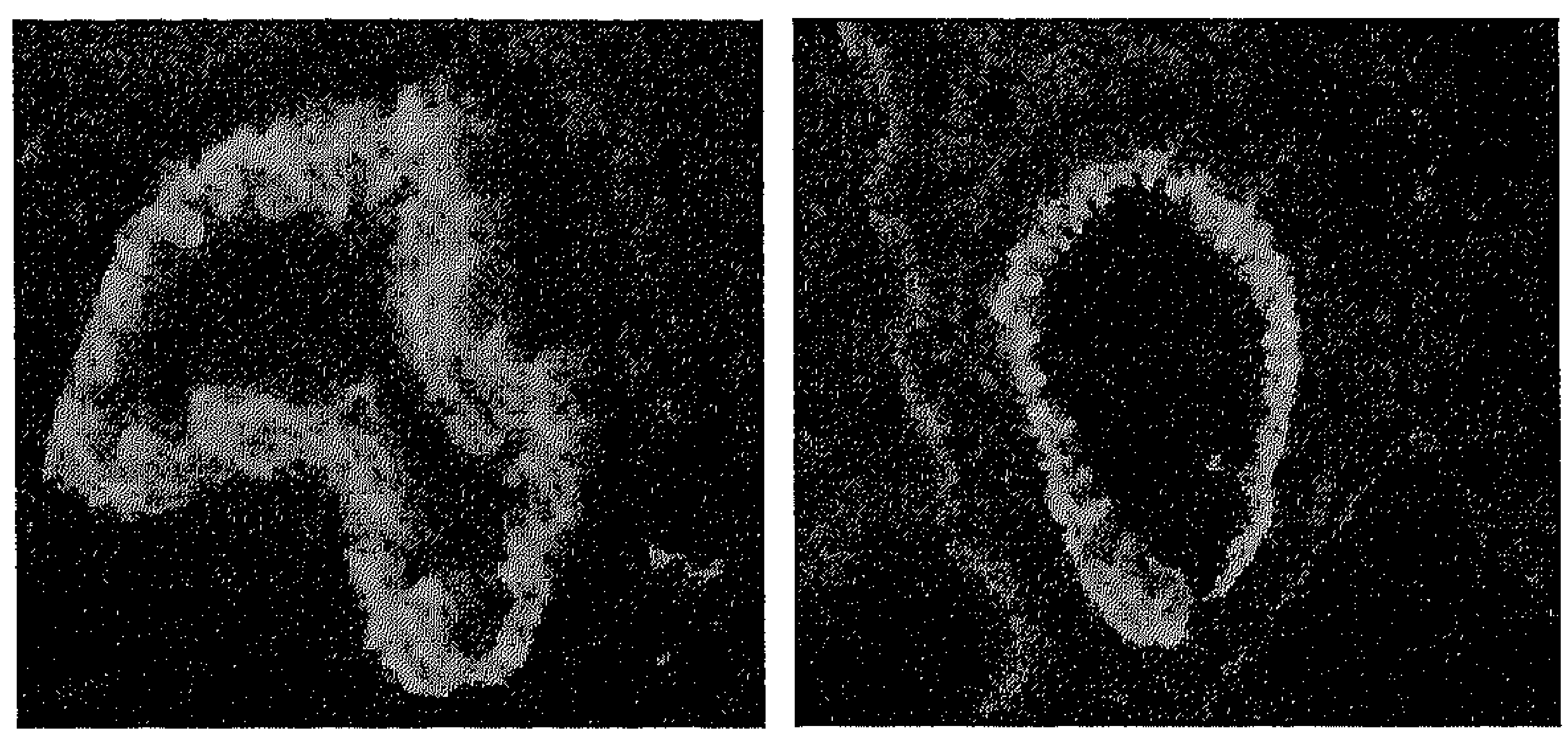

Figure 7.4 Representative immunohistochemical stainings of smoothelin in coronary arteries in hearts of Gal-1\% (left panel) and Gal-1 ${ }^{+/+}$(right panel) mice, showing no differences between the genotypes. See front cover for color pictures.

\section{Discussion}

The function of smoothelins in smooth muscle contraction is likely to be determined by their interaction with components of the contractile apparatus and/or the cytoskeleton. Previously, we established that smoothelins can bind to actin filaments. The calponin homology domain at the C-terminal end of both smoothelin-A and $-B$ appears to be involved, but other domains are required to strengthen the binding ${ }^{12}$. Since the two smoothelin isoforms have different $\mathrm{N}$ terminal ends, proteins binding to smoothelin-B specific domains may reveal a functional difference between smoothelin-A and $-B$.

In this study, using a yeast two-hybrid system, we identified interactions between smoothelins and a large number of proteins. For further analysis we focused on the two most abundantly represented molecules: galectin-1 and vimentin.

Galectin-1 is member of a protein family sharing a carbohydrate recognition domain which is responsible for $\beta$-galactoside binding ${ }^{19}$. The $14 \mathrm{kDa}$ protein forms a homodimer and is expressed in cells of mesodermal origin. It is particularly abundant in skeletal, cardiac and smooth muscle. Being a matricellular protein, galectin-1 is found in both the intracellular and extracellular compartments. However, its localization is predominantly intracellular, where it is distributed diffusely in the cytoplasm ${ }^{20}$. Intracellularly, galectin-1 interactions are mainly protein mediated in stead of carbohydrate based.

Galectin-1 has demonstrated a wide range of functions ${ }^{21,22}$. Depending on the circumstances and cell types, it may act as a mitogen, as an inhibitor of cell proliferation, or as a promoter of apoptosis ${ }^{23}$. In cultured vascular smooth muscle cells, galectin-1 affects cell adhesion and inhibits cell migration by interacting with $\alpha 1 \beta 1$ integrins and the extracellular matrix (ECM) proteins 
laminin and cellular fibronectin ${ }^{24}$. In addition, galectin-1 protein expression is up-regulated during cell growth ${ }^{25}$. Furthermore, galectin-1 mediated cross-talk between the cell surface and the ECM modulates cell morphology and rearrangement of actin filaments ${ }^{25,26}$.

The fact that galectin-1 interacts with several structural elements in SMCs implies that it might act as an intermediate in connecting SMC proteins to smoothelins. Previously, it has been suggested that smoothelins confer antiproliferative properties to SMCs because of their contractile SMC-specificity and the difficulties in creating a stably transfected cell line ${ }^{12}$. Integration of smoothelins into cellular structures by galectin-1 may establish a structure that stabilizes the contractile apparatus, which counteracts modulation towards a proliferative phenotype. On the other hand, galectin-1 upregulation during SMC proliferation may cause scavenging of smoothelins from the contractile filaments through a competition mechanism, thereby leading to the observed rearrangement of actin filaments by galectin-1. Expanding our knowledge about the function and binding site(s) of smoothelins and galectin-1 is necessary to clarify the biological relevance of the interaction between both proteins.

Vimentin, a $55 \mathrm{kDa}$ intermediate filament protein, is abundantly expressed in cells of mesenchymal origin. Based on observations in different cell types and during developmental stages, numerous functions have been ascribed to vimentin. An overall function, however, has remained elusive. As a part of the cytoskeleton, vimentin serves a stabilizing role as intracellular scaffold, it is involved in signaling associated processes and forms associations with components of the cytoskeleton and membrane adhesions ${ }^{27-30}$ (recent reviews ${ }^{31,32}$ ).

Previously, smoothelin-A has been shown to co-sediment with intermediate filamentous proteins after differential centrifugation of intestinal smooth muscle ${ }^{4}$. However, transfection experiments with smoothelin-A in muscle cells revealed co-localization with $\alpha$-SMA but not with intermediate filaments. On the other hand, in the absence of $\alpha$-SMA filaments, like for example COS-7 cells, smoothelins are organized into a network resembling the structure of vimentin filaments. However, these smoothelin and vimentin networks do not colocalize ${ }^{4}$. Now, the result of the yeast two-hybrid assay indicates that the two proteins, although they do not co-localize, may be connected.

Other studies have revealed proteins that connect the cytoskeleton to other structural cellular components. For example, plectin, a filament associated protein, has been shown to cross-link vimentin to microtubules, microfilaments and membrane adhesions ${ }^{30}$. A similar role for smoothelin-A, cross-linking $\alpha$-SMA to vimentin, is likely, thereby linking the contractile filaments to the cytoskeleton. Smoothelin deficiency decreases smooth muscle contractility ${ }^{14,15}$. Interestingly, absence of vimentin in fibroblasts also impairs their contractile 
capacity and downregulation of vimentin in smooth muscle inhibits passive tension and active force development ${ }^{33}$.

Although vimentin occurred twice in the smoothelin-B screen, cotransformation of vimentin and smoothelin-B did not show interaction. The difference between the initial screen and the direct co-transformation is the degree of stringency of the selection plates (-HLT for the screen and -HALT for the co-transformation). This indicates that the interaction of smoothelin-B with vimentin is weaker compared with smoothelin-A. A possible explanation for the weaker interaction is that the smoothelin-B specific part of the protein may interfere with the binding of vimentin, either because of steric hindrance or shifts in electrical charge, influencing the polarity of the molecular domains.

Interestingly, tropomyosin 2 was found to interact with both smoothelins, but only in the initial screens. This might be significant in light of the homology of a smoothelin domain with a region of troponin $T$ that is involved in interaction with tropomyosin ${ }^{34}$. The lack of binding in the more stringent screening might indicate that the interaction is weak or is stabilized by other proteins like for example $\alpha$-SMA.

Despite the fact that it has been shown in vitro that smoothelins co-localize with stress fibers and can bind to $\alpha$-SMA filaments ${ }^{12}$, no interaction between $\alpha$-SMA and either smoothelin isoform was found in the yeast two-hybrid screen. This illustrates one of the limitations of the yeast two-hybrid system. Although often used to identify novel protein interactions, the yeast two-hybrid system does not resemble the eukaryotic in vivo situation completely. The globular form of $\alpha$-SMA synthesized by the yeast from the plasmid is not processed into actin filaments, and as we have shown previously, smoothelins do not bind to the globular form of actin ${ }^{12}$.

Because of the solid interaction data for vimentin and galectin-1, it is possible that the expression levels of these proteins are co-determined by the availability of smoothelin-A or-B. However, in smoothelin-B deficient mice expression levels of either galectin-1 or vimentin did not change. This indicates that there is no direct feedback mechanism at the gene expression level. However, protein concentrations may be regulated post-transcriptionally and the absence of effects at the mRNA level needs to be confirmed at the protein level.

To further validate the interaction between smoothelins and either galectin-1 or vimentin, their interaction needs to be confirmed in vivo by showing colocalization in tissues and in tissue lysates by immuno-precipitation and immuno-staining. Furthermore, it would be interesting to study the localization of both galectin-1 and vimentin in smooth muscle tissues of smoothelin deficient mice. 
Taken together, these preliminary results identify galectin- 1 and vimentin as potential binding partners of smoothelins and imply smoothelins as potential intermediates between the contractile apparatus and structural cellular elements.

\section{Acknowledgements}

This work was supported by a Kootstra fellowship granted to PN. The authors would like to thank Dr. L Baum (UCLA) for providing the galectin-1 antibody. 


\section{References}

1. Van Eys GJ, Niessen PM, Rensen SS. Smoothelin in vascular smooth muscle cells. Trends Cardiovasc Med. Jan 2007;17(1):26-30.

2. Christen $T$, Verin $V$, Bochaton-Piallat $M L$, et al. Mechanisms of neointima formation and remodeling in the porcine coronary artery. Circulation. 2001;103(6):882-888.

3. van der Loop FT, Gabbiani G, Kohnen $G$, et al. Differentiation of smooth muscle cells in human blood vessels as defined by smoothelin, a novel marker for the contractile phenotype. Arterioscler. Thromb. Vasc. Biol. 1997;17(4):665-671.

4. van der Loop FT, Schaart G, Timmer ED, et al. Smoothelin, a novel cytoskeletal protein specific for smooth muscle cells. J. Cell Biol. 1996;134(2):401-411.

5. Rensen S, Thijssen V, De Vries C, et al. Expression of the smoothelin gene is mediated by alternative promoters. Cardiovasc. Res. 2002;55(4):850-863.

6. Bar $H$, Wende $P$, Watson $L$, et al. Smoothelin is an indicator of reversible phenotype modulation of smooth muscle cells in balloon-injured rat carotid arteries. Basic Res Cardiol. Jan 2002;97(1):9-16.

7. Hao H, Gabbiani $G$, Camenzind $E$, et al. Phenotypic modulation of intima and media smooth muscle cells in fatal cases of coronary artery lesion. Arterioscler Thromb Vasc Biol. Feb 2006;26(2):326-332.

8. Maeng $M$, Mertz $H$, Nielsen $S$, et al. Adventitial myofibroblasts play no major role in neointima formation after angioplasty. Scand Cardiovasc J. 2003;37(1):34-42.

9. Tharp DL, Wamhoff BR, Turk JR, et al. Upregulation of intermediate-conductance $\mathrm{Ca}^{2+}$ activated $\mathrm{K}+$ channel (IKCa1) mediates phenotypic modulation of coronary smooth muscle. Am J Physiol Heart Circ Physiol. Jun 232006.

10. van der Heijden $O W$, Essers $Y P$, Fazzi $G$, et al. Uterine artery remodeling and reproductive performance are impaired in endothelial nitric oxide synthase-deficient mice. Biol Reprod. May 2005;72(5):1161-1168.

11. Verhamme P, Quarck $\mathrm{R}, \mathrm{Hao} \mathrm{H}$, et al. Dietary cholesterol withdrawal reduces vascular inflammation and induces coronary plaque stabilization in miniature pigs. Cardiovasc Res. Oct 2002;56(1):135-144.

12. Niessen $P$, Clement $S$, Fontao $L$, et al. Biochemical evidence for interaction between smoothelin and filamentous actin. Exp Cell Res. Jan 1 2004;292(1):170-178.

13. Christen $T$, Bochaton-Piallat $M L$, Neuville $P$, et al. Cultured porcine coronary artery smooth muscle cells. A new model with advanced differentiation. Circ. Res. 1999;85(1):99-107.

14. Niessen P, Rensen S, van Deursen J, et al. Smoothelin-a is essential for functional intestinal smooth muscle contractility in mice. Gastroenterology. Nov 2005;129(5):1592-1601.

15. Rensen SSM, Niessen PMG, van Deursen JM, et al. Smoothelin-B deficiency results in severely reduced arterial cantractility, hypertension, and cardiac hypertrophy in mice. Submitted. 2007.

16. Li S, Fan YS, Chow LH, et al. Innate diversity of adult human arterial smooth muscle cells: cloning of distinct subtypes from the internal thoracic artery. Circ. Res. 2001;89(6):517-525.

17. van der Veer E, Nong Z, O'Neil C, et al. Pre-B-cell colony-enhancing factor regulates NAD+-dependent protein deacetylase activity and promotes vascular smooth muscle cell maturation. Circ Res. Jul 8 2005;97(1):25-34. 
18. Poirier F, Robertson EJ. Normal development of mice carrying a null mutation in the gene encoding the L14 S-type lectin. Development. Dec 1993;119(4):1229-1236.

19. Barondes SH, Castronovo V, Cooper DN, et al. Galectins: a family of animal betagalactoside-binding lectins. Cell. Feb 25 1994;76(4):597-598.

20. Liu FT, Patterson RJ, Wang JL. Intracellular functions of galectins. Biochim Biophys Acta. Sep 19 2002;1572(2-3):263-273.

21. Camby I, Le Mercier $M$, Lefranc $F$, et al. Galectin-1: a small protein with major functions. Glycobiology. Nov 2006;16(11):137R-157R.

22. Elola MT, Chiesa ME, Alberti $A F$, et al. Galectin-1 receptors in different cell types. J Biomed Sci. 2005;12(1):13-29.

23. Scott K, Weinberg C. Galectin-1: a bifunctional regulator of cellular proliferation. Glycoconj J. 2004;19(7-9):467-477.

24. Moiseeva EP, Spring EL, Baron JH, et al. Galectin 1 modulates attachment, spreading and migration of cultured vascular smooth muscle cells via interactions with cellular receptors and components of extracellular matrix. J Vasc Res. Jan-Feb 1999;36(1):4758.

25. Moiseeva EP, Javed $Q$, Spring EL, et al. Galectin 1 is involved in vascular smooth muscle cell proliferation. Cardiovasc Res. Jan 14 2000;45(2):493-502.

26. Moiseeva EP, Williams B, Goodall AH, et al. Galectin-1 interacts with beta-1 subunit of integrin. Biochem Biophys Res Commun. Oct 24 2003;310(3):1010-1016.

27. Evans RM. Vimentin: the conundrum of the intermediate filament gene family. Bioessays. Jan 1998;20(1):79-86.

28. Georgatos SD, Maison C. Integration of intermediate filaments into cellular organelles. Int Rev Cytol. 1996;164:91-138.

29. Seifert GJ, Lawson D, Wiche G. Immunolocalization of the intermediate filamentassociated protein plectin at focal contacts and actin stress fibers. Eur J Cell Biol. Oct 1992;59(1):138-147.

30. Svitkina $T M$, Verkhovsky $A B$, Borisy GG. Plectin sidearms mediate interaction of intermediate filaments with microtubules and other components of the cytoskeleton. J Cell Biol. Nov 1996;135(4):991-1007.

31. Chang L, Goldman RD. Intermediate filaments mediate cytoskeletal crosstalk. Nat Rev Mol Cell Biol. Aug 2004;5(8):601-613.

32. Ivaska J, Pallari HM, Nevo J, et al. Novel functions of vimentin in cell adhesion, migration, and signaling. Exp Cell Res. Jun 10 2007;313(10):2050-2062.

33. Wang R, Li Q, Tang DD. Role of vimentin in smooth muscle force development. Am J Physiol Cell Physiol. Sep 2006;291(3):C483-489.

34. Quensel C, Kramer J, Cardoso MC, et al. Smoothelin contains a novel actin cytoskeleton localization sequence with similarity to troponin T. J. Cell. Biochem. 2002;85(2):403-409. 
Chapter 8

General Discussion 
One of the most remarkable characteristics of smooth muscle is the lack of terminal differentiation. In vitro, smooth muscle cells (SMCs) have a strong tendency to modulate to a synthetic phenotype. This complicates the investigation of phenotype specific proteins like smoothelins and indicates the use of genetically manipulated mouse models. In this thesis both in vitro and in vivo studies have been implemented to unravel the function of smoothelins. In vitro experiments have been used to characterize expression, distribution, and interaction characteristics of smoothelin in cells, whereas mouse models have been employed to investigate the consequences of smoothelin deficiency for contraction in various smooth muscle tissues.

\section{Interaction of smoothelin with other proteins}

Immunohistochemical observations showed co-localization of smoothelins and $\alpha$-smooth muscle actin ( $\alpha$-SMA) stress fibers in SMCs ${ }^{1,2}$. We extended this work by demonstrating that, under physiological conditions, smoothelins are able to bind to $\alpha$-SMA filaments (chapter 3 ). Like other $\beta$-spectrin family members (e.g. $\alpha$-actinin and dystrophin), smoothelins bind to the filamentous form of actin ( $F$ actin), but not to globular actin (G-actin). From these observations we deduced that smoothelins are not involved in the promotion or acceleration of actin polymerization. Rather, smoothelins could be implicated in contraction by affecting actin filament rigidity or actin bundle stabilization. Another possibility is that smoothelins contribute to contraction by acting as an intermediate between actin filaments and other components of the cytoskeleton. The latter suggestion is supported by the co-sedimentation of smoothelin-A with intermediate filament proteins during differential centrifugation of intestinal smooth muscle ${ }^{2}$. Moreover, the yeast two-hybrid screen described in chapter 7 identified vimentin as a potential smoothelin binding protein. However, transfection experiments with smoothelin-A in rat embryonic fibroblasts revealed co-localization with $\alpha$-SMA but not with intermediate filaments (chapter 3). On the other hand, in the absence of $\alpha$-SMA filaments, like for example in COS-7 cells, smoothelins are organized into a network resembling the structure of intermediate filaments ${ }^{2}$. This indicates that smoothelin and vimentin may be connected and suggests that smoothelin may either link actin and vimentin or stabilize this interaction, thereby mediating cytoskeletal crosstalk.

The calponin homology domain at the C-terminal end of both smoothelin-A and $-B$ is involved in the binding with actin filaments. However, sequences located upstream of the $\mathrm{CH}$ domain appear to stabilize the association of smoothelin with actin by providing additional binding sites to actin (chapter 3). More specifically, a region of smoothelin-B encompassing residues 535-682 
(upstream of the $\mathrm{CH}$ domain) has the ability to co-distribute with actin in NIH3T3 fibroblasts ${ }^{3}$. Furthermore, as shown by Quensel et al, smoothelins contain a 37 amino acid sequence that displays homology to the tail domain of troponin $\mathrm{T}^{3}$. In skeletal muscle, this domain is not only required for troponin $\mathrm{T}$ interaction with tropomyosin, but also involved in activation of actomyosin ATPase ${ }^{4}$. Therefore, smoothelins might be part of a structure resembling the tropomyosin-troponin system of skeletal muscle. The increased strength of the binding to actin by smoothelin containing these troponin-like sequences supports this idea (chapter 3). Interestingly, tropomyosin was one of the proteins that was identified in both the smoothelin-A and smoothelin-B yeast two-hybrid screens (chapter 7). However, targeted transformations under the most stringent conditions could not confirm the interaction between smoothelin and tropomyosin. This may indicate that the binding is weaker compared to vimentin. Additional tests, like for example immunoprecipitations, are necessary to investigate the suggested hypothesis. In summary, these data indicate a role of smoothelins in the contractile apparatus on the one hand and a function as a connector of contractile and cytoskeletal structures on the other hand.

\section{Smoothelins and smooth muscle cell proliferation}

During blood vessel remodeling, a process accompanied by SMC modulation, concentrations of smoothelins decrease transiently. After reaching a new, stable situation, smoothelin concentrations return to previous levels. This has been demonstrated in physiological conditions such as those encountered in the uterine artery during pregnancy ${ }^{5}$, but also when the vessel wall is compromised by disease or malfunctioning, as is the case in aneurysms and during restenosis. In vitro, the moment smooth muscle cells are brought into culture, they start to modulate towards a synthetic proliferative phenotype. During this process, smoothelin expression is rapidly down-regulated as well. These characteristics make smoothelin not only the best marker of the contractile smooth muscle phenotype, but also imply that to start proliferation, SMCs have to go through a series of events that include shutdown of smoothelin expression. This concept is supported by the fact that attempts to establish SMC lines stably transfected with smoothelins were unsuccessful ${ }^{6}$. Although the number of transfected cells was normal, the presence of smoothelin appeared to interfere with proliferation, since transfected cells became senescent and disappeared during further culturing (chapter 3 ). This suggests that the presence of smoothelin may lock SMCs in the contractile phenotype, possibly by formation, regulation or stabilization of contractile structures in SMCs, which interfere with cell division. A similar mechanism has also been suggested for caldesmon ${ }^{7,8}$. Such a 
mechanism could be investigated by transfecting primary SMCs with constructs in which smoothelin expression is activated when the cells modulate towards the proliferative phenotype. This could be achieved by using promoters from proteins specific for the proliferative smooth muscle phenotype, like osteopontin or the embryonic form of myosin (Smemb), to drive smoothelin expression. If the modulation ends prematurely or the cells stop dividing this will confirm our hypothesis.

\section{Smoothelin function in vivo}

The actin binding properties of smoothelin and the specific expression in contractile SMCs suggested a function for smoothelin in smooth muscle contraction. To develop a more adequate concept of this function, we decided to generate smoothelin-deficient mice. This was complicated by the possible existence of two physically separated promoters for smoothelin-A and -B, which had already been shown for the human smoothelin gene. Therefore, we studied the mouse smoothelin promoter in more detail (chapter 4). These analyses confirmed that, like the human gene, the mouse smoothelin gene contains two separate promoters. Moreover, we showed that both promoters differ from most of the promoters of other genes that are specifically expressed in smooth muscle. For instance, the smoothelin-B promoter lacks conserved CArG boxes, considered to be a key feature for muscle-specific expression ${ }^{9}$. On the other hand, the smoothelin-A promoter does contain conserved CArG boxes, but upregulation of expression after interaction with myocardin is low compared with other smooth muscle-specific genes (chapter 4). Although these results should be interpreted with caution since cultured SMCs express little or no smoothelin, they show that both promoters have their own dynamics. In vivo, the two promoters are capable to direct smoothelin expression in a smooth muscle phenotype- and tissue-specific manner (chapter 6 ). The extraordinary tissuespecific expression pattern of smoothelin- $A$ and $-B$ may in part be explained by the different structure of the promoters and their different mode of interaction with transcription factors.

Interruption of the smoothelin gene in mice by removal of the $\mathrm{CH}$-domain, present in smoothelin-A as well as - $B$, was lethal at young age. A number of smooth muscle tissues were affected but the phenotype was dominated by the effects on the intestinal tract (chapter 5). Interestingly, two recent papers involving conditional SRF deficient mice describe a similar dominant effect on the intestine ${ }^{10,11}$. The two smooth muscle layers of the small intestine were enlarged, being approximately four times as thick as in wild type mice. However, the maximal contractile force was still only about $20 \%$ of wild-type mice. This resulted in decreased peristalsis and subsequently starvation and death. A 
similar decrease in contractility was observed in the vasculature of these mice. To exclude secondary effects of for instance starvation on vascular contractility, mice deficient in only smoothelin-B were generated (chapter 6). Interestingly, although $S m t n \cdot B^{\prime}$ mice displayed no overt phenotype, they showed the same decrease in contractility of the vascular smooth muscle tissue as $5 m$ tn-A/B mice. In addition, they developed high blood pressure and concomitant cardiac hypertrophy.

The difference between the life span of the two mouse modeis is remarkable. The reason for this difference may be the type of contraction performed by the smooth muscle. In case of a peristaltic contraction pattern, as in the intestine, absence of smoothelin completely blocks functional contraction. In case of tonic contraction, as in blood vessels, the effect is less deleterious, since neural or hormonal compensation may neutralize the decreased contractile potential. In addition, more or less tone of the blood vessel will only slightly modify transport capacity, instead of block it like in the intestines of $S m t n-A / B^{\prime}$ mice. In this regard it would be interesting to challenge the $S m t n-B \%$ mice, for example by giving them a hypovolemic shock. If their baseline blood pressure is raised by the action of compensatory mechanisms, the drop in blood pressure caused by this life threatening situation would result in early death compared to wild-type littermates, since blood pressure stimulating mechanisms have already been activated. This hypothesis is supported by unpublished observations showing that a significantly higher percentage of $5 m \mathrm{tn}-\mathrm{B}^{\%}$ mice die due to surgical procedures like blood pressure measurement with intravenous catheters.

The data obtained from the smoothelin deficient mice, so far, confirm that smoothelin is a component of the contractile apparatus, necessary for optimal performance in tonic smooth muscle and crucial for phasic smooth muscle. Many mouse models deficient in proteins involved in smooth muscle contraction have been generated. Surprisingly, only full deletion of the SMMHC gene is embryonically lethal ${ }^{12}$, while none of the other major smooth muscle specific proteins currently described are required for long term survival $\left.\right|^{13-16}$. Moreover, like smoothelin, these proteins are not required for the formation of smooth muscle containing organs, such as the cardiovascular system, gastrointestinal tract, and the lungs, and most of these mice feed and reproduce normally. They have no obvious phenotype, and in most models the smooth muscle containing organs are histologically and morphologically not different from wild type mice. This lack of effect is often explained by upregulation of other isoforms or similar proteins that are partially substituting for the deleted genes. However, physiologically the substituting proteins cannot fully compensate, resulting in a compromised function. For example: despite increased expression of alpha skeletal actin in the aorta of $\alpha$-SMA deficient mice, these mice show highly compromised vascular contractility, tone and 
blood flow, suggested to result from a fundamental dysfunction of the contractile system. Deficiency of calponin and telokin also results in reduced contractility. Other knockout models display differences in the organization of the contractile structures, which have (tropomyosin), or have no (SM22 $\alpha$ ) effect on the contraction characteristics. However, none of them is lethal or interferes with reproduction. In comparison with these mouse models, the effect of complete smoothelin deficiency on intestinal function is remarkable and may be explained by the absence of a compensatory protein. However, all these models, including smoothelin, show that the vascular system is robust and able to compensate for the lost or severely reduced production of one of the components of the contractile apparatus as long as the motor molecule, myosin, is not affected.

The rather moderate effect of ablation of most of the components of the smooth muscle contractile machinery shows that evolution has build in compensatory mechanisms. It is, therefore, not surprising that only few diseaserelated mutations have been described for smooth muscle tissues. Only mutations in myosin have been found to cause a pathological phenotype. A small search for mutations in the coding sequence of the smoothelin gene was performed in patients with impaired intestinal smooth muscle contraction. Based on the results of the smoothelin deficient mouse model, we focused on children with visceral (intestine and bladder) smooth muscle pathologies similar to the aberrations observed in the mice. No genetic mutations were found and in the few tissue samples available, smoothelin protein was present (Wijnen and van Eys, unpublished observations).

\section{Conclusion}

Contraction of SMCS is the result of the interaction of a number of proteins. SMC-specific types of actin and myosin are the major components of the contractile machinery, but additional proteins are needed to regulate and elicit full contractile potential.

Instead of merely reflecting the SMC contractile phenotype, smoothelins not only appear to maintain the SMCs in this state, but also actively participate in the contractile process itself. Based on the two smoothelin deficient mouse models, we can generalize that lack of smoothelin decreases the contractile potential of SMCs and hence impairs smooth muscle function. The decreased contractile capacity of the smooth muscle was observed regardless of the signal transduction pathway that was activated to induce contraction. Together with the binding of smoothelins to $\alpha$-SMA filaments ${ }^{6}$, this non-selective reduction of contractility suggests that smoothelin has a role at the core of the SMC contractile machinery. We hypothesize that the important role in contraction is 
accomplished by affecting actin filament rigidity or actin bundle stabilization, probably via interaction with vimentin. 


\section{References}

1. Christen $T$, Bochaton-Piallat ML, Neuville $P$, et al. Cultured porcine coronary artery smooth muscle cells. A new model with advanced differentiation. Circ. Res. 1999;85(1):99-107.

2. van der Loop FT, Schaart G, Timmer ED, et al. Smoothelin, a novel cytoskeletal protein specific for smooth muscle cells. J. Cell Biol. 1996;134(2):401-411.

3. Quensel C, Kramer J, Cardoso MC, et al. Smoothelin contains a novel actin cytoskeleton localization sequence with similarity to troponin T. J. Cell. Biochem. 2002;85(2):403-409.

4. Perry SV. Vertebrate tropomyosin: distribution, properties and function. I Muscle Res Cell Motil. 2001;22(1):5-49.

5. van der Heijden OW, Essers YP, Simkens $L H$, et al. Aging blunts remodeling of the uterine artery during murine pregnancy. J Soc Gynecol Investig. Jul 2004;11(5):304310.

6. Niessen $P$, Clement $S$, Fontao $L$, et al. Biochemical evidence for interaction between smoothelin and filamentous actin. Exp Cell Res. Jan 1 2004;292(1):170-178.

7. Seow CY. Myosin filament assembly in an ever-changing myofilament lattice of smooth muscle. Am J Physiol Cell Physiol. Dec 2005;289(6):C1363-1368.

8. Hai CM, Gu Z. Caldesmon phosphorylation in actin cytoskeletal remodeling. Eur J Cell Biol. Apr 2006;85(3-4):305-309.

9. Miano JM. Serum response factor: toggling between disparate programs of gene expression. J Mol Cell Cardiol. Jun 2003;35(6):577-593.

10. Angstenberger $M$, Wegener J, Pichler $B$, et al. Severe intestinal obstruction upon induced smooth muscle-specific ablation of the transcription factor SRF in adult mice. Gastroenterology. 2007; In Press.

11. Mericskay $M$, Blanc J, Tritsch E, et al. Inducible mouse model of chronic intestinal pseudoobstruction by smooth muscle-specific inactivation of the SRF gene. Gastroenterology. 2007; In Press.

12. Morano I, Chai GX, Baltas LG, et al. Smooth-muscle contraction without smoothmuscle myosin. Nat Cell Biol. Jun 2000;2(6):371-375.

13. Khromov AS, Wang $H$, Choudhury $N$, et al. Smooth muscle of telokin-deficient mice exhibits increased sensitivity to $\mathrm{Ca}^{2+}$ and decreased $\mathrm{CGMP}$-induced relaxation. Proc Natl Acad Sci U S A. Feb 14 2006;103(7):2440-2445.

14. Matthew JD, Khromov AS, McDuffie MJ, et al. Contractile properties and proteins of smooth muscles of a calponin knockout mouse. J. Physiol. 2000;529 Pt 3:811-824.

15. Schildmeyer LA, Braun R, Taffet $G$, et al. Impaired vascular contractility and blood pressure homeostasis in the smooth muscle alpha-actin null mouse. FASEB J. 2000;14(14):2213-2220.

16. Zeidan A, Sward K, Nordstrom I, et al. Ablation of SM22alpha decreases contractility and actin contents of mouse vascular smooth muscle. FEBS Lett. Mar 26 2004;562(13):141-146. 
Summary 
Smooth muscle cells (SMCs) constitute an important part of the walls of various hollow organs and tubes. They regulate the diameter of a tube and thereby the flow of its content by contraction and relaxation. To adapt to changing conditions, SMCs can modulate their phenotype from a contractile to a synthetic state, a process called phenotypic modulation. In the synthetic state, the cells gain properties that facilitate proliferation, migration and the production of components of the extracellular matrix, at the expense of their contractile capacity. In this way, SMCs contribute to structural remodeling of a tissue.

To contract and develop force, SMCs use interactions (so called crossbridges) between actin and myosin. These crossbridges are initiated by changes in the cytoplasmic concentration of calcium ions and the presence of adenosine triphosphate. Smooth muscle contraction is a tightly regulated process in which the characteristics of the interaction between actin and myosin are determined by chemical modifications of the myosin complex and a number of actinassociated proteins such as tropomyosin, caldesmon, calponin, SM22 $\alpha$, and telokin. Contraction regulation as well as relaxation and the proteins involved are described in more detail in chapter 1.

The phenotype of a SMC can be monitored by the expression of certain smooth muscle specific proteins, called marker proteins. The contractile phenotype is characterized by the expression of smoothelins. Smoothelins were discovered in 1996 as smooth muscle specific proteins (chapter 2). The two major smoothelin isoforms are differentially expressed. The small $59 \mathrm{kDa}$ isoform, smoothelin- $\mathrm{A}$, is predominantly expressed in visceral SMCs, while smoothelin-B, the larger 110 $\mathrm{kDa}$ isoform, is only expressed in vascular SMCs. During vascular remodeling as well as under pathological conditions with impaired smooth muscle function, like in restenosis and aneurysms, expression of smoothelins rapidly decreases, either temporarily or definitive.

Both smoothelin-A and $-B$ transcripts are generated from a single-copy gene by two physically separated promoters. Smoothelin-B is encoded by 21 exons, whereas smoothelin-A transcription starts in the middle of exon 10. At the Cterminal end, smoothelins contain a calponin-homology domain, which is, in other proteins, involved in actin binding. In cultured primary SMCs, smoothelinB shows co-localization with $\alpha$-smooth muscle actin ( $\alpha$-SMA).

Based on previous findings, we hypothesized that smoothelins are involved in smooth muscle cell contraction, presumably via interaction with actin. The interaction of smoothelins and actin was demonstrated by several in vitro assays which showed that 1 ) smoothelin-B co-immunoprecipitates with $\alpha$-SMA, 2) transfected smoothelin-A and $-B$ both associate with actin stress fibers in rat 
embryonic fibroblasts and 3) smoothelin-A binds to filamentous actin, but not to monomeric G-actin (chapter 3). In addition, transfection of a truncated smoothelin, which still contained the calponin homology domain, revealed association with stress fibers and binding to actin filaments, but with lower affinity. The binding of smoothelin to actin has no significant actin isoform specificity as shown by ELISA. Collectively, these results indicate an interaction between smoothelin and actin filaments. Moreover, the calponin homology domain and its surrounding sequences appear to be sufficient to accomplish this interaction, although the presence of other domains facilitates and/or strengthens the binding to actin.

Smoothelin-A and -B isoforms are highly restricted to contractile SMCs. Serum response factor (SRF) and myocardin are essential transcriptional regulators of SMC differentiation. We investigated the contribution of SRF/myocardin to transcriptional regulation of smoothelins (chapter 4). Several smoothelin-A and smoothelin-B promoter reporter constructs showed promoter activity in vascular SMCs. Comparative sequence analysis of the mouse, rat, and human smoothelin genes revealed two conserved CArG elements in the smoothelin-A promoter that bind SRF as shown by chromatin immunoprecipitation. The proximal CArG-near bound SRF stronger than the more distal CArG-far in gel shift assays. Mutagenesis studies confirmed that CArG-near is more important than CArG-far for regulating smoothelin-A promoter activity. Myocardin augmented smoothelin-A promoter activity in a CArG-near-dependent manner. In contrast, myocardin had little effect on smoothelin-B promoter activity, which is in line with the absense of conserved CArG elements in the smoothelin-B promoter.

The in vivo function of smoothelins was studied in two different smoothelindeficient mouse models. By deletion of exons 18, 19, and 20 (coding for the calponin-homology domain) of the smoothelin gene, the expression of both smoothelin isoforms was disrupted yielding $S m t n-A / B^{-1-}$ mice (chapter 5 ). The intestines of these mice were fragile and less flexible compared with wild-type littermates. The circular and longitudinal muscle layers of the jejunum were hypertrophic. Furthermore, deficiency of smoothelin-A led to irregular slow wave patterns and impaired contraction of intestinal smooth muscle, leading to hampered food transport in vivo. This caused obstructions that provoked intestinal diverticulosis and occasionally intestinal rupture. Taken together, these data show that smoothelin-A is essential for functional contractility of intestinal smooth muscle. The pathology of mice lacking smoothelin-A is reminiscent of that seen in patients with chronic intestinal pseudo-obstruction. 
The studies described in chapter 6 revealed a cardiovascular phenotype in mice lacking only smoothelin-B $\left(S m t_{n}-B^{-1}\right)$, in which exons 3 to 7 were deleted. Myograph studies showed reduced contractile capacity of the aorta and the femoral artery, irrespective of the contractile agonist used to trigger contraction. Arteries from $S m t n-A / B^{-1-}$ mice exhibited a very similar contractile deficit. Although $S m t n-B^{-1}$ arteries had a normal architecture and expressed normal levels of a number of SMC specific genes, smoothelin-B deficiency resulted in hypertension and concomitant cardiac hypertrophy. MRI experiments revealed that cardiac function was not changed, whereas distension of the proximal aorta during the cardiac cycle was increased in Smtn$B^{\%}$ mice. This indicates that the higher blood pressure in Smtn- $B^{-\%}$ mice is caused by increased peripheral vascular resistance. Collectively, these results identify smoothelin-B as a key determinant of arterial smooth muscle contractility and cardiovascular performance.

Although the studies described in this thesis strongly support that smoothelins are part of the contractile apparatus of SMC, the way in which smoothelins exert their function at the molecular level remains unknown. However, it is likely that interactions with additional proteins next to actin are involved. To reveal the identity of these proteins, a yeast two-hybrid screening was performed (chapter 7). Both smoothelin-A and smoothelin-B screens identified a considerable number of proteins, of which several interacted with both smoothelin isoforms. Further analyses focused on galectin-1, a matri-cellular protein, and vimentin, an intermediate filament and component of the cytoskeleton. These preliminary results imply smoothelins as potential intermediates between the contractile apparatus and structural cellular elements.

The significance of the results and their interrelationship are discussed in chapter 8. It was concluded that instead of merely reflecting the SMC contractile phenotype, smoothelins also appear to maintain the SMCs in this state. Moreover, they seem to actively participate in the contractile process itself. We hypothesize that the important role of smoothelins in contraction is accomplished by affecting actin filament rigidity or actin bundle stabilization, probably via interaction with vimentin. 


\section{Samenvatting}


Gladde spiercellen maken deel uit van de wanden van verschillende holle organen en buizen. Ze kunnen door samentrekken en relaxeren de diameter van een buis veranderen en zo de stroomsnelheid van de inhoud reguleren. Om zich aan te passen aan veranderende omstandigheden kunnen gladde spiercellen hun fenotype veranderen van een samentrekkende naar een synthetische staat, een proces dat fenotypische modulatie wordt genoemd. In de synthetische staat verwerven de cellen eigenschappen die het gemakkelijker maken om te prolifereren, migreren en componenten van de extracellulaire matrix te produceren. Dit gaat ten koste van hun samentrekkend vermogen. Op deze manier dragen gladde spiercellen bij aan structurele verandering van een weefsel.

Om samen te trekken en kracht te ontwikkelen gebruiken de gladde spiercellen interacties (zogenaamde kruisverbindingen) tussen actine en myosine. Deze kruisverbindingen worden tot stand gebracht na verhoging van de cytoplasmatische $\mathrm{Ca}^{2+}$ concentratie in anwezigheid van ATP. Gladde spier samentrekking is een nauw gereguleerd proces waarin de karakteristieken van de interactie tussen actine en myosine worden bepaald door chemische modificaties van het myosine complex en een aantal actine-geassocieerde eiwitten zoals tropomyosine, caldesmon, calponine, SM22 $\alpha$ en telokine. Zowel contractie regulatie als relaxatie en de hierbij betrokken eiwitten worden in detail beschreven in hoofdstuk 1 .

Het fenotype van een gladde spiercel wordt gekarakteriseerd door de expressie van bepaalde gladde spier specifieke eiwitten, marker eiwitten genaamd. Kenmerkend voor het contractiele fenotype is de expressie van smoothelines. Smoothelines werden in 1996 ontdekt als gladde spier specifieke eiwitten (hoofdstuk 2). De twee hoofdvormen van smootheline komen differentieel tot expressie. De kleine, $59 \mathrm{kDa}$ grote isovorm genaamd smootheline-A wordt voornamelijk tot expressie gebracht in viscerale gladde spiercellen, terwijl smootheline- $B$, de grotere $110 \mathrm{kDa}$ isovorm, alleen voorkomt in vasculaire gladde spiercellen. Tijdens zowel fysiologische als pathologische vasculaire structuurveranderingen, zoals bijvoorbeeld bij restenose en aneurismata, vermindert de expressie van smoothelines zeer snel, hetzij tijdelijk dan wel definitief.

Zowel het smootheline-A als het - $B$ transcript wordt afgeschreven van hetzelfde gen, gereguleerd door twee fysiek gescheiden promoters. Smootheline-B wordt gecodeerd door 21 exonen, terwijl smootheline-A transcriptie in het midden van exon 10 begint. Aan het carboxyl uiteinde bevatten smoothelines een 'calponinhomology' domein, waarvan bekend is dat het in andere eiwitten betrokken is bij actine binding. In primaire gladde spiercellen laat smootheline-B dan ook colocalisatie zien met $\alpha$-gladde spier actine. 
Gebaseerd op eerdere bevindingen werd de hypothese opgesteld dat smoothelines betrokken zijn bij gladde spiercel samentrekking, waarschijnlijk via de genoemde interactie met actine. De daadwerkelijke interactie van smoothelines en actine werd aangetoond door verschillende in vitro experimenten die lieten zien dat 1) smootheline-B co-immunoprecipiteert met $\alpha$-gladde spier actine, 2) getransfecteerd smootheline- $A$ en $-B$ beide geassocieerd zijn met actine 'stress vezels' in embryonale fibroblasten van de rat, en 3) smootheline-A bindt aan filamenteus actine, maar niet aan het monomere G-actine (hoofdstuk 3). Daarbij liet transfectie van een korter smootheline, dat nog steeds het 'calponin-homology' domein bevatte, associatie met 'stress vezels' en binding aan actine filamenten zien, maar met een lagere affiniteit. De binding van smootheline aan actine is niet actine isovorm specifiek zoals werd aangetoond door middel van ELISA. Samen wijzen deze resultaten op het bestaan van een interactie tussen smootheline en actine filamenten. Bovendien lijken het 'calponin-homology' domein en de omringende sequenties voldoende te zijn om deze interactie te bewerkstelligen, alhoewel de aanwezigheid van andere domeinen de binding aan actine faciliteert en/of verstevigt.

Expressie van smootheline-A en -B isovormen komt alleen voor in samentrekkende gladde spiercellen. Serum respons factor (SRF) en myocardine zijn essentiële transcriptie regulatoren van gladde spiercel differentiatie. We onderzochten de bijdrage van SRF/myocardine aan de transcriptionele regulatie van smoothelines (hoofdstuk 4). Verschillende smootheline-A en -B promoter reporter constructen vertoonden promoter activiteit in vasculaire gladde spiercellen. Vergelijking van de DNA sequenties van het smootheline gen van de muis, de rat en de mens onthulde het bestaan van twee geconserveerde CArG elementen in de smootheline-A promoter. Beide binden aan SRF, zoals duidelijk werd door middel van chromatine immunoprecipitaties. De proximale CArG box bond sterker aan SRF dan de verder distaal gelegen CArG box in gel shift assays. Mutagenese studies bevestigden dat de proximaal gelegen CArG box belangrijker is voor de regulatie van de smootheline-A promoter activiteit dan de distaal gelegen CArG box. Myocardine versterkte de smootheline-A promoter activiteit via de proximale $C A r G$ box. Myocardine had daarentegen weinig effect op smootheline-B promoter activiteit, wat te verwachten is gezien het ontbreken van geconserveerde $\mathrm{CArG}$ boxen in de smootheline-B promoter.

De in vivo functie van smoothelines is bestudeerd in twee smootheline deficiënte muizen modellen. Door middel van deletie van de exonen 18, 19 en 20 van het smootheline gen (die coderen voor het 'calponin-homology' domein) werd de expressie van beide smootheline isovormen onmogelijk gemaakt, 
resulterend in $S m t n-A / B^{-/-}$muizen (hoofdstuk 5). De darmen van deze muizen waren fragiel en minder flexibel in vergelijking met die van hun normale nestgenoten. De circulaire en longitudinale spierlagen van het jejunum waren verdikt. Tevens leidde smootheline-A deficiëntie tot onregelmatige 'slow wave' patronen, verstoorde samentrekking van de gladde spier van de darm, en daarmee verminderd voedsel transport in vivo. Dit veroorzaakte obstructies die diverticulose van de darm uitlokten en incidenteel leidden tot darm ruptuur.

Samen genomen laten deze data zien dat smootheline-A essentieel is voor functioneel samentrekken van de gladde spier van de darm. De pathologie die wordt waargenomen bij muizen die smootheline-A missen, doet denken aan die van patiënten met chronische pseudo-obstructie van de darm.

De studies beschreven in hoofdstuk 6 onthulden een cardiovasculair fenotype in muizen die alleen smootheline-B missen $\left(S m t n-B^{-1-}\right)$. Bij deze muizen werden de exonen $3 \mathrm{t} / \mathrm{m} 7$ van het smootheline gen gedeleteerd. Myograaf studies lieten een verminderd samentrekkend vermogen van de aorta en de femorale arterie zien, ongeacht welke agonist werd gebruikt om de samentrekking op te wekken. Arteriën van $S m t n-A / B^{--}$muizen vertoonden een gelijkwaardige tekortkoming van het samentrekkend vermogen. Smtn- $B^{-1}$ arteriën hadden een normale architectuur en ze brachten normale hoeveelheden van een aantal gladde spier specifieke genen tot expressie. Desondanks resulteerde smootheline-B deficiëntie in hypertensie en bijkomende hypertrofie van het hart. MRI experimenten onthulden dat de hartfunctie onveranderd was, terwijl de distensie van de proximale aorta tijdens de hartcyclus was toegenomen in Smtn$B^{-1}$ muizen. Dit geeft aan dat de hogere bloeddruk in $5 m t n-B^{-1}$ muizen waarschijnlijk wordt veroorzaakt door toegenomen perifere vasculaire stijfheid. Al met al lijkt smootheline-B een hoofdfactor te zijn bij het bepalen van het samentrekkend vermogen van arteriële gladde spieren, en daarmee heeft het grote invloed op het cardiovasculair presteren.

Hoewel de studies beschreven in dit proefschrift het concept ondersteunen dat smoothelines deel uit maken van het samentrekkende apparaat van gladde spiercellen, blijft de manier waarop de smoothelines hun functie uitoefenen op het moleculaire niveau onbekend. Het is echter waarschijnlijk dat er, naast actine, interacties met additionele eiwitten bij betrokken zijn. Als eerste aanzet om de identiteit van deze eiwitten te onthullen is een yeast two-hybrid screening uitgevoerd (hoofdstuk 7). In de smootheline-A en -B screens werden een aanzienlijk aantal eiwitten geïdentificeerd, waarvan er verschillende een interactie aangingen met beide smootheline isovormen. De verdere analyses werden toegespitst op galectine-1, een matri-cellulair eiwit, en vimentine, een intermediair filament en component van het cytoskelet. De voorlopige 


\section{Samenvatting}

resultaten impliceren dat smoothelines fungeren als intermediaire eiwitten tussen het samentrekkende apparaat en structurele cellulaire elementen.

De betekenis van de resultaten en hun onderlinge verband worden bediscussieerd in hoofdstuk 8 . Er werd geconcludeerd dat smoothelines niet alleen het samentrekkende fenotype van de gladde spiercel weerspiegelen, maar ook de gladde spier cellen in deze staat behouden. Daarnaast nemen ze ook actief deel aan het contractie proces zelf. We veronderstellen dat de belangrijke rol van smootheline in het samentrekken wordt bereikt door vergroting van de stijfheid van actine filamenten of door stabilisatie van de actine bundels, waarschijnlijk via interactie met vimentine. 
Dankwoord 
Ik heb vaak gedacht dat ik nooit zou toekomen aan het schrijven van het dankwoord, maar uiteindelijk is het dan toch zover. En ondanks dat het schrijven me niet is meegevallen, is dit misschien nog wel het moeilijkste van het hele boekje, want je wilt toch echt niemand vergeten te bedanken. Dat klinkt misschien erg cliché maar het geldt in het bijzonder voor dit proefschrift, want er zijn een heleboel mensen die hier hun bijdrage aan geleverd hebben.

Allereerst natuurlijk Guillaume. Ooit is onze samenwerking begonnen met een stage van 6 weken in het lab, toen nog bij MCB. Gelukkig wist $u$ een project te verzinnen dat 'te doen' was in 6 weken en dus mocht ik komen. Want laten we nou eerlijk zijn, niemand zit te wachten op een student die maar 6 weken komt stage lopen. Waarschijnlijk had ik binnen die korte tijd toch wel een goede indruk achter gelaten want tijdens mijn 'grote' stage bij pathologie heeft u mij gevraagd voor een project in Genève waar een Dekkerbeurs voor werd aangevraagd en goedgekeurd. I $\mathrm{k}$ had in het begin mijn twijfels, aangezien ik eigenlijk graag toegepast onderzoek wilde doen, maar ik heb er nooit spijt van gehad. Ik heb ontzettend veel ervaring, contacten en indrukken opgedaan die ik goed kon gebruiken tijdens mijn promotie traject. Ook in Genève gingen de experimenten goed, zo goed zelfs dat ik daar nog drie maanden mocht blijven om het af te maken en tijdens die ene week dat ik tussendoor thuis was werd het AlO project voorgesteld en mocht ik meteen op gesprek bij Marten. De weg van het project was voorzien van hobbels en kuilen, maar ja welke AlO heeft dit nou niet? Uiteindelijk hebben we het toch goed kunnen afronden. Ik hoop dat er nog een smootheline AlO na mij komt, want het zou toch zonde zijn van alles wat er in het 10-jarig bestaan van smootheline is bereikt. Bedankt, voor alle steun en inzet die overgoten werd met een sausje van cynisme en enthousiasme. Ik heb veel geleerd!

Zoals genoemd was er het een en ander veranderd toen ik terugkwam uit Genève. De grootste was de verandering van afdeling. Marten, bedankt dat je me de gelegenheid gaf het project in jouw vakgroep uit te voeren. Met de verandering van afdeling kwam ook de uitbreiding van het aantal collega's. Het uit de grond stampen van een nieuw goed georganiseerd lab is niet niks maar het ook zo houden is misschien nog moeilijker. Patrick en Monique, petje af, ik heb een goed voorbeeld gekregen. Natuurlijk bestond de groep uit meer personen en groeide die gestaag. Met de (oud-)kamergenoten Mathijs, Daphna, Stijn, Kristiaan, Jana, Olivier en Roy, was het erg (te?) gezellig en waarschijnlijk werkt het efficienter nu ik weg ben....... Mathijs en Stijn, jullie hebben ervoor gezorgd dat ik toch iets meer van computers af weet dan helemaal niets. En ook voor de promovendi uit de andere AlO-kamer geldt: succes met jullie promotie en als het even tegenzit: gewoon doorgaan, het komt uiteindelijk wel goed. De 
overige MolGenners Wilma, Marjon, Menno, Susan, Pieter, Inge, Arjen, Jan, Will, Mohammed, Joost, Raymond, Claudia, Iris, Vivian, Willem, Céline, Frank, Ellen, Wino, Hanneke, Maurice, Debby, Ronit, Anne, Sofia, Danielle, Le en Yvonne hebben niet alleen het werkplezier verhoogd, maar ook de stemming in de pauzes. De koffiekamer werd dan vaak een kippenhok.

Vooral ook de studenten op het smoothelineproject hebben veel werk verzet. Kloneren, coupes snijden en kleuren en genotyperen tot je een ons weegt, maar het heeft uiteindelijk heel wat opgeleverd! Peter, Mike, Inge, Daphna, Diane, Wino, Janneke, Alexandra, Gülten, Patricia, Roel, Marjolein en Maud bedankt. Ik voel me zeer vereerd dat een aantal van jullie na het afstuderen als collega's bij de groep kwamen.

Professor Gabbiani, dear Giulio, thank you for your hospitality and valuable comments. I learned a lot about protein work and enjoyed staying in your lab. Dear Sophie, you were the driving force behind chapter 3. Thank you for all your input! Dear Marie-luce, I am very pleased that you are one of the committee members and are finally visiting Maastricht. Of course I also would like to thank all the other members of the lab: Christine, Patricia, Boris, Stephanie, Marc (thank you for learning me how to make cryosections in French! I'm still glad you lend me the radio), Philippe (when are you coming to visit the dutch mountains?), Giuseppe, Antoine, Eveline, Leonardo, Anita, Hiroyuki (how are the dogs?) and Gilbert (I will never forget the flight!). All of you made sure I had a great time in Geneva.

Naast Genève heeft het smootheline onderzoek plaatsgevonden op nogal wat andere plekken. Op zoek naar expertise in de darm wereld kwamen we terecht in Antwerpen. Joris, Ann en Jean-Marie, bedankt voor de prettige samenwerking en de zeer snelle reacties.

Ook in Eindhoven werden we hartelijk ontvangen. Edwin, Gustav en Klaas, jullie resultaten hebben hoofdstuk 6 een heel stuk mooier gemaakt. Edwin, veel succes met het afronden van jouw promotie, soms duurt het wat langer dan gepland, maar je moet ook niet alles tegelijk willen (hoor wie het zegt.......). Natuurlijk wil ik in dit rijtje ook de mensen van Pie Medical Imaging bedanken. Cindy, Jean-Paul en René, bedankt voor jullie gastvrijheid.

Ook binnen de universiteit hebben een heel aantal mensen bijgedragen aan het uitzoeken van wat het missen van smootheline nu eigenlijk betekent. Zo was ik vaak te vinden op de vierde verdieping waar zowel het lab van Ben Janssen als dat van Jo De Mey zijn bijdrage leverde. Ben, Jacques, Agnieszka, Peter, Jo, Rob, Gregorio, Marijke, Paul, Jos, Pieter en Merlijn, bedankt voor jullie hulp en 
discussies. Zal het ooit helemaal duidelijk worden? Ik vind het leuk dat onze samenwerking gewoon doorgaat, ook al betreft het nu een ander onderwerp. Voor hoofdstuk 7 heb ik hulp gekregen van een andere (oud)AlO van 'de snor'. Victor, bedankt dat je me hebt geïntroduceerd in de wereld van yeast-twohybrid en eh ..... wanneer gaan we nu eindelijk eens Puerto Rico spelen?

Ook de collega's van MCB wil ik niet vergeten. Wiel, Mieke, Helma, Jos, Sandra, Miriam, Frans, Francine, Jorike, Marie-Hélène, Monique, Ton, Bert, Hans en alle anderen, ik kon altijd aankloppen met een vraag of als ik weer eens op zoek was naar iets. Bedankt!

Of het nu tijdens een AlO-cursus, sporten of zomaar op de gang was, Imke, Marijke, Marij, Marjon, Bianca, Erika, Birgit en Kirsten, bij jullie kon ik altijd even kletsen over werk-gerelateerde dingen maar gelukkig ook over totaal andere onderwerpen.

Alle medewerkers van het CPV, en in het bijzonder Paulien, Richard, Rik, Wendy, Arnoud en Huub, bedankt voor jullie hulp. Er is veel veranderd sinds 2001, maar ik kon altijd op jullie inzet rekenen.

Al zou ik het de laatste tijd niet zeggen, gelukkig bestaat er ook nog een leven naast het werk. Susan en Erik, Rien en Marije, Anita en Michel, Victor en Rachel, Guillaume en Jeanette, Jessica, Sabrina en Carl, Olivier en Ivanka, Sonja en Christiaan, Oscar, Edwin en Carolien, Antoinette en Arnold, Patrick, Raimond en Joanda, Oscar (deze is om het goed te maken), Pauline en Geert, Kelly en Erik, Fleur en Patrick, Annemarie en Aldrik, Marian en Mark, Alinda, Marielle, Desiree en Wilbert, Anouk en Johan, bedankt voor alle lekkere etentjes, weekendjes/vakanties en spelletjesavonden. $\mathrm{k}$ hoop dat deze in tegenstelling tot het laatste (half) jaar weer wat vaker gaan plaatsvinden.

Ik werk alweer anderhalf jaar bij Interne, de tijd vliegt. Marjo, Olaf, Katrien, Vicky, Marleen, Casper, Carla, Eric, Steven, Marjon, Lian, Roel, Johanna, Josephine, Dany en Margee, jullie hebben me vanaf het begin het gevoel gegeven welkom te zijn. Eindelijk hoeven jullie het gezeur over dat boekje niet meer aan te horen.

Natuurlijk hoort ook de familie thuis in een dankwoord. Lieve pap en mam, jullie waren er altijd voor me en hebben me altijd vrij gelaten in mijn keuzes. Bedankt voor de fijne tijd, liefde, hulp en steun. Lieve oma en opa, jullie zijn een geweldig voorbeeld. Ik zal al die zondagmiddagen nooit vergeten! En ook Frank en Marion, Dennis, Frits en Margriet, Wouter, Marjolein en Ewout zorgden voor 
veel gezelligheid op die zondagmiddagen. Ik kan het gelach, de discussies en het commentaar tijdens een voetbalwedstrijd nóg horen!

Lieve Hanneke, op de eerste plaats mijn lieve zusje, maar ook collega en paranimf. Ik zou niemand anders hebben gewild! Heel veel succes met je eigen promotie. Het zal hard werken worden, maar ik weet zeker dat het een mooi boekje wordt en dat alles goed komt.

Ik ben als Limburgse meid met open armen ontvangen in Raalte. Ans, Joop, Marc, Ans, Margo, Ruben, Anneke en ook familie Rensen en familie Kievitsbosch, ik kan eindelijk zeggen dat het af is en het is jammer dat de afstand zo groot is.

Lieve, lieve Sander, je leest het vaak maar ik ben een van de weinigen die dit met recht kan zeggen: zonder jou was dit boekje er echt niet gekomen. Van begeleider tot collega-AlO, tot vriend en paranimf, op alle fronten heb je je steentje bijgedragen en kon ik altijd op je rekenen. Bedankt voor al je hulp en steun! Ik heb het stokje van je overgenomen en het potje afgemaakt. Nu is er hopelijk meer tijd voor leukere dingen.

Petra 


\section{Curriculum Vitae}


Petra Niessen werd geboren op 18 augustus 1978 in Roermond waar ze opgroeide in het dorpje Leeuwen. In 1989 begon de middelbare school periode die ze doorliep op het Bisschoppelijk College Broekhin. De interesse voor de biologie werd hier gewekt en de keuze voor de studie Gezondheidswetenschappen aan de Universiteit Maastricht was makkelijk gemaakt. Hiermee startte ze dan ook in augustus 1996. Ook de richting Biologische Gezondheidskunde stond al vanaf het begin vast en de moleculaire biologie had haar interesse. Stages in het lab van Dr. G. van Eys en Prof. H. Hoogenboom zorgden voor een brede ontwikkeling op dit gebied. In augustus 2000 studeerde ze af en vertrok ze voor 3 maanden naar Australië om te genieten van een geweldige vakantie.

Door een gehonoreerde studenten Dekkerbeurs van de Nederlandse Hartstichting werd het mogelijk om 3 maanden onderzoek te doen in Genève aan het Centre Medical Universitaire in het lab van Prof. G. Gabbiani. Tijdens dit bezoek werd de basis voor haar onderzoek naar smootheline bindende eiwitten gelegd en uiteindelijk werd de onderzoeksperiode verlengd tot 6 maanden. Aansluitend startte zij haar promotie onderzoek bij de vakgroep Moleculaire Genetica binnen het Cardiovasculaire Research Instituut Maastricht. Binnen het onderzoek stond de functie van smootheline centraal en die werd dan ook vanuit verschillende invalshoeken onderzocht. Dit leidde tot vele samenwerkingen zowel binnen als buiten de universiteit in binnen- en buitenland. De uitbraak van het muizen hepatitis virus in de stallen van de centrale proefdier voorzieningen gooide bijna roet in het onderzoek, maar gelukkig werd dit goed gemaakt door verlenging van de promotie periode met 5 maanden. Een toegekende Kootstra fellowship zorgde er uiteindelijk voor dat het onderzoek naar smootheline bindende eiwitten verder uitgediept kon worden.

Sinds oktober 2006 werkt ze met veel plezier bij de vakgroep Interne Geneeskunde op het MVM lab, waar ze een bijdrage levert aan het ophelderen van de vasculaire complicaties van diabetes. 
List of publications

Abbreviations 


\section{Papers}

Sander S. Rensen*, Petra M. Niessen*, Jan M. van Deursen*, Ben J. Janssen, Edwin Heijman, Evelien Hermeling, Merlijn Meens, Natascha Lie, Marion J. Gijbels, Gustav J. Strijkers, Pieter A. Doevendans, Marten H. Hofker, Jo G. De Mey, and Guillaume J. van Eys. Smoothelin-B deficiency results in reduced arterial contractility, hypertension, and cardiac hypertrophy in mice. (Submitted)

Heijman E, Aben JP, Penners C, Niessen P, Guillaume R, van Eys G, Nicolay K, Strijkers GJ. Evaluation of manual and automatic segmentation of the mouse heart from CINE MR images. J Magn Reson Imaging. 2008;27(1):86-93.

Heijman E, de Graaf W, Niessen P, Nauerth A, van Eys G, de Graaf L, Nicolay K, Strijkers GJ. Comparison between prospective and retrospective triggering for mouse cardiac MRI. NMR Biomed. 2007;20(4):439-47.

van Eys GJ, Niessen PM, Rensen SS. Smoothelin in vascular smooth muscle cells. Trends Cardiovasc Med. 2007;17(1):26-30.

Rensen SS, Niessen PM, Long X, Doevendans PA, Miano JM, van Eys GJ. Contribution of serum response factor and myocardin to transcriptional regulation of smoothelins. Cardiovasc Res. 2006;70(1):136-45.

Niessen P*, Rensen $\mathrm{S}^{*}$, van Deursen J*, De Man J, De Laet A, Vanderwinden JM, Wedel T, Baker D, Doevendans P, Hofker M, Gijbels M, van Eys G. Smoothelin-A is essential for functional intestinal smooth muscle contractility in mice. Gastroenterology. 2005;129(5):1592-601.

Niessen P*, Clement $\mathrm{S}^{*}$, Fontao L, Chaponnier C, Teunissen B, Rensen S, van Eys $G$, Gabbiani G. Biochemical evidence for interaction between smoothelin and filamentous actin. Exp Cell Res. 2004;292(1):170-8.

(*equal contribution) 


\section{Abstracts and oral presentations}

P. Niessen, S. Rensen, J. van Deursen, M. Gijbels, E. Heijman, B. Janssen, J. De Mey, G. van Eys. Smoothelin-B is essential for functional vascular smooth muscle contractility. The 14th International Vascular Biology meeting, 2006. Vascular Pharmacology. 2006;45(3):e104-e105.

Petra Niessen, Guillaume van Eys. Smoothline-A knockout; Een muizenmodel voor verminderde darm contractiliteit. Nederlandse Vereniging voor Kindergeneeskunde Sectie Chirurgie bij Kinderen en sectie Gastroenterologie, 2006. (oral presentation)

P. Niessen, S. Rensen, J. van Deursen, M. Gijbels, E. Heijman, B. Janssen, M. Hofker, J. De Mey, G. van Eys. Smoothelin-B is essential for functional vascular smooth muscle contractility. $9^{\mathrm{e}}$ Dutch Atherosclerosis Society symposium, 2006. (oral presentation)

Petra Niessen, Sander Rensen, Marion Gijbels, Ann De Laet, Joris De Man, Jan van Deursen, Marten Hofker, Jo De Mey, Guillaume van Eys. Impaired smooth muscle contractility in smoothelin deficient mice results in lethality. The 13th International Vascular Biology meeting, 2004. Cardiovascular pathology. 2004;13(3), supplement.

Rensen S, Niessen P, van Deursen J, Fazzi G, Janssen B, van Eys G, De Mey J. Inactivation of the smoothelin gene leads to reduced arterial reactivity. $8^{\text {th }}$ Annual Meeting of the European Council for Blood Pressure and Cardiovascular Research, 2003. Hypertension. 2003;42(4):628.

Petra Niessen, Sander Rensen, Jan van Deursen, Marion Gijbels, Pieter Doevendans, Marten Hofker, Jo De Mey, Guillaume van Eys. Effects of smoothelin targeting are body-wide. ZonMW Genetica Retraite, 2003. (oral presentation)

Rensen S, Niessen P, van Deursen J, Gijbels M, Doevendans P, Hofker M, De Mey J, van Eys $G$. Inactivation of the smoothelin gene leads to aberrant vascular functioning. $4^{\text {th }}$ Annual Conference on Arteriosclerosis, Thrombosis and Vascular Biology, 2003. ATVB. 2003;23(5):a-6,32.

P. Niessen, S. Rensen, M. Hofker, G. Gabbiani, G. van Eys. Function and regulation of smoothelins, markers of contractile smooth muscle cells. ZonMW Genetica Retraite, 2001. (oral presentation) 
Abbreviations

\begin{tabular}{|c|c|}
\hline $5-H T$ & serotonin \\
\hline$\alpha-C A$ & $\alpha$-cardiac actin \\
\hline$\alpha-S K A$ & $\alpha$-skeletal actin \\
\hline$\alpha-S M A$ & $\alpha$-Smooth muscle actin \\
\hline$A B D$ & actin-binding domain \\
\hline ADP & adenosine diphosphate \\
\hline ANF & atrial natriuretic factor \\
\hline ATP & adenosine tri-phosphate \\
\hline BNP & brain natriuretic peptide \\
\hline CaM & calmodulin \\
\hline CAMP & $\begin{array}{l}\text { cyclic adenosine } \\
\text { monophosphate }\end{array}$ \\
\hline Carb & carbachol \\
\hline cGMP & $\begin{array}{l}\text { cyclic guanosine } \\
\text { monophosphate }\end{array}$ \\
\hline $\mathrm{CH}$ & calponin-homology \\
\hline ChIP & $\begin{array}{l}\text { chromatin immunoprecipitation } \\
\text { assay }\end{array}$ \\
\hline $\mathrm{CIP}$ & $\begin{array}{l}\text { chronic intestinal pseudo- } \\
\text { obstruction }\end{array}$ \\
\hline CLIK & calponin-like \\
\hline $\mathrm{CM}$ & circular smooth muscle layer \\
\hline $\mathrm{CO}$ & cardiac output \\
\hline CSA & cross sectional area \\
\hline DAG & diacylglycerol \\
\hline ECM & extracellular matrix \\
\hline EDV & end diastolic volume \\
\hline $\mathrm{EF}$ & ejection fraction \\
\hline EFS & electrical field stimulation \\
\hline ELISA & $\begin{array}{l}\text { enzyme-linked immunosorbent } \\
\text { assay }\end{array}$ \\
\hline EMSA & $\begin{array}{l}\text { electrophoretic mobility shift } \\
\text { assay }\end{array}$ \\
\hline ES & embryonic stem \\
\hline ESV & end systolic volume \\
\hline F-actin & filamentous actin \\
\hline G-actin & globular actin \\
\hline Gal1 & galectin-1 \\
\hline Y-SMA & $\gamma$-smooth muscle actin \\
\hline GEFs & $\begin{array}{l}\text { guanine nucleotide exchange } \\
\text { factors }\end{array}$ \\
\hline GST & gluthation-S-transferase \\
\hline $\mathrm{HA}$ & hemagglutinin \\
\hline HR & heart rate \\
\hline $\mathrm{HW} / \mathrm{BW}$ & heart weight to body weight \\
\hline ICC & interstitial cell of Cajal \\
\hline IgG & immunoglobulin G \\
\hline
\end{tabular}

ILK integrin-linked kinase

$I_{3} \quad$ inositol triphosphate

IPTG isopropyl $\beta$ -

thiogalactopyranoside

kDa kilo-Dalton

KO knock-out

LM longitudinal smooth muscle

layer

MAP mean arterial pressure

MLCK myosin light chain kinase

MLCP myosin light chain phosphatase

MRLC myosin regulatory light chain

MYPT1 myosin phosphatase subunit 1

NEO neomycin resistance gene

$P C R$ polymerase chain reaction

PDEs phosphodiesterases

PGF2 $\alpha$ prostaglandin $F 2 \alpha$

PHE phenylephrine

$\mathrm{Pi} \quad$ inorganic phosphate

PKA CAMP-dependent kinase

PKC protein kinase $C$

PKG CGMP-dependent kinase

PLC phospholipase $C$

PVA polyvinyl alcohol

Q-PCR quantitative PCR

RhoGDI Rho-GDP dissociation inhibitor

ROK Rho kinase

RT room temperature

SDS sodium dodecyl sulfate

PAGE polyacrylamide gel electrophoresis

SEM standard error of the mean

SMCs smooth muscle cells

Smemb embryonic form of myosin

SMMHC smooth muscle myosin heavy chain

Smtn smoothelin gene

SRF serum response factor

SubP substance $P$

SV stroke volume

TK herpes simplex virus thymidine kinase gene

USF upstream stimulatory factors

WT wild-type

X-a-GAL 5-bromo-4-chloro-3-indolyl alpha-D-galactopyranoside 